\title{
Health policy : an exploratory inquiry into the development of policy for the new public health in the Netherlands
}

\author{
Citation for published version (APA):
}

de Leeuw, E. J. J. (1989). Health policy : an exploratory inquiry into the development of policy for the new public health in the Netherlands. [Doctoral Thesis, Maastricht University]. Rijksuniversiteit Limburg. https://doi.org/10.26481/dis.19891208el

Document status and date:

Published: 01/01/1989

DOI:

10.26481/dis.19891208el

Document Version:

Publisher's PDF, also known as Version of record

\section{Please check the document version of this publication:}

- A submitted manuscript is the version of the article upon submission and before peer-review. There can be important differences between the submitted version and the official published version of record. People interested in the research are advised to contact the author for the final version of the publication, or visit the DOI to the publisher's website.

- The final author version and the galley proof are versions of the publication after peer review.

- The final published version features the final layout of the paper including the volume, issue and page numbers.

Link to publication

\footnotetext{
General rights rights.

- You may freely distribute the URL identifying the publication in the public portal. please follow below link for the End User Agreement:

www.umlib.nl/taverne-license

Take down policy

If you believe that this document breaches copyright please contact us at:

repository@maastrichtuniversity.nl

providing details and we will investigate your claim.
}

Copyright and moral rights for the publications made accessible in the public portal are retained by the authors and/or other copyright owners and it is a condition of accessing publications that users recognise and abide by the legal requirements associated with these

- Users may download and print one copy of any publication from the public portal for the purpose of private study or research.

- You may not further distribute the material or use it for any profit-making activity or commercial gain

If the publication is distributed under the terms of Article $25 \mathrm{fa}$ of the Dutch Copyright Act, indicated by the "Taverne" license above, 


\section{HEALTH POLICY}

An exploratory inquiry into the development of policy for the new public health in the Netherlands

\section{Proetschrift}

ter verkrijging van de graad van doctor aan de Rijksuniversiteit Limburg te Mastricht, op gezag van de Rector Magnificus, Prof.Dr. F.I.M. Bonke, volgens het besluit van het college van Dekanen, in het openbaar te verdedigen op vrijdag, 8 december 1989 , om 14.00 uur

door

Evelyne Johanna Janet de Leeuw

geboren te Haarlem in 1960 


\section{promotor: Prof.dr. G.J. Kok}

co-promotor: Prof.dr. N. Milio

\section{Beoordelingscommiss ie:}

Prof.dr. J.M. Greep (voorzitter)

Prof.dr. A. van der Werfe

Prof.dr. L.W. Green

Prof.drs. J, van Londen

Dr. L.M. Gunning-Schepers

Lay-ow:

Guas van Rooiji

Ruud Leliveld

Laidginge rupport:

Rund Loliwel at

Vakgrop $\mathrm{BOO}$

Cower desigh:

Gerjo Kok

Marthas Sawannah

Obserwant

Aro athailfable:

Fuelyne de Leeww (1989), The Sane Revolution.

Health promotion: backgrounds, seopw, prospects, Wan Goncuin, Assen/Mastriche, The Netherlands ISIBN 9023224361

Distribution:

Boekhandal De Tribune

Kapoenstraat 8

$6211 \mathrm{kKW}$ Maastricta

The Natharands

Publiculion of this work was finath tally supported by: Fonds Dortor Catharine van Tussentroek

Stiching Het Scholten-Cordes foronds 


\section{FOREWORD}

Doing research, and writing a dissertation, seems to be a solitary endeavour, especially in the prewailing educational system in The Netherlands. Some have compated the exercise with running a marathon. Luckily, I haven't had the latter experience.

Moneover, it is not a solitary enterprise. Many people have been involved in ny academic work over the past years. To name them all would take too much space. However, to some I would like to express my gratitude.

Without the zest for work, many, many questions, and support by Nicole Nijssen I wouldn't probably even have started this investigation in time at all. Nicole, your influence has been tremendous, although you might not clearly recognize your valuable suggestions in this book. Further, professor Gerjo Kok and professor Nancy Milio have continuously and consistently pressed me to explore my own limits. Gerjo, in spite of your sometimes seemingly stoic supervision of my wild plans, I feel that your mere presence and questions have meant a lot to the production of this work, and life in general. Nancy, we have had some hard times discussing my stupidities, but without your being there and asking these nasty questions I would probably have got stuck somewhere half way chapter one.

Other people have meant a lot, particularly in the last stages of writing. The participants in the Biellefeld Seminar, early June 1989, have through their discussions contributed significantly to the ripening of my writings. Especially, a session with Gail Siler-Wells, Len Duhl, Hans Saan, and Michel O'Neill got me on my academic and emotional feet again. It made the difference. Further, my colleagues in the Scientific Committee of the Research for Healthy Cities Conference (The Hague, late June 1989) have supponed me in times of severe stress. Henk, Chris, Jan, Evert, and Louise, you have almost become family.

Colleagues are important anyway. Without the utterly pleasant working atmosphere at Carre and Kapoenstraat the clouds of data could easily have created a depression. One colleague needs separate mentioning: Jan van der Made, take my word for it that you would have deserved it more than me to be standing up there in the Aula (auditorium). Your suggestions were more than significant.

Talking about family... My parents must have wondered regularly whether all this traveling, interviewing, analyzing and writing would really contribute to my personal well-being. In times of doubt, they were there to support me in any possible way. No words of thanks could express what that meant for me.

I'll leave it at

"Goeden Dág!" 


\section{CURRICULUM VITAE}

Evelyne de Leeuw was born in Haarlem, the Netherlands, 25 June, 1960. After finishing her gymnasium- $B$ in 1979, she tried, largely in vain, to study garden- and landscape-architecture at the Agricultural University, Wageningen, the Netherlands.

She then turned to the newly established programme in Social Health Sciences (now Health Sciences) at the University of Limburg, Maastricht, the Netherlands, in 1981. There she had a hard time to choose between the health education, and health policy \& administration specializations. She chose the latter, but opportunity gave it that she could integrate both health promotive approaches through research projects and supported by national and intemational developments.

After graduation in 1985 (MA, thesis on policy-making in the European office of WHO) she studied one year at the University of California, Berkeley, USA (MPH, thesis on cultural differences in health sciences education), after which she had three years for the research project culminating in this $\mathrm{PhD}$ thesis.

Apart from a satisfying scientific life, she follows another carreer path in creative writing. 
"Life is short, science is long; opportunity is elusive, experiment is dangerous, judgement is difficult. It is not enough for the physician to do what is necessary, but the parient and the attendants must do their part as well, and circumstances must be favourable."

Hippocrates, Aphorisms, I, Section I

"Ourtelescopes are now that magnificent that we could say that Earth-beings, if they should exist, would be less than 0.03 mile tall, otherwise we could see them. Such small propontions are improbable, but theoretically not impossible."

Raoul Chapkis, Geen Leven op Aarde (Raoul en de Mensheid) 



\section{TABLE OF CONTENTS}

1.

1.1

1.2

1.3

1.4

2.

2.1

2.1. 1

2.1 .2

2.2

2.2.1

2.2 .2

2.2 .3

2.3

2.3 .1

2.3 .2

2.3 .3

2.4

3.

3.1

3.1.1

3.1 .2

3.1 .3

3.2

3.2.1

3.2 .2

3.2 .2 .1

3.2 .2 .2

3.2 .2 .3

3.2.2.4
Introduction

What:

Why

Which

Where, when, wiezoe

References

Health policy: development

The 'founding fathers'

Blum

Lalonde

WHO programmes

Primary Health Care

Health for All by the Year 2000

Health promotion

Nota 2000

Chromology

Characteristics

A discussion document

Discussion and conclusion

References

Healthy public policy

Public health policy

Dexelopment

Thrust

Pitfalls and bottlenecks

Healthy public policy

Characteristics

Unresolved problems

Policy theory

Intersectoral cooperation

Interventions for health

Measurement and evaluation 
4.

Feasibility of health policy: theory of agenda-building

4. 1

Agenda-building theory

Outside iritiatiwe model

Inside initiative model

Mobilization model.

Healthy public policy and agenda building

Issue expansion criteria

Additional theoretical considerations

$\begin{array}{ll}\text { Perception vs. 'reality' } & 71\end{array}$

Action and value

References

5.

Method and methodology

Qualitative inquiry: rationale

Quality control

Data collection

Data processing.

References

6.

\section{Findings}

6.1

Interview and delphi response

Perceived status

Knowledge and value

Interview and delphi material 94

\section{4}

Organizational documents

Media coverage

Involvement and action

Feasibility and barriers $\quad 99$

6.6

Issue expansion and organizational documents $\quad 106$ 


\section{Anmexes}

\section{Annex I}

: targets for health for all

Annex II

: Delphi-questionnaire

Annex $V \quad$ : Delphi report

Annex VI : KAP-chart I (value, feasibility, barriers)

Annex VII : KAP-chart II (value and action)

Annex VIII : semi-structured interview $\quad 176$

$\begin{array}{lll}\text { Annex IX } & \text { : power base of respondent organizations } & 178\end{array}$

\section{Table of contents: figures}

2.1

The force-field and well-being paradigms of health

The Health 2000 Report Model 23

Nota 2000 Health Basis Model $\quad 27$

The cyclical development of social/health policies 37

Memorandums, legislation and budget regulation 38

Solutions to health problems $\quad 44$

Health promotion intervention framework $\quad 47$

Kok \& Jonkers intervention grid $\quad 47$

Hierarchical intervention framework 48

The scene and the players in the process of making policy 67

Theoretical focus of investigation $\quad 73$

Methodology and validation procedures. 84

Media coverage Nota 2000 over time 93

Media coverage and attitude expressed toward Nota 2000

Media attitude cluster analysis 97

$\begin{array}{ll}\text { Media coverage modes } & 108\end{array}$

$\begin{array}{ll}\text { Applicability of theory of agenda-building } & 128\end{array}$ 
Table of contents" lables

2.1

6.1

6.2

6.3

6.4

6.5

6.6

6.7

6.8

6.9

6.10

6.11

6.12

6.13

6.14

6.15

6.16

6.17

6.18

6.19

6.20

6.21

6.22

6.23

6.24

7.1

7.2

7.3

7.4

Reactions to Nota 2000 by sector and profession

Reserach population by cluster and response 89

Response second Delphi-round 90

Aggregate response characteristics $\quad 91$

Organizational document analysis: characteristics $\quad 92$

Respondents vs. perceived status of Nota 2000

Organizational document amalysis: presence Nota 2000

Perceived involvement vs. action underaken 97

Perceived barriers vs. actions to overcome them (all) 98

Perceived barriers ws. actions to overcome them (value) 99

Perceived barriers vs. actions to overcome them (aspects) 100

Perceived barriers vs. actions to overcome them (non) 100

Issue expansion by agenda-building criteria $\quad 102$

Respondents related to issue expansion and value 103

Isstie expansion vs. perceived barriers and actions (5) 103

Issue expansion vs. perceived barriers and actions (4) 104

Issue expansion vs. perceived barriers and actions (3) 104

Issue expansion vs. perceived barriers and actions (2) 105

Issue expansion vs. perceived barriers and actions (1) 105

Issue expansion vs. perceived barriers and actions (0) 106

Organizational document analysis: presence Nota $2000 \quad 107$

Respondents vs. perceived opposition 108

Respondents vs. contribution to prevention policy 110

Perceived effectiveness of child accident prevention 111

Prefered intervention types child accident prevention $\quad 112$

Perceived conclusions by respondents 116

Interests of respondent organizations 131 .

Relation between relative power and perceived interest 133

Relation between relative power and 'actual' interest 133

Overlap between tables 7.3 and $7.4 \quad 134$ 


\section{INTRODUCTION}

\subsection{What}

On April 28, 1986 the secretary of state for health in the Netherlands sent a 381-page memorandum to parliament: "On the development of health policy: facts, considerations and policy intentions (Nota 2000)' (Tweede Kamer, 1986). The facts and considerations took 374 pages, the policy intentions a mere seven.

The publication of Nota 2000 marked a shift in public thealth policy in the Netherlands. For the first time a govemmental document for health focused on the substantial content of health and the outputs of the "health field" (containing environmental, hereditary health care system factors that affect health).

In the years which followed, much deliberation was devoted to Nota 2000. As the issue was quite innovative, government organized lengthy discussion seminars and supported the publication of several books on health policy.

This inquiry investigates the scope and thrusts of Nota 2000, and in general, the feasibility of health (in contrast to health care) policy in the Netherlands. As an introduction, in 1.2 we will explain the relevance of such an inquiry, and the position of this study in the international context. In 1.3 the research questions are presented. In 1.4 some additional information will be given on the time frame of the investigation, methods and procedures followed, and we will present the reader with a guide through the rest of this work.

\subsection{Why}

Developments in the $1960 \mathrm{~s}$ and $1970 \mathrm{~s}$ have urged international authorities and national. governments in industrialized nations to reconsider the question of the state of their populations' health. A growing awareness arose that health is not merely the end point of a trip through the medical-industrial complex (IIlich, 1976), but rather the complex resultant of the interaction between lifestyles, biological factors, management of health services and physical and social environments (De Leeuw 4 1989).

Initially, the urge for preventive actions to tackle lifestyles with adverse effects on health was stressed. But gradually, on international fora the awareness grew that all afore-mentioned factors could be addressed in a comprehensive health policy.

Initiatives in the development of such policies were especially spurred by the activities of the regional European office of the World Health Organization, drawing up a Regional Strategy for Health for All (WHO/EURO, 1980). Member states were asked to develop national plans for Health for All. Further initiatives led to establishment of the health promotion concept. the necessity of "healthy public policy", and a "Healthy Cities Project' (De Leeww, 1989). 
Of courge, these developronents did not occur in a vacuum. The emergence of the women"s healih movement, consumer emancipation, growing concern about pollution and the physical enwironment, reports on irequities in health, people being at variance with growing medicalization of their lives, the growing need for cost-effectiveness analyses and technology assessment of health care services, among others, contributed to the increasing desire to address problems in a less structure-oriented and rather contents-oriented policy framework. Nota 2000 is the reflection of that desire. The Netherlands is not in the least the only nation having developed such a initiative. Sweden (HS90, 1984), Hungary (Kbkeny, 1987) and Australia (Commonwealth of Australia, 1986a, 1986b, 1988) are among the nations having developed similar plans.

Thus fat, no empirical studies are avalable in which the initiation and options for implementation of such comprehensive frameworks are investigated.

This makes Nota 2000 a fascinating research object. This is first, because it is of high interest how the culmination of societal concerns into a Nota 2000 can get an adequate instrumental follow-up; second, because through investigation of such a comprehensive health policy barriers and options may surface that can either contribute to further development of health policy in the Netherlands (with its unique health system), or indicate problems other nations will have to face when developing health policies. And finally, such an investigation may shed a first light on the possibilities and problems of empirical health policy research.

\subsection{Which}

An investigation of Dutch thealth policy necessarily has to be exploratory: as we have noted, there are no theoretical policy frameworks readily available for such study, and the content of the field is of a complex nature for which investigators seem not yet to have developed adequate instruments of measurement. Therefore, this investigation has to start at the very beginning.

An exploratory inquiry of this kind will have to focus on processes bringing about the policy. and on perceptions by partmers in the game of making pollicy of the status and problems of such a policy. Questions of that kind are to some extent abstract by necessity. To grasp the whole issue more adequately, presentation of a case study to illustrate aspects of perception by partners could yield valuable information.

Considering the above, the following research objectives were formulated:

a. what are thrust and status of Nota 2000 ;

b. what do the relevant groups in Dutch society know of Nota 2000

c. what use do they make of its ideas in their own organizational policy making, thus laying a basis for inferting

d. whether full implementation of Nota 2000 is feasible.

More concrete, research questions are:

- In which phase of the policy process is Nota 2000 ? What are the prospects for progress of that process?

- Which actors are and have been involved in that process?

What is their role in the progress of the process?

- Is "healtiy public policy" a feasible option for Dutch health policy?

* What are the prospects for a prevention policy in the light of Nota 2000 ?

- How do partners in health perceive the feasibility of a specific healthy public policy for accidents in the home among children $0-5$ years of age?

\subsection{Where, when, wiezoe}

This investigation started off in August, 1985 as a project to investigate health education policies in the Netherlands in the light of recent developments in the European Region of the World Health Organization. With the publication of Nota 2000 in April, 1986, the research 
object was shifted toward the more comprehensive health policy the latter encompasses. Literature reviews, research question development and protocol development took about a year, because the field of health policy was found to be wery dynamic, and research priorities had to be reevaluated and adjusted continuously. Data collection started early 1988, and were finalized in April, 1989. By that time, a Core Document (a follow-up piece on Nota 2000 ) was published. Issue of such a document was beyond the content and time scope of the rinitial investigation, though strongly related to it. Therefore, a separate chapter (Epillogue) is added in which we will reflect on the most recent developments in health policy development.

The lay-out of this report became thus:

In chapter 2 we will present the developments leading up to publication of Nota 2000 . The early efforts by Blum and Lalonde arguing for comprethensive health policies are presented, and the WHO programmes leading to stimulation of national health policies are laid out. "The chronology of the development of Nota 2000 and its characteristics are reviewed in the last part of this chapter.

In chapter 3 the distinction between public health policy and healthy public policy is reviewed. The latter part of the chapter is devoted to problems related to the concept of health policy. They deal with the available theoretical frameworks for study and developments of health policy, the problematic issue of intersectoral cooperation, the question of an integrated intervention mix (legislation, education, and facilitation) in the health policy framework, and issues of measurement and evaluation of health policy.

Chapter 4 continues to develop a specific theoretical model to study factors bringing about policy: the mobilization model of the theory of agenda-building. The various constituent parts, such as composition of interested publics (or groups), role of media, and properties of conflictual issues related to the agenda status of policy ideas, are presented and operationalized.

Chapter 5 introduces the framework of qualitative methodologies employed in this investigattion. The issue of quality control (confidence, walidity and reliability) in qualitative inquiry is investigated, and triangulation presented as a valuable tool in quality assurance. Some unorthodox and adwanced methods in qualitatiwe health policy inquiry are presented in the latter part of this chapter.

In chapter 6 the findings of our investigation are presented. They are structured along the lines of the theory outlined in chapter 4 , and aforementioned research objectives and questions.

Chapter 7 represents the conclusion and discussion sections of this report as well as research recommendations, while we will reflect in chapter 8 on the most recent developments in the Netherlands" health policy, such as the Core Document and the Collective Prevention Act. 


\section{References}

Commonwealth of Austrulia (1986a) Looking forward to better health. Better Health Commission, Voll. 1, Final Report, Canberra

Commonwealth of Australia (1986b) Looking forward to better health. Better Health Commission, Vol. 2, The taskforces and working groups: reports to the Better Health Commission, Canberra

Commonwealth of Australia (1988) Health for All Australians. Report of the Health Targets and Implementation (Health for All) Committee to Australian Health Ministers, Canberra HS90 (1984) The Swedish Health Services in the 1990s. Giowernment Printing Office, Stcckholm

Illich, I. (1976) Limits to medicine: Medical Nemesis, The Expropriation of Health. Marion Boars, London

Kokerny, M. (ed.)(1987) Promoting health in Hungary. Report of a group established by the Council of Ministers of the Hungarian People"s Republic. Central Statistical Office, Budapest

Leeuw, E. de (1989) The Sarne Revolution. Health promotion: backgrounds, scope, prospects. Van Gorcum, Assen/Maastricht

Tweede Kamer (1986) Over de ontwikkeling van gezondheidsbeleid: feiten, beschouwingen en beleidsvoornemens (Nota 2000). Tweede Kamer, zitting 1985-1986, 19 500, nrs. 1-2 (28 April 1986)

WHO/EURO (1980) Regional Strategy for attaining Health for All by the Year 2000, doc. EUR/RC30/8 rev. 1, Copenhagen. 


\section{HEALTH POLICY: DEVELOPMENT}

In this chapter we will review the development of health policy, that is, policy beyond the traditional concem for health care infrastructure and funding. Health policy focusses on the output of various interacting interventions on determinants of health. The developments described here include the re-emergence of a wide and comprehensive public health concept presented in the Canadian Lalonde report and the writings of Henrik Blum (2.1), and the shift of attention in WHO policies and programmes from medicall care prowision toward an emphasis on structural, lifestyle-related and environmental deteminants of health from the early 1970 s onward (2.2).

On national levels, these developments have culminated in a variety of programmes, plans and policies. One of these is Nota 2000. The thrust of the document is explored in 2.3, and particularly its initiation and creative process, and parliamentary involvement will be described.

First, however, it seems important to establish unequivocal definitions of some key concepts such as 'health' and 'policy'. 'Policy' will be defined as 'a long-term, continuously used, standing decision by which more specific proposals are judged for acceptability in terms of means to be employed, ends to be pursued, and time frame in which these proposals will have to be fit'; justification of this definition will be found in 2.1.1. 'Health' is defined into more operational terms than the standard WHO-definition ("Health is a state of complete physical, mental and social well-being and not merely the absence of clisease or infirmity") as "the extent to which an individual or group is able, on the one hand, to realize aspirittions and satisfy needs, and on the other, to change or cope with the environment" (3.2, explored further in De Leeuw, 1989). 'Health policy' thereby becomes to be defined as 'a long term. continuously used, standing decision by which more specific proposals aimed at, or related to the realization of optimal conditions under which individuals or groups can realize aspirations and satisfy needs and change or cope with the environment are judged for acceptability in terms of means to be employed, ends to be pursued, and time frame in which these proposals will have to be fit.' It will be clear that 'health policy' is not inluerently related to medical care provision policy, although it may definitely contain that emphasis. "This exactly is the thrust of the writings of Blum $(1974,1981)$ and Lalonde (1974) we will describe in the following section.

\subsection{The 'founding fathers'}

The development of health policy is generally retraced to the works of McKeown (reflected in his 1979 work 'The role of medicine'), and to a lesser extent llich (1976). Both authors 
show that medicine has only limited effects on the health status of populations, and that medicine may even have deteriorating effects on health. Nevertheless, the first scholar to incorporate these and similar thoughts into a concise policy framework was Henrik Blum in 1974, and the Canadian. Health Minister Lalonde proposed a factual policy framework based on the work of Laframboise (1974) that same year (Van der Werf, 1976). Thus, Mckeown and Illich can only be viewed as supportive of the writings of Lalonde and Blum.

\subsubsection{Birm}

The health planning theory of Herrik Blum relies on three basic premises:

1 An understanding of the force-field and well-being paradigms of health, visualized in figure 2.1;

2 Insight into the complex nonsubstantive, and therefore political, nature of health and health sector problem issues;

3 The need for rational analysis of the problem as well as rational planining and implementa tion approaches. The theoretical angle chosen for this approach is the systems theory.

In this paragraph we will review each of these premises to clarify the innowative nature of Blum's approach.

In the words of Blum, "in the case of a health deficiency, substantive or technologic factors concern the basic nature of the condition at hand, e.g., the causes, the nature of the disordered condition or functioning, and the means of preventing, countering or controlling the condition" (p. 5). Note that this conceptual framework may not include positive health practices as long as they do not aim at specific prevention of unfaworable conditions. Blum condenses these substantive factors at work in the model presented in figure 2.1 .

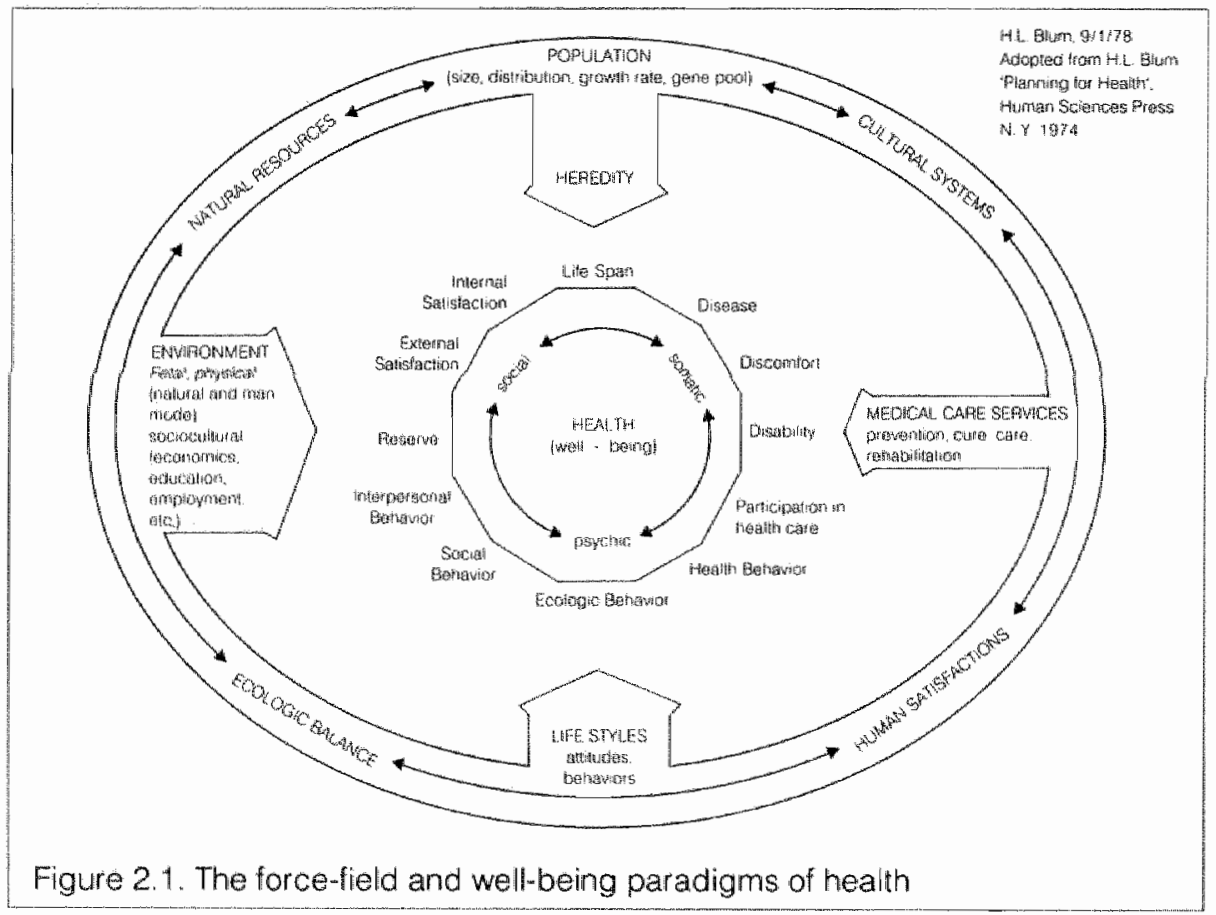

The outer ellipse represents the "force-field paradigm", the inner circle the "well-being paradigm of health. The components of the force-field paradigm resemble the four components of the Health Field Concept (2.1.2): heredity, lifestyles, environment and medical care services. The relative weights of the components are represented (the width of the four force arrows) as well as their interrelations (the ellipse itself): the whole field of forces symbolizes 
the ecologic wiew of what affects health.

The inner circle is the 'well-being paradigm'. The basic notion is, that health is holistically determined, i.e. that there is an inseparability and transmutability of the aspects of health that in industrialized societies have been separated from each other and each for themselves have been reduced to loose components: psychic, social and somatic health. The well-being paradigm dictates a holistic view of health, with the various determinant aspects surrounding it. The politicall problem for health is, that there is a high complexity of intertwined substantive and nonsubstantive aspects of health concerns, for which politics would make policy choices; still, as long as policy is not made, according to Blum, nonexplicit policy exists and is operational: those in power (say, the medical-industrial complex) will dictate resource allocation and thereby pollicy thrusts.

In Blum's view, a thorough, step-by-step, methodologically accounted for, systems analysis of the problem would produce ways of dealing with those 'wicked' (cf. Churchman, 1967) problems.

Blum tries to establish a framework for publicly planned deliberate social change, as it will be clear from the above premises that health cannot be isolated from society and the social process. Assessment of the present situation, i.e. the identification of health needs and translation of those into health goals is a first step. Problem and goals analysis should subsequently give weighted priorities for a range of intervention types. Establishing an implementation instrumentarium is a crucial step in the development of health policy, Bum asserts, and part of that is creating an accountable planning body. Finally, evaluation is required to adjust goals and means to changed conditions.

Blum's work is a landmark work in health policy writing, though not the end point: it rather gives suggestions for the creation of a true health policy, and knowledge gaps and organixational issues as we will describe them in chapter 3 have not been addressed entirely adequately. Blum first and foremost seems to rely on rational-deductive approaches to health problem solving, and as we will see in the next chapter, such an approach is not always fruitful, especially in situations of complexity and uncertainty.

His achievement, nevertheless, has been the launching of a new interpretation of the term 'health policy' beyond concerns for insurance matters and health care infrastructure. On the basis of his work we will propose a workable definition of "health policy'. Policy, according to Blum, is 'a long-term, continuously used, standing decision by which more specific proposals are judged for acceptability' (p. 229). Public policy, according to Blum. stipulates ends, may prowide resources, and may spell out specific means to reach these ends. Crichton (1981) subscribes to this view, but Hoogerwerf (1982) rather prefers a wide conceptualization of policy: "Policy is the endeavour to reach certain goals in a certain time frame, employing certain means". The behavioral consistency and repetitiveness on the part of those who make policy and those who abide by $\mathrm{it}_{\text {. }}$ presented as a condition for policy by Blum is thus not supported explicitly by the latter definition.

A constitutive definition of health policy is given by Dekker (1989): 'Health policy is policy" aimed at maintenance or improvement of the health status of (part of) the population through the employment of means aimed at the determinants of health (including health care)." The definition is constitutive, as it does not explatin what is to be understood by 'policy' or "health", while 'determinants of health' are not entirely unequivocally related to the Health Field Concept (cf. 2.1.2).

As we are studying explicit policy (Nota 2000 is a fonmal government statement) it seems appropriate to adhere to the more strict definition given by Blum, and include the goals, means and time dimension. The definition of policy thus becomes: "a long-term, continuw ously used, standing decision by which more specific proposals are judged for acceptability in terms of means to be employed, ends to be pursued, and time frame in which these proposals will have to be fit'. And as we have suggested above, health being the focus of the 
explicil policy (Nota 2000 ) ror which specific proposals will have to be developed, "health policy" is "a long-term, continuously used, standing decision by which more specific: proposals airned at, or related to the realization of optimal conditions under which indiwiduals or groups can realize aspirations and satisfy needs and change or cope with the environment are judged for acceptability in terms of means to be employed, ends to be pursued, and time frame in which these proposals will have to be fit. "We will retum to this definition in 23.3 to review whether Not 2000 in this light may be called "health policy".

\subsubsection{Lalonde}

Alhough only 76 pages and one annex, the Lalonde report has been -and still is- one of the most influential governmental documents on health ever published. Certainly the document is not unique in its comprehensive view on health services. Van der Werf (1976) shows that in ten European countries and Canada, 17 laws and organizational proposals were passed to that extent in the early seventies (until 01.01.1975). Yet, the Lalonde report is unique in its recognition of the various determinants of health (the "Health Field Concept') apart from the organization and quality of medical care delivery: hereditary factors (human biology), lifestyles and enwironmental factors pllay important roles in the making or promotion of health. It is the first statement establishing shifting priorities for health investment and action (Evans, 1982). The need for changes in personal lifestyles was stressed in the early translation of the working document into concrete measures; since the establishment of a Health Promotion Directorate within the Canadian federal Department of National Health and Welfare in 1978 (the first of its kind in the world, according to Kickbusch, 1986) the predominance of personal lifestyle interventions has shifted toward a search for a more balanced intervention mix aimed at all four factors (Pederson et al., 1988).

The Lalonde report has not been without criticism. Hancock (1986) summarizes some of the criticism into two major obstacles: no implementation framework available, and the multiinterpretability of the document. The implementation of the 74 proposals of the report was frustrated by the infrastructure of the Canadian health system, where provinces have responsibility for health services, while the federal govemment failed to show how the objectives had to be obtained. The multi-interpretability of the document is shown by Evans (1982), analyzing that different interest groups could make the document serve their own, often juxtapositional, organizational purposes. This point is enhanced by Van der Maas \& Habbema (1987).

Although Laframboise claimed that the Health Field Concept as a conceptual model met cruciall characteristics of a useful concept-comprehensiveness, ease of classification, facilitation of further subdivision, and matrix analysis (Hancock, 1986), Van der Maas \& Haberna assert that drawbacks of the model, and for that matter of all presert health models, are a lack of causality and quantifiability, as well as the incomparability of the components of the models which are yet placed at a same level. The interpretation of the component keywords almost automatically introduces a biased view; Van der Maas and Habbema (1987) show, that for one health condition (phenylketonuria, PKU) one could argue that biological/ hereditary deteminants are $100 \%$ responsible, environmental determinants for $100 \%$ as well 1 , as well as lifestyle determinants (100\% responsible for PKU) or health services" determinants $(100 \%)$. The interrelations and incomparability of those groups of determinants make simple, and generalizable health models nearly an impossibility. This is not to say that these models are without value; they have set our thoughts on health, health care, and health determinants.

Apart from that, mathematical or computer health models may still be possible, if sufficient data are available, if the conditions under which they are transformed into 'information' have been made clear, if other inputs are considered, and if there would be available a 'hierarchy of explanatory models" (De Leeuw, 1989). 
Noteworthy, in this respect, is the work of Van Doorslaer (1987) and Gunning-Schepers (1988). They show by econometric and epidemiological analyses that investment in one of the determinant fields of the Health Field Model may yield higher retums than in any other field. Van Doorslaer (1987) finds, for instance, that investment in general education has more favorable impacts on health status than investment in the health care system, while Gunning Schepers (1988) in her mathematical PREVENT-model shows the interactive time effects of quit-smoking interventions: the effects of these interventions on the conglomerate of lung cancer, ischaemic heart disease and chronic respiratory diseases (CARA) mortality are definitely different from what would have been singular causal relation effects between smoking and only one disease group: the net results of quit smoking programmes and all disease groups are significantly higher than targeting and measuring only one one-to-one relation. However, making policy is not just a matter of the availability of sufficient scientific data, but also of political will and policy priorities (cf. 3.2). For instance, a department of health would not easily be willing to spent monies from its budget on investment in general education, however large the health gains of such an investment might be: the policy spectrum of such a department is limited by many factors.

Of course the Lalonde report has had an enormous impact on international thinking on health policy. Hancock (1986) presents us the 'Prevention \& Health' document from the United Kingdom (1976), 'HS90' from Sweden (1981), and 'Healthy People' from the USA (1979, 1980 ), all drawing heavily on the thrust presented by the Lalonde report. Nota 2000 could easily be added, as its "Health Basis Model' (cf. 2.3.2) is directly derived from the health field concept. Thus, we can agree with Hancock (1982): "In spite of its faults, the Lalonde report was a truly significant milestone in the renaissance of public health. Perhaps the best tribute to its authors is to accept it for what it is -the signpost pointing the way at the start of a journey - and to move off in our more sophisticated promotional vehicles down the road to improved health for all which the Lalonde report was pointing" (p. 100).

\subsection{WHO programmes}

The World Health Organization seems to have played a crucial role in the development of health policy since the early $1970 \mathrm{~s}$. Various programmes have contributed to the emergence of the 'healthy public policy' concept in the realm of health promotion in the second half of the 1980s; notably, they were 'Primary Health Care', 'Health for All by the Year 2000', and the 'Health Promotion Programme'. Although these programmes are interwoven and have global significance, we will present them in chronological order and with a focus on westem industrialized nations.

\subsubsection{Primary Health Care}

In the early $1970 \mathrm{~s}$, a realization grew in international circles that traditional health serwices were not tuned to changing conditions, neither in developing countries (where more basic health services were needed on a local level instead of highly specialized serwices in urban areas), nor in developed countries (where the welfare society had brought about new types of health risks and inequities). A study by WHONUNICEF (1975) summarized the (new) health needs in developing countries, and altemative approaches to meet them. In 1978 , in the light of the new long-term programme of WHO, "Health For All by the Year $2000^{\prime}$ (cf. 2.2.2), at conference was convened in Alma-Ata to discuss one particular approach: primary health care. 'Primary health care is essential health care based on practical, scientifically sound and socially acceptable methods and technology made universally accessible to individuals and families in the community through their full participation and at a cost that the conmunity and country can afford to maintain at every stage of their development in the spirit of selfreliance and self-determination. It forms an integral part both of the country"s health system, of which it is the central function and main focus, and of the overall social and economic 
development of the community. It is the first level of contact of individuals, the family and community with the national health system bringing heialth care as close as possible to where people liwe and work, and constitutes the first element of a continuing health care process" (WHO/UNICEF, 1978, YO).

The noteworthy thing about this declaration on primary health care, of course, is that it deals. not only with health care, but also with its social and economic enwironments. According to the Alma-Ata Declatation, primary health care includes things such as promotion of food supply and proper nutrition, adequate supply of safe water and adequate sanitation, and requires the inwollwement, in addition to the health sector, all related sectors and aspects of development, such as agriculture, food, industry, education, housing, public works, communications. Furthermore, primary health care relies on lay care, community involvement and participation, and all kinds of para-medical professionals such as midwives, nurses, and traditional health practitioners. Finally, national policies, strategies and plans of action are rejuired to launch and sustain primary health care programmes.

Clearly, the Declaration of Alma-Ata marks a fundamental, or even revolutionary, shift in the thrust of WHO priorities (De Leeuw, 1985, Pannenborg, 1978). Although the ideology of primary health care has met with much criticism (cf. Van Amelsvoort (1983) on the disbelief about the value of PHC for developed countries; Bryant (1984), on insufficient manpower planning; Carstairs (1984) on political barriers to PHC; Heydelberg (1985) on the dualism between traditional medical care and lay care; De Kadt (1982) on the weakness of ideology pertaining to policy; and Navarro (1984) on the fundamental disregard for the relation between class struggle and alienation, and health status), the main thrust of the idea that thealth is made by more than the adequate delivery of services is still standing up, and by now extended ${ }^{*}$ through subsequent WHO-policies, in several policies of nations endorsing the philosophy of primary health care, and health for all (Gunning-Schepers, 1986). Moreover, Muller (1983) views primary health care to be also of importance for developed countries: an ideology of adequate basic health services (not just care, but also collective prewention and a multisectoral scope) is also to be pursued in western nations.

\subsubsection{Health for All by the Year 2000}

Primary Health Care may be viewed as the first operational stage of the implementation of a major WHO programme, "Health for All by the Year 2000" (HFA2000). A year before the Alma Ata conference, the World Health Assembly, during its thirtieth session, decided that the main social turget of governments and the World Health Organization in the coming decades should be the attainment by all the citizens of the world by the year 2000 of a level of health that will permit them to lead a socially and economically productive life (WHA $30.43,1977$ ). It was agreed that each of the WHO regions should develop regional strategies for the attainment of the goals of HFA2000. Primary health care was to be a leading principle in this development.

Initially, in the European region of WHO no urgent need was felt to develop a regionall strategy for MFA2000; it was felt that the level of health in the region was sufficiently high (De Leeuw, 1985). Work on a regional strategy did not receive a high priority, although member states had committed themselves to that work. But due to personal commitments at the managerial level of the European regional office, work was taken up more rigorously. A needs assessment of, and strategic framework for tackling them in the European region, was prepared (between September 1978, and September, 1980 (De Leeuw, 1985, p. 39)) and published in popular form ( $\mathrm{O}^{\prime} \mathrm{Neill}, 1983$ ). It appeared that the main issue in European thealth status was inequity in health, between groups within countries, and also between countries themselves. The member states of the region committed themselves to this regional strategy, and the development of national plans concordant with the WHO/EURO plan.

To support these developments, the European regional office started to develop indicators for 
the monitoring of improwing health status in the member states and decreasing health inequities. This development stalled because it was felt that first of all tangible targets thad to be set which could be pursued by the member stares. Major efforts in the development of these targets took place between July, 1982 and July 1983, and November, 1983 and July, 1984. During this period the scope and thrust of indicators thas shifted from detailed contentoriented targets toward targets aimed at structural determinants of health along the lines of the work of Blum and Lalonde (De Leeuw, 1989, cf. also Annex D). De Leeuw (1985) credits personall efforts of some influential staff members of WHOMEURO for this shift away from health care oriented toward structural modes, although these changes may certainly be ascribed to societal developments as well, only voiced by these staff members.

The target approach, leading to strategic policy-making, has been taken up by many mational health officials (Van Eijk, 1987a), and may thus be called a useful contribution by WHO to national health policy development (Gunning-Schepers, 1986).

\subsubsection{Health promotion}

The specific problems of industrialized welfare states called for an operational programme to tackle health inequities beyond the ideology of primary health care. In the light of the European Regional Strategy for HFA2000, WHO developed a "health promotion" programme. Although the term "health promotion" has been used earlier in a North American context aiming at lifestyles and behaviour modification, WHO added new impetus to the concept. The programme originated in the European regional office, and has clearly been influenced by a social concept of health as described in 2.1 (cf. Kickbusch, 1981, Garretsen \& Raat, 1989). Health promotion thereby also focusses on the other determinants of health apart from lifestyles, and takes as a premise that people themselves (and their elected representatives) are the most important factor in influencing all of these determinants. In a series of discussion documents and conferences the European vision of health promotion was gradually developed further. Health promotion was thus defined to be "the process of enabling individuals and communities to increase control over the determinants of health, and thereby to improve their health' (WHO, 1986, De Leeuw, 1989). This process employs various complementary approaches, such as health education, facilitation, and regulation (cf. 3.2.2.3). Its focus is on advocacy, enabling and mediation of health (more directly related to an extended typology of health education (Tones, 1987)); building healthy public policy (cf. 3.2); creation of supportive environments (cf. 2.1); strengthening of community action; development of personal skills; reorientation of health services; a public commiment to the thrust of health promotion; and support of the concept on international fora and in national policies and strategies for the improvement of health (WHO, Health \& Welfare Canada. Canadian Public Health Association, 1986).

Development of healthy public policy thus becomes an important prerequisite of healoh promotion. This is reaffirmed in the Adelaide Recommendations (WHO \& Commonwealth Department of Community Services and Health, 1988), calling for more specific action in the light of making healthy public policies in relation to public accountability for health, support of the health of women, the area of food and nutrition, tobacco and alcohol programmes, and the creation of supportive environments.

De Leeuw (1989) goes deeper into the essential concepts, practical examples and research gaps of the health promotion field. In this study we will further explore the notion of healthy public policy in chapter three.

\subsection{Nota 2000}

The Netherlands' health memorandum Nota 2000 is explicitly presented as the consequence of, among others, a commitment to the European regional strategy for Health for All (Haslinghuis, 1987). It may therefore be viewed as one culminating point of the develop- 
ments described above. In this section we will review the chronology of its development, characteristics of the document, and briefly go into the question what the status of a memorandum (or "Nota") in policy terms will be. In doing so, we will reflect on the health policy definition given in 2.1 .

\subsubsection{Chronollogy}

Clarification of the chronology of the devellopment of a certain policy is an important aspect of the study of policies in general; such a chronology will shed light on interests at stake. actors playing a role, and relative priorities given to the policy at hand.

Around 1980/1981 the Department of Health (of the Ministry of Health and Environment) started integrating two major policy-making units: Long Term Planning (dealing with strategic long-term matters pertaining to health) and the Staffbureau of Policy Development (occupied with legislation on infrastructure of health care delivery, political aspects of health policy, and research programming). The new director of the newly created Staffbureau Policy Development (STABO) had high affinity with long-range planning for health on the basis of the works of Blum, and he and his staff had close contacts with WHO/EURO staff developing the European HFA2000 strategy. Along with the development and operationalization of the latter, inside the Department of Health there was a growing awareness that it should be possible to develop future-oriented health policies. The director-general, and finally the Minister of Health were won over on the idea.

In the presentation of the health budget and her policy intentions to parliament early 1983 (and in fact in her last days in government; elections were to be held that same year), the minister reflected on efforts on the intemational fora, and in countries such as Sweden, USA, Canada and Japan to establish long-range priorities for health (Tweede Kamer, 1983a, p. 58). She urged parliament to create a clear policy framework to set priorities, and suggested to establish a study group to develop a range of future scenarios for health in order to weigh these priorities properly. The policy framework was to be laid down in a memorandum, 'Priorities of policy in relation to public health until the year 2000'. This was promised to be presented to parliament in 1984. An very rough outline of the document was presented to parliament in late 1983 , and it is noteworthy that the sixty lines of text devoted to the document seem to be a near-perfect translation of an abstract of the regional strategy (Tweede Kamer, 1983b, p. 108).

The situation within the Department of Health with regard to the status of the document and the study group was not entirely clear. The Steering Group Future Scenarios for Health (STG) was inaugurated in March 1983, supported by a small sub-unit (Section Long Range) of STABO, and some work was done on the policy framework itself. It was felt that the document should be the translation of the scientific analyses into political priorities. At least three staff nembers were appointed to work on the issue, but this was a relative small staffing. In the course of 1983 and 1984 various units of the Department of Health were asked to give their views on future developments. Work on the memorandum thus became fragmented, as no oflicial focal point for the work was established.

A first concrete outline of the report was presented in August 1984, at a WHO conference on planning and management for health (Department of Health, 1984). The outline of the

1

Information for this section has been obtained from three sources: 1. a search in the on-line computer information service of the Netherlands" government PARAC (data on parliamentary deliberations), 2 . a review of the flles of the ministerial unit rasponsible for production of Nota 2000 (data on in-house discussions and prionity shifts. It is noteworthy what these files were found to be incomplete; of five draft versions of Nota 2000 , only the last i wo could be retrieved. Correspondence from the unit with outs ide informers turned out to be very limiledy, and 3 . intervews with three key officials: the former director of the responsibie unit, a former semior staff member of the anit who had been working on Nota 2000 , and the present sub-unit director responsible for thealth pollicy development cobrdination. 
document was based on an extended version of the Health Fild Concept (Figure 2.2), and leaning heavily on the future scenarios which were expected to be produced in the very near future. However, development of the whole range of these studies stalled. The investigators encountered many methodological problems, and only very limited number of studies wert

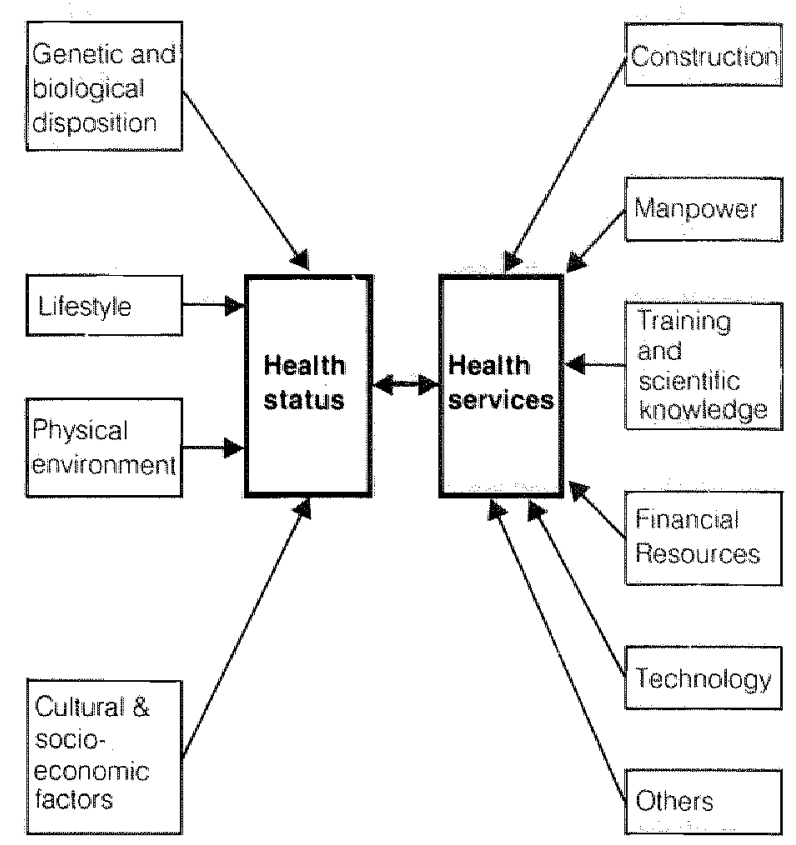

Figure 2.2. The Health 2000 Report Model (Dept. of Health, 1984)

produced in the short run.

Further development of the memorandum thereby became largely an in-house exercise, where neither the vision and scope of the document, nor official responsibilities for its production became clear.

Furthermore, it was felt that 'counterforces' were beginning to grow inside the department. Some departmental units may have felt that STABO became a mini-ministry in itself. Production of a report "Public health policy in times of limited means" (Tweede Kamer, 1984) was by STABO felt to be counterproductive to the ends of the future health policy memorandum.

Also, it became clear that the memorandum could not be presented to parliament in 7984 . In subsequent drafts, the size of the document grew disproportionally; some staff clearly wanted to include their own hobby horses extensively. A good example is an expose of forty pages on international health relations in one of the drafts, finally reduced to only one page in Nota 2000. Other interest areas were left out, as there was no unequivocal expertise on the issue within the department. For instance, women"s thealth only became included in the last draft. A retrospective evaluation by both former staff members of the last stages of production of the document: "The document is unbalanced, not entirely consistent, and without much character, but the best we could do.'

Henceforth, further development of the memorandum was been considered difficult, but in 
Spite of that, in the summer of 1985 the strategic decision was taken by STABO to present the document in the spring of 1986. In May, 1986, there were elections and the session of the Cabinet would teminate. Uncertainty existed among staff as to what the next session would bring with regard to future-oriented health policy. It was implicitly clear that yet another centre-right Cabinet would focus on short-term large-scale restructuring of the health system. In the summer of 1985, STABO started to consult a limited number of outside experts. They seem to have been chosen on the basis of personal contacts. Drafts of the memorandum amounted mean while to several hundreds of pages. An opinion-leading cardiologist reacted (on August, 14) that although the work in itself was commendable, the size and lay-out of the document were hardly surveyable, and that some content areas were very vague. He urged STABO to write a concise policy summary. A mental health researcher found (August, 22) the mental health section to the point, though with some "romantic" notions about the possible prevention of mental health conditions. An intemal consultation (August, 28) with the Health Edacation unit revealed the same types of criticism, in addition to unclarity on the purpose of the document. An internal consultation with the Directorate General Health Care (AGZ, August, 28) revealed exactly the same criticism, and the counterparts of STABO felt that the memorandum could be written in a politically more daring style. At the same time the $A C Z$ staff acknowledged that on various issues, such as prevention of mental health conditions, and the implications of a comprehensive health policy, the available information was very limited. In a session with the Products Safety Unit (September 5), staff agreed to translate existing policies into the memorandum framework; this was not considered to be much of an effort.

On October 1, 1985, there was a meeting of the editorial group of the memorandum with the director-general of health. Generally, there was a high degree of agreement with the scope and lay-out of the document, although a waming was given not to forget the health care aspects of health policy. The department should aim for Nota 2000 to become a major policy document on which future Cabinets may base their programmes. To that end, every four years a similar 'progress memorandum" would have to be published.

In a reaction on October, 9 , an outside health education specialist remarked that the draft he reviewed is inconsistent in several aspects: the officialese and analytic parts of the document are too much intertwined, the responsibility of consumers is denounced, future trends in lifestyles and their consequences for mortality, morbidity and well-being are underexposed, and finally there is an unresolved dualism between the ideal of health as a societal objective, and the factual situation where infrastructure and budgets dictate the functions of only health care services.

Three weeks later (November, 1), al professor of health sciences remarked that the model used for Nota 2000 is inappropriate; hereditary factors, environments, lifestyles and health services miy be determinants of health, but the intervention level was left out of the model of the extended Health Field Concept (figure 2.2 , above). The critique said that interventions may be aimed at endogenous determinants (hereditary factors) through medical health care; and at exogenous determinants (environment, lifestyles, socio-economic services) through collective health actions. It suggested, therefore, restructuring the policy model for the Nota 2000 .

An evaluation by STABO of all the reactions on December 18 in preparation of a Ministry of Health Directorate Council. suggested adding a section on intersectoral, or rather facet policy (intersectoral policy presuming that for all problems many sectors have to be involved, while facet policy aims at bringing together relevant sectors around a problem analyzed), and to clarify concrete policy implications of Nota 2000 further. The status of the document still was to be "policy". Although the scope on health and not on services may be a difficult one inside the Ministry, it was felt that this still is the crucial characteristic of the document, and perhaps should be extended even further. On February 20,1986, the problems seem to have 
been tackled by the various units of the ministry.

Nevertheless, the policy status of the document was lowered after the Directorate Council meeting. Concrete policies would have to be presented in follow-up documents

A final draft of Nota 2000 was discussed on April 3, 1986 in the Interdepartmental Coordination Committee Welfare Policy (a group of key civil servants from ministries such as Social Affairs, Environmental Protection \& Public Housing, Internal Affärs, General Affairs, Economic Affairs, Education \& Science, Agriculture and Justice and govermmental units such as the Socio-Cultural Planning Office and the Welfare Councily. Although the members of the Committee commended STABO for the work done, the status of Nota 2000 wis decreased further. The size of the document was felt to be a problem, and it would have to be made clear that only a very limited par of the document could come under the responsibility of the Cabinet. The STABO-representative suggested that the policy intentions may be printed on paper of a different color. Concrete policy-making would be postponed to subsequent Cabinet periods, and STABO agreed to negotiate financial matters pertaining to possible policy shifts further with the Ministry of Finance and the Ministry of Economic Affairs.

In one of the last drafts of Nota 2000 (Spring, 1986), chapter 10 ("Implementation') was rewritten. Ten concrete policy intentions are given:

1. establishment of working groups establishing concrete options for prevention and facet policy,

2. presentation of a memorandum 'Alcohol \& Society' in 1986 ,

3. establishment of a Committee drafting recommendations for strengthening health facet policy at the national level,

4. support of, and consultation with interest groups for further implementation of care models (Ch. 6 of Nota 2000),

5. further operationalization of care policy toward the year 2000 with regard to the elderly, cancer patients, accidents, and alcohol abuse,

6. establishment of a study group advising on institutional and instrumental aspects of health policy, and monitoring developments in this field on local levels,

7. definitive proposals for a comprehensive health insurance system in 1986 ,

8. organization of a set of three to five study days about Nota 2000 ,

9. further development of adequate collection of health statistics appropriate to prevention and facet health policy, and

10.establishment of new scenario committees, adjustment of the outcomes of alleady available scenarios, and development of instruments to implement findings on local levels.

In the final version of the memorandum, only seven intentions remained on the pink pages, and of a less definitiwe nature; the order in which the above intentions are presented became $5,2,6$ (allihough the proposals for studying these aspects are less rigorous), 4,7 (but "introduction of a comprehensive system" has been replaced by "further exploration of health insurance system changes" $) .8$, and 9 .

It may be concluded that the intentions aiming at formal consultation with interest groups and more daring suggestions to establish groups to work on facet (intersectoral) policy and prevention policy (in short: health policy), are left out under severe pressure: this seems strange, as all the implicit intentions presented throughout Nota 2000 would lead the reacler to conclude that these consultation and working group recommendations are the only sensible conclusions of the memorandum.

Reflecting on the health policy definition given in 2.1 , it may be clear that the pink pages of Nota 2000 hardly may be called a health policy. At the most they give a framework for 
development of fuire health policy.

On A pril 28, 1986, Nota 2000 is published and sent to parliament as a discussion document with a separate section on policy intentions.

In the Orficial Gazette, societal and professional groups were asked to react on the memoran. dum on June, 18.

Under a new post-election Cabinet, a Committee Structure and Financing of Health Care ("Commissie-Dekker") was inaugurated on August 25, 1986. The Committee reported on March 26, 1987. It focused entirely on structural and financial/medical-technical aspects of the Netherlands ${ }^{\circ}$ health care system.

On April 5, 1989, the first follow-up document ('Kemdocument') on Nota 2000 was officially presented.

\subsubsection{Characteristics}

The governmental memorandum Nota 2000 will be characterized in some short statements, in order to clarify the content and conceptual framework we will be working with in this investigation. Emphasis will be laid on policy relevant characteristics. A short description of the scope of the Nota 2000 is necessary before we proceed to establishing these policy relevant characteristics.

\section{Scope}

The Nota 2000 is a series of health oriented policy and discussion documents, the first two being published April 1986 (kamerstuk 19 500, nrs. 1-2), the third in May 1987 (nr. 3); follow-up documents will be published regularly.

The largest part of Nota 2000 is intended to be analytic in nature, describing health status for different population groups and disease categories, and prognoses of their development in the future. Only five pages of nrs. 1-2, printed on pink paper, relate to policy, and then only as 'intended policy'. No concrete pollicy instruments are operationalized.'

Nevertheless, these are the pages to which the Cabinet has committed itself. Number three is an annotated parliamentary hearing proposal, including an overview of the reactions on the initial document.

The document is not so much a political statement as an 'objective' description of the state of affairs put together by non-elected ministerial bureaucrats, ideally on the bases of reports of Scenario Committees. "These Committees consist of panels of experts with the assignment to produce one (or more) reports on the present state of affairs, "worst", 'best" and "preferred' scenarios for future developments, and policy recommenctations, with regard to their field of expertise (e.g. 'Cardiovascular disease", 'Rheumatology", "Technology assessment', "Lifesty. les", etc.). The Scenario Committee Reports are not exclusively used for the Nota 2000; they are available to any interested person, group or institution.

Because of the nature of Nota 2000, the total document so far comprises of 406 pages of data, policy options and constraints, mixed with futures scenarios.

The Nota 2000 is not a policy position paper in the traditional sense. According to the "Introduction", the document tries to open up discussion on future developments and longterm planning for health. The memorandums conclude with a section "intended policy", rather than with definite measures and interventions. Shaping of the factual policy is expected to take quite a long period and involve considerable effort and communication with organizations involved.

The authors of Nota 2000 have opted for a series of open discussion forums with organiza-

2

'To operationalize" we will take to mean: make functional instruments (to camy out a policy) awailable and operational (i.e. assure that they work) 


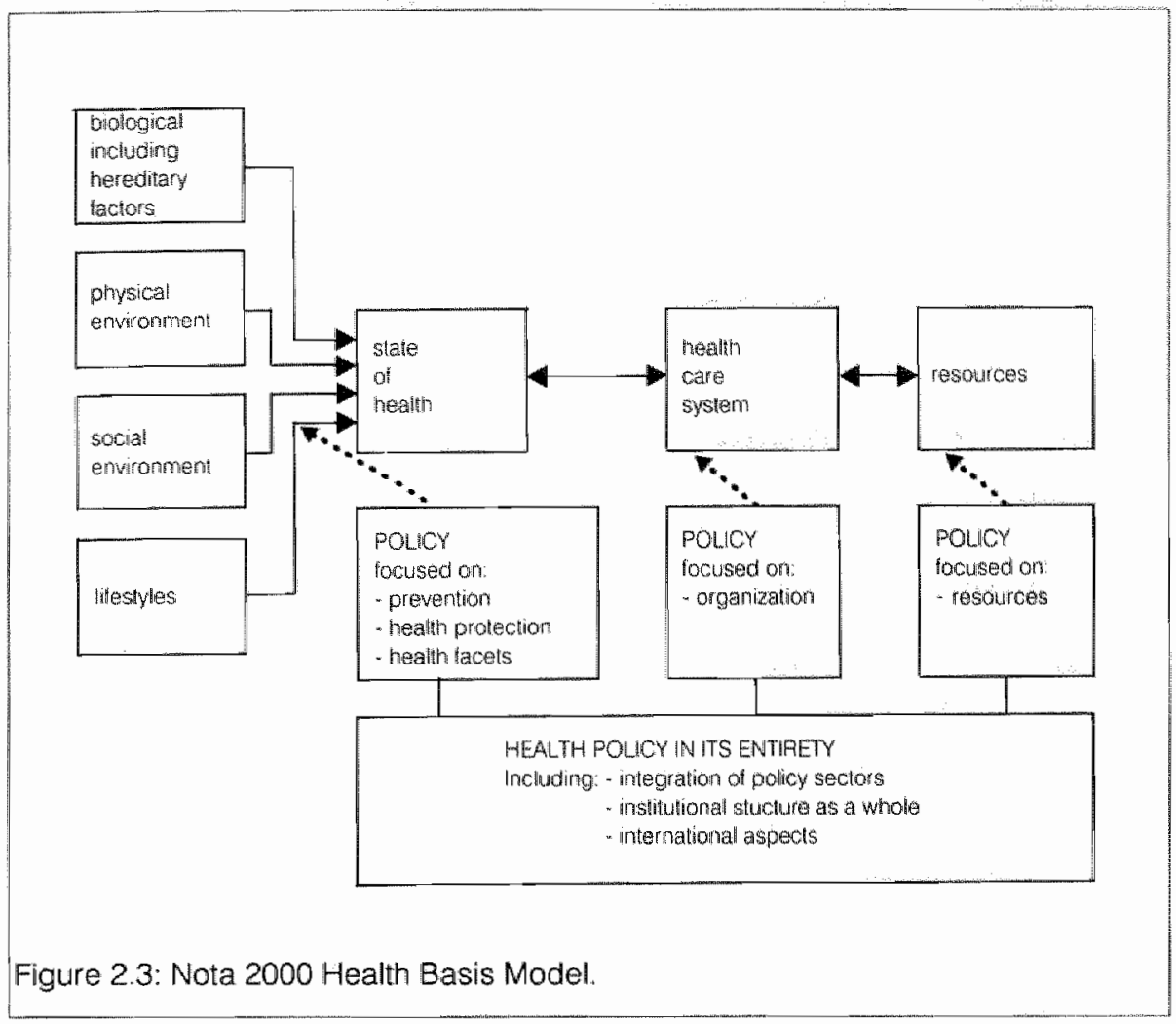

tions and professionals involved, in onder to clarify the interpretation of the document. Reports of these 'study days" or seminars are freely available.

\section{Characteristics}

- Nota 2000 is a future-oriented and goal-seeking policy intention document; it is a strategic memorandum (intended to shape strategic policy-making, i.e. the document itself plays a crucial role in further establishment of plans).

- The intended policy is explicitly health oriented, and not health care (organizational, or health care structure) oriented.

- A Health Basis Model is used to distinguish among the factors and environments influencing health and different types of policy related to these determinants (figure 2.3).

Presumably, the Model would help distinguish policy options and structure prioritysetting for future policies and future support policies.

- Two main intended policy orientations shape Nota 2000:

a. Prevention policy. This "policy system" aims at a more integral and comprehensive view of all prevention modes (health education, environmental protection, population screening, etc.) and preventable causes of ill health, and eventually health promotion in the widest sense.

b. Facet policy. The fact that 'health' is a complex and complicated determined capacity of humans to perform valued tasks is recognized. The logical implication is, then, that all policy and societal sectors may be affecting health. This 'policy system' aims at increasing the visibility of the health component in all relevant policy and societal sectors by the 
Ministry of Welfare, Heath and Cultural Affairs, and eventually participating in estabIishmient of health-relevant policies outside the traditional health sector.

- The need for support policies is recognized. Intended policy would aim at financial and structural (manpower, infra-structure, information transfer, research) support of the other policy systemts. Setting up a "contents budget' ("inhoudelijk FOGM") in which health states and conditions in the population are directly related to various imvestments and intervention structured through the Health Basis Model, apart from a structural input"financhal budget" (financieel FOGM") is strongly recommended. The "contents budget" sllould allocate resources and services for health and social welfare, while the "financial budget" would remain to be a monetary instrument.

\subsubsection{A discussion document}

On April 28, 1986, Nota 2000 was published and sent to parliament as a discussion document with a separate section on policy intentions.

In the Official Gazette (Staatscourant), societal and professional groups were asked to react on the memorandum on June, 18.

In this section the discussions will be reviewed. Discussions have taken place in Parliament and in five disscussion seminars in November, 1986 (Schrameijer et all. 1987).

Only two organizations have reacted on the announcement in the Officlal Gazette: the Association of Dutch Health Insurance Funds (VNZ), and the Cross Association (Nationale Kruisvereniging, a large out-patient service NGO), both on September, 26. VNZ focuses understandably - on the aspects of care and financing, and suggests an altemative to Nota 2000 in which free market principles and more comprehensive insurance schemes are included. The plan is more compatible with the suggestions of the Dekker-Committee than it is with the policy intentions of Nota 2000.

The Cross Association is very enthused by Nota 2000, and would like to make it clear that there is a crucial role for the organization in the provision of home care and prevention, and contribution to further establishment of local facet policies. Newertheless, the NK in its reaction also largely deals with problems of the health care system, as they seem to be more imminent.

\section{Parliament}

In the annual parliamentary Ministry of Welfare, Health and Cultural Affairs budget deliberations, the secretary of state in October, 1986, presented Nota 2000 formally to parliament. In their responses, the representatives acknowledged that a reorientation of policy for health was appropriate ${ }_{n}$ but that Nota 2000 offered a very limited instrumentarium to really carry out that orientation. The Christian-Democratic representative asked for a concise follow-up document to be presented to parliament after the deliberations on the Dekkerreport (Handelingen TK17, 1986, p. 880). Another Christian-Democratic representative called for more rigorous attention for strengthening prevention policy (p. 885), while the Liberal representative argued that in spite of all that the prevention and facet policies intended, disease and ill health will continue to exist, and that cate policy should thus continue to have high priority (p. 894). In his rebuttal, the secretary of state for health promised to send parliament an annotated parliamentary hearing proposal, instead of a more concrete policy proposal.

This hearing proposal was sent to parliament on May, 25 1987. In preparation of the hearing, staff members of STABO gave interested parliamentary representatives a briefing on the 
content of Nota 2000 and reactions from the five discussion seminars held in November; 1986.

In the annual parliamentary Ministry of Welfare, Health and Culmal Affairg budget deliberations, the secretary of state in September 1987 reaffirmed that, in spite of the wide attention given to the proposals of the Dekker-Committee proposals, Nota 2000 was still one of the pillars governmental health policy was standing on (Tweede Kamer, 1987a). ln that light, a health policy research memorandum was to be presented to parliament, based on the lines of Nota 2000. Moreover, the FOGM (budget overwiew health care and welfare) lay-out was brought in concondance with the objectives of Nota 2000 (Tweede Kamer, 1987b). On the 21 st of September, 1987 , the parliamentary committee for health was in session to discuss Nota 2000 (Handelingen UCV, 1987).

In general, the seven representatives present at the meeting supported a reorientation of the Netherlands" health policies. However, Nota 2000 was felt to be in general vague (Liberal representative) or vague on its policy instrumentarium (Social-Democratic representative). The majority, however, concluded that further devellopment of health policy should be pursued. Especially the Christian-Democratic and Social-Democratic representatives urged the secretary of state to produce a concrete follow-up policy soon. In addition, the SocialDemocratic representative asked for more attention for health policy on local and regional levels. Consensus existed on the need to strengthen epidemiological capacities, as a prerequisite for adequate health policy.

The Committee seemed to be confused about the relation between Nota 2000 and the recommendations of the Dekker-Committee (Commissie Structur en Financiering van de Gezondheidszorg, 1987), and feared that two mainstreams of policy might be counterproductive to both plans. Therefore, especially the Social-Democratic representative asked that eventual implementation of the Dekker-proposals should not hinder further development of health policy. Finally, two confessional (religious party) representatives urged the secretary of state for health to include the outcomes of scenario studies in future governmental memorandums and white papers, or to formulate separate position papers on the outcomes of such scenario studies.

In the plenary session of parliament, the Secretary of State for Health subsequently promised to present parliament with a Kerndocument ("core document') further concretizing the policy intentions of Nota 2000 in the second half of 1988 (Tweede Kamer, 1987c).

\section{Interest group discussions}

Toward the end of 1986 , on several fora were held on Nota 2000 . Groups perceived to have an interest in Nota 2000 (Nota 2000 being promotive or detrimental to group or organizational objectives) were invited to participate. In November, five seminars were organized: Nota 2000 and primary health; Nota 2000 and institutional care; Nota 2000 and mental health; health education, prevention and facet policy in Nota 2000; and Nota 2000, managerial and institutional aspects (reported in Schrameijer et al., 1987). The scientific journal Gezondheid en Samenlewing (1986) devoted a special issue to Nota 2000. The reactions are condensed and summarized by Dekker (1989) and Van Eijk (1987b).

The reactions to Nota 2000 were extremelly diverse. Some groups totally subscribed to the views presented in it, and even argue for fast implementation of its intentions. Other groups completely repudiated the whole document, and argued that it is not dealing with the real problems.

Nevertheless, a majority of the groups involved in the discussions felt that it is a good thing to have an analytic piece like Nota 2000 , and to give health policy based on that analysis a chance. However, the vagueness of vision, operationalization and implementation of such a policy frustrates many of the groups. Two major 'pièces de resistance' nurned out to be the unclear status of the document (discussion or policy document), and an inadequate notion of 
efficiency in health care (where health care is considered to be inefficient, and prevention efficienit) in Nota 2000. If is not at all clear to the interested groups whether Nota 2000 is a discussion memorandum, a policy paper, a budget cutting white paper, or perhaps it may even be a diversion from the real problems in health care in the 1980 s.

Implicit in Nota 2000 is the idea that the 'new interventions' (the prevention and facet componenits) would yield higher health gains than the traditional ones. This idea is denounced by a large proportion of the groups participating in the discussions. Prevention, they say, thay not be cost-effective: a person not dying from lung cancer today may get AIDS tomorrow (a far more costly condition to treat). Health gains in terms of reduction of mortality and morbidity through prewentive interventions and home care among the elderly may be expected to be minimal. Improvement of the quality of life instead of health gains in these terms was thought to be understated in Nota 2000.

So, with regard to the section "Health status and objectives" of Nota 2000, participants felt that methods to measure health gains are at present inappropriate. Further, setting health targets may be considered to be of strategic importance, but spelling those out might cause very contentious situations, politically as well as professionally.

As to prevention and facet policy, reactions have been quite diverse. Generally, participants called for more cost-effectiveness studies in the realm of prevention, and remarked that probably the financial gains of prevention would be minimal. As to facet policy, the discussion groups felt that Nota 2000 omitted the power factor in society. Interests at stake, organizational and professional turfs, and financial considerations all pertain to a notion of power which is poorly addressed in Nota 2000 . However, participants hardly suggested solutions for the problem. Generally, they felt that there should be some supportive role for government.

With regard to the organization of health care (its infrastructure), participants in the discussions: said that the contribution in Chapter six of Nota 2000 was minimal. No new solutions to the weak structure of community and primary health care were presented. Moreover, most participants agreed that the position of the patient and consumer is underemphasized.

The role of government in thealth policy is evaluated by participants to have an ambiguous nature. On the one hand, they said, central government is deregulating and decentralizing, and on the other, Nota 2000 calls for extensive governmental involvement in health. Especially the latter is seen to be very pretentious. Some participants argued for more rigorous regulation, but outside the health sector, and related to quality control with regard to health. threatening conditions.

As to financing and planning, participants largely focused on the institutional aspects, and anticipate on the report of the Dekker-Committee. Planning and financing health should becorne the responsibility of one body, while free market mechanisms should not hinder the uccessibility and acceptability of services, they felt. Furthermore, the groups suggest that government and parliament should establish content oriented priorities, and translate these into packages of services to be delivered.

Research and epidemiology are felt to be of crucial importance, but new instruments have to be developed to investigate health status and well-being.

Dekker (1989) summarizes the positions of the various groups (table 2.1).

Dekker asserts that the distinction berween the three categories in table 2.1 is rather rough, because very few groups were entirely satisfied, nor were the critical reactions only negative. When a 'support system' is to be found for health policy, i.e. a set of groups subscribing to the objectives of health policy, Delkker infers that preventive and welfare orientated sectors working for health are generally supportive of it, while the curative, medical-technical sector is not.

The tentative power division in Dutch health care (Van de Vrie \& Van Elzakker, 1988), suggests that those in favour of health policy are the less powerful groups, while the power- 
generally positive

* epidemiologists

* health educators

* prevention

* health scientists

" primary heallh services positive \& negative

* National Health

Council

* National Cross

Association

* general practitioners

* nurses

* welfare services

* mental health

* patient/consumer

* organizations generally negalive

"National Hospital

Council

* Association Health

Insurance Funds

"medical specialists

Table 2.1. Reactions to Nota 2000 by sector and profession (Dekker, 1989)

ful oppose it. Of course this it not very surprising. The latter groups have the highest stakes in the maintenance of the status quo in health care. We will return to this issue in chapter 7.

\subsection{Discussion and conclusion}

In this section we have reviewed the factors leading to the development of Nota 2000 . We have noted that already in the early 1970 s the scientific material was available to call for health policy. The Lalonde report was a landmark publication in which for the first time a comprehensive policy for health and its determinants was suggested. In spite of its drawbacks, the Lalonde report has set the pace and direction for other efforts, in many countries (USA, Sweden, etc.) and in international fora of WHO.

WHO, performing societal, demographic and epidemiological analyses, established a European regional strategy especially to tackle issues pertaining to inequities and health, acknowledging and endorsing many societal developments that had to be dealt with. Health promotion and healthy public policy are programmes to solve the problems found. In light of international commitments and similar developments in the Netherlands, an initially small group of bureaucrats suggested development of a future-oriented, strategic health policy memorandum. The plan was endorsed by the leaders of ministry of health, and a memorandum was promised to government. The further development of Nota 2000 took place within the ministry of health. However, civil serwants do not work in bureaucratic isolation. Thus, even when we found little evidence of 'outside inputs' in the developmental stages of Nota 2000 , it could be expected that bureaucrats honored outside information from other sources: Nota 2000 is one of very few documents with extensive lists of reference. In the negotiations over the status of Nota 2000 , it decreased from "major policy document" via "priority setting working document" to "discussion document".

It may be that because of its unclear, unthreatening status that during the developmental process both within the ministry, and between the ministry and outside informants interest in it seemed light. In Parliament atso, Nota 2000 seems to have been second on the list of priorities. Even in public discussions, there was little firm or heavy negotiation on the issue of health policy. We will return to these tentative observations in chapter six. 


\section{References}

Amelswoort, V. van (1983) Primary Health Care, historische aanloop tot een begrip. Medisch Contact, 15, pp. $437-439$

Blum, H. (1974, 1981) Planning for Health. Human Sciences Press, New York (1st and 2nd edition)

Bryant, J.H. (1984) Health services, health manpower, and universities in relation to health for all: an historical and future perspective. American Joumal of Public Health, 74 (7), pp. $714-719$

Carstairs, M. (1984) political and factional obstacles in attaining 'Health for Ali by the Year $2000^{\prime}$. Intemational Joumal of Sociall Psychiatry, $30(1 / 2)$, pp. 143-147

Churchman, C.W. (1967) 'Wicked problems', Management Science, 14 (4)

Commissie Structurur en Financiering van de Gezondheidszorg (1987) Bereidheid tot verandering. (Commissie-Dekker). "S-Gravenhage

Dekker, E. (1989) Gezondheidsbeleid en de Nederlandse gezondheidszorg. Ch. 26, pp. 297 308 in. Maas, P.J. van der, A. Hofman \& E.Dekker (eds.) Epidemiologie en gezondheidsbeleid. Reeks Gezondheidsbeleid 3, Samsom Stafleu, Alphen a/d Rijn

Department of Health (1984) Summary Outline of the Health 2000 Report The Netherlands. A short selection of HFA2000 Policy Issues in The Netherlands. WHO European Conference an Planning \& Management for Health, Staffbureau for Health Policy Development, 31 August, The Hague/Scheveningen

Doorslaer, E.K.A. (1987) Health, knowledge and the demand for medical care. An econometric analysis. Van Gorcum, Assen/Maastricht/Wolfeboro

Evans, R. (1982) A retrospective on the 'New Perspective'. Journal of Health Policy, Politics and $\mathrm{Law}, 7$ (2), pp. $325-344$

Eijk, E.A.M.J. van (1987a) Nota 2000: over de ontwikkeling van gezondheidsbeleid. Ch. 3, pp. 5-20 in: Universitaire Leergangen Gezondheidszorg (ed.) De Nota 2000: Theoretische en praktische aspecten van gezondheidsbeleid. Verslag symposium 26 september 1986.

Rijksuniversïteit Groningen, Groningen

Eijk, E. van (1987b) Inventarisatie van REACTIES op de 'Nota 2000'. Internal publication Ministry of Welfare, Health and Cultural Affairs, STABO, Rijswijk

Garretsen, H.F.L. \& H. Raat (1989) Gezondheid in de vier grote steden. Serie Voorstudies en achtergronden nr. V65. Wetenschappelijke Raad voor het Regeringsbeleid, 's-Grawenhage

Gezondheid en Samenleving (1986) 2000 over 2000. Gezondheid en Samenleving. 7 (4), pp. $178-228$

Gunning-Schepers, L.J. (1986) Health for All by the Year 2000: a mere slogan or a workable formula? Health Policy, 6, pp. 227-237

Gunning-Schepers, L. (1988) The health benefits of prevention. Dissertation, Erasmus Universiteit Rotterdam

Handelingen TK17 (1986) Tweede Kamer. Volksgezondheid. TK17, 29 oktober 1986. 'sGiravenhage

Handelingen UCV (1987) Vergadering UCV Vaste Commissie voor de Volksgezondheid, II 
UCV 1987-1988, nr. 003, pp. 1-35

Haslinghuis, D. (1987) Memorandum health 2000: intersectoral planning for health in the Netherlands. Health Promotion - An International Joumal. 2 (4), pp. 393-399

Heydelberg, E. (1985) Het Medusa-hoofd en de zonnebank. Tijdschrift voor Gezondheid en Politiek, 1. (April), p. 36

Hancock, T. (1986) Lalonde and beyond: Looking back at "A New Perspective on the Health of Canadians'. Health Promotion, an international journal, 1 (1), pp. 93-100

Hoogerwerf, A. (1982) Overheidsbeleid. 2de druk, Samsom-Stafleu, Alphen a/d Rijn

Illich, I. (1976) Limits to medicine: medical nemesis, the expropriation of health. Marion Boars, London

Kadt, E. de (1982) Ideology, social policy, health and health services: a field of complex interactions. Social Science \& Medicine, 16 (6), pp. 741-752

Kickbusch, I, (1981) Involvement in Health: a social concept of health education. International Joumal of Health Education, 24 (4), supplement December

Kickbusch, I. (1986) Health promotion: a global perspective. CJPH, 77 (sep/oct) pp. 321 . 326

Laframboise, H.L. (1973) Health policy. Breaking the problem down into more manageable segments. Canadian Medical Association Joumal, Feb. 3, 178, pp. 388-393

Lalonde, M. (1974) A new perspective on the health of Canadians - a working document. Govemment of Canada/Gouvernement du Canada, Ottawa

Leeuw, E. de (1985) 2000 - A health odyssey. University of Limburg, Maastricht

Leeww, E de (1989) The sane revolution. Van Gorcum, Assen/Maastricht

Maas, P.J. van der \& J.D.F. Habbema (1987) Modelontwikkeling en informatie: twee voorwaarden voor gezondheidsbeleid. pp. 112-126 in: Dekker, E. \& B. Wijnberg (eds.) Gezondheidsbeleid over de grenzen wan de gezondheidszorg. Reeks Gezondheidsbeleid, deel 1, Samsom Stafleu, Alphen a/d Rijn

Mckeown, T. (1979) The role of medicine. Basil Blackwell, Oxford

Muller, F. (1983) Primaire gezondheidszorg, de betekenis van de "Primary Health Care" benadering voor Nederland. Medisch Contact, 41, pp. 1303 1306

Nawarro, V. (1984) A critique of the ideological and political position of the Brandt Report and the Alma Ata Declaration. International Joumal of Health Services, $14(2)$, pp. 159.172

O'Neill, P. (1983) Health Crisis 2000. Heinemann, London

Pannenborg, Ch. O. (1978) A new international health order. An inquiry into the international relations of world health and medical care. Davids Decor, Alblasserdam

Pederson, A.P., R.K. Edwards, M. Kelner, V.W. Marshall \& K.R. Allison (1988) Coordinating healthy public policy. An analytic literature review and bibliography. Minister of National Health and Welfare, Ottawa

Schrameijer, F., J.M. Boot, E. Jurg, H. Saan, C. Tonnaer \& J, van der Velden (eds.) (1987) De Nota 2000 ter discussie. Reeks Gezondheidsbeleid nr. 2, Samsom-Stafleu, Alphen a/d Rijn 
Tones, B.K. (1987) Promoting health: the contribution of health education. In: Education for Health in Europe, a report on WHO consultation on co-ordinated infrastructure within a health promotion strategy. WHO/EURO, Copenhagen

Tweede Kamer (1983a) Rijksbegroting VoMil, zitting 1982-1983, 17600 , hoofdstuk XVM, nr. 2

Tweedle Kamer (1983b) Rijksbegroting WVC, zitting 1983-1984, 18100 , hoofdstuk XVT, nr. 2

Tweede Kamer (1984) Volksgezondheid bij beperkte middelen. zitting 1983-1984, 18108 , nrs. $1-2$

Tweede Kamer (1986) Nota 2000. Over de ontwikkeling van gezondheidsbeleid: feiten, beschouwingen en beleidsvoomemens (Nota 2000), zitting 1985-1986, 19 500, nrs. 1-2-3

Tweede Kamer (1987a) Rijksbegroting voor het jaar 1988. Welzijn, Volkgezondheid en

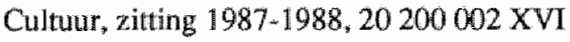

Tweede Kamer (1987b) Rijksbegroting voor het jaar 1988. Welzijn, Volksgezondheid en Cultuur, brief wan de staatssecretaris, 17.09, zitting 1987-1988,20200007 XVI

Tweede Kamer (1987b) Rijksbegroting voor het jaar 1988. Welzijn, Volksgezondheid en Cultuur, mondeling overleg met de staatssecretaris, 30.09, zitting 1987-1988, 20200012 XVI

Vrie, R. van de \& A. van Elzakker (1988) Gezondheidsbeleid en machtsversnippering. 1: gezondheidsbeleid en de verdeling van macht. Medisch Contact, 43 (38), pp. 1119-1122

Werff, A. van der (1976) Organizing health care systems, a developmental approach. Dissertation, University of Utrecht

WHA, World Health Assembly (1977) Resolution 30.43 on 'Health for All by the Year 2000*. Geneva

WHO/UNICEF (1975) Joint study on altemative approaches to meeting basic health needs of populations in developing countries. Report JC20/UNICEF - WHO/75.2, Geneva

WHO/UNICEF (1978) Alma-Ata 1978. Primary Health Care. Health for All-series nr. 1, Genewa

WHO (1986) Health promotion - Concept and Principles - In Action - A Policy Framework. Copendagen

WHO, Heath \& Welfare Canada, Canadian Public Health Association (1986) Ottawa Charter for Health Promotion. An International Conference on Health Promotion - The Move Towards A New Public Health, nov. 17-21, Ottawa

WHO \& Commonwealth Department of Community Services and Health (1988) Report on the Adelaide Conference - Healthy Public policy. Second Intemational Conference on Health Promotion, apr 5-9, Adelaide 


\section{HEALTHY PUBLIC POLICY}

In this chapter we will delineate two major modes of policy for health: public health policy, and healthy public policy. Public health policy is traditionally viewed as that part of government policy concemed with the public's health, focussing on aspects of deliwery and financing the services and protective devices for health (tactical aspects of achieving the goal of public health). Healthy public policy, on the contrary, is more strategic (serving long-term purposes in itself): this type of policy sets objectives (better health) and explores unconditionally ways by which these objectives may be reached. As we have seen in chapter 2 , these ways go beyond the traditional boundaries of the health care system.

In this chapter we will briefly describe the traditional policy mode, its development and the pitfalls and bottlenecks it has faced in the Netherlands. We will not do so extensively; there have been other studies that have done this more successfully, and it is unnecessary to replicate them. The second half of the chapter is a review of the literature on "the new health policy mode'; this will be done more extensively, as there are relatively few studies that have attempted this

\subsection{Public health policy}

Juffermans (1982) distinguishes two clear breaking-points in the history of Netherlands' public health policies: 1865 and 1945 . Regarding the post-1945 period, he sees a distinction into three phases. The latter period will be reviewed in 3.1 .1 , as it has immediate relevance for the possible emergence of healthy public policy in the Netherlands.

Regarding the pre-1865 period, Juffermans views national governmental health interventions as minimal. Health policy is in this period characterized as "passive" (p.112). In at marxistsocialist analysis (aided by an overview by Querido (1965)), this passive stance of government is attributed to the fact that care for public health was regarded unnecessary because the proletariat was not yet an economic force of importance: there was a large labour market, and health of the worker was therefore not considered to be of importance. The "Geneeskundige staatsregeling* (Medical State Regulation) dating back to 1818 was standing on two pillars: private philanthropy regarding pauper-dom in the proletariat, and legal-policing control of that part of the population.

In 1865, another Medical State Regulation was enforced: it set the standards for the medical profession, and govemmental control on delivery of services. However, the latter part tumed out to be very meager in implementation: only two medical officers were appointed, and the budgets were continuously cut. This induced that the Netherlands Medical Association had 
the opportunity to acquire considerable professional, socio-economic and curation-oriented powers. As Juffermans assents (p. 119): "In the course of history the state inertia with regard to prewertative services was so much, that thereby created lacunae had to be filled by private initiative".

Newertheless, in 1872 a law on contagious diseases was issued; it addressed hygienic conditions, primarily leading to cholera outbreaks. However, the law was mainly the result from pressures by the higher middle classes fearing the dangers of unhygienic living conditions of the proletariat. Yet, the state inertia was not contained by this legislation: private enterprise proved to remain the most important control factor.

As from 1900, gowemment increasingly focussed on social insurance legislation. Attempts to regulate health insurance, however, failed. Juffermans distinguishes between two important complexes of causes: first, there appeared to be an inherent animosity between the Medical association, and the already existing private health insurance funds. The profession feared loss of identity and free enterprise in case their services were to be provided through state controlled funds. However, a more important set of causes for a failing untroduction of health insurance legislation was the aversion of the parliamentary coalitions to attribute health insurance costs to industry and private enterprises. To overcome this objection, a prospect of a subsidy of ten million guilders was held out in 1920. Due to lengthy considerations in parliament, however, the subsidy could not be given by the time the representatives felt the insurance proposal was adequate: the economic situation by that time restricted govemment to allot such sibstantial monies; the proposal finally failed in 1937. During the German occupation a Sickness Fund legislation was enacted (1941), based on the German model stemming from the times of Bismarck. This legislation still is in place.

With regard to public health legislation (municipal primary health services, and sanitary engineering), the start of the century was hopeful: generally, in the years between 1918 and 1920 government was striving for a solid social development, reflected in many sectors, thus also the health sector. The Health Law of 1901 was expanded; the organization of state medical officers was strengthened, and the Health Council (an advisory body) was installed. Prevention of tuberculosis was taken up more rigorously, and municipal health services were intended to be given wide-ranging tasks with regard to collective prevention. Alas, this upsurge of interest in health disappeared soon; in the mid-twenties, the proverbial governmental inertia had returned to The Hague. This regression is generally attributed to stagnating economic conjuncture and confessional particularism (Juffermans, 1982, p. 133).

Of course, the second world war did have many adverse effects on the organization of health services in The Netherlands. Apart from the Sickness Funds legislation, there were no developments in public health policy. This gave the new govemment which retumed from exile good hopes of a new, visionary future: finally there were reasons and possibilities to address the health field rigorously.

\subsubsection{Development}

Indeed, the period of govemmental inertia had ended after the war. Elsewhere, we have described the post-war era (De Leeuw, 1989). The era may be divided into three main periods (Van der Werff, 1984), the first of which may be divided in two sub-periods (Juffermans, 1982):

1. (1945 1970) Regulated growth of the health sector through allocation of resources:

a. regulated post-war reconstruction (1945-1960), and

b. expansion and liberalization (1945-1970);

2. (1970 1980) Health care infrastructure and economic constraints were on the govemmental agenda in this period;

3. (1980 and beyond) Health and well-being of the population become to be considered the final output of a health (and not care) system. 


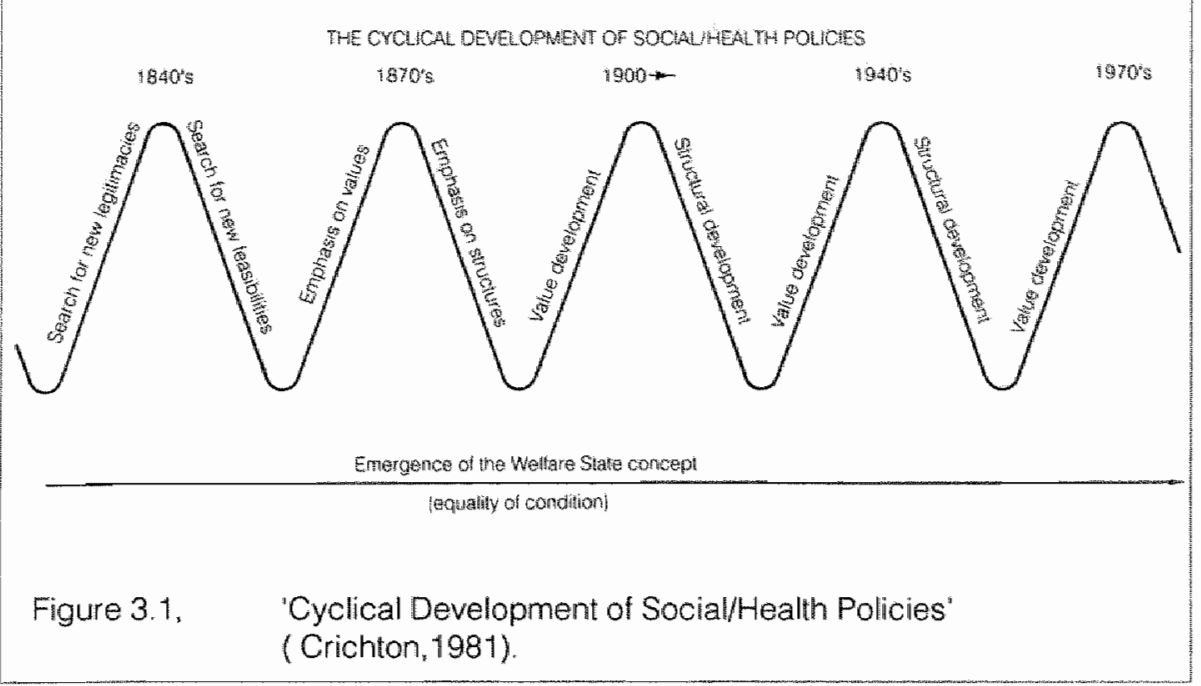

This description of the development of the Netherlands' public health policies is mirrored in Crichton's figure 3.1, "Cyclical Development of Social/Health Policies' (1981), and by the analysis of De Kervasdoue \& Rodwin (1984), describing an expanding though not decisive role of the state in health policies.

However, the original reasons for governmental inertia were not removed, and policies only partially successful (Commissie Structuur en Financiering Gezondheidszorg, 1987). For instance, in 1945 and 1946 the Van Rhijn-Committee recommended setting up a governmentcontrolled structure of district health centers in which the total health system was to be contained (Juffermans, 1982). The recommendations were clearly inspired by the BeveridgeReport (1943). While a National Health Service came into place in the United Kingdom among others inspired by Beveridge's 'Social Insurance and Allied Services"-, the Van Rhijn-Committee was less successful. Again, the fear among professions for limited freedom and a sense in parliament that private institutions could take care of a wide range of services meant that the Van Rhijn-recommendations were not formalized into policy. Juffermans concludes (p. 200) that the new ideas about reconstruction ended in frustration.

\subsubsection{Thrust}

The thrusts of public health policies in recent decades have adequately been summarized in a figure (figure 3.2 ) by Van der Zee (1987).

Van der Zee concludes that there is a significant increase of the number of memorandums rather than legislation during the years depicted. He views this to be a bad sign, or rather an admission by government that it cannot contain exploding costs and structures anymore. In that light, he refers to Dekker (1986a), who admitted that policy in reality is made in a complex of parastatal bodies and interest mediating structures (the "iron ring"), and that probably even inside the ministry of health coalitions are formed between health content oriented bureaucrats on the one hand, and systems-oriented instmumentalists on the other. Further, Wan der Zee remarks that, in the sense that Nota 2000 is a successor of the contentoriented 'Volksgezondheidsnota' (1966), the latter has been issued at a time of upward conjuncture and was no success, so that the intended thrust of Nota 2000 may be doubted as well. 


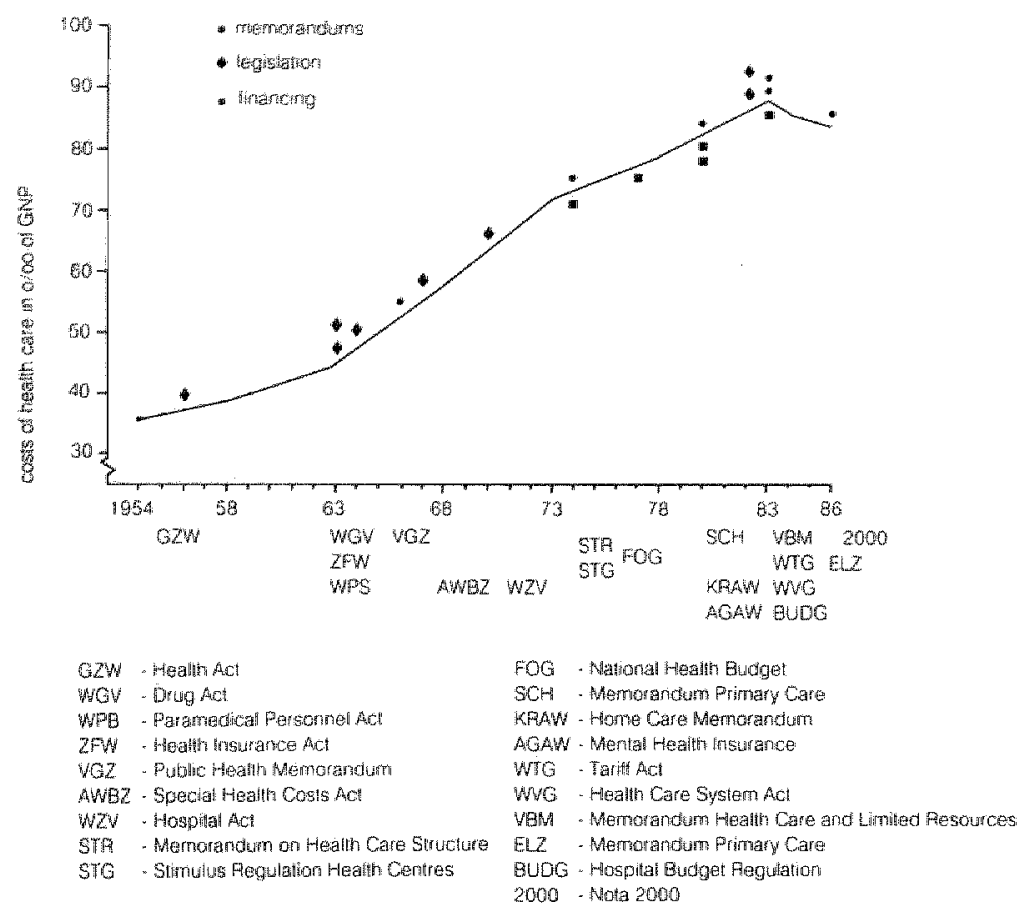

Figure 3.2. Memorandums, legislation and budget regulation with financial paragraphs, issued by The Netherlands' government (Van der Zee. 1987)

In sum, Van der Zee lists three major causal complexes for failure of public health policy focused on infrastructure for services and financing these: the impotence of govemment to hold planning and financing in one hand; the power of professional groups and vested interest protection; and

the failing prerequisite of public pollicy being integral and without clauses of escape (i.e. a too rigorously restrictive policy) for specific groups. Van der Zee asserts that the instruments used by the Netherlands" govemment to contain the soaring costs of health care have totally failed, a view supported by the Exchequer and Audit Department (Algemene Rekenkamer, 1987).

However, Van der Zee only marginally focusses on the importance of the shift from policy on structure of care toward strategic thinking in terms of health, and the relative gains that might be expected from such a new orientation.

\subsubsection{Pitfalls and bottlenecks}

In the various reactions on Nota 2000 , the importance of such a shift indeed is only scarcely highlighted (Gezondheid \& Samenleving, 1986, Schrameijer et al, 1987). Apparently, the pitfalls and bottlenecks of the current system continue to focus actors on issues of infrastructure and financing rather than contents of health: of 45 contributions, eleven focussed on the contents of Nota 2000 being innovative, ten focussed on the various complexes of determinants of health (lifestyles, environments, etc.). Over half took the constraints of the present system and public health policy mode as a starting point: sixteen contributors reflected on the impotence of old policies (doubting whether Nota 2000 could break the vicious cycle), five emphasized financial aspects of present policies, and three presented epidemiological 
evidence, either with respect to the apparent success of old policies (through clinical epidemiological approaches) or regarding many unresolved problems (using nore appropriate social epidemiological techniques).

In sum, the present public health policy mode is felt to be failing to some extent. An analysis of the papers compiled in Gezondheid \& Samenleving (1986) and Sehrameijer et al. (1987) shows that the following constraints are considered to be urgent:

* The Deparment of Health (Ministry of Welfare, Health and Cultural Affairs) is rather a department of Sickness Care, focussed on adequate provision of curative and protective disease-oriented services and not strategically concerned with health;

* A majority of contributors feels that health needs are indeed less urgent than infrastructural and financial matters: generally, they assert, the Netherlands" population is among the healthiest in the world. Yet, costs are soaring and structures expanding: thus, the latter should have priority;

* Some authors, however, view that the present system does not adequately address growing health status inequities in the population, and that preventative measures of many kinds (aimed at social as well as physical environments, lifestyles, etc.) deserve to receive more attention;

* Although most contributors stress the importance of prevention and education, there are very few concrete proposals. (The inertia of govemment apparently has retumed, and now in the field of prevention. This is not surprising: the prevention lobby is relatively small in comparison to the professional powers of organizations with traditionally curative or structural prime objectives);

* Some policy-oriented contributors underline the observations by analysts whom we have summarized above: the impotence of government to hold planning and financing in one hand, the power of professionals groups and vested interest protection, and the failing prerequisite of public policy (being integral and without clauses of escape for specific groups) seem to be the most crucial bottlenecks and pitfalls in the present mode of public health policy in the Netherlands.

However, a general thrust with regard to the complexities of making policy in the Netherlands has thus far been left out. In the above we have focused mainly on the role of the state in making and implementing policy. Yet, in the post-World War II period it has been noted by numerous authors that the state has increasingly left responsibilities for making and implementing policies to QUANGOs and NGOs. The historic description given above may be regarded as a prelude on this development. The phenomenon is called "corporatism", creating a highly complex situation.

Van Mierlo \& Gerrichhauzen (1988) and Van Mierlo (1989) give a concise overview of corporatism, shifting responsibilities between the state and conglomerates of societal groups (in Dutch society referred to as ideological "pillars'), and related issues such as privatization. commercialization, the priwate sector, etc.

The following four nules apply to the game of pacification democracy leading to corporatism (Van Mierlo, 1989):

1. Broad cooperation among the ruling pillared elites in various forms of govemment, leading to all party govemment and 'Grand Coalitions'.

2. Application of a principle of proportionality, i.e., the various groups are represented in civil functions and roles in public management on the basis of proportionate size of the different groups.

3. Pillared groups are given the right of veto over political decision-making in matters touching on vital and fundamental characteristics of confessionalism and ideology as perceived by the groups themselves.

4. As large as possible an autonomy is reserved to the groups in general terms, as well as in matters of initiation and implementation of public policy. Those matters which can be 
andressed, even to a mall extent, by the groups themselves are fully left to their discretion.

Application of these rules has led Baakman (1988) to conclude that the distinction between govermment and society has fully disappeared. State functions such as public decisionmaking are no longer reserved to state bodies, but are also carried out by para-political organizations and other QUANGOs. In this realm, the term 'privatization' acquires in the Dutch context more or less unique meaning. Whereas the notion in other nations has a connotation of "independency", in the Netherlands it may be understood to mean "mutual control under conditions of assured autonomy of state and pillars'.

With regard to the public health and bealth care sector in The Netherlands, Van der Made \& Janssen (1989) show that, in line with the historical overview given abowe, the traditional corporatist tendency in this country has shifted toward increasing government interference in the 1970s. This has led to less rigorous application of the four rules given. In recent years, government decided to pass over the pillared para-political advisory bodies in matters of restnucturing the health care system. The role of the private sectors in this realm seems to be decreasing.

In this investigation we will therefore focus mainly on the thrust of action between government and societal groups for three reasons: traditionally, the public health sector has come under the responsibility of government; second, health policy as it is supposed to take shape (3.2) seems to have to be initiated by the state; and third, government apparently wishes to increase the distinction between public and private sector by passing over the latter.

However, in our theoretical chapter we will yet have to face the traditionally intertwined responsibilities of various groups as given in this section (4.2.2).

\subsection{Healthy pulblic policy}

In the above section, we have given a historical overview of the development of public health policy in The Netherlands. However, as we have reviewed in chapter 2, public health policy is not necessarily concerned with health policy or 'healthy public policy'. In this second section of chapter 3 we will present the notion of "healthy public policy" and review its characteristics and problems related to the concept.

"The rationale behind the strategy of "coordinating healthy public policy" is the belief that public policies, in general, act as incentives or disincentives to health. Policies that concern, for example, nutrition, housing, defense and recreation all have an impact on preventing health problems or actually enhancing the health status of the population" (Pederson et al, 1988). Milio (1980) shows that health policy makers are generally unaware of the prime contribution of these nonhealth sector forces that determine our health, and shows how economic policies affect sector policies which in turn affect health. Blum (1981) takes this observation, as we have reviewed in 2.1 .1 ass a starting point for the development of real health policies.

What, then, is exactly "healthy public policy"? As Pederson et al. (1988) observe, there is some confusion as to the exact terminology. "Health promotion", "new public health', "health promotion policy" and "healthy public policy' seem to be strongly intertwined terms, often. used interchangeably (De Leeuw, 1989). All of these take as a starting-point a definition of health which is a resource or capacity of people, rather than the absence of discomfort: 'Health is the extent to which an individual or group is able, on the one hand, to realize aspirations and satisfy needs, and on the other hand, to change or cope with the environment" (WHO, 1986).

"The new public health" is an umbrella term to denote the new ecological perspective to enhancemerit and protection of health rather than a single focus on medical care delivery. Kickbusch (1986) relates the term to the emergence of public health in the nineteenth century, a public health which has increasingly been medicalized. The "de-medicalization" of 
public health into a mone popular movement, participatory and ecological by nature is labeled "the new public health"; rather, it is the original public health adjusted to the denands of our time.

"Healith promotion" is a generic term for all actions aimed at health protection, prevention and promotion (De Leeuw, $1989, \mathrm{p}$. 4). Its definition is therefore: "health promotion is the process of enabling individuals or groups to increase control over and to improve their health" (WHO, 1986a). It may be clear that health promotion is not in the least limited to health education, although it is among the crucial components of health promotion (Green, 1989). Rather, public policy is considered to be the most important determinant of health, as we have seen above: public policy, Milio (1986a) asserts, "sets parameters for the mode and character of industrial and agricultural production, corporate management, and individual behaviour. By laying out the range of options from which organizations and individuals make their choices, public policy is not only an influence on environment: it is an inextricable and critical part of today's and tomorrow's environment" (p. 3).

This assertion could indicate a large optimism held by some in the "makeability of society" through policies. However, such makeability is after large degrees of positivism in the $1960 \mathrm{~s}$ and 1970s ("War on Poverty' in the USA, welfare-policies in the Netherlands, (Peper, 1976. WRR, 1982)) by now generally doubted by policy makers. The rational-comprehensive planning approach to policy is by Dekker (1986a) said to be naive: blueprint-planning, rationalism and top-down approaches caused centralism and appeared to be incompatible with autonomous societal dewelopments. Public policy is therefore considered to be a less than all-powerful instrument for societal reform.

Nevertheless, as the determinant power of policies or non-policies (conscious non-decision making, and thus non-policy making, may be considered a determinant force as well, cf. Van der Eijk \& Kok (1975)) continues to be large, this observation creates an interesting dilemma to the thrust of healthy public policy: if pubilic policy in general affects health to a large extent, and if it is also true at the same time that planning and policy-making procedures have only a limited impact on the structure of society, what then is the potential of public policies for the improvement of health within the framework of "health promotion'?

Reframing the issue: policies deeply determine options for healthy liwing of people. At the same time, governments seem to realize that their work is to set prerequisites rather than being involved in detailed regulation. The question would thus be: how and to what extent are these prerequisites set, while at the same time preserving the WHO-credo 'make the healthier choices the easier choices'?

The question is especially relevant if we take Nota 2000 to be an example of the initiation of healthy public policy in The Netherlands: what problems is Nota 2000 facing in its further development in light of the existing body of literature?

Through a more concise analysis of the characteristics and problematic aspects of healthy public policy in the following paragraphs we will try to answer that question in 3.3.

\subsubsection{Characteristics}

Pederson et al. (1988) list some thrusts of healthy public policy, and propose an unequivocal definition of the concept; we will adhere to that definition.

Healthy public policy, in their review, has been conceived of as "policy of the people and their elected representatives characterized by an explicit concern for health', "health-making policies', 'multi-sectoral policies to achieve equity in health', and public policy supportive of health". Hancock (1982) is credited to be among the first to coin the term. He conceptualizes: healthy public policy by being characterized as focused on the determinants of health, chiefly concerned with creating a healthy society by low-technology approaches, holistic, and questioning the status quo of the existing structures. Healthy public policy, therefore, is multisectoral and recognizes the importance of public participation in policy formulation and 
implementation.

Pederson et al. (1988) consequently define healthy public policy as "sectoral policy of gowerrment aimed specifically at health promotion", and use the foundations of definition of health and health promotion given above. Thus, the development of healthy public policy may take place through multisectoral approaches, but is guided by one governmental health sector crossing traditional departmental and ministerial boundaries. Healthy public policy is an owerarching notion that links pollicy sectors through a concern of health (p. 5). However, Pederson et al. evaluate the literature in the area of healthy public policy to be *... largely non-empirical and theoretically weak. Most of the literature is not even descriptive; it is largely prescriptive; and many of the recommendations found in this literature have at best a tenuous grounding in established social science theory' (p. 8). In the following paragraphs we will further review this criticism.

\subsubsection{Unresolved problems}

In chapter 2 we already have explored the various definitions of policy; we have taken the definition given by Blum (1981) as a standard. In the innovative realm of healthy public policy, however, the more traditional ways of policy analysis may be less appropriate (Ziglio, 1988). In the following we will explore some theoretical approaches to policy making and their meaning for healthy public policy making, the problem of intersectoral cooperation in the formulation and implementation of such policy, the ways in which a policy for health may be shaped (what types of interventions may considered appropriate in healthy public policy), and finally, how measurement and evaluation of healthy public policies may look like. The latter section is also a preview of the conceptual framework used in this inquiry, to be presented in chapter 4.

\subsection{2,1 Policy theory}

In the quite limited amount of literature on theory for healthy public policy, authors generally reflect on three major approaches to policy development: the rational-comprehensive (or rational-deductive), the incrementalist, and the mixed-scanning approach (Dekker, 1986a. Pederson et al, 1988, Ziglio, 1988). In addition, there is some debate regarding the directions of policy development and implementation: top-down, bottom up, or something in between (Sabatier, 1986).

\section{Thrust of decision-making}

In the rational-deductive approach, policy is structured in purely logical-strategic terms, as inwolving a series of sequential steps worked out to attain a given objective. Rationality of the process is extremely important: policy-makers consider the scientific data which are aval lable, and logical-deductive approaches to the solution of the problem sufficient input into the policy formulation (Van Vught, 1982). Ziglio (1987) argues, however, that this approach is in fact only feasible if policy-makers avoid prionity judgements and value orientations. Yet, Crichton (1981) clearly shows that these value judgements are inherent to the policy process. It is therefore not surprising that the rational-deductive approach has been critiqued as politically naive and utopian and not appropriate to healthy public policy making, the environment of which holds many uncertainties and complex interactions between determinants and actors (Milio, 1986b). Pederson et al. (1988) cite Dumoulin, who adequately critiques the rational-deductive approach: "A rational framework of analysis which ignores conflicts, interpersonal and power relations is completely cut off from the reality of decision-making structures and therefore can have no influence over it". The second approach has emerged as a reaction to the first: incrementalism. The approach adwocates the science of 'muddling through': because human intellectual capacity is limited, comprehensive scientific knowledge is utopian, and the political context may be considered 
of utmost importance, incrementalists argue that only marginal adjustments to existing policies and structures are possible based on value judgements, personal or group skills and through careful negotiation with interest parties. This muddling through (or "garbage can management", De Leeuw, 1982) remains to be marginal and back-lagging to socieral developments. It may be clear that the approach is only remedial, and not geared toward fundamental changes called for in healthy public policy. Ziglio (1987) argues that incrementalism reinforces inertia and discourages this innowation.

The solution to problems of the rational-deductive approach as well as incramentalism is sought in 'mixed-scanning' (Etzioni, 1986). Mixed-scanning tefers to taking fundamental decisions (based on rational deductive reflection on awailable knowledge and on intervention steps) on the one hand, and incremental changes (based on value judgements and reflection on power structures) on the other. The two types of decisions are to be adjusted to each other. Mixed scanning has emerged out of a notion that many incremental decisions will not account for one major fundamental shift. and that rationalism supposes total information. which in fact never can be made available. In the light of healthy public policy making the mixed scanning approach seems to be the best theoretical framework; a view supported by Van Beilen (1989). Dekker (1986a, 1986b) and Ziglio (1987). However, Ziglio views neither of the three approaches really appropriate for the complex process in a changing social, economic and political environment healthy public policy is. Nevertheless, mixed-scanning is the best of the worst as uncertainty may require more planning rather than its abandonment. The central issue and paradox in healthy public policy design remains that it is most required under conditions of complexity and uncertainty, but under such conditions causal relations can be only tenuously identified, making policy design least feasible (Dryzek, 1983 , Ziglio, 1986).

\section{Thrust of action}

Policy being an iterative process, problem-definition and implementation phases cannot always clearly be distinguished. Regarding implementation (which thus can be part of problem-definition as well), two thrusts of action have been defined in literature (Sabatier, 1986): the top-down approach, and the bottom-up approach.

The top-down approach is characterized by policy formalization at the top bureaucratic level and subsequent downward implementation. The approach is effective if there are clear and consistent objectives, adequate causal theory, a legally structured implementation process, commitment by implementing officials, support of interest groups, and a stable socioeconomic dlevelopment not hindering objectives and conceptual framework (Sabatier, 1986). The bottom-up approach assigns factual problem-framing and implementation authorities to 'street level bureaucrats' or key community actors. Policy thus is determined by explicit bargaining over objectives, control devices and strategies among policy actors at all levels. Networking thereby becomes a crucial prerequisite for effective implementation.

Both approaches have their shortcomings. Pederson et al. (1988) review those. The top-down approach is critiqued because it emphasizes the key function of top bureaucrats too much; it is hard to apply to situations in which many directives and actors are involved; the perspecrive may ignore expertise and accountability of street level bureatucrats; finally, policy is continuously formed (it is iterative) and thus a unique focus on implementation is illusory. The bottom-up approach is especially hindered by meager theoretical support for the processes taking place; the pervasive expression that participation is always appropriate (cf. Bjorkman (1985) and Green (1986) both asserting that participation is not necessarily contributing to effective policy-making); and overemphasis of a so-called unique expertise of the street level bureaucrats.

Pederson et al. (1988) show that there is some convergence in the views on these strategies: generally, top-down approaches and bottom-up approaches may be viewed as complemen- 
tary rather than contradictory. Elsewhere we have suggested that the type of problem and its policy framing may detemine types of intervention and implementation (De Leexw, 1989, p. 64). Especially in a mixed-scanning context under the uncertain and complex conditions of healthy public policy (and excluding the option of rewolution), it seems suitable to leave implementation of the fundamental decisions to a top-down approach, and more incremental changes to a bottom-up technique.

\subsubsection{Intersectoral cooperation}

As we have seen above, there is a growing awareness that prerequisites and prospects for health promotion cannot be confined to the health sector alone. Healthy public policy seeks to expand the accountability for health to gowernment as a whole, as well as other societal sectors such as industry and non-governmental organizations. (WHO \& Commonwealth. Department of Community Services and Health, 1988). These policies are therefore bound to adopt a multisectoral or intersectoral perspective to the promotion of health (Ziglio \& McQueen, 1989).

However, the available body of literature on the development and formalization of intersectoral cooperation in healthy public policy focusses on descriptive studies of the phenomenon, and prescriptive writings on intersectoral cooperation. Thus, there is no conceptual framework regarding intersectoral cooperation other than analyses of organizational interplay, bargaining and suggestive indicators.

However, the rationale for intersectoral cooperation is clear (Milio, 1986b, WHO, 1986). Several projects have been described and subjected to analysis of determinants of intersectoral cooperation. The results are meager: Kimberly \& Rodwin (1984) conclude that intersectoral policy-making may only be possible if there is sufficient political commitment and one authoritative body for its coordination, an observation reiterated in Nota 2000 but largely denounced there because of 'traditional pluralism' in the Netherlands which would not easily facilitate establishment of such a coordinating body. Altenstetter (1987) does not view such a coordinating body though possibly extremely influential when in existence- an absolute necessity: "When long established officials in ministries, planning offices, field offices, or quasi-public or private organizations are asked to pursue intersectoral, goals rather than sectoral objectives, they tend to resist giving up sectoral power bases and organizational turfs. When they are also asked to develop mechanisms for involving a wide range of

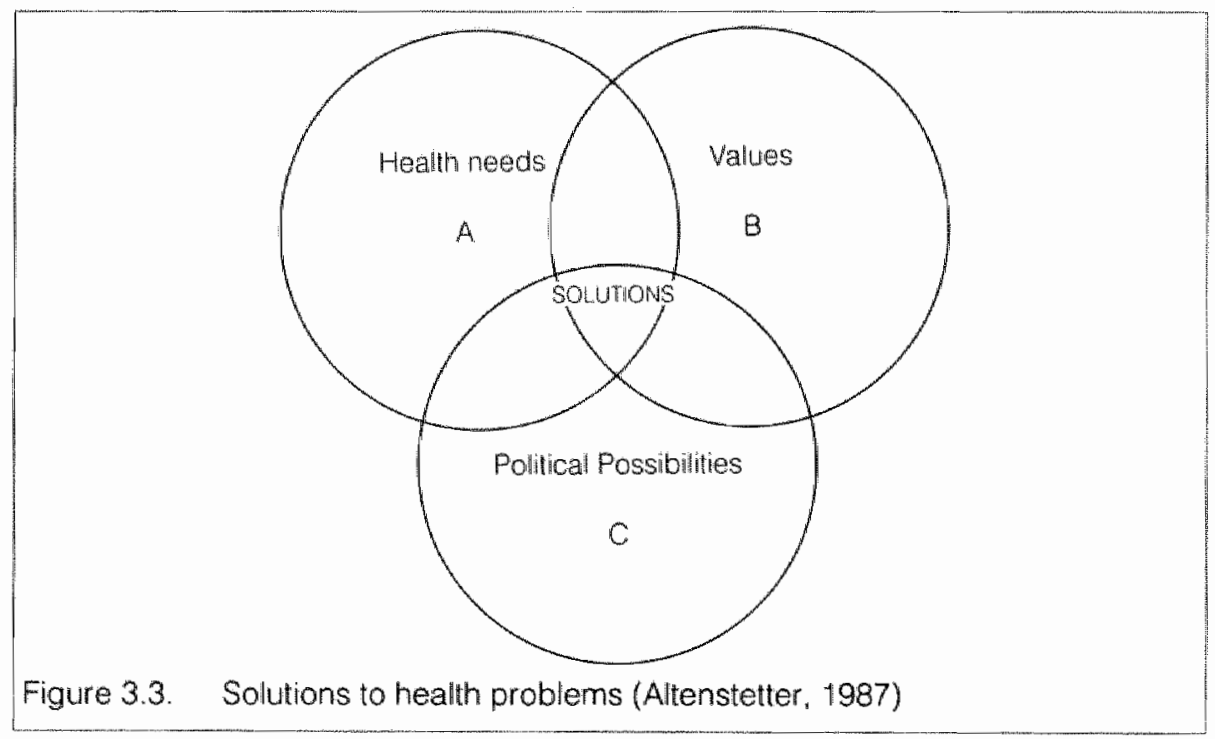


participants in decentralized strategies, the power bases are redistributed, while previously mechanisms fostering centralization were operating to preserve their own power. If should be clearly understood that all political players have certain authority and responsibilities which they are not necessarily willing to abdicate. In consequence, intersectoral action should not be expected to come fast or easily:" She proceeds, however, by indicating how intersectoral cooperation might be put into place. The intersectoral policy initiator (geverally a government official) would have to carry out a feasibility analysis of a prospective program. Institutional and contextual field analyses will have to be carried out to determine whether the other sectors might want to be involved in the program. Guiding principle for this analysis is figure 3.3, in which the overlapping segments of health needs, values and political possibilities present the analyst with possible solutions.

In securing support and coordination of a program, Altenstetter distinguishes between informal means to do so (personal contact and influence), and formal means (a Coordinating Council). The latter may even be functional without much formal authority, she asserts: even then, such a Council may contribute to consciousness raising and public debate, facilitating more long-term advances in intersectoral action.

Parrish (1987) describes the Heartbeat Wales program in these terms: through various modes of intervention intersectoral action was secured. All of these originated initially in the Heartbeat Wales offices, but were soon adopted by other sectors than the health sector (media, the Meat \& Livestock Commission, supermarket chains). Through strategic thinking, securing popular support by media interventions, the Heartbeat Wales program managed to offer other sectors a "win-win"-situation in which it was made clear that all organizations had interests at stake in the promotion of people's health: intersectoral cooperation was created. Gray (1985) also shows why the present health problems call for healthy public policy. He suggests that collaboration (rather than cooperation or coordination, terms which have a too much non-committal or authoritative connotation) is warranted in situations in which a problem is 'indivisible', i.e., too complex for a single organization acting alone to solve. However, the realization of such a complexity is sometimes far from the reality of organizational objectives confined to a single group. Further, organizations may want to collaborate when traditional organizational methods are too limited, when organizations are already interdependent, and when there exists a certain 'domain consensus' (Van Rijn \& Gerards, 1988).

Pederson et al. (1988) list seven barriers to coordination (or collaboration, cf. Gray (1985)) for healthy public policy:

* Lack of political will; leadership and political commitment at top bureaucratic levels seem to be of crucial importance;

* Competing interests among stakeholders within the health sector and between health sector and other sectors prevent organizations to acknowilledge their factual interdependence;

* Distribution of national and regional powers may frustrate intersectoral collaboration;

* Participation is valued, but often the participatory machinery and experiences from the past do not seem to fit present problems;

* The media may play roles facilitating or inhibiting the preference for intersectoral collaboration and coordination, as they have an agenda-setting function (cf. 4.2.3);

* Implicit tensions between top-down and bottom-up approaches may hinder effective colllaboration among organizations; and

* An immense lack of experience with intersectoral policies forces organizations to stick to the status quo, not only outside the health sector, but mostly within it.

In sum, there is no concise conceptual framework giving exact guidelines for intersectoral action. Effective intersectoral action and collaboration is apparently achieved through adequate power analysis and the presentation of advantages ("challenges') to all sectors of 
intersectoral cooperation. A coordinating council may facilitate this process, but may not be appropriate fin political constellations of all nations. In cases where such a council does nor have large formal authority, informal strategies would have to be employed. However, determinatits of intersectoral actions have not been made unequivocally clear (De Leeuw", 1989).

The Ministry of Health (WVC, 1988) in its HFA2000-report to WHO/EURO acknowledges thiat intersectoral cooperation is a field of complexities and difficulties. In the Netherlands' sittuation, the only formal institutional mechanism for intra-governmental intersectoral coordination is through the interdepartmental coordination committee, a subcouncil of the Cabinet, and finally Cabinet itself. Health targets are not dealt with in these bodies systematically, nor the health consequences of policies in other sectors. An exception to the latter are the Environment-Effect-Reports issued before important environmental decisions. The health component is taken into account here.

\subsubsection{Interventions for health}

Healthy public policy calls for a variety of complementary interventions (WHO, Health and Welfare Canada, CPHA, 1986, De Leeuw, 1989). As we have seen in 3.1, traditional public health policy has limited itself to regulatory measures, and to lesser extents economic allocation, direction of services, information and research. Healthy public policy would also include legislation, education, facilitation, mediation, financial (dis)incentives, etc, linked to sectors outside the health service. How do these interventions relate to each other, and what is the experience of national authorities to develop those complementary interventions and tune them to each other?

Cobb and Elder (1983) distinguish three types of policies: distribution, redistribution, and regulation policies. Distribution refers to establishment of new priorities within existing (abstract) frameworks; redistribution deals with reallocation of means and priorities within existing intervention programmes; and regulation deals with parliamentary intervention in the form of legislation. Policy may shift from one to another phase: where distribution or redistribution fails, regulation may have to be considered.

Each state has its own way of dealing with these policy types. Rodwin (1984) describes three perspectives: the conservative, radical and liberal. Conservative states, according to Rodwin, would primarily be interested in issues of redistribution. Radical states would prefer regulatory and distributive policies, while liberals would lean toward limited regulation and, to a larger extent, distribution of resources. Because '...post-World War II liberals depart significantly from conservatives, for they identify with social democratic ideals and with the principles of the welfare state" (Rodwin, 1984, p. 40), the present pluralist status quo of the Netherlands' society resembles the liberal perspective on policy.

A number of intervention types is found in literature. De Leeuw (1989) mentions 'facilitation, legislation, education, and many others' (p. 28). Ziglio (1988) refers to educational, regulatory, and facilitating policy measures. Educational interventions may be divided into critical consciousness-raising, agenda-setting, provision of skills, lobbying, mediation and advocacy (Tones, 1987) or health education type I. II, III and IV (De Leeww, 1989). Regulatory measures are mainly legislative (including sanctions) in order to prevent undesirable actions or regulate production, distribution and consumption of goods. Jonker \& De Leeuw (1988) have shown that there may be a hierarchical structure in strict regulation, from directive and sunction legislation, framework legislation (conferring certain authorities to, for instance, lower governmental levels), and directive non-legislative regulation (for instance, through establishment of quality standards). Educational measures may be established through regulatory measures (for instance, the obligation to include health education in primary schools' curricula).

Regulation is not always effective, depending on how unambiguously goals are set, and 
instruments available to carry out the task (De Leeuw Jonker, 1988).

Facilitating measures, finally, include educational and regulatory measures, and may allso incorporate fiscal measures (and other (dis)incentives) to direct the flow of action towards

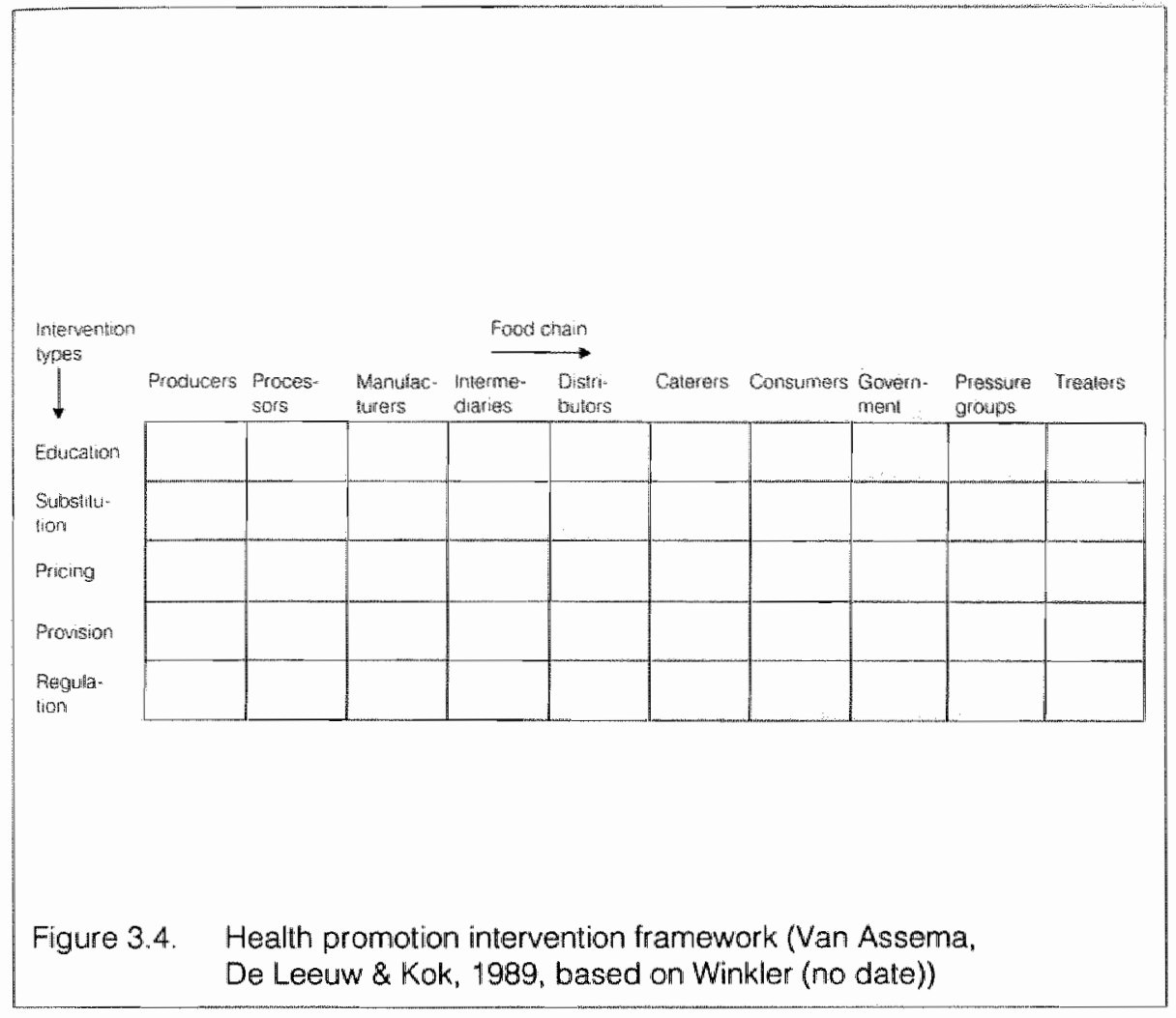

\begin{tabular}{|c|c|c|c|c|c|}
\hline $\begin{array}{l}\text { Health behavior } \\
\text { modification }\end{array}$ & Posslitwe frealith & Prevention & Eariy detection & Cure & Care: \\
\hline \multicolumn{6}{|l|}{ Worivation } \\
\hline \multicolumn{6}{|l|}{ Faclitation } \\
\hline Regulation' & & & & & \\
\hline
\end{tabular}

Figure 3.5. Kok \& Jonkers intervention grid (1986) 


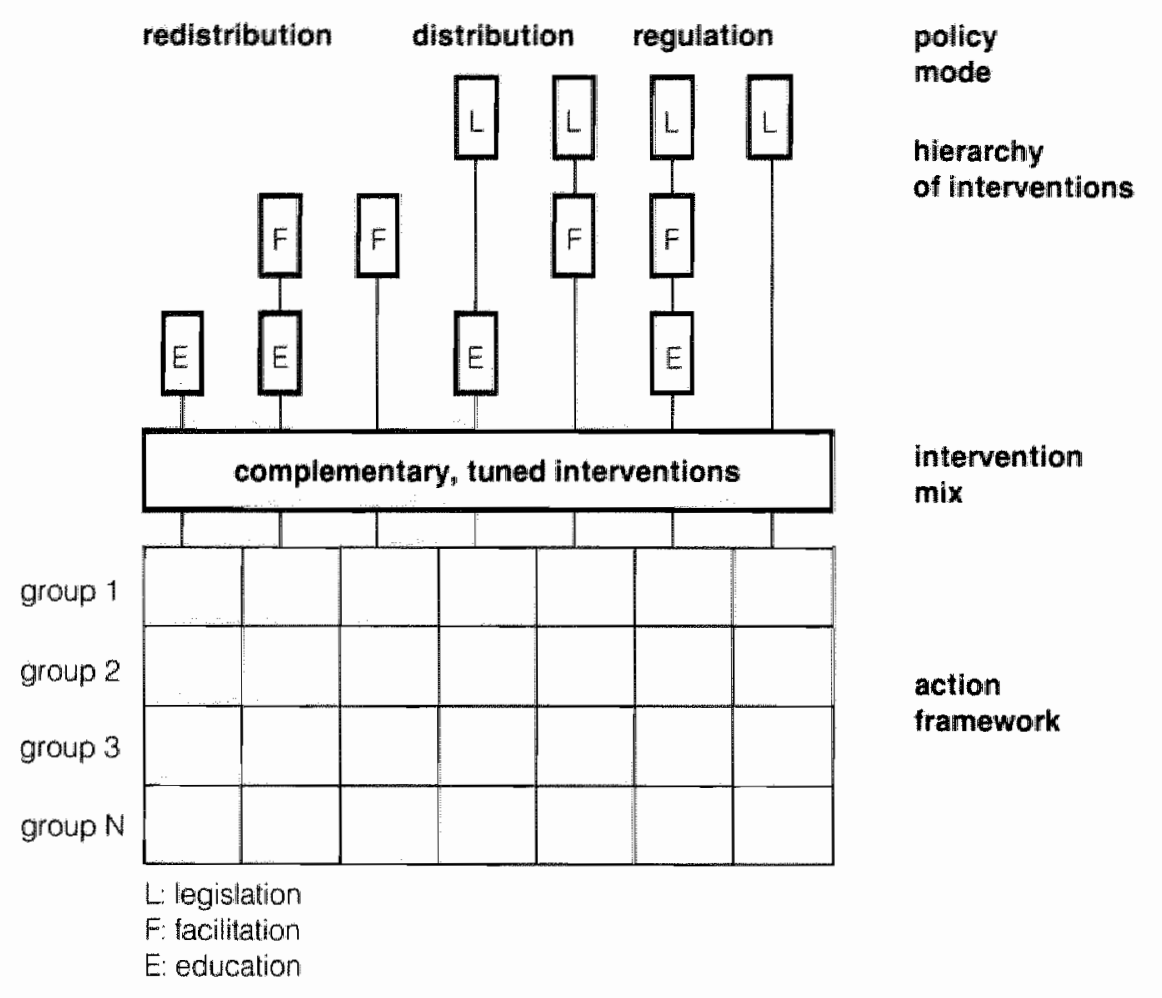

Figure 3.6. Hierarchical intervention framewark

certain desired goals. Facilitating measures may be taken by lower authorities that do not have regulatory powers.

These types of interventions are not mutually exclusive. They might have a multi-dimensional or hierarchical relation. Legislation might induce, for instance, education and facilitating measures which in turn might be operationalized in terms of educational interventions. Few studies are available in which the combination of complementary interventions has adequately been laidl out; the matter seems to bee too complex.

Van Assema, Kok and De Leeuw (1989) suggest an intervention framework for nutrition policy (figure 3.4).

Kok \& Jonkers (1986) suggest another framework, in which interventions are not linked with actors, but with problem fields (figure 3.5 ).

An empirical study of complementary interventions developed in a rational and concise way is presented by Leppo \& Vertio (1986).

In a healthy public policy to control smoking they present health education (through a Tobacco Act), price policy (Excise Duty Act) and restrictions (Tobacco Act), all backed by a research, planning and evaluation plan (through the Tobacco Act). All of these are linked 
through a goals-means tree with specific actions.

Reviewing the literature, it seems impontant to develop a conceptual framework for the establishment of complementary interventions in healthy public policy "The framework will have to contain the hierarchical nature of various intervention types, styles of policy (regulatory, distributive, redistributive), and a link with either concrete actions, problem fields, or actors. The hierarchical intervention framework (figure 3,6) is proposed.

Once a problem area is identified (smoking or fat-intake, for instance) and sectors to be involved defined through interest and power analyses described above, policy-makers (govemment, parliament) will have to establish which intervention types seem to be feasible in the prevailing nature of policy-making. These interventions having thus been explicitly chosen, this enables policy-makers to fine-tune various intervention types to eachother, and actions derived from them. Specific actions will fill the cells, addressing those groups involved in the various aspects of the intervention plan (cf. Van Assema, De Leeuw \& Kok, above).

In the Netherlands' situation, as described above, preference for intervention types and policy style emphasis will be situated toward the left of the framework (although pure regulation is not at all out of the questiony.

A concrete operationalization of Nota 2000 should take this emphasis in account, and try to establish deliberately and explicitly an integral, complementary and intersectoral mix of interventions.

\subsubsection{Measurement and evaluation}

Measurement and evaluation are intrinsic formally or not parts of policy-making. Numerous authors stress the importance of evaluation for the further development of healthy public policy (Abelin, 1986, De Leeuw, 1989, McQueen, 1986, Milio, 1986a, 1988, Ziglio, 1988). Ziglio (1988) gives the best account of problems" evaluation of healthy public policy (by Ziglio called 'health promotion policy', but entirely compatible with our defintion of healthy public policy given above, in 3.2) faces. He focusses on indicators as measurement instruments for healthy public policy, and concludes that very little work on the development of such indicators has been carried out (cf. Milio, 1988). This knowledge gap is caused, according to Ziglio, by a predetermination among researchers of a rational-deductive inquiry framework; "when analyzing Health Promotion Policy, however, it is necessary to consider the meaning, values, aspirations and motivations which participants themselves attach to the project under investigation, all of which are less susceptible to meaningful quantification " $(p$. 13). Ziglio continues to propose healthy public policy indicators for the process as well as the outcomes of policy development.

As we have reviewed above, healthy public policy is characterized by dymamic interactions among policy-makers and various policy sectors in incremental or mixed-scanring decision modes, aiming at multi-dimensional intervention types derived from a multi-causal and $\mathrm{em}$. powering health concept. In canclusion, healthy public policy indicators have to be dynamic and innovative in themselves. Process indicators will have to be dynamic, of a subjectivetype nature and directly associated with the dialectics of policy-making (Ziglio, p. 28). A combination of qualitative and quantitative indicators on process and outcome of policy is therefore called for. This still implies rigorous research methodology (cf. Chapter 5). Yet, empirical studies beyond the descriptive have not been carried out to a large extent, and the testing of indicators and possible theories has not been found in the literature (De Leeuw, 1989. Ziglio, 1988).

\subsection{Conclusion}

It seems as if more issues hawe been raised than questions answered in this chapter. That is not entirely true. The initial question was: which problems might Nota 2000, as a piece of healthy public policy, might face in its further operationalization and implementation. To 
answer that question, we have reviewed policy theory, the concept of intersectoral cooperation, the 'intervention mix' which ix expected to be created in healthy public policy, and measurement and evaluation issues related to that type of policy.

Generally, and entirely concordant with the observation made by Pederson et al. (1988) that healthy public policy studies offer descriptive investigations and normative conclusions, thete does not seem to be a consistent set of parameters for healthy public policy.

From policy theonies it is argued that a mixed-scanning style of decision-making seems to be the most promising: the fundamental shifts in thinking required by healthy public policy cannot be brought about by incrementalism (which is marginal and remedial) or by the rational-deductive approach (overlooking essential aspects of bealthy public policy making such as conflict management, interest mediation and power relations). Dekker (1986b) has argued that mixed-scanning indeed is the style consciously pursued in Nota 2000 . However, the distinction between fundamental and marginal decisions has not been made entirely clear, much less operationalized into some sort of policy instrumentarium. In further operationalization and implementation of Nota 2000 , the latter is an important issue.

Intersectoral cooperation us an issue in policy-making which has not been studied in empirical investigation to a large extent. More barriers for intersectoral collaboration are listed than frameworks for such collaboration presented. Intersectoral collaboration seems to be a matter of bargaining. Pedlerson et al. (1988) have listed major barriers to intersectoral collaboration and successful bargaining which seem to be applicable to Nota 2000 as well: lack of political commitment, competing interests, distribution of powers, inadequate public participation, role of media, tension between traditional top-down, and bottom-up approaches, and the scope of authority of Ministries of Health all might hinder healthy public policy.

The case for Nota 2000 is no different. In Chapter 2 we saw that political commitment is not high, in 3.1.2 we reviewed that interest differences are not promoting intersectoral collaboration, distribution of powers in the Netherlands' situation is indeed not ameliorating the feasibility of healthy public policy (the traditional gap between planning and financing, $\mathrm{cf}$. Juffermans, 1984). And with reference to public participation it has been observed that representation of the public in advisory bodies is meager (Hofland \& Wilms, 1984). The other barriers will be investigated further in Chapter 6. But so far the prospects for Nota 2000 do not seem to be good when viewed in the light of intersectoral collaboration.

The same is valid for integral intervention mixes (assumed to have synergistic effects for health) as we have reviewed them in 3.2.2.3. The operationalization of instruments for healthy public policy in Nota 2000 is marginal and only relative: reference is made to existing intervention patterns, but no attempt is made to recreate those in patterns attuned to the requirements of healthy public policy. This is not surprising: literature reviews did not produce workable guidelines. Indeed the establishment of these intervention mixes seems to be a case for 'developing the science by leaming the art' (Milio, 1987).

Finally, indicators for healthy public policy measurement and evaluation are only in their early stages of development (Ziglio, 1988). More innovative studies, using dynamic and subjective-type indicators in addition to more traditional research methods will have to be carried out. However, such studies are not encouraged in the Netherlands ${ }^{*}$ Public Health Research Policy (WVC, 1987) which focusses primarily on traditional methodologies. These conclusions may sound pessimistic as to the prospects for Nota 2000. Nevertheless, it should be noted that the Netherlands is among the first countries in the world to produce such a document and therefore has a unique opportunity to promote healthy public policy by "learning the art". We will review that prospect in Chapter 6. 


\section{References}

Abelin, T. (1986) Positive indicators in health promotion and protection. World Healith Statistics Quarterly, 39 (4), pp. 353-364

Algemene Rekenkamer (1987) Instrumenten en doelwerailing kostenbeheersing gezondheidszorg: een inwentarisatie. Tweede Kamer, 1986-1987, 19 794, nrs. 1-2

Assema, P. van, G.J. Kok \& E de Leeuw (1989) Gedragsbeinvloeding, Ch. 9 in: Voedingsbericht. Voedingsraad, 's-Gravenhage (to be published)

Baakman, N.A.A. (1988) Transformaties van staat en samenleving. Ch. 3, pp. $51-75$ in: Mierlo, J.G.A. van \& L.G. Gerrichhauzen (eds.) (1988) Het particulier initiatief in de nederlandse verzorgingsmaatschappij. Een bestuurskundige benadering. De Tijdstroom, Lochem

Beilen, E. van (1989) Lokale GVO. Dissertation, University of Limburg, Masstricht (in press)

Bjorkman, J.W. (1985) Who governs the health sector? Comparative European and American experiences with representation, participation, and decentralization. Comparative Politics, July, pp. 399-420

Blum, H. (1981) Planning for health. Generics for the eighties. 2nd edition. Human Sciences Press, New York

Cobb, R. W. \& C.D. Elcler (1983) Participation in American Politics: The Dynamics of Agenda-Building, The Johns Hopkins Liniversity Press, Baltimore Commissie Structuur en Financiering van de Gezondheidszorg (1987) Bereidheid tot verandering. Statsuitgeverij, "s Gravenhage

\section{Crichton, A. (1982) Health Policy Making. Health Administration Press, Ann Arbor}

Dekker, E. (1986a) Achtergronden van de Nota 2000 en de rol van de sociale wetenschappen. Gezondheid \& Samenleving, 7 (4), pp. 180-186

Dekker, E. (1986b) De realisering van gezondheidsbeleid: een kwestie van marges. Ch. 5, pp. 74-89 in: Dekker, E. \& B. Wijnberg (eds.) Gezondheidsbeleid over de grenzen van de ge zondheidszorg. Reeks gezondheidsbeleid, deel 1, Samsom Stafleu, Alphen a/d Rijn

Dryzek, J.S. (1983) Don"t toss coins in garbage cans: a prologue to policy design. Joumal of Public Policy, 3 (4), pp. 345-368

Eijk, C. van der \& W. Kok (1975) Nondecisions reconsidered. Acta Politica, 10, pp. 277-302

Etzioni. A. (1986) Mixed scanning revisited. Public Administration Review, 46 (1), pp. 8-j4

Gezondheid \& Samenleving (1986) Themadeel 'Tweeduizend over 2000" 7 (4), pp. 178-228

Gray, B, (1985) Conditions facilitating interorganizational collaboration. Human Relations, $38(10)$, pp. $911-936$

Green (1986) The theory of participation: a qualitative analysis of its expression in national and international health policies. Advances in Health Education and Health Promotion. voll. 1, A, pp. $211-236$

Green, L.W. (1989) Foreword, in: Leeuw, E. de (1989) The Sane Revolution, Van Gorcum. Assen/Maastricht

Hancock, T. (1982) Beyond health care. The Futurist, August, pp. 4-13 
Jonker, H. \& E. de Leeww (1988) Gezondheidsbevordering en wetgeving: enkele paradoxen. Deel 1: Concepten en achtergronden van "health promotion". Metamedica, 67 (4), pp. 251258

Juffemans, P. (1982) Stat en Gezondheidszorg in Nederland. SUN, Nijmegen

Kervasdoue, J. de \& V.O. Rodwin (1984a) Health Policy and the expanding role of the state: 1945-1980. Ch. 1, pp. 3-34 in: Kervasdoue, J. de, J.R. Kimberly \& V.G. Rodwin (eds.) The and of an illusion. The future of heralth policy in western industrialized nations. University of California Press, Berkeley

Kickbusch, I. (1986) Health Promotion: a global perspective. Canadian Joumal of Public Health, 77, pp. $321-326$

Kimberly, J.R. \& V.G. Rodwin (1984b) The future of health policy: constraints, controls and choices. Ch. 10, pp. $257-286$ in: Kervasdoue, J. de, J.R. Kimberly \& V.G. Rodwin (eds.) The end of an illusion. The future of health policy in western industrialized nations. University of Califonia Press, Berkeley

Kok, G.J. \& R. Jonkers (1986) GVO \& Preventie. pp. $45-57$ in: Hameren, J.A.M. van, P.T. van Splunteren \& B. Stoelinga (eds.) Reader GVO AGGZ-Preventie. LCDGVO, Utrecht

Leeuw, A.C.J. de (1982) Organisaties: management, analyse, ontwerp en verandering. Een systeemwisie. Van Gorcum, Assen

Leeuw E. de \& $\mathrm{H}$. Jonker (1988) Gezondheidsbevordering en wetgeving: enkele paradoxen. Deel 2: een juridisch perspectief. Metamedica, 67 (5), pp. 356-364

Leeuw, E. de (1989) The Sane Revolution. Van Gorcum, Assen/Maastricht

Leppo, K. \& H. Vertio (1986) Smoking control in Finland: a case study in policy formulation and implementation. Health Promotion - an intemational joumal, 1 (1), pp. 5-16

Made. J.H. van der \& R.T.J.M. Janssen (1989) Privatisering en particulier initiatief in de gezondheidszorg. Ch. 6, pp. 124-139 in: Mierlo, J.G.A. van (ed.) (1989) Particulier initiatief in de klem. Gemangeld tussen politiek en bedrijfsleven. De Tijdstroom, Lochem.

McQueen, D.V. (1986) Directions for research in health behaviour related to health promotion: a general overview. Working paper no. 6, Research Unit in Health and Behavioural Change, Edinburgh

Mierlo, J.G.A. van \& L.G. Gerrichthauzen (eds.) (1988) Het particulier initiatief in de nederlandse verzorgingsmatschappij. Een bestuurskundige benadering. De Tijdstroom, Lochem

Mierlo, J.G.A. van (ed.) (1989) Particulier initiatief in de klem. Gemangeld tussen politiek en bedrijfsleven. De "Tijdstroom, Lochem

Milio, N. (1986a) Promoting health through public policy. CPHA, Ottawa

Milio, N. (1986b) Multisectoral policy and health promotion. Health Promotion, an international journal, 1 (2), pp. 129-132

Parrish, R., J. Catford H. Howsen (1987) Promoting health through collaboration with industry and commerce. In: Community Based Prevention and Health Promotion. Report of an international Conference. German Society of Social Hygiene \& Prophylactic Medicine, WHO

Pederson, A.P., R.K. Edwards, M. Kelner, V.W. Marshall \& K.R. Allison (1988) Coordi- 
nating healthy public policy. An analytic literature review and bibliography Munister of National Health and Welfare, Ottawa

Peper, B. (1976) Vorming vari welzijnsbeleid. Evolutie en evaluatie van het welzijnsbeleid. Boom, Meppel

Querido, A. (1965) Een eeuw staatstoezicht op de volksgezondheid. "s-Gravenhage

Rodwin. V.G. (1984) Perspectives on the State; amplications for health policy. Ch. 2, pp. 35 55 in: Kervasdoue, J de, J.R. Kimberly \& V.G. Rodwin (eds.) The end of an illusion. The future of health policy in westem industrialized nations. Uniwersity of Califomia Press, Berkeley

Rijn, O. van \& F.M. Gerards (1988) Samenwerking tussen GVO en de RIAGG-preventie. GVO/Prewentie, 9 (1), 38-47

Sabatier. P.A. (1986) Top-down and bottom-up approaches to implementation research: a critical analysis and suggested synthesis. Joumal of Public Policy, 6 (1), pp. $21-48$

Schrameijer, F., J.M. Boot., E. Jurg, H. Saan, C. Tonnaer \& J. van der Velden (eds.) (1987) De Nota 2000 ter discussie. Reeks Gezondheidsbeleid, 2, Samsom Stafleu, Alphen a/d Rijn

Tones, B.K. (1987) Promoting health: the contribution of education. In: Education for heallth in Europe; a report on a WHO consultation on co-ordinated infrastructure within a health promotion strategy. WHO/EURO, Copenhagen

Vught, F.A. van (1982) Experimentele beleidsplanning - bestuurskundige expedities in de jungle van het plannings-denken. VUGA, "s-Gravenhage

WHO (1986a) Health promotion: concepts and principles, In action, A policy framework. Copenhagen

WHO (1986b) Intersectoral action for health. Technical discussions background paper. Geneva

WHO, Health \& Welfare Canada, Canadian Public Health Association (1986) Ottawa Charter for Health Promotion. An International Conference orn Health Promotion - The Move Towards a New Public Health. Nov, 17-21, 1986, Ottawa. Canadial

WHO \& Commonwealth Department of Community Services and Health (1988) Report on the Adelaide Conference - Healthy Public Policy. 2nd Intemational Conference on Heallh Promotion, April 5-9, 1988, Adelaide, South Australia

Werff, A. van der (1984) Rolverdleling arts en overheid bij beleidsontwikkeling. Een weranderend toekomstperspectief. Medisch Contact, 47 (pp. 1522-1824), 48 (pp. 1954-1956)

WRR (1982) Herwaardering van Welzijnsbeleid. 22/1982, Staatsuitgeverij, "s-Gravenhage

WVC (1988) Health for all by the year 2000. Rapportage Nederland 1988. Ministerie van Welzijn, Volksgezondheid en Cultuur, Rijswijk

Zee, J. van der (1987) Het falen van het structuurbeleid in de gezondheidszorg. Ch. 2, pp. 2232 in: Schrameijer, F., J.M. Boot., E. Jurg, H. Saan, C. Tonnaer \& J. van der Velden (eds.) De Nota 2000 ter discussie. Reeks Gezondheidsbeleid, 2, Samsom Stafleu, Alphen a/d Rijn

Ziglio, E. (1986) Uncertainties and dilemmas in future health policy scenarios: some cautionary issues. Futures research quarterly, 2(4), pp. 5-15 
Ziglio, E. (1987) Policy-making and planning in conditions of uncertainty: theoretical considerations for health promotion policy. Draft paper nr. 7. Research Unit in Health and Behavioural Change, Edinburgh

Ziglio, E. (1988) Indicators for Health Promotion Policy? Directions for Research. Working Paper no. 19, Research Unit in Health and Behavioural Change, Edinburgh

Ziglio, E. \& D.V. McQueen (1989) Evaluation and Planning Issues in Health Promotion.

Paper proposal Research Unit in Health and Behavioural Change, Edinburgh 


\section{FEASIBILITY OF HEALTH POLICY: THEORY OF AGENDA-BUILDING}

Making policy is a highly complex and little understood process. The existing knowledge is diffuse and dependent on the apparent idiosyncracy of the researcher (Crichton, 1981, p. 24). Policy scientists single out components of the process in order to study them more adequately. Such components include, anong others, decision-making, organizational design, determinants of planning, management of conflict and issue creation. Such attempts at "research manageability" hold all the problens of a reductionist approach to knowledge, therelby impaiting understanding (cf. Ch. 5).

With this acknowledgement we nevertheless will not attempt to develop a comprehensive policy-making theory. This much needed work has been tried in the past, and is as yet in vain. Even more limited studies do not seem to be free of (normative) value-expressions. 'Truth' is always subjective (De Leeuw, 1989). But according to Crichton (1981, p. 67), normative, i.e. value-laden, scientific interpretations seem to be better than no interpretations at all. In the following we will focus on the very first steps in the development of policies. Policy scientists have distinguished between several phases in the making of a policy. In a circular form, these phases resemble the empirical cycle.

Although there may be a dispute over naming the phases, they include at least the following: initiation of the policy development process, adoption of formal policy, operationalization of planning mechanisms and instrumentarium to carry out policy, implementation of policy with those instruments, evaluation, and reformulation of the policy.

However, the orthodox notion of policy development being a linear process with a feed-back loop at the end (thus becoming circular) has been left. Milio (1987), for instance, shows that for analytical purposes such a distinction may be useful, but that in reality different phases may be intertwined, predetermined, left out or may not in any way be final or causal to each other

Nevertheless, there can be no formal policy without an initiation and adoption phase. These need to precede any other step in the policy process. In the case of Nota 2000 , in seems appropriate to focus on the policy initiation and adoption phases. Our focus will be on adoption of Nota 2000 on the level of central govemment, although local adoption may be a heavy indicator for feasibility of central adoption (cf. 4.1.3),

It is extremely relevant to present a set of policy theories for the analysis of health policy, i.e. Nota 2000 . In the following we will try to establish an appropriate framework.

There is a difference between theories of policy-making and theories in policy development 
worth mentioning: The first relate to processes bringing about policy, the second on the conterts of policy. Leeww (1986) has shown that Nota 2000 may be based on many implicit policy theories or assumptions, but that none of these is explicitly presented in the document. Policy theories relate to sets of assumptions of normative, final or causal relations underlying the problem definition and modes of policy formulation (Hoogerwerf, 1984). We might also speak of policy meta-theories when we would address the routes through which the problem formulation and initiation phase (on which these assumptions may be based) end up in some kind of policy work. We will take a theory to be: 'A system of interconnected general and concrete propositions, of which at least several take the form of a prediction that under given conditions given phenomena are to be expected, i.e. the propositions may be tested against empirical reality" (Swanbom, 1981 , pp. 89-90).

The notion of feasibility is generally perceiwed as having a relation with implementation studies. Ringeling (1981) reviews the works of Bardach (1977), Dunsire (1978a, 1978b), Hill (1976). Hood (1976) and Mayntz al. (1978). These studies specifically relate to operational versions of policy, implementation processes and feasibility in terms of output, effects and impact (Maarse, 1989). However, as we have reviewed in chapter 2, health policy in the Netherlands may barely be called operational, can therefore as yet not be implemented, and will thus not be evaluated in these terms. Our analysis will emphasize the pre-policy processes and 'feasibility" as we will. operationalize the term in 4.3 .4 will relate to the perception by actors whether health policy in the Netherlands will have the probability of being operational, and therefore have chances to be implemented.

The following will be an account of theories explaining how an issue may turn into an item on the institutional political agenda. We will use the works of Cobb \& Elder (1983), Cobb, Ross \& Ross (1976), Milio (1987), and Koppenjan et al. (1987) to develop an understanding of these first phases in making policy, and methodologies to reveal relevant data.

\subsection{Agenda-building theory}

In a response to stagnating development of theories of democracy, Cobb and Elder tried to establish an "agenda-building theory" in 1972. Their work is still popular, as it had a reprint in 1983. There are several empirical studies that utilize the theory.

Cobb and Elder distinguish among four sets of factors which may cause such stagnation of theory development. They are acknowledged by political scientists, but barely developed any further (p. 10-12).

First, the distribution of influence and access in any system has inherent biases. Some groups, consequently, will be fawored by the societal and institutional system, while others suffer disadvantages.

Second. the range of issues and decisional alternatives that will be considered by a polity is limited. Two reasons for this are that on the one hand the capacities of any human organization are limited, and on the other, that any political organization lives by the exploitation of conflict; some issues are addressed, while others are suppressed.

Third, the system's inertia makes it wery hard to change anything. According to Cobb and. Elder, the institutional structure of a society has a strong 'status quo bias' to reinforce and defend the existing situation. This has much to do with vested and intertwined interests. The fourth observation may be the most crucial for the further development of the theory: pre-political, or at least pre-decisional processes often play the most critical role in determining what issues and alternatives are to be considered by the polity and the probable choices that will be made.

\subsubsection{Outside initiative model}

Given that these four sources of systems dynamics are strongly intertwined, the central question for Cobb and Elder becomes: how does an issue or demand become or fail to become the focus of concern and interest within a polity? In other words; how does legitimi- 
zation of a social problem to a policy problem take place?

The basic notion is, that for a policy to develop. there should be a need for such a policy. In their conception, the pubic plays a role to get issues on a systemic (or "soctetal") agenda. Only after sufficient public and interest group pressure and various mechanisms to transfer the perceived need, the issue on the systemic agenda will find a place on the institutional agenda. This mode of pressing issues onto the institutional agenda is labeled as the "outsideinitiative" model (Cobb et al, 1976). "Institutional agenda' refers to 'a general set of political controversies that will be viewed at any point in time as falling within the range of legitimate concems meriting the attention of the polity, i.e. a particular institutional decision-making body" (Cobb \& Elder, 1983, p. 14). An issue on the institutional agenda has thus a very large probability of being addressed by formal policy (although non-decision may be policy as well).

In the foliowing we will further describe the theoretical idea of Cobb \& Elder, its scope, and implications. After that, a critical appraisal will follow, and modifications of the theory as suggested from empirical settings will be provided (Koppenjan et al., 1987). Finally, we will take a look at the relevance of the agenda-building theory for the study of healthy public policies (Milio, 1988, Altenstetter, 1987).

\section{Categories of issues, conflict and mechanisms}

Cobb and Elder depend heavily on theoretical formulations of conflict in their attempt to address the agenda-setting problem. Conflict arises out of scarcity. Scarcity relates to material as well as non-material commodities. So-called 'entrepreneurs', "initiators" of issue formulation, 'trigger-devices' for issue establishment, various publics and the mass media play an apparently important role in voicing concems ower issues of scarcity. As long as the issue is contained to few parties which agree upon the scope of conflict and strategies to cope with it, the conflict will remain confined to the initial group of contestants with a perceived interest in issue. In all other cases, the weakest party will try to coalesce with other groups, and try to extend the scope of conflict. Conflict thus escalates among more interested parties, and finally reaches the highest level of societal decision-making capacity: government. Government is considered to be the supreme authority in solving societal conflict. However, government -including elected as well as appointed officials and bureaucrats- is not an independent, insular judge. In most cases it is an involved party with its own interests to protect as well. For theoretical purposes, though, Cobb and Elder make a clear distinction between governmental ("institutional agenda") capacities, and societal ("systemic agenda") capacities.

Whenever an issue reaches this highest level, it may acquire institutional agenda status. This depends on the reformulation of the issue by those in charge: "The redefinition phase is critical in determining whether or not a particular issue will receive formal agenda attention" (Cobb \& Elder, 1983, p. 44).

The general hypothesis of Cobb and Elder becomes thus: the higher public (i.e. societal) support for an issue, the better are the chances for an isste to enter the systemic agenda, and in tum to be on the institutional agenda. By manipulation of the definition of the conflict, the scope, the intensity and visibility of the issue can be modified.

Classification of the issues according to Cobb and Elder follows suit. They determine five fundamental dimensions. These are the specificity of the issue, its social relewance, temporal relevance (long term or short term), complexity, and finally, available precedents for the issue. Issues relate to matters of distribution, regulation, and redistribution. These subsume all possible policy types.

Cobb and Elder delineate three prerequisites for an issue to obtain access to the systemic agenda:

1. Widespread attention or at least awareness, 
2. shared concem of a sizeable portion of the public that some sort of action is required, and

3. a shared perception that the matter is an appropriate concem of some govemmental unit and fallsw within the bounds of its authority (p.86).

Based on the above classification in five dimensions, the authors suggest that an issue will (through increased scope of the conflict) have better chances to appear on the systemic and institutional agendas if the issue per se has the following characteristics:

- the issue is defined equivocally;

- the social relevance is perceived as high:

- the issue relates to the long term:

- it is not techuical or technocratic; and has

- few historical precedents.

Issue and conflict expansion is a societal mowement used by or exerted upon the various publicss (interested groups; defined below) to increase the chances of an issue to turn up on the systemic and institutional agendas. According to Cobb and Elder, more publics will be reached if the initial contestants cannot limit the scope of the issue conflict, acknowledge that the conflict centers around socially and temporally relevant questions, can not be laid in the hands of a small (technocratic) clite, and that solutions to the conflict are not readily available from previous experiences. In such cases, more publics will be mobilized to press for the conflict to acquire (systemic and institutional) agenda status.

Although individuals may play different roles in a conflict (they may be members of different organizations or overlapping reference groups), for analytical purposes Cobb and Elder distinguish among four general ty pes of publics (p. 105-106):

- identification groups: those groups who are oriented towards, or focus attention upon, the group of primary stakeholders, identifying their interests generally with those of that group or having a persistent sympathy with its generic interests. Ties between members of these groups tend to be relatively stable and lasting.

- attention groups, which Cobb and Elder label issue publics: persons in such groups are not concerned about most issues, but they are informed about and concemed about certain specific issues. Attention groups include pressure groups with single interest areas focused on specific groups (politicians, policy-makers). They are readily mobilizable as soon as 'their' issue is at stake.

- the attentive public: a generally informed and concemed stratum of the population. The attentive public is not homogeneous, but is relatively stable in its composition. "Opinion leaders" find their roots in the attentive public. Rosenau (1968) estimates that about $10 \%$ of the total population may be assumed to be an 'attentive public'.

- the general public. This is a statistical artifact, because the public at large cannot be mobilized at once for one issue. The general public is that part of the population which is generally less active less concerned and less informed. An issue must be highly general. ized and symbolic to attract attention.

We will operationalize this group typology into healthy public policy groups in 4,2.2.

The various publics are mobilized in the above order when an issue is at stake; the identification groups will react first, and strongest. Their 'constituency', or power base, is largest. The attention groups or issue publics follow. They may identify strongly with one issue, but are not to be nobilized for any other. Their power base may be diffuse. The attentive public is next; they may have a role in further dispersion of information and concern. As noted above, the general public is hard to mobilize, and does generally not have a power base to sustain long commitment to one issue.

To reiterate some key concepts: in the above we have come across a notion of "issue definition'. We have noted that redefinition of an issue into an item on systemic and institutional agendas may take place. The various stake-holders may try to put the issue on the systemic agenda by 'issue manipulation', trying to extend the scope of the conflict. This is an 
important mechanism in the agenda-building theory.

Cobb and Elder speak of "issue expansion". Issue expansion, ite the process of enlarging the size of the audience responsive to the issue, may be done through various modes. "The mass media play important roles which we will lay out in 4.2.3. It should be remarked, though, that none of the mass media are necessarily independent and objective. They address specific publics and constituencies, and may have a preconceived notion of "news" (Donohue, Tichenor \& Olien, 1984).

Again, in terms of the five issue characteristics given above, Cobb and Elder assert (p.112122) that issues are likely to be expanded when:

- the issue is defined equivocally;

- the social relevance is perceived as high;

- the issue relates to the long term;

- it is not technical or technocratic; and has

- few historical precedents.

Use of symbols and imagery with emotional connotations is another important technique in issue expansion. Symbolism and imagery specifically relate to the definition of the issue. What is important is not the factual description of a symbol, but people"s emotive response to it. Symbolism is culturally and temporally determined. For instance, 'communism" has a connotation of 'totalitarian regimes" and "oppression' to most Americans, while 'anti-revolutionary" in the Dutch context has a completely different emotive response (a Christian political party with a solid democratic reputation - it relates to the French Revolution) from the Nicaraguan context (where it has an emotive response of subversion, relating to the Sandinista revolution).

Symbol-use in issue expansion should be appropriate and appealing to the publics to whom the issue is to be expanded. Further, symbolls have an 'internal' role in confirming the identity of the identification group or issue public working with it; easy reference to a recognizable symbol (e.g., the swastika) may create solidarity and sense of belonging. Such references may in consequence be used by the media.

Summarizing, the key features of the original agenda-building theory are the following. Policy makers will only be willing to put an issue on the institutional agenda (and consider it for policy) if it has reached systemic agenda status. Systemic agenda status can only be acquired after issue expansion from the original conflicting parties to larger publics. Four of those have been identified. Issue expansion takes place through the media and by the use of symbols and imagery. Five theoretical propositions are suggested: an issue is viable for policy if it is defined (it would be false to speak of factual problems) more ambiguously, as having higher social relevance, having extended temporal relevance, is being non-teclanical, and without precedent.

By inference, issues entering the institutional agenda in this way would lead to a policy decision. However, Cobb and Elder assert that the mere recognition of an issue on the institutional agenda might be satisfactory to the original contestants. The groups that attempt to raise the issue to system agenda status may be satisfied by recognition of the issue on governmental levels, and not press for further action. Policy would not be necessary anymore in such a case, Cobb and Elder suggest.

Peper (1972) in the same year as Cobb and Elder develops: theory of institutionalization which has many similarities with the theoretical construct of agenda-building. The process of institutionalization is in fact the crucial part of establishment of formal policy. In the development of institutionalization, four phases are identified:

1 Subjective dissatisfaction among one or more persons, or an aggregate of persons is the starting point;

2 followed by an articulation of the perceived, or subjective problem among these groups:

3 through personal or concerted efforts the problem is eliminated, or the need satisfied, and 
4 finally, new social concepts are developed or existing forms modified (p. 48).

These steps are wery similar to the process Cobb and Elder suggest, although the latter add specifically aspects of issue conflict among contestants, and the role of media in issue expansion in order to address the perceived problem. Peper merely views these as general pretequisites for the process ( $\mathrm{p} .42$ ); he suggests the following factors are involved in synergistic ways:

1 Frequent interaction among interest groups and persons;

2 coordination of action among these;

3 the presence of an urgent problem among these groups and persons;

4 some substratum of shared culture (a consistent set of values and norms, beliefs and attitudes among a well-definable group);

5 the availability of leaders.

In their analysis of decision-making and particularly non-decision-making, Van der Eijk and Kok (1975) delineate more specific wants of contestants, (societal and institutional) systems boundaries, aggregation of demands, issue fornulation and decision output. Their analysis is an addition to Peper's work, but not fundamentally new in relation to the work of Cobb and Elder.

However, non-decision-making. Van der Eijk and Kok assert, may frustrate the agendabuilding process in each of the phases distinguished. Non-decision-making ('benign neglect' by issue contenders) can relate to the prevention of want-demand conversion, prevention of issue-formation, demand perversion, the decision-making process itself, and the implementation phase ( $p .291$ ). Cobb and Elder take the non-decision-making barrier into account by viewing issue expansion and agenda-formation as a dynamic and continuous societal process, acknowledging that non-decision-making might be a satisfactory outcome of the agendabuilding process to some of the publics once they see their issue has been recognized by decision-makers.

\section{Agenda-building theory: critical appraisal}

Koppenjan et al. (1987) recognize some pitfalls in the original agenda-building-theory. Their critique centers around

- its static character;

- problems regarding the delineation of systems;

- the mediating function of mass media between systems;

- issue definition; and

- policy typologies.

First, Koppenjan and his colleagues recognize, as we have, that the "real-life" policy process cannot be divided into clear chronologically successive phases (p. 39). This may be done for analytical purposes (as, for instance, in the rational-comprehensive approach to policy studies), but in fact, there may be overlaps and gaps between the various phases. Apart from that, the policy process is not an isolated phenomenon. Termination of one policy may automatically result in initiation of another. Very few policies are in fact completely "new": from an incremental point of view it may be argued that each policy in a certain societal sector ('health', for instance) is based on other policies. Revolutionary innovation is rare. However, as we have noted above, policy is not created out of chaos or vacuum; a phase of initiation of policy may certainly be recognized. Koppenjan and his colleagues find that agenda-building processes may be applicable to all phases of policy making. The purely orthodox view, in line with Cobb and Elder, would be that agenda-building theory only refers to the initiation and adoption phases in the governmental bureaucracy. And even that might be problematic: "..., formal agenda status does not necessarily imply remedial or corrective action; it simply means that decision-makers will officially recognize and consider a matter." (Cobb \& Elder, 1983, p. 161). 
However, the theory of agenda-building indeed seems static rather than dymamic. It describes the state of affairs (agenda status of issues) but not the factual processes having brought about that status. This makes it hard to infer activities among interested groups to either increase (or decrease) agenda status, or feasibility of proposed policies. After the following review of further characteristics of the theory and several models which may be suggested within the theoretical framework, we will retum to this matrer in 4.3 .4 , and finally in 7.5 . Cobb and Elder seem to be quite clear in their distinction of system boundaries. General systems theory (the foundation of their agenda-building theory) requires an Operating System and Operated System. In various phases of a process these positions may change. Cobb and Elder distinguish between 'the public' and "the policy makers': an issue must pass the system boundary to get from the systemic agenda onto the institutional agenda. Koppenjan et al. show that this distinction may be superficial and perhaps even misleading ( $\mathrm{p}$. 42). First, they question what constitutes the systemic agenda, or the "public opinion". It may" refer to attitudes and beliefs of the mass public and should thus be operationalized as mass attitudes and beliefs reflected through opinion polls. On the other hand, it could also refer to the beliefs and attitudes of more politicized and activist segments of the population, these could be measured through analysis of media coverage and demonstrations or picket lines. Koppenjan et al. find the theory on this aspect weak; even with the various publics as distinguished by Cobb and Elder, operationalization remains hard. We adopt the view here, that pressure on policy makers through issue (or conflict) expansion (cf. Cobb and Elder) may be measured through content analysis of mass media and public outcry, and that the 'width' of issue expansion is revealed by mass opinion polls.

The second theoretical pitfall with regard to system boundaries and flow of information across these boundaries is one of intertwinedness of interests. Hofland \& Wilms (1984), for instance, refer to the Netherlands' health bureaucracy as entangled in an "iron triangle" as well as 'iron circle'. It is not just so that interest groups and governmental buneaucracy may have opposing views, the iron circle and triangle almost dictate that elected and appointed governmental officials play roles on both sides of the system boundary simultaneously. This notion tends to 'pollute' the dichotomous view of Cobb and Elder.

Third, Koppenjan et al. assert that the role of "the" mass media may not be as prominent as suggested by Cobb and Elder. Verification of this hypothesis is found in research by Kok (1981). He made an inventory of the information sources of governmental bureaucracy (ministerial directorates). Seven were found: the elected and appointed top-officials of the apparatus; the directorate itself; formal consultations with the "field"; interdepartmental contacts; mass and specialized media; parliament; and informal networks. However, the effects of the communication processes of all these sources are of a high complexity. It is asserted that the scope of the mass media is temporally limited ${ }_{n}$ and thus may not have the influence on agenda-setting matters given to it by Cobb and Elder.

A fourth problem Koppenjan et al. distinguish is one of issue typology and definition. The causality Cobb and Elder suggest between issue definition and the scope of conflict is questioned. Does an issue mobilize a wide public because its definition is equiwocal, or is the issue defined equivocally because the public is so large? The propositions of Cobb and Elder bear a danger of circular argumentation.

Other (for instance, socio-economic) contextual factors, on the other hand, seem to be left out of the process. Hall et al. (1975) suggest a more differentiated typology of issues. They recognize three types, relating to legitimacy, feasibility, and support. An issue, according to them, would only enter the institutional agenda if it is perceived to be a legitimate concem of government, if technical and theoretical notions indicate a high feasibility for policy develop ment, and if there is sufficient support. The variables having an influence on the perception of legitimacy, feasibility and support are first, the degree of expansion of issue conflict, and whether it is perceived as legitimate or controversiall. Second, they point to the urgency of the 
problem: will it develop in a linear way, or exponentially? They also look at whether the inithiative for agenda-setting is inside or outside govermment. The athority ("credibility") of the sources of information related to the issue is another aspect. Finally, the ideological "load" of the issue is important, and whether or not it is compatible with existing ideology. We view this typology as an addition to the one proposed by Cobb and Elder. The latter view the typology of Hall et a]. as mere prerequisites (Cobb \& Elder, 1983, p. 86). Thus, the typology is only of a different aggregate level.

Finally, Koppenjan and his colleagues find that the theory of agenda-building does not take policy typologies and organizational configurations into account. Policies can be seen as innowation, continuation, modification or termination within the present context. Cobb and Elder do not seent to recognize any of these types, they only refer to another lewel of policy typologies: distribution, tegulation and redistribution. The former is a more dynamic typology. Koppenjan's critique on this aspect of agenda-building theory seems to be of a too abstract theoretical nature. If we are to investigate a given case-study (Nota 2000), it should be possible to determine the policy type and further apply the (modified) agenda-building theory of Cobb and Elder.

\subsubsection{Inside initiative model}

To clarify some of the problems raised by Koppenjan et al., Cobb et al., (1976) proposed an addition to the original view of the agendaubuilding theory. The original model could be labeled "outside-initiative": sufficient public pressure under appropriate conditions would lead to policy considerations by politicians and bureaucrats. The model seemed appropriate to most industrial democracies.

Cobb and his colleagues proposed an 'inside-initiative model': it appeared possible as well that policy makers place issues on the institutional agenda more or less independently. In the "inside initiative", or 'inside access' model, policy originates within a governmental agency, or in a group that has easy access to the policy makers and political decision makers. To protect interests to be served by the new policy, these groups try not to expand the range of issue conflict. They attempt to confine it to the circles where it arose, which are also the circles responsible for policy development and adoption. However, different issues may compete for agenda status among the top leaders. The contestants will try to coalesce with groups with similar of interests. Issue expansion is therefore limited and controlled, and the set of interest groups pressing for the issue generally homogeneous. This will more easily induce attention to the issue arnong the top leaders responsible for agenda status of an issue. An important characteristic of the inside access model is that undesirable expansion to attentive and general publics will hinder formalization of the issue into policy: the interests at stake are too limited to attract the wide audience that would be required in an outsideinitiative model. If a wider public would become involved or concemed about the proposed plans, it might oppose serving those limited interests. Cobb et al. (1976) assert that "... the insicte access model of agenda building will occur with greatest frequency in societies characterized by hign concentration of wealth and status" (p. 136). Although this characterization is quite ambiguous, the "concentration of wealth and status" seems to refer not to those societies as a whole, but rather to specific groups within society. The societies in which the inside-initiative model may be employed are not wealthy in themselves, but rather rulled by a wealthy oligarchy (elite). Following Cobb et al. (1976) the model would thus not readily apply to (western) democracies, although industrial oligarchies (cf. Marxist analyses) may very well be pressing for an inside-initiative type of model.

Finally, the inside access model to agenda-building provides policy makers with very concrete proposals for policy. The outside-initiative and mobilization models demand policy in more general forms. 


\subsubsection{Mobilization model}

The third model, "mobilization model' was more or less an extension of the inside-initiative model: here, decision-making is already tinalized but policy-makers seek support in the public to realize implementation. The process is essentially the sanie as in the original agenda-building theory: for effective implementation of the policy, public support is needed. In the mobilization model, policy is considered formal (though not necessarilly adopted) as soon as political leaders in government make an explicit statement (which could be a trial balloon) on the issue. Political and bureaucratic leaders may seek support for the pollicy, for instance when it is dependent on voluntary adherence by (groups in) society, or when success of the policy is dependent on a change in attitude. The expansion of the issue, then, takes place from inside govemment (bureaucratic decision-makers) to groups who have not been aware before of the issue conflict. The initial formal statement may often be considered a starting point for public debate and discussion. Policies stemming from the mobilization model are generally less concrete than inside-initiative policies; popular support and public pressure might indeed induce further sharpening of the demand for concreteness. This might in turn be an objective of the initial decision maker.

The mobilization model of the agenda-building theory seems to be an appropriate tool to study the development of health policies. Indeed, there are many contestants in the definition of the issues (various publics may identify the issue to be 'appropriate services', 'costcontaimment', 'manpower-planning', 'health protection', 'health advocacy', etc. etc.), while govemment has legitimacy to deal with health issues in general (Article 22 paragraph 1 of the Netherlands' Constitution makes government responsible for protection of the public thealth), although the individual cannot derive particular rights from this article (De Leetuw \& Jonker, 1988).

Moreover, there is a very intricate intertwinedness of health bureaucracies and publics interested in health affairs. In line with Visser (1989), introducing concepts of "bargaining democracy' and 'bargaining economy', the Netherlands' health system typically may be called a 'bargaining health system". As Hofland and Wilms (1984) have investigated, the neo-corporatist structure and nature of health policy-making in the Netherlands almost dictates continuous inwolvement of interest groups of various kinds in the process. More often than not, they assert, there is no sharp distinction between the policy-initiating body and interest groups assembled in QUANGOs: "The service sector is marked by a multitude of systems of decision-making which de facto cannot be structured hierarchically. but rather have to be seen side-by-side, co-ordinate" (p. 101). The multitude of health advisory bodies (QUANGOS), together having a larger staffing than the total directorategeneral for health of the ministry of health, sometimes paralyzes adequate and timely decision-making. The nature of healthy public policy (intersectoral approach, integral intervention mix, participatory nature, of. De Leeuw (1989) and 3.2) requires negotiation rather than direction (in terms of the theory: mobilization rather than inside access), and consultation rather than bottom-up pressure (mobilization rather than outside-initiative). The intricate situation of inertia in the Netherlands' health sector, where a single power hierarchy is hard to establish (Juffermans, 1982), has been assessed by the Scientific Council on Government Policy (1977), the Committee Main Structure of Government (Van Delden. 1981) and the Project Group External Advise (1983). There has been relatively little action on the recommendations of these bodies. These included setting up cone ministries and project ministries, and establishing fewer numbers of QUANGOs with more adequate feedback mechanisms. The recommendations of the Dekker-Committee (Commissie Structuur en Financiering van de Gezondheidszorg, 1987) on health care planning and financing in The Netherlands (cf. 2.3.1) also deal with the stagnating circuits of advice and consultation.

In summary, the situation in Dutch health policy making appears to require a mobilization 
model of the theory of agenda building for effective policy making.

We will assume that the dlevelopment of Nota 2000 has been along the lines of the mobilization mode $1_{\text {. }}$ and we will subsequently test whether the components of the theory hold in this specific case study. This will offer opportunities to make grounded evaluations of the present status of Nota 2000 on systemic and institutional agendas, the options of further advancement of Notat 2000 toward formal policy status, and in turn indicate the feasibility of a Dutch health policy.

\subsubsection{Healthy public policy and agenda building}

In the above we have reviewed the components of the agenda-building theory, and the nature of the Netherlands' health care system calling for employment of its mobilization model. There is one more reason to use either the outside-initiative model or mobilization model in studying development of healthy public policy.

As the Adelaide Recommendations on Healthy Public Policy (WHO \& Commonwealth Department of Community Services and Health, 1988) state: 'Healthy public policy is characterized by an explicit concem for health and equity in all areas of policy and an accountability for health impact.' Participation in making policy by all interest groups (including the less powerful) is of utmost importance for the establishment of healthy public policy (Milio, 1987 "De Leeuw, 1989). The mobilization model of the agenda-building theory has the highest potential for adequate communication between interest groups and decision-makers. Dekker (1986) argues for a mixed-scanning approach (Etzioni, 1968) to the establishment of healthy public policy (or rather, a virtual health policy). In mixed-scanning, a distinction is made between fundamental policy choices and incremental policy options. Dekker translates these into scientifically appropriate decisions, limited by the margins of societal desirability. A dialogue would have to be set up to establish the final policy direction, the translation of scientific (fundamentall) thrusts into societal (incremental) policy objectives. In terms of the mobilization model, this would mean that some agency (or Policy Keeper, cf. Milio, 1987; the agency is likely to be governmental, but not necessarily so) sets the fundamental social and scientific issues and options, and tries to translate these into socially relevant ones through rounds of consultation, bargaining and participation with interest groups. This requires strategic consideration of the issue and policy modes required. The interest groups addressed in turn would be able to expand the issue to more publics, and finally the issue (in this case, a (comprehensive) healthy public policy) would retum to the initiating govermmental agency, pressing for establishment of concrete policy. In sum, a mixed-scanning approach to healthy public policy is fully compatible with the mobilization model of the theory of agenda-building:

\subsection{Constituent parts operationalized}

Before we proceed to test the theory as we have described it, we will operationalize the various components of the mobilization model of the agenda-building theory. Constructs and variables (such as 'issue expansion' and 'media coverage') have to be defined in unequivocal terms in order to measure them adequately. There is a distinction between constitutive definitions and operational definitions (Kerlinger, 1973). A constitutive definition defines some construct with other constructs. Constitutive definition is merely substitution of one construct by one or more related others. Constitutive definition is useful in relating some theory to other theories. It is not appropriate for measurement purposes.

The operational definition is. It assigns meaning to a construct or variable by specifying the operations needed to measure it. Operational definitions are instructions on what and how to observe. In the following, we will suggest operational definitions of 1 . the issue expansion criteria Cobb and Elder have formulated, of 2. publics involved in healthy public policy making, and 3. operational definitions related to symbolism and media. These three fields 
and sets of variables to be derived from it comprise the essential components of the theory.

\subsubsection{Issue expansion criteria}

"An issue is a conflict between two or more identifiable groups over procedural or substantive matters relating to the distribution of positions or resources" (Cobb \& Elder, 1983, $\mathrm{p}$. 82). In this investigation, 'Nota 2000 ' is too broad a construct to define as an 'isstie'. The characteristics of Nota 2000 as defined in 2.3.2 are specific enough to define them, as a complex, as 'the issue' at stake: 'the conflict among identifiable groups (cf $4,2,2$ ) over a health policy which is future-oriented and strategic, health (not care) oriented, structured by an explicit policy model, based on prevention and facer policy, and ombedded in a distinctive set of support policies, and the implications of the proposed health policy for (rie)distribution of positions and resources'.

According to Cobb and Elder, issues should have the following characteristics in order to achieve systemic and institutional agenda status, and therefore be considered for formal policy by decision-makers. The issue is:

- defuned equivocally;

- of perceived social relevance;

- related to long time ranges;

- is of a non-technical and non-technocratic nature; and has

- few historical precedents.

In the following we will give operational definitions for each of these five characteristics.

Although Cobb and Elder refer to the five sets as being continua, we will establish trichotomies for measurement of the issue characteristics: "yes, the issue is (characteristic), though inappropriate to our interests', 'yes, appropriate', and 'no'.

The first characteristic is the degree of specificity of the issue. Specificity refers to how abstractly or concretely the issue is perceived to have been defined. In this investigation, specificity is measured by the response to the question "Is Nota 2000 perceived by the respondent group to be intangible?' "Intangible" here refers to the impossibility of the group to translate Nota 2000 into concrete organizational objectives or actions. The proposed trichotomy in response categories will be perceived by respondent organizations to be adequate: groups indeed may perceive the nature of the issue as totally inappropriate for their own organization to act upon, appropriate for further action (cf. 4.1.3: in the mobilization model contestants are asked to concretize the issue), or not intangible at all. In the latter case, groups do not belong to the group of contestants over the issue.

The second dimension is sociall significance. 'Social significance refers to the number of persons who will potentially be affected" (Cobls \& Elder, p. 97). In this investigation, social significance is measured by the response to the question "Does Nota 2000 , when imple. mented, in the perception of the respondent group substantially affect groups in society?" The third characteristic, temporal relevance, relates to whether the issue has limited, circum stantiat relevance or longer-lasting, fund amental relevance. Temporal relevance is measured by response to the question "Is Nota 2000 by the group perceived to have fundamental, enduring relevance for activities to be employed by this group or for society as a whole?' Recognition and appraisal of the future-oriented characteristics of Nota 2000 thus scores 'yes', while dismissal of the walue of the future-orientation will score 'no'.

Complexity is the fourth dimension. Simple, non-technical issues, according to Cobb and Elder, will have easier issue expansion than complex technical ones. Complexity thus relates to "how an issue will be delineated along a continum from the highly complex and technical to the simple and easily understood" (Cabb \& Elder, p. 98-99). It is measured through the question 'Does the group perceive the nature of Nota 2000 to be non-technical?' 'Nontechnical" refers to the way in which problems in Nota 2000 will have to be addressed; non. technical problems cannot be solved by highly educated policy experts or scientists alone. 
but are rather a matter of discussion and iteration among many groups in society.

Finally, the fufth dimension is categorical precedent. It indicates the extent to which an issue is a foutine matter having more or less clear precedents (and consequently known procedures for its resolution), or the extent to which it is extraordinary (p. 100). This characteristic is scored by response to the question "Has there never been a document like $\mathbb{N o t a} 2000$ in the past?"

These operational definitions of issue expansion characteristics give the opportunity to evaluate the extent to which groups who have interests at Nota 2000 agree on the nature of the issue dimensions. Following the agenda-building theory, a significantly large proportion of answers being in the "yes"-category would indicate presence of the issue on systemic and. institutional agendas, this in tum meaning that there would be sufficient public pressure for formal policy.

\subsubsection{Publics}

The question of what congtitutes a public has troubled policy investigators over the years. (Schmitter, 1977), Cobb and Elder distinguish -as noted above- between:

- identification groups: those groups who are oriented towards, or focus attention upon, the group of primary stakeholders, identifying their interests generally with those of that group or having a persistent sympathy with its generic interests. Ties between members of these groups tend to be relatively stable and lasting.

- attention groups, which Cobb and Elder label issue publics: persons in such groups are not concerned about most issues, but they are informed about and concerned about certain specific issues. Attention groups include pressure groups with single interest areas focused on specific groups (politicians, policy-makers). They are readily mobilizable as soon as 'their' issue is at stake.

- the attentive public: a generally informed and concemed stratum of the population. The attentive public is not homogeneous, but is relatively stable in its composition. 'Opinion leaders" find their roots in the attentive public. Rosenau (1968) estimates that about $10 \%$ of the total population may be assumed to be an 'attentive public'.

- the general public. This is a statistical artifact, because the public at large cannot be mobilized at once for one issue. The general public is that part of the population which is generally less active, less concerned and less informed. An issue must be highly generalized and symbolic to attract attention.

This distinction between publics does not seem quite appropriate for the field of health policy, as Hofland and Wilms (1984) distinguish the actors in that field into goods and service deliverers, fHenciers, government, employers and unions, independent experts (scientists); and consumers. Hofland. and Wilms, as well as Van de Vrie and Van Elzakker (1988a, $1988 \mathrm{~b})$ have listed the actors in this order along the lines of a diminishing power base (deliverers having the highest power base, consumers the lowest; they refer to degree of organization, representation in various QUANGOs and financial backing in the establishment of this hierarchical order). This order is not entirely in accord with the classification made by Cobb and Elder.

Milio (1987) broadly defines publics, 'the major players', or interest groups, as any organized groups or parts of groups whose resources, authority , status, influence, or survival is affected by a policy. This is a rather abstract distinction, particularly in the complicated situation in the Netherlands with regard to policy responsibilities given to para-political organizations as described in 3.1. The operationalization that follows ('Such groups include political parties; parliamentary committees, ministerial offices and bureaucratic units; commercial enterprises; and voluntary, professional, religious, communications, or minority organizations', p. 266) does not seem to be conceptually concise; in fact, it means 'such groups include every organized interest entity". 
In an analysis of intersectoral action for matemal and child health promotion, Altenstetter $(1987, \mathrm{p} .40)$ however distinguishes between the following organizations in some way involved in the decision-making and policy process in a specific policy sector: governmental law-making machinery, ministries, public or quasi-public corporations, advisory councils on health needs, nutrition council, national planning board, economic development board, government and non-government research centers, health care delivery networks, hospitals, university medical schools, political parties, interest groups, trade unions, consumer organizations, religious groups, business associations, women's groups, teachers" association, and mass media.

The list seems to be exhaustive, although we would like rather to have a concise framework to classify all these actors in order to distinguish between clusters of various organizational thrusts, scopes, perceptions and artitudes.

Fully in line with the theory of agenda-building and the limitations for composition of publics given above, Milio (1987) proposes a conceptual framework to structure the scene and players in the policy-process (figure 4.1). It is noted that "conceptually, within an enabling or restrictive social context or climate, a specific policy issue draws the attention of the groups within and outside government that view a policy change as important to their

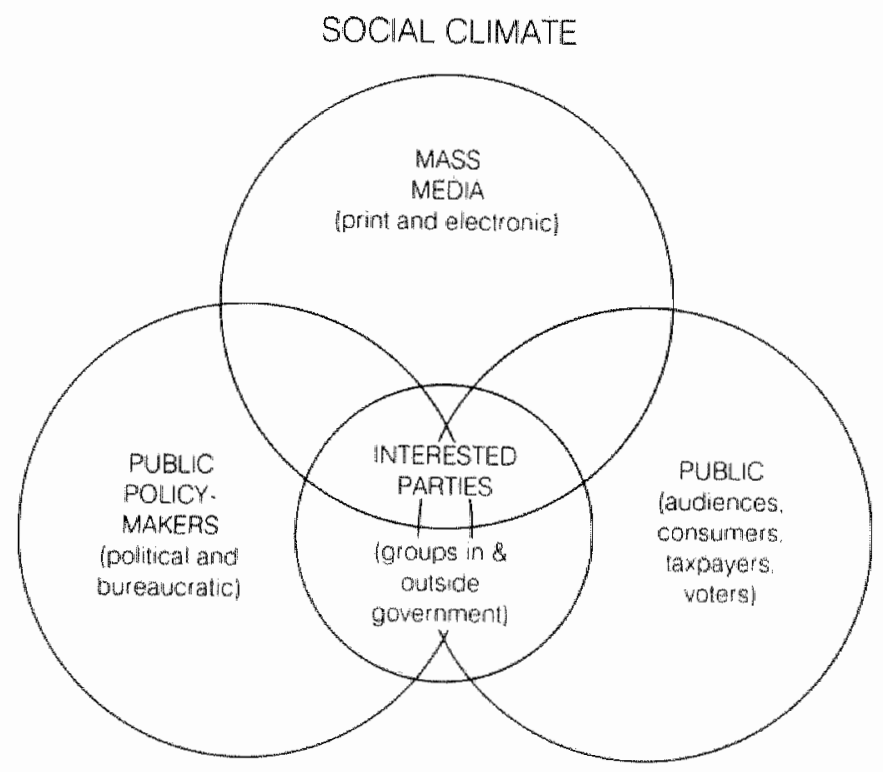

Figure 4.1: The scene and the players in the continuous process of making policy (Milio, 1987).

interest. Depending on their priorities, the groups deploy their resources to influence the shape, pace, or direction of policy-making in ways that will either enhance or at least not harm their interests. The effectiveness of their efforts depends on their influence, status, resources, and skill relative to competing groups that have different interests' (p. 268). Figure 4.1 is conceptually adequare, and it exactly addresses the issue raised by Crichton (1981, p. 123): no interest mediation structure is adequate by itself; however, several frameworks taken together in juxtaposition or synthesis might be able to provide a satisfactory basis for analysis. The overlapping sectors presented in figure 4.1 do address the 
intertwhedness of different interests and power bases of various actors. However, the Netherlandss "situation in health policy making is far more complicated than the figure

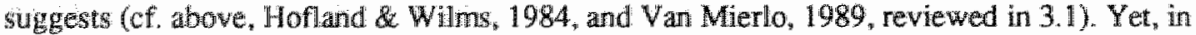
the irivestigation at hand we have used this conceptuall model as a starting point.

First of all, in the present situation, we have singled out the mass media. The remaining circles have been subdivided into political parties, bureaucratic officers, political officers ("public policy-makers"), research organizations, non-govemmental organizations and professionals ("interested parties"), and consumer organizations ("public"). In fact, all groups may be considered interest groups, as we have reviewed. It will be clear that in some cases there is not too sharp a distinction between those groups, and that therefore the allocation of an organization to a centain sector might be considered arbitrary -yet, this is self-evident from the figure above; for instance, is the Netherllands" Health Council a research organization ("interested party") or a bureaucratic body ("public policy-maker")? The objective of the organization uss to provide government with adequate scientific assessments of the state of affairs in health matters. It is fully financed by the government. The issue is to be resolwed. empirically in chapters 6 and 7.

Neither of the above categorizations of (interest) groups seems appropriate in the study at hand. Cobb \& Elder's conceptualization of publics causes problems because in the Netherlands" health system no clear-cut distinction may be made between identification groups, attention groups and the attentive public as all of them are aggregated into organizations participating in the same set of QUANGOs. Alternstetter"s delineation is a purely functional one, while Millo's more abstract figure 4.1 causes serious problems if "interested party" operationally has to be distinguished from 'public policy-maker' and 'public"; however, the figure presents us with clear overlapping sectors so that combinations of organizationall or academic scopes may be feasible.

A some what ecclectic approach seems to be needed here, and to clarify these problems analytically, the following operational distinctions have been develloped:

Political parties are groups which have as sole objective to further their ideas and ideologies by means of representation in parliamentary bodies. Their interests lay in the realm of gaining and pertaining power in office, i.e. attraction of specific constituency support. Their ideas and ideologies are formulated in a platform ("partij-programma"), which is generally based on a set of assumptions regarding the ideal composition and behavior of society.

Political parties may consist of a membership body, a party bureau, and representatives of the party in parliament. The latter ('fractie') is the organization considered to belong to the circle of public policy-makers.

Bureaucratic organizations are those groups within governmental bureaucratic bodies fully fintinced and employed by government, and solely working to further the objectives of these bodies. In addition, their interests lay in sirengthening their budget, influence and control over the specific unit and outside constituencies. Bureaucratic officers are non-appointed tenured officials and are presumed to thave no political (i.e. party-related) loyalties. Their scope of work is generally limited to a particular bureaucratic sector, and although the impact of their work has societal spin-offs, the thrust of bureaucratic organization's work is within the organization itself, or related to the work of a limited number of other bureaucratic organizations.

Political officers are elected officials, leaders of governmental bureaucracies. They may be expected to transpose the ideas and ideologies of their political party to the work of the organizations they are heading. Their interests are survival in office, but also securing their constituencies through the policies proposed or defended.

Research organizations are groups which have as sole formal objective to further scientific knowledge in certain sectors of society. They may be considered 'objective', although specific research organizations may stand for a certain set of beliefs (research bureaus of 
political parties), a limited scope of work (primary health care, mental health or prevention), or specific target groups (health bureaucracies, hospitals). It is certainly not part of their stated mission to directly influence the course of affairs in (groups in) society: decisionmaking and policy interpretation of their research findings is uswally (though not always) left to others. Therefore, their interests are found in the field of organizational. growth and coverage of the research objectives.

Non-governmental organizations (NGOs) are those publics which, by tradition and/or mission, operate fully independent from official govemmental interventions. They include so-called quasi-autonomous non-gowemmental organizations (QUANGOs), which may have strong liaisons with govemmental objectives because of their dependency on govemment financing or govemmentally institutionalized mission, but still operate as an independently administered entity. Those organizations whose mission would mean inclusion along these lines in either 'NGOs' or any other cluster of publics are put in this other class as soon as the composition and/or mission of the group would be more compatible with the other cluster population. For instance, the Nationale Raad voor de Volksgezondtheid (National Public Health Councily is more strongly allied with govemmental bureaucracy than our operationalization would account for inclusion as NGO (or rather QUANGO). Empirically, the Council is classified as a bureaucratic body. On the other hand, the Nationale Kruisvereniging (National Cross Association), being traditionally an NGO for home and community care of the purest kind, and by now almost fully financed by governmental monies, is because of its standing mission considered an NGO and not a professional organization. Therefore, we still consider the Association to be an $\mathrm{NGO}$.

'Professionals' are perhaps the hardest public to define. There have been many debates over the exact constitution of a profession. Gienerally, workers in medicine are presented as the strongest form of a profession, together with lawyers (Parry \& Parry, 1976). Johnson (1972) gives as the one major and overriding characteristic of professionalism that it is "a peculiar" type of occupational control rather than an expression of the inherent nature of particular occupations' (p. 44). In line with this characteristic definition, we would present "professions.' in this investigation as those groups which have organized mainly to protect occupational interests. These interests may be of an abstract or material nature. The 'occupation' may be defined broadly, ranging from medical specialists to $\mathrm{CEO}$ s of large corporations (organized in employer's organizations), or from institutional occupational interests (institutes for ambulatory mental health care represented in one umbrella organization) to monodisciplinary occupational interest groups (nurses" organizations).

Consumer organizations, finally, are those groups which have organized in order to protect the adequate and efficient delivery of goods and services to individuals. Agtin, these goods and services may be of an abstract as well as material nature. "Employment', therefore, is seen as a commodity, and the large Netherlands' conglomerate trade urions therefore regarded to be among the consumer organizations, although their interests do not necessarily coincide with those of other consumer groups. But then, the cluster of consumer organizations is not homogeneous; various organizations stand for a multitude of positions (patient emancipation, environmental protection "consumer safety, etc.).

One question in this paragraph on operational publics remains to be resolved: who or what makes up for the stance of a public, and where should, transposing the question, be the entry point for an investigator in an inquiry in which organizations are involved? Necessarily, when carrying out interviews to obtain organizational data individuals are involved.

However, the level of analysis remains to be the organization, or organizational unit (Pfeffer, 1985, Milio, 1987). An interesting dilemma arises: contrary to organizational publications (which will be considered as consensus stances by the organization as a whole), individual responses to questionnaires might be biased by individual charisma, idiosyncracy, belie/s or attitudes (Cox, 1969, Haas, 1964, De Leeww, 1985). When forced to interview individuals, 
how will a researcher achieve "organizational" replies? It is assumed that the higher an indiwdual respondent is positioned in the hierarchy of the organization, the more cautious the respondent will be to reflect on personal beliefs or attitudes. In conclusion, chief executive officers, chairpersons, directors, and other leaders will be more inclined to voice an organizational consensus point of view. As they are opinion leaders and public figures, they are supposed to be very cautious in woicing their own beliefs.

An additional reason to address the higher hierarchical leaders is the issue of 'organizational support": policy staff from staff units or research depanments might generally be more informed regarding the issue at hand, while the CEOs would only respond along lines of major organizational thrusts and objectives. Questioning the latter would yield more accurate results regarding the organizational position.

\subsubsection{Media and symbolism}

It is generaly accepted that the mass media play an important, perhaps even crucial, role in agenda-setting. However, the mass media do not play fully independent roles in issue expansion, nor are they the sole source of information among publics (Donohue, Tichenor \& Olien, 1984). This would indicate that sometimes too large a power base is attributed to the mass media. For instance, Cobb and Elder (1983), Milio (1987), Milio (1988) and De Leew (1988) suggest that the mass media are a prime factor responsible for issue expansion. However, research by Donohue, Tichenor and Olien (1984) reveals that among the various groups and organizations that receive media coverage, those that occupy more established and dominant power positions in society will evaluate media coverage as more favorable to their collective ends than will members of groups and organizations with less established power positions (p. 207).

In addition, the theory of agenda-setting (McCombs \& Shaw, 1972) asserts that mass media are only partly successful in the modification of modes of peoples" thought, but thave a rather important function in the presentation of issues to consider by people. This theory is focuses on actualities (events fixed in short time ranges) and not on ranges of effects. McCombs and Shaw suggest that the media do not have a rigorous effect on behavior and attitudes of publics.

Moreover, Kok (1981) identifies more information sources important to decision makers (cf 4.1.1, above). Thus, issue expansion takes place through other modes such as bargaining. face-to-face information exchange, representation, etc., as well. This makes media coverage less crucial, though still important.

The important factor in media coverage is the way in which messages are conveyed. Cobb and $\mathbb{E}$ lder refer to this as making use of symbolism (cf. above).

Mass media are considered to be modes of communication through which large publics may be reached, and in which there is no direct interaction or communication between transmitter and receiver (Van den Ban, 1980, p. 284). Media coverage is defined to be any report on a given issue in any mass medium. Symbolism is a simplification or metaphor of a standing issue (Health policy, Nota 2000) in order to increase the probability (perceived by the communicator, i.e. the news maker, i.e. editor or reporter) that the reframed issue will serve certain purposes, for instance reach certain sectors of society, increase sales of media, etc. In the present investigation, we will look at timeliness of media coverage of the issue (is coverage recent? changing over time?), adequacy of factual representation of the issue (is Nota 2000 presented according the characterizations of. 2.3 .2 ? Which sub-issues are singled out? What is their nature? Note that 'symbolism' is equivalent to the media's translation of factual characteristics into scoops or caption), power base of respective media channels related to the coverage (ideological leaning of media as well news source). 


\subsection{Additional theoretical considerations}

There are some mone theoretical considerations to be presented before methodology and findings may be given in the next chapters. We have, for instance, made assumptions as to the distinction between perceived (or defined) issues and "real" issues. Further, we assume some telation between perceived value among publics of Nota 2000 , and subsequent action. Finally, there are some considerations as to the nature of the institutional healti agenda (the important issues to be addressed in the govemmental bureatucracy). These assumptions will be spelled out and given a place in our conceptual framework.

\subsubsection{Perception ws. 'reallity"}

The relation between perception by actors of an issue and some 'reality' regarding that issue may be viewed as problematic. Perception is subjective, while reality seems to be objective. With regard to research methodology in the pursuit of the "truth content' of some inquiry system, some observations will be made in chapter five (following, cf. also De Leeuw, 1989 , p. 60-64). However, there are also some theoretical issues with regard to the relation perception-reality. We will only touch on this vastly complex subject.

Cobb and Elder (1983) clearly state that issue expansion is a matter of issue definition by the various publics. Issue definition per se may be to some extent 'objective'. We have, for instance, tried to characterize the issue at hand in 2.3 .2 by summarizing the intentions of the authors of Nota 2000, while relating these to a developmental chronology. However, the definition of the issue, and the issue expansion characteristics as we have presented them in 4.2 .1 are matters of subjective perception by relevant groups (although these may be measured by relatively 'objective' methods, cf. Ch. 5).

At the same time, this subjective perception is of crucial importance to the ways in which issues are expanded. Moreover, media, reframing issues by means of symbolisn and metaphors, try to evoke subjective responses to the message (cf. Donohue, Tichenor \& Olien, 1984, above). The agenda-building theory predicts that as soon as perception of the matter (issue definition) among a sufficient number of actors is similar, the issue is placed on the systemic agenda.

Theoretically, this stance seems to be weak: the expression of the perception (or group subjective definition) of the issue is in fact what binds publics together. But factual expression makes the issue perception again reality, or rather one part of reality in the policy initiation or problem framing phases. This would lead us to conclude that in fact there is no distinction between perception and reality, and the relation not as ambiguous as we first presented it. Thus, querying the perceptions of actors is merely trying to understand limited parts of a composite reality. And this is exactly the thrust of the agenda-building theory.

\subsubsection{Action and value}

Detached from the agenda-building theory presented above is the assumption we have made with regard to the perception by publics of the value of Nota 2000 , their perceived involve ment in the policy process (in the mobilization model of the theory, this would apply to either the initiation phase at the institutional agenda level, as well as the issue expansion phase in the discussion phase at publics level), and action undertaken in the light of the issue. Two types of actions may be distinguished: $\mathbb{1}$ those actions aimed at removing barriers to formalization and implementation of the policy, and 2 those actions by publics related to the contents areas of the proposed policy (publics may feel allied to policy objectives, and feel that organizational objectives "fitt" that policy, and therefore might want to reorient their actions toward the proposals without the policy already being formalized).

The assumption is that the higher the perceived value of policy proposals is among publics, the higher the probability of appearance of the proposals on the formal (instifutional) agenda will be, which will be an indicator of feasibility. Actions undertaken, correlated with perceived value, should show this higher probability of agenda status and feasibility. 
Further, we have assumed that inwolvement in the policy process would have spin-offs with regard to the actions undertaken to advance the policy formalization phase. In other words: if actors feel that they have actively been involved in the policy initiation phase, we would expect more specific actions in the light of that policy in later phases because it is probable that their views thave been reflected better in the document at hand, which in tum would be an incentive for action.

\subsubsection{Institutional health agenda}

Finally, some temarks as to the constitution of the "institutional health agenda". Cobb and Elder (1983) are not at all cleat about its nature. The institutional agenda is not an unambiguous set of policies and policy proposals. Although Cobb and Elder acknowledge that the constitution of the systemic agenda is a matter of conflict over issues in society, they do not view the institutional agenda capable of contaning two competing issues explicitly. The

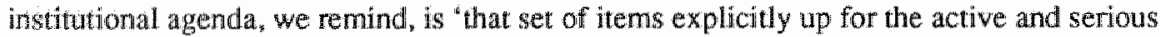
consideration of authoritative decision-makers $(\mathrm{p}$. 86). The ser of items seems to be of a non-competitive nature within one institutional policy realm. However, they distinguish between agenda items and "pseudo-agenda items" (items which are registered or acknowledged without explicitly considering their merits).

With regard to Nota 2000 , we have seen in 2.3.1 that the document may have been "overtaken" by the Dekker-report. Question now is whether either of these two policy proposals from the "set of items" has agenda or pseudo-agenda status. In case both have factual agenda status (which we have analyzed as being possible in 2.3.1), the question remains whether the two items are competing for an equal amount of "active and serious consideration". This is not only is matter of priority attributed to the issue at governmental and societal levels, but also whether instrumentation for both competing issues is considered to be feasible.

At the same time, uncertainty with regard to 'issue status' in the institutional agenda may complicate the situation among the publics which affect the systemic agenda. Consider, for instance, the situation described in the latter part of 2.3 .1 , where two seemingly incompatible major policy proposals compete for agenda status: the Dekker-report, launched by government from an "inside initiative model', and Nota 2000 , presented through a 'mobilization model" of agenda-building. Does the general theory hold at a point in time where two issue conflicts compete for more active and serious consideration, rather than -as the theory suggests- one set of issue conflicts leading to agenda status for only one policy?

The agenda-building theory tends to assume a relatiwely stable systemic as well as institutonal agenda environment. In the case of two competing items (two sets of issue conflicts), the theory would probably liave to be modified. In chapter six we will test whether the theory atso holds for the unstable environment as we have described it in 2.3.1.

\subsubsection{Dymanics of agenda-building: theory and pitfalls}

'Feasibility" is a key concept in this study: feasibility is "that which can be done." (Hornby, 1974). We now define the concept in a more concise way suited to the realm of health policy. Further, as feasibility is always 'that which can be done' in the future, and because we are dealing with perceptions by actors in the health policy game, the concept of feasibility has to be framed in a set of adequate prerequisite conditions.

"Feasibility of Dutch health policy", we suggest, may be defined as 'the perception by various publics of whether or not Dutch health policy (Nota 2000) will be operational and implemented in the foreseeable future through concrete health objectives/targets, allocation of resources and capacities to that end. This will include the establishment of time frames for this operationalization, implementation, setting of appropriate objectives, allocation of resources and establishment of such a time frame."

The investigation will focus on matters of feasibility. We would be interested in the current 
status of "the feasibility of Dutch health policy"; and in the processes that brought about that situation, and where appropriate, mechanisms to increase (or decrease, for those whose interests are threatened by Nota 2000 ) such feasibility.

However, the mobilization model of the theory of agenda-building as we have presented in 4. 1 and operationalized in 4.2 describes the state of affairs (agenda status of an issue) but not these processes. Indeed, in this respect the theory is static rather than dynamic, as Koppenjan et al. (1987) argue.

In order to include dynamics in the theory, conflict characteristics may have to be included. These are, among others, power distribution, interests at stake, organizational turfs, etc. We have touched upon such characteristics repeatedly in the previous chapters, and although the theory of agenda-building bases its construct and premises on conflictual situations, its crucial components exclude these.

In 1.3 we have presented the principal questions of this investigation. They fall within the boundaries of the theory as graphically presented in figure 4.2 . We would investigate the

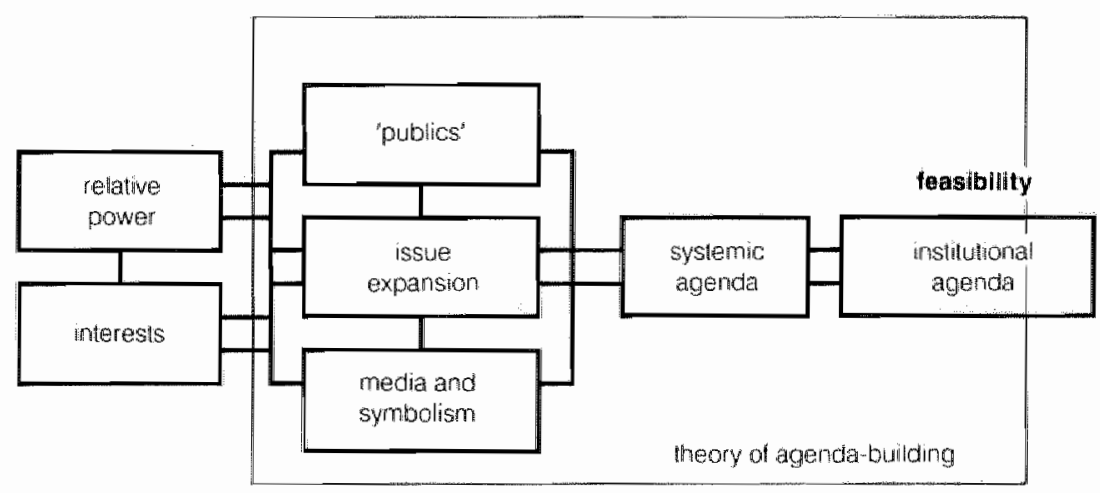

Figure 4.2. Theoretical focus of investigation

current state of feasibility of Nota 2000 . Only the first explicit research question addressess the prospects for progress of the policy formulation process. The static nature of the theory will probably prevent us from inferring action recommendations.

Although we recognize this theoretical pitfall, we will proceed by using the original mobillzation model of the theory of agenda-building. Principal reason for this is that the power distribution in the Netherlands' health system is higlly complex. In chapter 7, after answering the initial research questions, we will review whether and how power distribution and the interests of organizations (in Nota 2000) could reveal new information on the progress of the policy-making process. Further, we may want to modify or reject the theory as formulated above in chapter 7 .

\subsection{Hypotheses}

It will have become clear from these last three chapters that the field of healthy public policy is covered with uncertainties and gaps in knowledge. The theoretical considerations presented here therefore do not offer rigorous guidelines for the study of the feasibility of Nota 
2000. This investigation is thus an exploratory inquiry.

Although we will formulate some thypotheses below, the exploratory nature of the investigation is reason for some caution. The hypotheses are tentative, for two reasons. First there is no extensiwe body of empirical testing material available of the theory of agenda-building.

The operationalizationg we have presented in 4.2 are quite modest, and of a rather qualitative nawre. Second, the field of thealth policy is, ass we have observed in $\mathrm{Ch} .3$, a field of dynamic interrelations with multi- and inter-sectoral perspectives on comprehensive and integral intervention mixes inwolving popular participation and other innowative approaches to health. Very little is known about empirical inquiry in this realm, let allone what exactly should be investigated.

Thus, although we have only singled out the first steps in the policy development process in this inquiry, there are undoubtedly many confounding factors "polluting" the scope of this investigation. Consequently, rigorous bypotheses formulation and testing would at present certainly not contribute to the advancement of scientific knowledge in this field. Hypotheses therefore have to be conditional, and may only point at future research directions.

\section{Hypothesis 1}

If public support for health policy is high enough, health policy will have a position on the systemic agenda, and therefore seriously be considered for operationalization, implementation and allocation of resources on the institutional health agenda.

(general hypothesis of the theory of agenda-building , 4.1.1)

\section{Subhypothesis 1.1}

"The perceived feasibility of Dutch health policy will be high if the issue is perceived to be equivocal, of high societal relevance, having temporal relevance, non-technocratic, and with few or no historical precedents.

\section{Subhypothesis 1.2}

The perceived feasibility of Dutch health policy will be high if the issue of health policy is known by all relevant publics.

\section{Hypothesis 2}

The mobilization model of the theory of agenda-building adequately establishes public support for health policy on systemic and institutional agendas.

(mobilization model of theory of aggenda-building, 4.1.3)

\section{Hypothesis 3}

If the feasibility of Dutch health policy is perceived to be low by professional publics, general perceived feasibility will be low.

(power role of professional groups, 4.2.2)

\section{Hypothesis 4}

If media coverage is characterized by the persistent use of positive metaphors and/or symbolism in relation to Dutch health policy, the feasibility of Dutch health policy will be high.

(role of media coverage, 4.2 .3 )

\section{Hypothesis 5}

If the media cover Dutch health policy consistently ower time, the feasibility of Dutch health policy will be high.

(role of media coverage, 4.2 .3 )

\section{Hypothesis 6}

If there has been high perceived involvement among publics in the preparatory stages of 
Dutch health policy, the feasibility of Dutch health policy will be high.

(role of involvement, 4.3.2)

\section{Hypothesis 7}

If publics perform actions congruent with Dutch health policy (Nota 2000), the feasibility of Dutch health policy will be high.

(role of actions, 4.3.2)

\section{Hypothesis 8}

If the institutional health agenda is heterogeneous, the feasibility of Dutch health policy will be low.

(homogeneous condition of theory of agenda-building theory, 4.3.3)

\section{References}

Altenstetter, C. (1987) Intersectoral Action to aid maternal and child health. Understanding the Policy Process. ICP/MPN 016, World Heaith Organization, Copenhagen

Ban, A.W. van den (1980) Inleiding tot de voorlichtingskunde. Boom, Meppel

Bardach, E. (1977) The implementation game: what happens after a bill becomes law. MIT Press, Cambridge, Mass.

Cobb, R. W, \& C.D. Elder (1983) Participation in American Politics: The Dynamics of Agenda-Building. The Johns Hopkins University Press, Baltimore

Cobb, R., J-K. Ross \& M.H. Ross (1976) Agenda-building as a Comparative Political Process. The American Political Science Review, 70, pp. 126-138

Commissie Structuur en Financiering van de Gezondheidszorg (1987) Bereidheid tot verandering. Staatsuitgeverij, 's Gravenhage

Cox, R.W. (1969) The Executive Head: an Essay on Leadership in International Organization. Intemational Organization, $23(2)$, pp. 205-230

Crichton, A. (1981) Health policy making. Fundamental Issues in The United States, Canada, Great Britain, Australia. Health Administration Press, Ann Arbor

Dekker, E. (1986) De realisering van gezondheidsbeleid: een kwestie van marges. Ch. 5, pp. 74-90 in: Dekker, E. \& B. Wijnberg (eds.) Ower de Grenzen wan de Gezondheidszorg. Reeks Gezondheidsbeleid, Deel 1 . Samsom Stafleu, Alphen aan de Rijn

Delden, A.Th. van (1981) Adviesorganen, achtergrondstudie 4 aan Commissie Hoofdstructuur Rijksdierst. 's-Gravenhage

Donohue, G.A., P.J. Tichenor \& C.N. Olien (1984) Media evaluations and group power. Ch.13, pp. 203-215 in: Amo, A.\& W. Dissanayake (eds.) The News Media in National and International Conflict. Westview Press, Boulder 
Dunsire, A. (1978a) Implementation in a bureaucracy, the execution process. Volume 1. Martin Robertson, Oxford

Dunsire, A. (1978b) Control in a bureaucracy, the execution process. Volume 2. Martin Robertson. Oxford

Etzioni, A. (1968) The active society: a theory of societal and political processes. The Free Press, New York

Eijk, C. wan der W. Kok (1975) Nondecisions reconsidered. Acta Politica, 10, pp. 277-302 Johnson, T.J. (1972) Professions and Power. London, MacMillan

Haas, E.B. (1964) Beyond the Nation-State: Functionalism and Intemational Organization. Stanford University Press, Stanford

Hall, P., H. Land, R. Parker, A. Webb (1975) Change, Choice and Conflict in Social Policy. London

Hill, M. (1976) The state, administration and the individual. Fontana/Collins, London

Hofland, J. \& P.J.M. Wilms (1984) Onder behandeling: strategische keuzen bij de kostenbeheersing in de gezondheidszorg. Onderzoeksreeks Instituut voor Onderzoek van Overheidsuitgaven nr. 14, " $\$$-Gravenhage

Hood, C. C. (1976) The limits of administration. John Wiley, London

Hoogerwerf, A. (1984) Beleid berust op veronderstellingen; de beleidstheorie. Acta Politica, 19 , pp. 493-531

Hornby, A.S. (1974) Oxford Advanced Leamer's Dictionary of Current English. Oxford University Press, London

Kerlinger, F.N. (1973) Foundations of Behavioral Research, 2nd ed. Holt Rinehart, New York

Kok, W.J.P. (1981) Signalering en selectie. Rapport over een onderzoek naar de agendavorming van de rijksdienst. "s-Gravenhage

Koppenjan, J.F.M., A.B. Ringeling, R.H.A. te Velde (eds.) (1987) Beleidsvorming in Nederland; een vergelijkende studie naar de totstandkoming van wetten. VUGA, 's-Gravenhage

Leeuw, F.L. (1986) Veel aandacht voor beleidsmodellen, te weinig aandacht woor belelidstheorieën. Gezondheid \& Samenleving, 7 (4), pp. 197-200

Leeuw, E de (1985) 2000 - A Health Odyssey. An inquiry into the planning and design of a regional strategy for health for all by the year 2000 in the European region of WHO, including a case-study -the lifestyle-issues- and the concerned interaction between WHO and the Netherlands government. Master"s thesis, University of Limburg, Maastricht

Leeuw, E. de \& H. Jonker (1988) Gezondheidsbevordering en wetgeving: enkele paradoxen. Deel 2: Een juridisch perspectief. Metamedica, 67 (5), pp. 356-363

Leeuw, $\mathbb{E}$, de (1988) Planning for health promotion: A new role for the media in health promotion. Proceedings II, III, First European Conference for Health Education IUHE. pp. 653-659 , IUHE, Ministeria de Sanidad y Consumo, WHO, Madrid 
Leeuw, E de (1989) The Sane Revolution; health promotion: backgrounds, scope, prospects, Van Gorcum, Assery/Maastricht

Maarse, J.A.M. (1989) De uirvoering van owerheidsbeleid. Ch. 8, pp. 148-164 in: Hoogerwerf, A. (ed.) Overheidsbeleid. Samsom, Alphen a/d Rijn

Mayntz et al. (1978) Vollzugsprobleme der Umweltpolitik: empirische Untersuchung der Implementation von Gesetzen im Bereich der Luftreinhaltung und des Gewässerschuzzes. Kohlhammer

McCombs, M. \& D. Shaw (1972) The agenda-setting function of the mass media. Public Opinion Quarterly, 36, pp. 176-187

Mierlo, J.G.A. van (ed.) Particulier initiatief in de klem. Gemangeld tussen politiek en bedrijfsleven. De Tijdstroom, Lochem

Milio, N. (1987) Making healthy public policy; developing the science of learning the art: an ecological framework for policy studies. Health Promotion, an International Journal, 2 (3), pp. 263-274

Milio, N. (1988) Making Policy - A mozaic of Australian Community Health Policy Development. Department of Community Services and Health, Canberra

Parry, N \& J. Parry (1976) The Rise of the Medical Profession. London, Croom Helm

Peper, B. (1972) Vorming van welzijnsbeleid. Evolutie en evaluatie van het opbouwwerk. Boom, Meppel

Project Group Extemal Advise (1983) Tweede interim-rapport. 's-Gravenhage

Ringeling. A. (1981) Implementatie als probleem. Acta Politica, 16 (1), pp. 121-142

Rosenau, J. (1961) Public Opinion and Foreign Policy. Random House, New York

Rosenaw, J. (1968) The attentive public and foreign policy: a theory of growth and some evidence. Center of International studies, Princeton.

Schmitter, P.C. (1977) Modes of interest mediation and models of societal change in Western Europe. Comparative Political Studies, 10, A pril, pp. 7.37

Scientific Council for Govemment Policy (1.977) Externe adviesorganen wan de centrale overheid. 's-Gravenhage

Swanborn, P.G. (1981) Methoden van sociaal-wetenschappelijk onderzoek. Inleiding in ontwerp-strategieèn. Boom, Meppel/Amsterdam

Visser, P. (1989) Overleg Economie. Dissertation University of Limburg, Maastricht

Vrie, R. van de \& A. van Elzakker (1988a) Gezondheidsbeleid en machtsversnippering. 1: Gezondheidsbeleid en de verdeling van macht. Medisch Contact, 43 (38), pp. 1119-1122

Vrie, R. van de \& A. van Elzakker (1988b) Gezondheidsbeleid en machtsversnippering. Slot: Achterliggende belangen bij de verschuiving van gezondheidszorgvoorzieningenbeleid naar gezondheidsbeleid. Medisch Contact, 43 (39), pp. 1162-1164

WHO \& Commonwealth Department of Community Services and Health (1988) Report on the Adelaide Conference - Healthy Public Policy. 2nd Intemational Conference on Health Promotion, April 5-9, 1988, Adelaide, South Australia 


\section{METHOD AND METHODOLOGY}

Investigation of healthy public policy poses unique challenges to scientific inquiry. In this chapter we will delineate these challenges and suggest methodological solutions to the problems that arise.

The challenges to methodology for inquiries into healthy public policy can be distinguished as:

1. The innovative character of healthy public policy itself;

2. The dynamic character of proposed healthy public policy-making;

3. The content of health policies;

4. The size of the samplle investigated;

5. The units and variables for research on healthy public policy.

\subsection{Qualitative inquiry: rationale}

We have noted above (chapter 3 ) that the literature on healthy public policy is largely nonempirical and that not much theory has been applied to the notion of healthy public policy. A review (Pedersen et al., 1988) revealed that the writings on the issue are prescriptive rather than descriptive. This is acknowledged by most authors of those articles themselves as well. However, some policy scientists have argued for new directions in healthy public policy research methodology. Generally, it is agreed that healthy public policy research should have a strong qualitative emphasis, though quantitative designs may contribute to the research area as well. Kickbusch (1986), McQueen (1987), Milio (1987) and Pedersen et al. (1988) present: us with a rationale for research designs balanced between quantitative and qualitative approaches. Their suggestions relate mainly to the nature of the 'new public health', and the meaninglessness of a distinction between qualitative and quantitative research. Apart from those, there are some technical considerations (sample size, and nature of units and variables) setting the prerequisites for a justifiable qualitative approach. These are dealt with below. Kickbusch (1986, p.325) has concluded from her analysis that the health promotion context for healthy public policy needs 'data for a new policy-relevant analysis or for a reality-based social epidemiology which are of an interdisciplinary mode we have yet to get accustomed to." Furthermore, new types of skills are needed among policy-makers and researchers: "analysis, strategic thinking, social competence, creativity, to name just a few. ' Clearly, the "old" quantitative paradigm for performing scientific inquiries would not fit the present problem any more.

This is supported by McQueen (1987), asserting that it is important to tell the story rather than to give a snapshot view. Longitudinal studies with qualitative as well as quantitative 
thrusts will reveal, according to McQueen, more valuable information. Further on this issue; he states that the distinction between qualitative and quantitative research designs is in fact illusory, not only in technique (validity and reliability measurements are comparable, cf: below), but also because even if this type of research were quantifiable, the outcomes would be trivial or misleading, because numerical data are severed out of their qualitativie context (White, 1970).

According to Milio (1987, p. 269), the ecological concept of health and healthy public policy making dictates that the researcher would have to collect information on the social context (available from public documents, opinion polls and the media), the nature and size of the actors in the field of health, perceptions of these parties on their interests in and positions on a policy issue, the strategies deployed to influence policy decisions, and their view of the long-term and short-term feasibility of a given policy. These components mirror some of the characteristics of the agenda-building theory (4.2).

Ziglio (1987) proposes four similar sets of indicators: description of social organizations and institutions engaged in policy-making; description of policy-making processes and outcomes; indication of policy directions; and illustration of past, present and future trends. The specific information would have to be collected through qualitative methods, e.g semi-structured interviews and content analyses (Van Maanen, 1983).

The nature of "the new public health" also dictates an investigative approach which ideally would employ qualitative and quantitative methodologies. Milio (1986, p.130) states the issue at stake thus: "What is different about health and how best to promote it today is that its sources are more numerous, varied, and interdependent, and so more complex." Because adequate healthy public policy should address this complexity, quantitative methodology which would necessarily single out specific aspects of the policy may not be considered appropriate alone. The complexity of health dictates rather a qualitative understanding ("verstehen" a la Weber) than pure quantitative "analysis" (in an etymological sense of "taking apart'). When there is sufficient insight into the complexity of the health issue, more analytical procedures would be appropriate.

Further, the issue of units and variables in healthy public policy analysis almost forces a qualitative approach. As yet, there is little research done on healthy public policy making, let alone existence of a distinctive and limited set of parameters and variables to be investigated. The very few descriptive analyses of healthy public policies (Leppo \& Vertio, 1986, Milio. 1981, Milio, 1988) indicate that even with a full coverage of actors and information, sample numbers are too small, and information too complex to carry out sufficient quantitative analyses. Actors (i.e. publics) involved in the process of making healthy public policy, the generators of data, do not exceed seventy, while dependent and independent variables in the analysis would count into the hundreds. The implication would be that in quantitative analyses the degrees of freedom would become unjustifiably high while cells for instance in a Chi-square analysis, would have no sufficient fill. This in tum would lead to degrees of significance and confidence that would no longer yield reliable information.

In sum, the rationale for use of qualitative methods is twofold. First, at the moment exploratory surveys need to be carried out to find theories for healthy public policy. Green \& Lewis (1986) put that in such situations qualitative inquiry has the potential of becoming a 'power booster' for theorizing and further research. Apart from that, a second reason for qualitative methods is the immense complexity of the concepts of health promotion and healthy public policy, not to be reduced into masses of numbers but rather expanded into understanding of the comprehensive nature of the issue (de Leeuw, 1989).

\subsection{Quality control}

The rigor of qualitative inquiry has repeatedly been questioned (Ratcliffe, 1986). As Fielding \& Fielding (1987, p.10) put it: "The caricature of qualitative research is that it is "soft" 
whereas quantitative research is 'hard'; qualilative researchers call quantitative researchers "number-crunchers", and the riposte of the latter is that the former are mere "navel-gazers". In would be absurd to deny a distinction which researchers feel with such immediacy, but it would be unwise not to face the issue posed by Zelditch in 1962: "Quantitative data are often thought of as "hard" and qualitative as "real and deep"; thus, if you prefer "hard" data you are for quantification and if you prefer 'real, deep' data you are for qualitative participant observation. What to do if you prefer data that are reall, deep and hard is not immediately apparent (p.566)." Thus, there is a deep polarization between "objective and rigorous" inquiry on the one hand, and "subjective and speculative" on the other. The need for more rigor in qualitative research is therefore urgent in order to integrate both views.

Quality control, a rigorous wiew of the research process, is intrinsic to any form of datagathering and processing. There are some structured modes of quality control which apply to qualitative as well as quantitative research. They are the concepts of confidence, validity and reliability.

Confidence is a measure in quality control relating to the generalizability of the outcomes of a survey among a sample or limited number of units toward the whole population. It gives. the probability that findings among the sample are applicable to the population as a whole $e_{0}$ in terms of 'confidence intervals'. In qualitatiwe inquiry, confidence is not a measure with much potency. Either the units of investigation are too uniquely identified (prohibiting any extrapolation toward a more general population), or the sample size in relation to the population is skewed; in healthy public policy analyses, the aggregate actor groups (which include the total population) are limited in themselves (cf, 4.22 , above). Thus, confidence intervals for categories would become meaningless. Either -with sufficient response- the data give a reasonable reflection of positions, or -with insufficient response- it would be useless to apply confidence to the data, because in the latter case the uniquely identified characteristics of actor groups bias the outcomes in a distinctive way. To achieve confidence in qualitative healthy public policy research, the delineation of units of investigation and response characteristics are therefore of utmost importance. Any flaw in adequate description of unit characteristics and response pattems would thus indicate decreased confidence.

There is no total clarity on the use and conceptualizations of two other quality control measures: validity and reliability. In their work on quasi-experimentation, Cook and Campbell (1979) focus on internal and extemal validity (and its various expressions) only. Reliability in their work acquires a more trivial-language connotation. It is conceptualized as stability, or test-retest consistency (p.43). Validity or invalidity, according to Cook and Campbell, is the best available approximation to the truth or falsity of propositions, including propositions about cause (p. 37). However, Fielding and Fielding (1986) distinguish clearly between validity and reliability , both being valuable quality control instruments of the same magnitude. Validity, in their concepnalization, deals with the question 'are we measuring what we intend to measure?' while reliabillity is concemed with adequacy of obserwation employing different instruments.

Validity has thus to do with the stability of outcomes of several measurements carried out with one instrument. Generally, validity thus applies to different measurements with one instrument over time. It is exactly for this reason that achievement of high walidity in qualitative inquiry is problematic: over time, the crucial variables and conditions which call for qualitative methodology will change. Dynamic settings frustrate validity measures. Other types of validity suffer similar drawbacks. Apparent or face validity is suspect anyway. It is applied to situations where a measuring instrument is (thought to be) so closely linked to phenomena under observation that it is "obviously" providing valid data (an IQ-test measuring IQ is based on so many implicit and explicit axioms and assumptions on what IQ is and how it should be tested that apparent validity appears to be high).

Instrumental or pragmatic validity refers to a measurement instrument which gives outcomes 
consistent with another already validated instrument. Criteria for the measurement of temperature, for instance, may apply equally to expansion of mercury, vapor pressure or electrical conductivity. In qualitative inquiry, pragmatic validity may be considered rare, as most instruments are uniquely designed for specific settings.

Construct validity exists if there is substantial evidence that the theoretical paradign correctly corresponds to observations (Kirk \& Miller, 1986). Operationalization of terms is a crucial prerequisite for establishment of construct validity, though not sufficient. Construct validity is established through an analysis of various tested but not yet falsified observations on possibly concurrent variables. By calculation of correlates and through factor analysis the construet validity of the instrument ("Do we measure what we intended to measure?") is settled (Swanbom ${ }_{*}$ 1981). Construct validity is the only validity measure having potency in qualitative research, providing there are enough observations relating to one construct. However, establishment of construct walidity in qualitative research may be obscured by the limited number of units of investigation and the immense complexity of variables under study. Adequate statistical analysis might prove to be impossible.

Reliability is the last, but in qualitative inquiry not the least, quality control concept. Reliability is achieved when several measurements with different instruments yield similar or comparative results. The concept is suited well to qualitative inquiry. In chapter 3 (Healthy Public Policy) and 4 (Theory) it has been noted that there are several data sources and mechanisms rellating to the concept of healthy public policy research. Acknowledging that these different data sources and mechanisms for healthy public policy need different instruments for measurements, achievement of reliability would have to account for:

1. Analysis of a variety of independent derivation, identification or measurement processes;

2. Search for and analysis of things which are invariant over or identical in the conclusions or results of those processes;

3. Determination of the scope of the processes across which they are invariant and the conditions on which their invariance depends; and

4. Analysis and explanation any relevant failures of invariance (Wimsatt, p. 126).

The process of comparison and analysis is called triangulation (Denzin, 1970, Fielding \& Fielding, 1986, Pedersen et all, 1988, Shortell, 1982). Fielding and Fielding (1986) distinguish among four potential triangulation types: data triangulation, investigator triangulation, theory triangulation and methodological triangulation.

Data triangulation refers to comparison of data in time (longitudinal designs), space (comparative research) and person (comparison of individual, group, and collective data). In investigator triangulation, the work of more than one investigator is compared. With theory triangulation, application of competing theories to one data set is compared.

Regarding methodological triangulation, there are two variants: within-method and between. method: Within-method triangulation is an attempt to check data quality and confirm validity (cf. above). Between-method triangulation approaches are carried out when different methods are applied to the same subject in explicit relation to each other.

Delphi-techniques seem to be adequate procedures to secure an efficient triangulation process. However, the Delphi-technique does not apply to all triangulation types presented above. It would be particularly suitable for data-triangulation and within-method triangulation. With the Delphi-technique, the units of investigation receive feedback on their response in arder to facilitate the creation of consensus on issues, or to delineate positions on those issues (Linstone \& Turoff, 1975). Respondents remain anonymous at al] times, thus securing optimal response without socially desirable bias. Therefore, the technique has potential to become a reliability-check on data collection and processing. However, there is considerable criticism of the Delphi-technique. Sackman (1975) determines two major flaws in the Delphi technique. First, it does not adhere to rigid scientific standards, and second, the technique seems to have served wrong purposes. Sackman uses 
the standards set by the American Psychological Association, the American Educational Research Association, and the National Council on Measurement in Education (the "Standards for Educationall and Psychological Tests and Manuals" ${ }^{*} 1966$ ). He asserts that especially reliability and walidity aspects of Delphi are neglected. The technique rarely is subjected to measures of quality control. The Delphi invertigators counter the accusation. stating that the technique is employed under such complex and uncertain conditions, that traditional quality control instruments would be useless. In that case, Sackman concludes (p. 53): 'Delphi opinion polls measure attitudes toward future events, not predictions of such events in their own right".

Further, Sackman objects to the heawy axiomatic narure of the Delphi technique. Delphi investigatory rely on a more or less homogeneous panel of experts, while Sackman shows that personal or organizational characteristics may influence the expert opinion. For instance, in a Delphi on medical technology forecasting, clinicians and researchers turned out to have distinctively different opinions. Aside from that, the literature on the question what constitutes an expert is extremely meager. Sackman (p.42) gives examplles of Delphi where students and housewives had opinions and perceptions of future trends very similar to those of a panel of "experts". Again, this indicates that Delphi results only reflect attitudes rather than facts. Anyone -be they housewives or nuclear physicists-could have an opinion on the feasibility of, for instance, nuclear fusion technology. Whether the prediction by the physicists is of more value than the one made by housewives seems to be of superficial concern for Delphi investigators, according to Sackman.

However, the issues raised by Sackman are essentially those addressed by this investigation. We are onlly interested in attitudes and perception. Interpretations by the researcher will be fed back to the research population in order to fine tune exactly those attitudes, and combined with other data sets, more reliable conclusions may be drawn. In the present investigation, moreover, we acknowledge the diverse character of the research population which is divided into clusters (along lines given by the theory on agenda-building (4.2.2) and by Milio (1987)). In the analysis, there will be no pretension to homogeneity of the population, or to consensus opinion.

There is also a critique of triangulation procedures. Fielding and Fielding (1986) argue that it is naive to assume that the use of several methods (between-method triangulation) necessarily ensures the validity or reliability of findings. Interpretation may bias outcomes with any method, and eventually lead to completely false conclusions when the researcher would purposefully investigate convergence rather than contrast, or contrast rather than convergence of opinions. Thus, the search for any 'objective truth' will at any point be in vain (Fielding \& Fielding, 1986, p. 32-33, De Leeuw, 1989, p.63-64). Careful employment of all types of triangulation -beyond between-method triangulation- where appropriate to the research design, should render higher reliability to the research outcomes. Overcoming investigator bias, however, should have highest priority in triangulation.

In the context of healthy public policy research, triangulation procedures have the potential to secure higher reliability. We will operationalize the various triangulation types in relation to the investigation at hand below.

\subsection{Data collection}

As we have seen in Chapters 3 and 4, there are two important sources for data on healthy public policy: the media (having to do with issue expansion and agenda-setting) and actors in the policy field (accountable for establishment of institutional and systemic agendas). With regard to the media, a search was carried out with a computerized media retrieval system of the University of Utrecht and PARAC, the parliamentary computerized information retrieval system. These systems are assumed to contain all publications in print (papers, tabloids, journals, official governmental publications) and media coverage on radio and television. 
The systems were asked to give all media coverage from April, 1986 (publication of Nota 2000) onwards, relating to key words "Nota 2000 and/or health policy and/or public health policy and/or public policy for health". Eighty-five items were produced. An additional search in a Library Clipping Service yielded ten more publications. A check with the University of Limburg Library Information Retriewal System did not give new information. With regard to the actors involved, 54 actors in the Netherlands" hesllth scene were identified (cf. 4.2.2, Publics). Five expert referees (not related to the groups) checked the composition of this research population. There were no objections or additions to the composition of the group.

Two types of data collection (a type of data-triangulation) were employed with regard to the actors: a semi-structured interview, and an analysis of documents produced by the actors. A semi-structured interview was developed (Annex VIII) in accordance with the framework developed by Milio (1987). She asserts (p.269) that it is important to retrace actors" positions on policy questions, resources and strategies employed, agendas and priorities set, perception of definition of the problem, criteria for policy solutions preferred by the actors, involvement in consultation and implementation, and shifting interests as a result of the proposed policy. The semi-structured interview in this inquiry addresses these issues in a sequentially logical way. After an organizational description, knowledge and perceived value of Nota 2000 were checked. Then, factual and preferred involvement in the Nota 2000 policy development process were asked for. Response would indicate organizational priorities.

Questions eight through fifteen relate to organizations' perceived scope of the policy problem and criteria for solutions. Question sixteen is intended to give an indication of the perception of actors of shifting priorities among the various publics with the possible realization of Nota 2000 . The final four questions are included for the purpose of internal data triangulation. They allow the more abstract responses to questions two through sixteen to be compared to concrete examples. As a quality control check, the responses to these last questions are expected to be compatible with the rest of the interview, thus increasing the reliability of the questionnaire.

It may be noted that explicit questions on issue expansion criteria (cf. 4.2.1) are not included in the interview. The reason for this is twofold. First, the necessary information is already available through response to the questionnaire, whereas, second, explicit questioning of the ambiguous character, temporal relevance, social significance, non-technical nature and nonprecedent to Nota 2000 might have been expected to produce biased and socially clesirable ("skewed") information.

With regard to the organizational documents, a framework (document score sheer. Annex III) was developed to structure those aspects of text produced by governments relating to Notat 2000. Eight student investigators were briefed on the warious notions of Nota 2000 covered by the document score sheet (cf. operational characteristics of Nota 2000, paragraph 2.3). No problems in filling out the sheets were encountered.

No search additional to the request for relevant organizational literature was carried out; all organizations but the bureaucrats within the Ministry of Health produced at least one document. It was assumed that respondents who gave documents had no reason to give biased information. Moreover, all formal publications are publicly accessible and have therefore "high reliabiliry". Although unpublished internal position or policy papers might have more decisive impact on organizational policy making, we have not asked explicitly for such papers. Only formal expressions in published documents were considered to be relevant to public policies.

In order to structure various outcomes it was necessary to set up an adequate chronology of the development of Nota 2000 (paragraph 2.3). Thus, the different opinions, perceptions and attifudes of actors and media would more easily relate to the process of policy formulation. This chronology enables us to establish starting point and formal end of the investigation. 


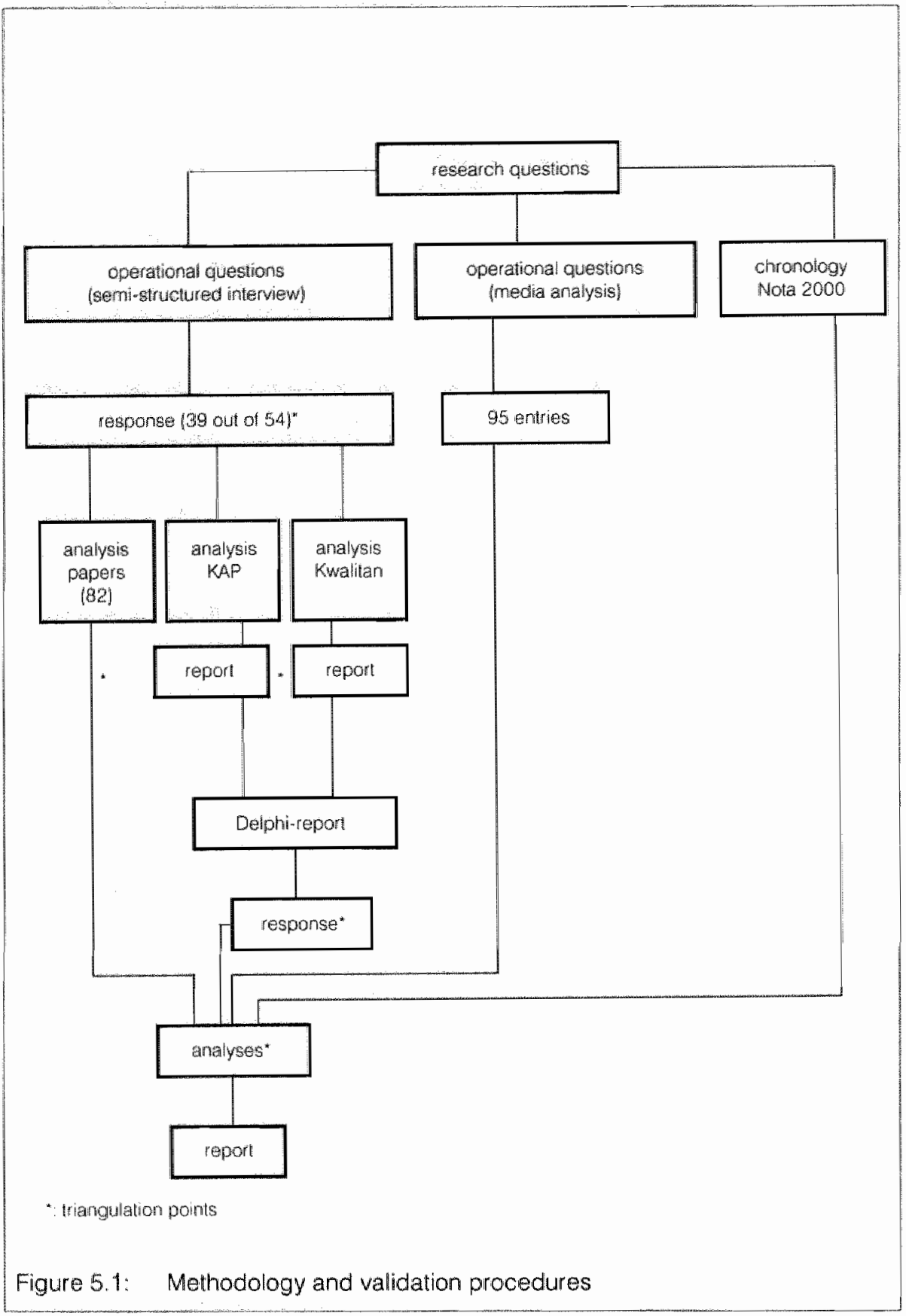

\subsection{Data processing}

Conscientious processing of the data obtained through interviews, document analysis and media analysis is a crucial component of quality control. The flow of transformation from data into information (data are not information; they are transformed into information by the investigator, $c f$. Churchman, 1971) are depicted in figure 5.1 below. It will be made clear that 
After operationalization of the research questions, data were collected. The text of the semistructured interview was written down during the interview by two interviewers. Thuss 'noise' (e.g., irrelevant passages or personal remarks) in the interview was filtered out. To check whether the write-up was adequate, reports of both interviewers were compared. Both sets of interviews contained 5850 lines of text each. Comparison of the material (datatriangulation) revealed that fourteen of these lines differed. Checked against the recordings of the interview sessions, the result was that the interviewee indeed gave multi-interpretable responses. The lines that were incompatible with each other were deleted, insofar this did not violate the thrust of the response. This was never the case.

Interviews then were transformed into manageable segments of information. This was done by two methods (Kwalitan and a Knowledge. Attitude and Perception chart) which were subsequently matched (between-method triangulation). The Kwalitan software-package enables investigators to attach codes to strings of text. The code book may be developed during the interview phase, as the range of possible replies may not be known beforehand. This procedure is in agreement with the guidelines set up by Glaser and Strauss (1967), asserting that discovery of theory and relevant data is a process of continuous adjustment and readjustment of interpretation until sufficient certainty of the applicability of theory and instruments is reached.

The final code book (Annex IV) was developed when two-thirds of the interviews were held and an adequate estimate of the range of replies was possible.

However, codes could not always be made mutually exclusive. The latter would have facilitated a more quantitative analysis of data. Whenever actors were asked to give only one category of response (for instance, question $10^{\text {"What is the one major problem you see?") }}$ they were not able to distinguish only one such category. In general, response was complicated. Therefore, developing the code book and the coding process itself was filled with uncertainties with regard to the possible subjective evaluations of the texts by the researchers. Clarity on meaning was established by continuous comparison of evaluations and reformulation and reoperationalization of concepts and codes.

The other line of processing interview data was carried out by employment of flow-charts in which knowledge, attitudes and perceptions of actors were presented (KAP-charts). Green and Lewis (1986, p.157) assert that such flow-charts are important information sources. The charts read from left to right, and have a logical design. In the first (Annex VI), knowledge of Nota 2000 is related to perceived value of Nota 2000 (either for the own organization or in general for society), perceived feasibility, perceived barriers hindering Nota 2000 , and finally actions undertaken by organizations to overcome these barriers. The second chat (Annex VII) relates knowledge of the memorandum to involvement in the policy process and any action indertaken in the light of Nota 2000 . In addition to these charts, the structured approach enabled evaluation of the issue expansion criteritas presented in 4.2. There have been no problems in filling out both KAP-charts. All intervilew data fit in the flow scheme. Kwalitan coding and its report, and KAP-chart coding and its report have been compared. Thrusts and directions of both methods are fully compatible, although Kwalitan coding gives more depth to the data. However, the danger is very real that depth of insight obscures. adequate perception of gross pattems. These pattems were provided by the KAP-charts, so that the overall view has depth as well as width. Methods thus were well matched. The outcomes of Kwalitan and KAP-charts were presented to the total research population by means of a short report. Organizations were asked to comment on the investigators' interpretation of the data (Annex II). Together with the results obtained from the organizational documents analysis, the media analysis and the chronology of Nota 2000 , the total result will be presented in Chapter 6 . 


\section{References}

Churchman, C.W. (1971) The design of inquiring systems. Basic Books, New York

Cook, T.D. \& D.T. Camphell (1979) Quasi-Experimentation. Design \& Analysis Issues for Field Sertings. Houghton Miffin Ca, Boston

Denzin, N.K. (1970) The research act in sociology. London, Butterworth

Frielding, N.G \& J.L. Fielding (1987) Linking data. Qualitative Research Methods, vol.4, Sage, Bewerly Hills

Glaser, B.C. A.L. Strauss (1967) The Discovery of Grounded Theory. Aldine, Chicago

Green, L.W. \& F.M. Lewis (1986) Measurement and Evaluation in Health Education and Health Promotion. Mayfield, Palo Alto

Kickbusch. I. (1986) Health Promotion: a global perspective. Canadian Journal of Public Health, 77, Sep/Oct, pp. 321.326

Kirk. J. \& M.L. Miller (1986) Reliability and validity in qualitative research. Qualitative Research Methods, vol.1, Sage, Beverly Hills

Linstone, H.A. \& M. Turoff (eds.)(1975) The Delphi Method - Techniques and Applications. Addison-Wesley, Reading, Mass.

Leeuw, E. de (1989) The Sane Revolution. Health promotion: backgrounds, scope, prospects. Van Gorcum, Assen/Maastricht

Leppo, K \& H. Vertio (1986) Smoking control in Finland: a case study in policy formulation and implementation. Health Promotion, an international journal, 1. (1), pp. 5-16

McQueen,D. (1987) Research in Health Behawiour, Health Promotion, and Public Health. Edinburgh, Scotland

Milio, N. (1981) Promoting health through structural change: analysis of the origins and implementation of Norway"s farm-food-nutrition policy. Soc.Sci.Med, 15A, pp.721-734

Milio, N. (1986) Multisectoral policy and health promotion: where to begin? Health Promotion, an international journal, 1 (2), pp. 129-132

Milio, N. (1987) Making healthy public policy; developing the science of llearning the art: an ecological Pramework for policy studies. Health promotion, an international joumal 2 (3), pp. $263-274$

Milio. N. (1988) Making policy - A moxaic of Australian Community Health Pollicy development Department of Community Services and Health, Canberra, Australia

Pedersen, A.P., R.K. Edwards, M. Kelner, V.W. Marshal, K.R. Allison (1988) Coordinating healthy public policy - an analytic review and bibliography. Department of Behavioural Science. University of Toronto. $71 \mathrm{pp}$.

Ratcliffe, J.W. (1986) Rigor in research: toward an expanded conceptualization. Knowledge: Creation, Diffusion, and Utilization, feb. $40 \mathrm{pp}$.

Sackman, H. (1975) Delphi Critique. Lexington Books, Lexington, Mass.

Shortell, S. (1982) Improving Health Care Policy Research. Journal of Health Politics, Policy and Law, 6 (4), pp. 681-701

Swanbom, P.G. (1981) Methoden van sociaal-wetenschappelijk onderzoek. Inleiding in 
ontwerpstrategieên. Boom, MeppelAmsterdam

Van Maanen, J. (1983) Qualitative methodology. Beverly Hills, Sage

White, R.K. (1970) Quantification and the crucial intangibles, in: Palmer, N.D. (ed.) A design for intemational relations research: scope, methods, theory and relevance. Monograph 10, The American Academy of Political and Social Sciences, Philadelphia

Wimsatt, W.C. (1981) Robustness, reliability and over-determination. p. 126 in: Brewer, M.B.\& B.E. Collins (eds.) Scientific Inquiry and the Social Sciences. San Francisco, JosseyBass

Zelditch, M. (1962) Some methodological problems of field studies. American Journal of Sociollogy, 67

Ziglio, E. (1987) Health Policy Study: Stimulus Protocol. Stimulus paper prepared for WHO meeting on health promotion research. Edinburgh, Scotland 


\section{FINDINGS}

In this chapter we will present the findings from the warious sets of data. We will summarize the latter again:

* interviews (analyzed with KAP-charts and Kwalitan)

* organizational documents

* media coverage

We will follow the lines set out in sections 4.2 and 4.3 , and the tentative hypotheses presented in 4.4 . This means that first, we will present response in the various data sets and the characteristics of that response. Then, the perceiwed status of Nota 2000 is analyzed.

Although Nota 2000 has explicitly been presented as a discussion document, the perception by respondents of this status may be different. In terms of the agenda-building theory, this perception is of crucial importance.

Knowledge of Nota 2000 , value attributed to it, and involvement in the process and followup of Nota 2000 will be analyzed next.

The perceived feasibility of Nota 2000 and acknowledged barriers to its further implementation are presented in 6.5 .

Degree of issue expansion -the determinant of institutional agenda status and therefore an indicator for feasibility- will be presented in the next section. In addition, we will explore whether the theory holds in relation to the analysis of variables pertaining to involvement and action in the light of Nota 2000.

Perceived opposition will be presented in 6.7. Analysis of Delphi-feedback on the presentam tion of opposition will give more information on factual opposition.

Finally, prevention policy and analysis of the response on the case of child accident prewention will give more information on the willingness of respondents to carry out one suggested policy set of Nota 2000.

The discussion of the results, and conclusions, will be found in chapter seven.

Remarkable comments of respondents will be presented as illustrations of the obserwations in boxes throughout the analysis.

\subsection{Response}

Response in this investigation has generally been adequate, as we will review in this section. However -as we have remarked in chapter 4 and 5 -groups and data sources in themselves are rather limited, at the same time producing large amounts of data. We will present some characterizations. 


\subsubsection{Interview and delphi response}

On average, 39 of 54 organizations of the research population participated in the first interview round (Table 6.1). Foumeen organizations did not participate in the first round, but out of this category, seven responded to the second Delphi-round (Table 6.2). Overall response thus became 46 out of 53 .

It is noteworthy that professionals, non-governmental organizations, political officers and research organizations are quite consistent in their relative response rates (rates of initial interviews and second Delphi-round compared). Further, there is a remarkable increase in the number of bureaucratic officers responding.

The response rates among political officers are disappointingly low. In addition, we have not succeeded to acquire data from political officers themselves, but only from high-ranking bureaucrats. Clearly, ministers of other departments lay all responsibility for health policy with the department of health, in spite of intended facet policy. It is in this light curious that neither the minister nor secretary-of-state of health have replied to any invitation for interviewing or any reminder letter for the Delphi-report: although political officers seem to assert that there is a prime official responsible for governmental health affairs, this authority has been found to be unable to participate in the study.

In the Delphi report (Annex V) we suggested that non-response was

Table 6.1. Research population by cluster and response

\section{Professionails}

KNMG, LSV, LHV, NVGVO, Het Beterschap, NVAGG, KLOZ, VNZ, VNO, NZR

(Total: 10. Response: $10 .[100 \%]$ )

\section{Consumer organizations}

Consumentenbond, LPCP, Konsumenten Kontakt, Stichting Natuur en Milieu, Werkgroep 2000, Pandora, FNV, CFO

(Total: 8 . Response: 7 [87.5\%])

\section{Non-governmental organizations}

Hartstichting, Koningin Wilhelmina Fonds, Stichting Volksgezondheid en Roken, Julianafonds, Nationale Kruisvereniging, Landelijk Centrum GVO

(Total: 6. Response: 5 [83\%])

\section{Research organizations}

NTVEL, NIPG-TNO, NZI, NcGv, Wetenschappelijk Bureau CDA, Teldersstichting. Wiardi Beckman-stichting

(Total: 7. Response: 6 [85.7\%])

\section{Political officers}

Ministers of Health, Finance, Economic Affairs, Education \& Science, Traffic \& Water, Social Affairs

(Total: 7 . Response: $2[28,6 \%]$ )

\section{Bureaucratic officers}

STABO, STTVA, Director-general for health, Epidemiology, GVO, Gezondheidsraad, Nationale Raad woor de Volksgezondheid, Office of Prime Minister, VDB, VNG

(Total: 11. Response: 6 [54.5\%])

\section{Political parties}

PvdA, D66, CDA, VVD

(Total: 4. Response:" 3. [75\%])

Totall population: 53 . Response: 39 (74\%) 


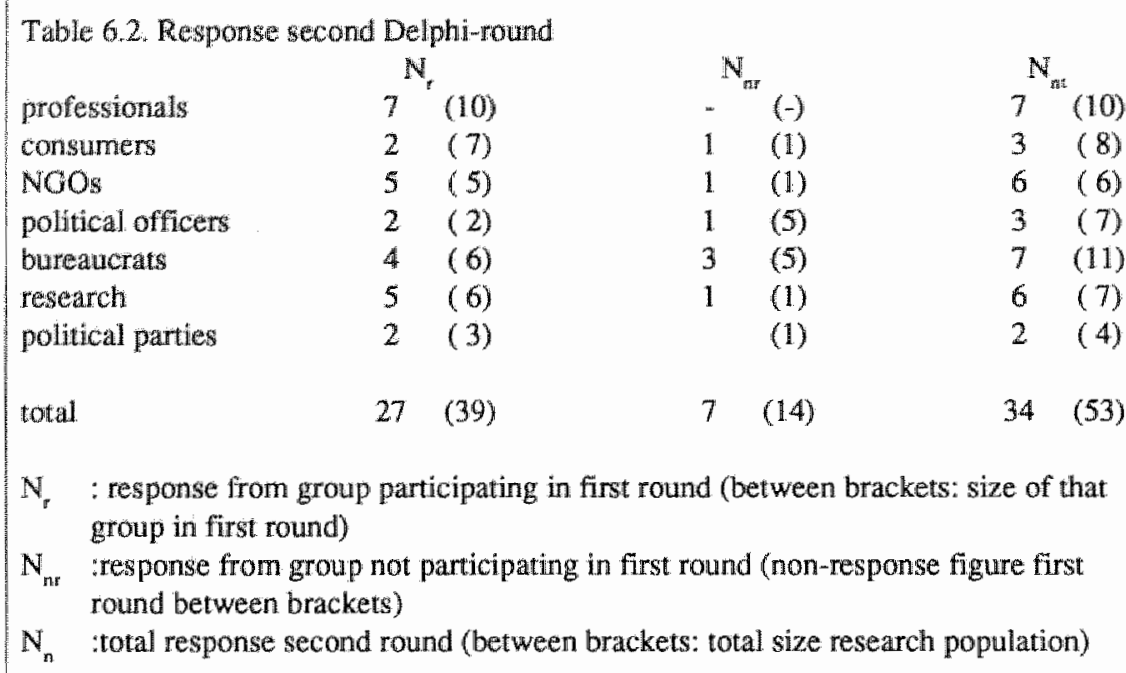

an indicator for non-feasibility of Nota 2000: non-response would be equivalent with noninterest. Although a limited number of respondents objected against that observation, two organizations (one of which was a non-respondent in the interview round) remarked that this analysis was appropriate. One Dejphi respondent suggested that non-response was only an indicator for a low degree of issue expansion. This may be true, but then the logical inference (supposing issue expansion is related to feasibility, cf. Ch. 4) would be that Nota 2000 again may not be considered feasible.

The nature of organizations is not just established from their categorical grouping. Power base and sphere of influence is also dependent on resources and objectives. Some aggregate response characteristics obtained through Kwalitan analysis of the first interview round were following (table 6.3): twenty-nine of the respondents were male, ten female. Thirteen respondents had a contents-oriented position in their organization, while twenty-six were in executive positions. Twenty-nine of the interviews were carried out by the principal researcher, ten by an assistant. These characteristics are not related to the composition and thrust of the respondent organizations.

Two respondent organizations saw as its principal objective support and service of the target group. Seven saw it as their main activity to advise and lobby on governmental policies, while thirteen groups were mainly active in the field of interest promotion of the larget group. Six respondents said their objective was making policy, another six were working on the promotion of certain ideological positions. Five organizations were chiefly oriented toward doing research.

With regard to the size of organizarions we have used indicators for the size of the staff of the organization, its membership, and size and source of financing of the organization. Five organizations had a membership of over 100,000 , three between 20,000 and 100,000 , and three organizations had a membership of less than 20,000. Total membership of all these organizations was nearly 10,000,000 (on a Dutch population of about 14,000,000), the National Cross Association (home care) making up for the majority of this number. These number relate to 'field organizations' (professionals, NGOs, consumer organizations). The other organizations did not have a membership, or only composite memberships. the Association for Ambulatory Mental Health Care, for instance, is composed of some fifty nation-wide organizations, and an environmental organization was composed of thirteen 
Table 6.3. Aggregate response characteristics.

$\operatorname{sex}$

male

female

position respondent

content-oriented

executive

interviews by

principal investigator

assistant

objectives respondents organization

support/service.

lobby/advocacy

interest promotion

making policy

promotion ideology

research

size (membership)

$>100,000$

$20,000-100,000$

$<20,000$

not available

size (staff)

$>25$

$10-25$

$<10$

not available

other organizations.

Twenty-two organizations had a staff over 25 , four between 10 and 25 , and four less than 10 . The remaining respondent organizations were sub-units of larger organizations with staff over 25.

Thirteen of the organizations received their monies from contributions, seven from the Ministry of Health, five from external sources (miscellaneous subsidies, etc.), four from govemmental sources, and one from the sales of products and services. The other organizations were financed from standard governmental budgets.

The size of financial resources could not be measured adequately, as in most organizations specific monies were labeled for specific activities, or the budgets could not be estimated adequately because the organization was part of an intricate bureaucratic web. Ten organizations found they had a budget over $\mathrm{df1} 1,500,000$. The others could not establish factual budgets adequately.

\subsubsection{Organizational documents}

Respondents were asked to give any document that would further illustrate their position toward Nota 2000 or health policy (cf. question 20 of questionnaire, Arriex VII, and 5.4). In 
Table 6.4. Organizational document analysus: characteristics

$$
\text { armual policy intern public study other }
$$

$\begin{array}{lllllllll}\text { professionals } & 24 & (2.4) & 7 & 5 & - & 7 & 3 & 2 \\ \text { consumers } & 17 & (2.4) & 3 & 4 & - & 9 & - & 1 \\ \text { NGOs } & 13 & (2.6) & 4 & 4 & - & 1 & 1 & 2 \\ \text { political officers } & 1 & (0.5) & - & 1 & - & - & - & - \\ \text { buretucrats } & 10 & (1.7) & 2 & 1 & - & 4 & 2 & 1 \\ \text { research } & 16 & (2.7) & 5 & 5 & - & 1 & 4 & 1 \\ \text { political parties } & 1 & (0.5) & - & - & - & - & - & 1 \\ \text { total } & 82 & (2.1) & 21 & 20 & - & 22 & 10 & 8\end{array}$

$N_{\text {dactot }}$ total number of documents (between brackets: documents/respondents,

$\mathrm{N}_{\text {typ }}$ type of document

annual : annual report

policy : policy document

intern : internal document

public : publication aimed at general public (magazine, etc.)

study : study report

other : other documents, or not classifiable

total, 82 documents were produced (Table 6.4).

Political officers, bureaucratic officers and political parties produce significantly less documents than the other categories. Bureaucrats generally refer to Nota 2000 itself, political parties to the minutes of parliamentary deliberations, and the political officers assert that the material they would have is of a confidential nature.

Annual reports, policy documents and general publications are mostly used in reference to Nota 2000. Research or study reports and miscellaneous documents play a more limited role. Internal documents thave not been handed over.

\subsubsection{Media coverage}

Ninety-five coverages by the media were retraced (cf, 2.3 and 5.4). Coverage over time has been presented in Figure 6.1.

Several peaks are visible in this graph, but they can be explained from events that have taken place in the chronolagy of Nota 2000. Of course, the first peak (A pril-June 1986) may be explained by the fact that Nota 2000 was published in April, 1986. Further, there are annuall peaks around September-October. In this period, the anmual budget and policy intentions of government ane presented to parliament. Consequently. Nota 2000 as a said thrust of govemmental policy is reaffirmed. Finally, there is an obvious peak in media coverage in January-March, 1987. This peak can entirely be attributed to the attention given to Nota 2000 at the discussion seminats organized in November, 1986: specialized magazines (bimonthlies or quarterlies) reported on these seminars during these months. 


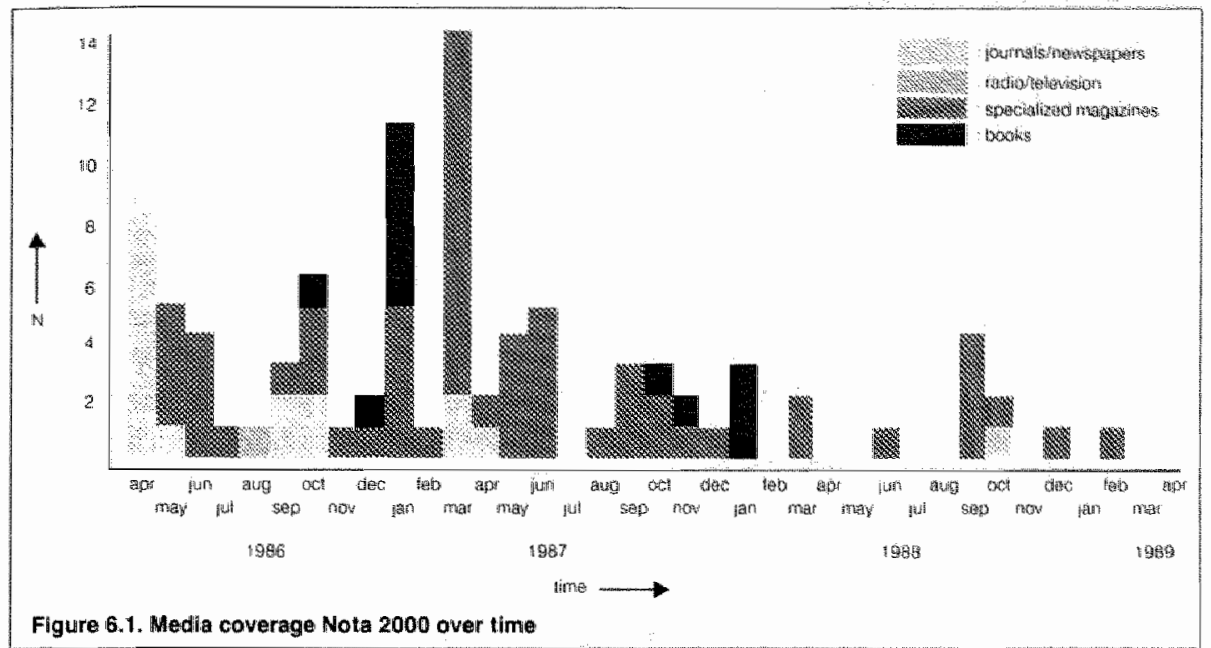

Table 6.5. Respondents vs. perceived status of Nota 2000.

policy discussion symbolic analysis political total

$\begin{array}{lllllll}\text { professionals } & 2 & 4 & 3 & 4 & - & 13 \\ \text { consumers } & - & 3 & 3 & 2 & - & 8 \\ \text { NGOs } & 1 & 3 & - & - & 1 & 5 \\ \text { politicall off } & 2 & 1 & - & 1 & - & 4 \\ \text { bureaucrats } & 4 & 4 & 1 & - & - & 9 \\ \text { research } & 3 & 2 & 1 & 3 & 1 & 10 \\ \text { pol. parties } & - & 1 & 1 & 1 & - & 3 \\ \text { total } & 12 & 18 & 9 & 11 & 2 & 52\end{array}$

\subsection{Perceived status}

Nota 2000 has explicitly been launched as a discussion document. The factual development of Nota 2000 is thus supportive for the assumptions of the mobilization model of the agendabuilding theory. Perception of this status has been tested among respondents. Generally, their perception is less unequivocal. Thirty-eight respondents give 52 qualifications to Nota 2000 . These have been grouped in five categories: policy, discussion, symbolic, analysis and political (Table 6.5).

The material from KAP-charts and Kwalitan in this respect is in full concordance: nearly laalf of respondents agrees Nota 2000 is a discussion piece. Remarkable, though, is that about one third considers the memorandum to be actual policy. Especially bureaucrats and research organizations feel so.

A considerable number of respondents feels that Nota 2000 has only symbolic status, analytical use, or that it is a political non-committing statement.

Further, it is interesting to see that the 10 professional organizations give 13 characterizations; only a minority perceives Nota 2000 'correctly' to be a discussion piece. 'The fact that the status of the document is unclear possibly obscures further development of policy. 


\section{"The taste of Nota 2000 is: disease is bad, health is good" \\ "Nota 2000 is a bible, a bit of a caricature." \\ "Nota 2000 is a ritual dance." \\ "The philosophy is coming from the WHO-kitchen, and therefore only applicable to Eastern Block and Third World countries:"}

It is surprising to find that consumers do not consider Nota 2000 a policy document. It might have been expected, from the characteristics of healthy public policy related to more adequate popular participation and explicir interest in the needs and demands side of the general health system, that consumers would prefer Nota 2000 to be a policy document legitimating their organizational objectives. However, the consumer organizations characterize Nota 2000 adequately as a document with more ambiguous characteristics.

When asked, in the second Delphi round, whether above analysis was appropriate and whether respondents had any remarks on these observations, there were some noteworthy comments. In general, respondents feel that the status of Nota 2000, whatever it may have been, is overgrown by ad-hoc problems stemming from the Dekker-discussions. Although the majority ( 8 out of 10 ) of Delphi-respondents agrees with the status analysis, some add that health policy is not onlly a matter of Nota 2000 , so that interested organizations can take the memorandum as a policy framework for their own organizational objectives. However, such a strong position is only taken by an extremely limited number (one or two) of organizations.

\subsection{Knowledge and value}

\subsubsection{Interview and Delphi material}

All respondents identified Nota 2000 correctly to be a health and content oriented strategic (i.e. future-oriented) document. However, and understandable, most organizations reflected on its impact on the health care system. Further, the perceived organizational and societal value of the document has been tested (KA.P-chart I, Annex VI). The thrust of this relevance is less uniquely identified: 23 of 39 respondents feel that Nota 2000 is a valuable document. Half of the remaining organizations feels that it is valuable on aspects (e.g., trend analysis or for specific groups) and the other half say the document is not valuable at all. The same analysis has been carried out by organizational cluster. Among professionals $(\mathrm{N}=10)$, Nota 2000 is considered substantially less valuable: only one fifth of professionals views the document unconditionally of value. The non-governmental organizations ( $N=5$ ) give another pattern: all view Nota 2000 to be of some value. Two respondents in this group manage to see only those valuable aspects of the document which apply to their own organizational objectives (reduction of certain disease categories). As to the political officers $(N=2)$, we maly see the same pattern, although the number of respondents may in fact be too small to generalize this. In the chuster of research organizations $(\mathrm{N}=6)$ the pattern is the same as for all respondents. Two of the research organizations do not consider Nota 2000 valuable at all; these organizations can be identified to have "reactionary" objectives (see also below, clusters 'political left' and 'right"). In the cluster of political parties $(\mathrm{N}=3)$ there is a 'full spread' over the 'value spectrum'. For the consumer organizations $(\mathrm{N}=7) 6$ organizations consider Nota 2000 valuable, in spite of their more ambiguous status perception. Bureaucrats $(\mathrm{N}=6)$ all consider Nota 2000 valuable. Finally, some organizations have been clustered into political 'right' and 'left' (political parties, political research institutes, employer's organizations and trade unions). It was assumed that political leaning would telate to attitucie toward Nota 2000 more homogeneously. For the cluster "right" $(\mathrm{N}=6)$ the assumption is not entirely supported, although half of respondents find the document not valuable. This is a substantial proportion, certainly when related to the overall view. As to the clluster "left' $(\mathrm{N}=4)$, all find the docu- 
ment valuable, one of which only on aspects.

However, in the second Delphi round respondents argued that the political interplay is an affair with extremely small margins, and that "political' analyses therefore would not yield informative outcomes. In this light, our findings that there are definite distinctions between a left-wing and right-wing cluster are the more significiant.

It is remarkable that consumer organizations seem to have similar perceptions of status and value of Nota 2000 as bureaucrats; this would indicate that Nota 2000 has high social relevance and seems to be tuned to consumer needs and demands rather than to those of professional interest groups. This distinction is of course also reflected in the views of the political left and right, respectively focused on (consumer) emancipation vs. maintenance of the status quo in health care policy. In the light of the present Dutch political constellation (center-right government) and its priorities, this would in tum indicate a low probability for Nota 2000 to become actual policy endorsed by Parliament.

When confronted with these conclusions in the Delphi report; half of respondents doubted the methodological approach leading to these observations. Especially the "political' analysis encountered severe criticism among these respondents. There was, however, no fundamental criticism but rather the observation that political margins are too small to make these

Table 6.6. Organizational document analysis: presence Nota 2000

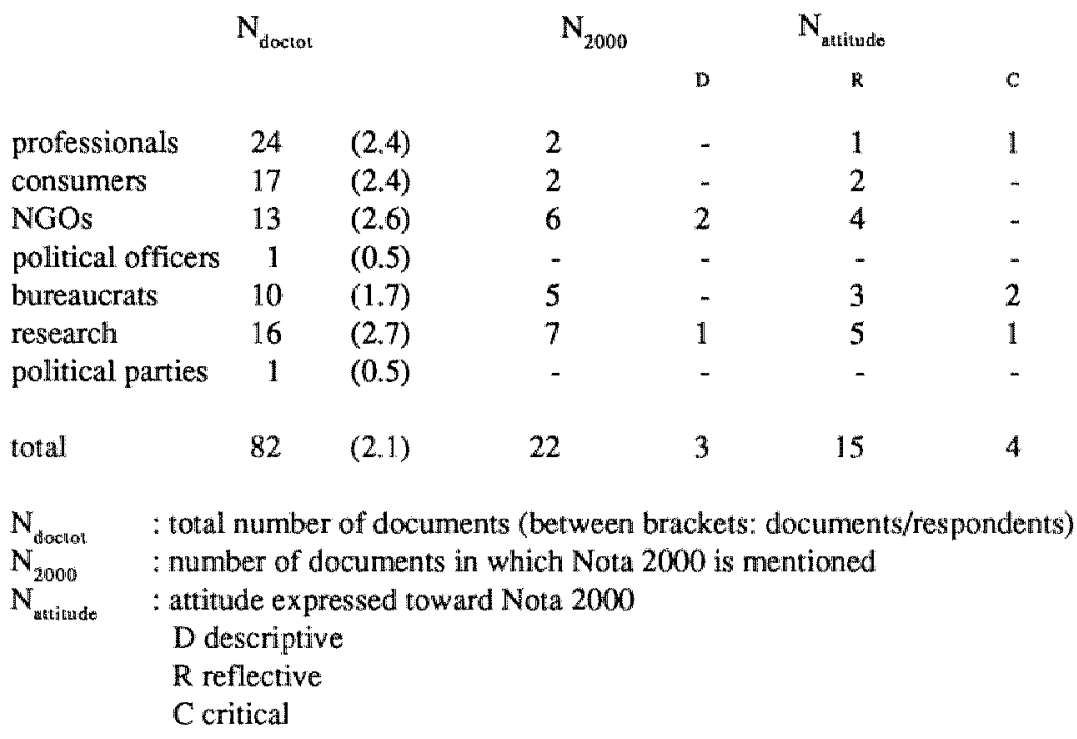

inferences. On the other hand, 20 of 34 respondents did not critique the factual analysis and its outcomes, while among those who commented on it, three respondents agreed under the condition that their positive attitude was not reflected sufficiently well.

\subsubsection{Organizational documents}

The soundest base on which knowledge and value of Nota 2000 among respondents may be measured is of course its expression in organizational documents. The 82 documents 
presented in 6.1 .2 have been screened for presence of Nota 2000 . The results are presented in Table 6.6 .

It is extremely curious that, although all organizations acknowledge to have knowledge of Nota 2000 , the memorandum plays such a minor role in organizational documents.

In 22 of 82 of these documents Nota 2000 is mentioned. NGOs, bureaucratic officials and research organizations mention Nota 2000 in about half of the cases; the other organizations have significanly lower ratings. Remarkable is the fact that of 17 consumer organization documents, only 2 actually mention Nota 2000 , although these organizations might have been expected to be attracted by the general orientation of Nota 2000.

We have reviewed in which way Nota 2000 has been present in the documents. Three attitudes have been distinguished: descriptive (factual, objective descriptions of the piece), reflective (what does Nota 2000 mean for our organization?) and critical About two-thirds of the document pool (mostly from research organizations and NGOs) is reflective in its attitude, and only one-sixth is critical. Although this might cause some optimism as to the acceptance of Nota 2000 , the overall picture remains to be clouded: only 15 of 82 take such a reflective stance.

\subsubsection{Media coverage}

Yet another indicator of knowledge and walue of Nota 2000 among organizations is media coverage, and attitude expressed in it (Figure 6.2).

Over time, the attention for Nota 2000 has clearly diminished. The attitudes expressed can also be presented in a more clustered way (Figure 6.3).

It is clear that descriptive attitudes expressed by the media have decreased in number most rapidly, while reflective attitudes decrease less rapidly. It is remarkable, however, that even when time passes and many other developments (like the Dekker report) have emerged, the critical attitude is persistent. Clearly, knowledge about Nota 2000 does exist among most organizations, but also, the document is evaluated critically over time.

\subsection{Involvement and action}

It was assumed that the degree of involvement in the policy-making process of Nota 2000 would have a significant relation with willingness to undertake action in the light of Nota $2000(4.3 .2,4.4)$. "Action" was considered to be any activity within the organization directly related to Nota 2000 , or any activity aimed at overcoming barriers to Nota 2000 (cf. 6.5). This assumption has been tested. An organizational KAP-chart has been produced (Annex

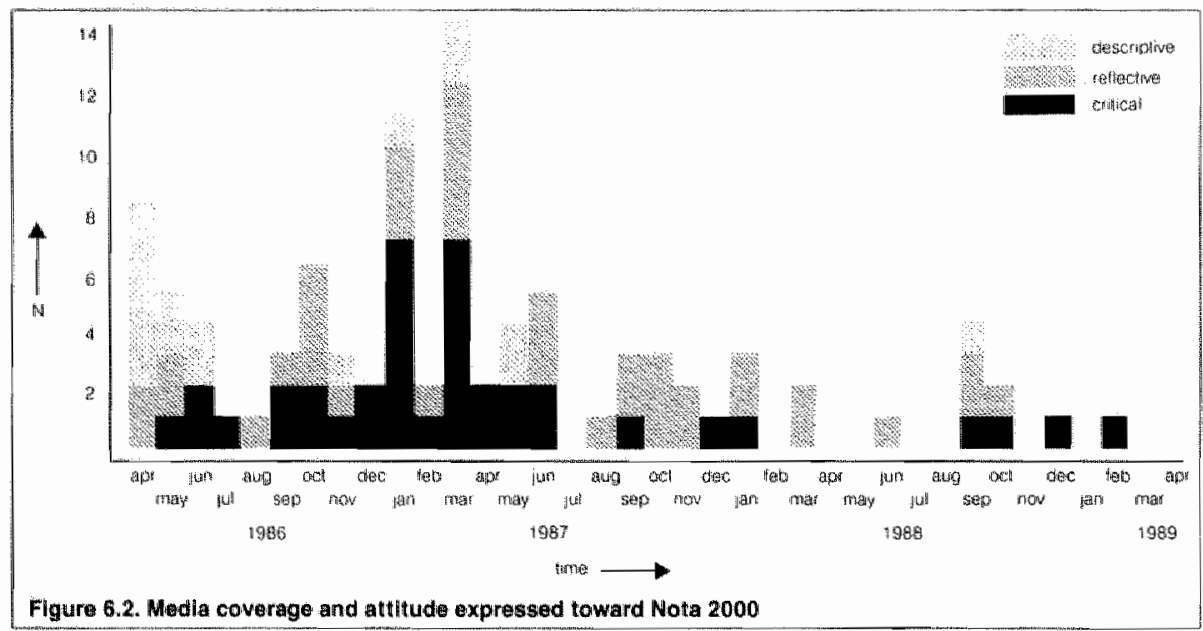




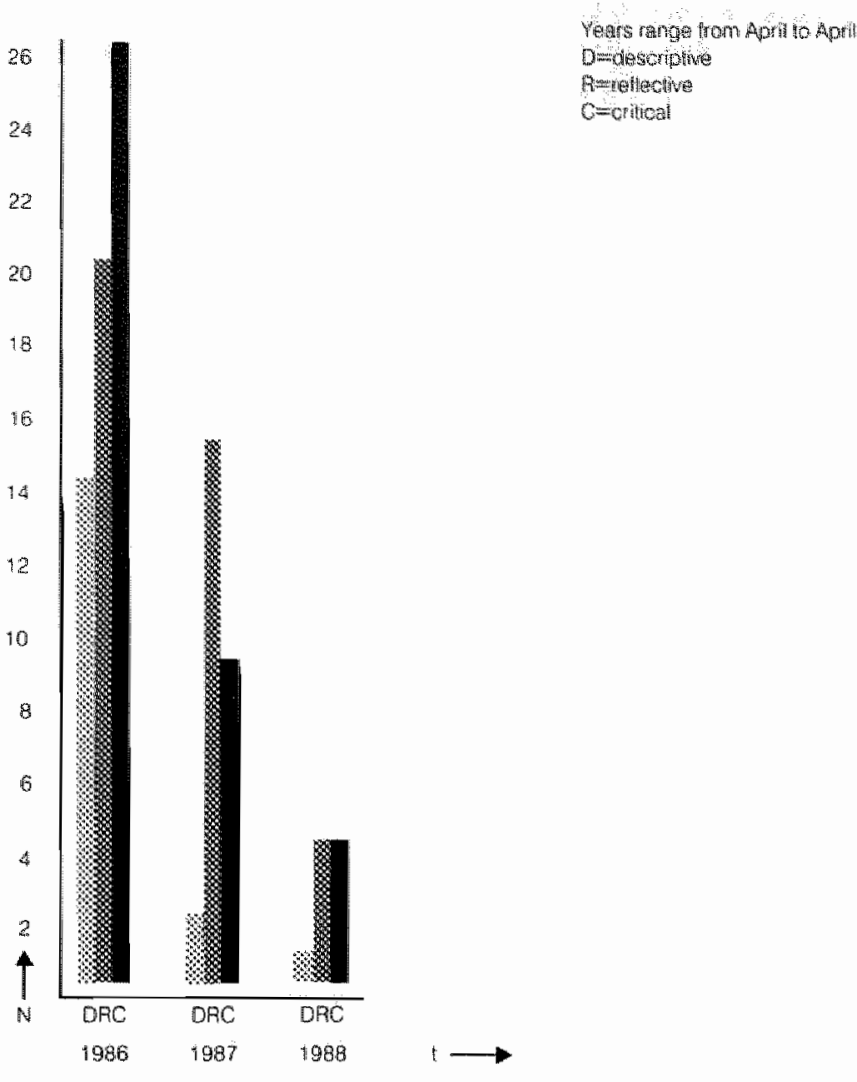

Figure 6.3. Media attitude cluster analysis

VII) in which perceived value of Nota 2000 is related to perceived involvement and action undertaken. Overall results have been represented in a $2 \times 2$ table and a Chi-square test has been carried out (Table 6.7).

Table 6.7. Perceiwed involvement ws. action undertaken in light Nota 2000

$\begin{array}{llll} & \text { action } & \text { no action } & \text { total } \\ \text { involved } & 10(8.84) & 5(6.15) & \mathbb{1 5} \\ \text { not involved } & 13(14.15) & 11(9.84) & 24 \\ \text { total } & 23 & 16 & 39\end{array}$

Between 0 : expected values when no relation.

df: 1

Chi-square: 19 
Aralysis does not yield significant results: there is no relation between perceived inwolvement and actions undertaken, although the relations not involved-action and involved-no action seem to stand out a bit more. It does not seem possible to come up with a consistent. explanation for an absence of any trend. For the separate clusters, a Chi-square would not be feasible: the cells of the $2 \times 2$ table would not be sufficiently filled (minimum expected $N=5$ per cell). Results per cluster will only be indicative. Seven out of ten professional organizations has not undertaken any action in the light of Nota 2000 while an even larger proportion ( 8 out of 10 ) feels they have not been involved. However, there is no distinct relation between invo]wement and action. Yet, here is a strong indicator that Nota 2000 may not serve professional organizational purposes. Four of five NGOs have undertaken action, although 3 of 5 have not been involved. This indicates that NGOs generally bave been stimulated to undertake action by Nota 2000 , whether or not they feel to have been involved. The political officers both feel that they have been involved, and both undertook action. But they feel that. being political officers, they are committed to relevant governmental activities. Of the research organizations, 4 out of 6 they feel they have contributed in some way to Nota 2000 (e.g., by supplying data). Three of those also have undertaken action. Yet, in total only half of these organizations took action. The others feel that action is not of legitimate concern to a research organization (in their pursuit of objective and independent muth). In the cluster of political parties, 2 of 3 feel they have been involved and took action in the Select Committee for Health. Moreower, one party stands for Nota 2000-like ideas in its platform. Of the consumer organizations, only one-third consider themselves to have been involved. Of the 6 not involved, a substantial number (4) has yet taken action. This supports the view that Nota 2000 is of high societal relevance. Of the six bureaucratic respondents, 3 feel to have been involved, although six have employed activities. Again -as with the political officers-, they have done so because of commitment to govemmental actions. An analysis of politicall left and right clusters did not yield any significant result.

Respondents in the second Delphi-round completely support the above analysis, but fail to come up with an adequate explanation of the pattern. On the one hand, there is a group of 8 respondents (of 16 commenting) blaming the nature of Nota 2000 for the litrle coherent relationship between involvement and action. Nota 2000 is far to vague for an adequate action response and not challenging any group to perform activities.

Table 6.8. Perceived barriers vs. actions to overcome them Respondents: all $(\mathrm{N}=39)$

$\begin{array}{lccr} & \text { action } & \text { no action } & \text { total } \\ \text { structure health system } & 6 & 1 & 7 \\ \text { structure government } & 5 & 7 & 12 \\ \text { interest conflicts } & 4 & 5 & 9 \\ \text { financial } & 11 & 6 & 18 \\ \text { general vagueness } & 2 & 8 & 10 \\ \text { implementation vague } & 3 & 1 & 4 \\ \text { political will } & 3 & 13 & 16 \\ \text { society } & 5 & 7 & 12 \\ \text { other } & 6 & 1 & 7 \\ & & & \\ \text { total } & 52 & 39 & \end{array}$


"They' re all waiting for the cat to jump."

"Involvement can be "momitoring on a distance", while

'action' can be almost anything in the light of Nota 2000.

The rest of those commenting in the second round blamed the way in which data were collected; either the composition of the research population or the method of data transformxtion could, according to these respondents, bias the outcomes.

Nevertheless, Kwalitan-analysis produced the same results; analysis of interview materiall with this method showed, moreover, that some organizations perceived to perform activities in the light of Nota 2000 while they were in fact part of on-going activity programmes: This shows that it is quite difficult to distinguish between actions; they might be old actions tuned to new health policy as well as newly initiated activities.

Finally, meither media analysis nor organizational document analysis yielded viable information. Organizational documents do not reveal concrete action, although Nota 2000 is mentioned several times as a document guiding health care into a new era and a memorandum on which future organizational policies might have to be based.

\subsection{Feasibility and barriers}

When directly asked, no respondent considered Nota 2000 unconditionally feasible. Barriers for feasibility were explored, and 39 respondents gave 97 barriers. These have been grouped into the following clusters: the structure of the health care system, structure of govemment (generally the strength of the Ministry of Health), conflicting interests, financial bartiers, general vagueness of Nota 2000 , vagueness on options for implementation, failing political will to work with Nota 2000 , trends in society, and 'other' barriers. Results are in tables 6.8 m 6.11. In Table 6.8 (all respondents) it is most remarkable that structure of government, financial barriers, general vagueness, political will and trends in society score highest. The internal structure of the Ministry of Health is curiously often mentioned to be a crucial barrier for Nota 2000 by respondents from all categories.

Table 6.9. Perceived barriers vs. actions to overcome them

Respondents: those who find Nota 2000 valuable $(\mathrm{N}=23)$

$\begin{array}{lrrr} & \text { action } & \text { no action } & \text { total } \\ \text { structure health system } & 2 & 1 & 3 \\ \text { structure government } & 3 & 5 & 8 \\ \text { interest conflicts } & 3 & 3 & 6 \\ \text { finatncial } & 10 & 2 & 12 \\ \text { general vagueness } & 1 & 2 & 3 \\ \text { implementation vague } & 3 & - & 3 \\ \text { political will } & 9 & 1 & 10 \\ \text { society } & 4 & 4 & 8 \\ \text { other } & 5 & 1 & 6 \\ \text { total } & & & 59\end{array}$


Table 6. 10. Perceived barriers vs. actions to overcome them

Respondents: those who find Nota 2000 waluable on aspects $(N=8)$

action no action total

structure health system $11 \quad-\quad 1$

$\begin{array}{llll}\text { structure government } & 1 & 1 & 2\end{array}$

interest conflicts $\quad 1 \quad 1 \quad 2$

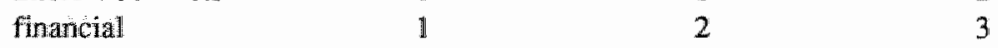

general vagueness $\quad 1 \quad 4 \quad 5$

implementation yague - - -

$\begin{array}{llll}\text { political will } & 1 & 1 & 2\end{array}$

society $\quad 1 \quad$ - 1

other 1101

$\begin{array}{llll}\text { total } & 8 & 9 & 17\end{array}$

Table 6.11. Perceived barriers vs. actions to overcome them Respondents: those who find Nota 2000 not valuable $(\mathrm{N}=8)$

action no action total

$\begin{array}{llll}\text { structure health system } & 3 & -\end{array}$

$\begin{array}{llll}\text { structure government } & 1 & 1 & 2\end{array}$

interest conflicts $\quad-\quad 111$

financial $\quad 2 \quad 2$

general vagueness $\quad$ - $\quad 22$

implementation vague $\quad-\quad 11$

political will

society

1

other

$3 \quad 3$

total

4

11

15

"We wonder whether the bureaucrats have been listening to the past at all."

"There is definitely a lack of quality in the whole governmental apparatus, and especially in the Ministry of Healh."

"Let"s admit it: the Ministry is not such a good partner."

"The Ministry has such an unfortunate culture: internally.

it is an extremely weak organization."

"As for me: I"d never like to be mr. Dees, the secretary of state for health." 
Regarding the structure of government, as many respondents feel they cam employ acrions to overcome this barrier as there are who feel not. Twice as many would like to work on financial barriers as those who do not feel like that. The wagueness of Nota 2000 is not a barrier respondents would like to work on.

In general, those barriers predicted in 3.2 .2 to arise around health policy seem to be of far less concern than the problems of the current health system. The fact that respondents do not want to give concrete form to the policy intentions indicates that the status quo in health care policy is of far higher concern. Nearly all respondents who see political barriers feel they could work on creating more political will. Finally, trends in society opposing Nota 2000 thrusts do not call for much specific action. It is remarkable that the types of barriers referred most to, are the same barriers that are addressed in the 'Dekker'-report. This would lead us to conclude that when the Dekker-recommendations are carried out, Nota 2000 will have higher feasibility to enter the institutional policy-making agenda again. It could be feared, though, that by that time the content-oriented thrust of healthy public policy is forgotten. Moreover, traditionally vested interests will not disappear with implementation of 'Dekker'.

Next, perceived barriers vs. actions have been clustered in the groups of perceived value (Tables 6.9-6.11). Most significant is, that those organizations who consider Nota 2000 valuable see relatively more barriers, but at the same time are also more willing to address these barriers. In the "not valuable'-cluster, the eight organizations see only few barriers, but are not at all inclined to work on them. Of course, the analysis is merely a confirmation of what already was known: those organizations who feel that Nota 2000 is not valuable and has no relevance in terms of their own organizational objectives, have no inclination to work on furthering the objectives of Nota 2000. And again, these groups may in their scope of work and organizational linkages generally be identified with a stable professional power base, and the present right-wing Dutch political constellation. In the response to the Delphi report, only three respondents disagreed with the above conclusion. The Dekker report is consistently mentioned as an important factor for the nonfeasibility of Nota 2000. However, respondents assert that problems distinguished for Nota 2000 may certainly also pertain to "Dekker'; in other words, the problems that are most. prominentlly present in our barrier analysis of Nota 2000 are not specifically problems for health policy, but rather for health care policy. The problems that might have been expected to arise for health policy (in the realm of 3.2.2: policy-making thrusts, intersectoral cooperation, interventions for health, and measurement) have not surfaced in the above analysis. Actors are struggling with direct threats in the spheres of financing and health care domain dissensus. Apparently, there are problems of a higher priority level that have to be addressed first, even before health policy can be suggested.

Finally, neither organizational documents analysis nor media coverage analysis produced data other than those presented above; especially the "traditional' problems pertaining to the health care system were presented as barriers. No actions have been suggested in these documents.

\subsection{Issue expansion}

The most prominent feature of the conceptual framework presented in chapter four is the notion of issue expansion. In this section we will measure the width of issue expansion ats operationalized in 4.2 . In that paragraph we suggested a dichotomy in possible answers (yes/ no score on issue expansion criteria); during the investigation, however, it was found that some of the criteria could be explained negatively by respondents. The ambiguity of the issue of health policy, for instance, would induce according to the theory of agenda-building an increasing circle of contestants over the issue, thus increasing probability of systemic agenda status. However, the ambiguity of Nota 2000 was by some perceived to be totally counterproductive in the sense that scope of conflict was not increased but rather sealed off by these 
orgaritzations. We have chosen to add this attitude as a separate answer category.

\subsubsection{Interview and delphi response}

When the issue of Nota 2000 (a virtual health policy) is sufficiently well expanded among. interest groups, this would indicate a public pressure high enough to get a health policy on the systemic and in turn on the institutional agenda. It would also mean that failing political will could disappear. An analysis has been carried out of the perception of issue criteria as presented above. In general, the issue seems to be expanded sufficiently well (Table 6.12). A minority of respondents wiews the ambiguity of Nota 2000 to be inappropriare: it is too vague to employ any action, and even leading to feelings of animosity. Remarkable is the number of respondents who regard Nota 2000 as having no social significance $(\mathrm{N}=13$ ); the issue a health policy does not prompt them to employ policy action. We have found a clear distinction in the composition of the group not considering Nota 2000 to be socially relevant. Six of these 13 respondents (i.e. nearly half) stem from the cluster of professional organizations; over half of these organizations (response $N=10$ ) seems to agree that Nota 2000 in fact is socially itrelevant. The group of 13 further consists -surprisingly- of consumer organizations (3) and research organizations (3), and an NGO.

Table 6.12. Issue expansion by agenda-building theory criteria $(\mathbb{N}=39)$

$\begin{array}{lccccc} & \text { inappropriate } & \text { yes } & \text { no } & \text { not known } & \text { total } \\ \text { ambiguous } & 6 & 26 & 6 & 1 & 39 \\ \text { social significance } & - & 26 & 13 & - & 39 \\ \text { temporal relevance } & - & 32 & 6 & 1 & 39 \\ \text { non-technical } & 1 & 22 & 12 & 4 & 39 \\ \text { no precedent } & - & 28 & 4 & 7 & 39 \\ \text { total } & 7 & 134 & 41 & 13 & 195 \\ \end{array}$

Those who find the issue to have a technical nature feel that the "policy technicians" (bureauw crats and political leaders) have a prime responsibility to make assumptions, goals and means for policy more concrete. Research is felt to be of utmost importance to those who consider health policy to be at technical problem. The research organizations, however, all agree that health policy is a non-technical, or rather societal and politicall problem. Those who score 'yes' on issue expansion criteria are willing to work on Nota 2000. This would indicate that the mobilization model of the agenda-building theory is appropriate.

To test the validity of the theory further, respondents have been clustered by score on the issue expansion criteria, and we have checked whether their perceived value of Nota 2000 is tuned to the thrust of the theory. In that case the assumption is that the higher the score on issue expansion criteriat, the higher Nota 2000 will be valued, and the more actions are employed to further Nota 2000 objectives (Tables 6.13-6.19). These relations are indeed significant: as issue score decreases, perceived value decreases (Table 6.13), and the rate of actions ws. non-actions decreases as well, from 4.5 to 0.33 . This proves the theory to be correct. However, there is a cautionary fact: the lower the issue expansion score, the fewer the number of respondents becomes. Probably, this could be reason to doubt the significance of the outcomes. On the other hand, such a decrease is entirely in line with what could have 
been expected from successful application of the theory.

"Full issue expansion" (issue expansion score 5, table 6.14) does not seem to fit in the pattern of tables 6.14-6.19. While tables 6.15-6.19 give a perfectly smooth decreasing issue expansion-action/no action ratio $(4.5-2-0.53-0.5-0.33)$, full issue expansion gives only a ratio of 1.09. Closer review of the respondent group, however, reveals that most bureaucrats are included in this group. Interview data show -as we have obsenved in the latter part of 6.4- that although all bureaucrats have undertaken action, the number of actions and scope of actions aimed at removing barriers are limited; bureaucrats feel that it is illegitimate to employ formal action in areas of interest conflict, political will, and societal developments, while influencing political will or addressing the structure of government is entirely out of the question. Bureaucrats remain to work within set parameters of work; this thrust of action

Table 6.13. Number of respondents related to issue expansion score and vallue of Nota 2000

Issue expansion score $\mathrm{N}$ respondents (a) number of those: Nota (b)/(a)

2000 is valuable (b)

$\begin{array}{cccc}5 & 13 & 12 & .92 \\ 4 & 8 & 7 & .88 \\ 3 & 8 & 3 & .38 \\ 2 & 6 & 2 & .33 \\ 1 & 2 & 0 & .0\end{array}$

Issue expansion score: cf. table 6.12: number of times of "yes'-answer

Table 6.14. Issue expansion score vs. perceived barriers and actions undertaken.

Issue expansion: 5

$\mathrm{N}$ respondents: 13

Composition group:

$\begin{array}{ll}\text { professionals } & 1 \\ \text { consumers } & 3 \\ \text { NGOs } & 2 \\ \text { political officers } & 1 \\ \text { bureaucrats } & 5 \\ \text { research organizations } & 1 \\ \text { political parties } & 0\end{array}$

structure bealth system

action no action

total

structure government

1

interest conflicts

2

financial

2

general vagueness

-

implementation vague $\quad 2$

political will 4

society 2

other

total

3

barriers/respondent

$\begin{array}{cc}\text { no action } & \text { total } \\ - & 1 \\ 2 & 3 \\ 1 & 3 \\ 3 & 5 \\ 3 & 3 \\ - & 2 \\ - & 4 \\ 4 & 6 \\ 1 & 3 \\ 14 & 30 \\ 1.1 & 2.3\end{array}$

action/no action 
Table 6.15. Issue expansion score ws. perceived barriers and actions undertaken. Issue expansion: 4

N respondents: $\quad 8$

Composition group:

$\begin{array}{ll}\text { professionals } & 3 \text { (social health circuit) } \\ \text { consumers } & 1 \\ \text { NGOs } & 1 \\ \text { political officers } & 1 \\ \text { bureaucrats } & 1 \\ \text { political parties } & -\end{array}$

\begin{tabular}{|c|c|c|c|}
\hline & action & no action & total \\
\hline structure health system & 1 & - & 1 \\
\hline stmucture government & 2 & 2. & 4 \\
\hline interest conflicts & 2 & - & 2 \\
\hline financial & 5 & - & 5 \\
\hline general vagueness & 2 & - & 2 \\
\hline implementation wague & 1 & - & 1 \\
\hline political will & 3 & 2 & 5 \\
\hline society & $\mathbb{1}$ & - & 1 \\
\hline other & $\mathbb{1}$ & - & 1 \\
\hline total & 18 & 4 & 22 \\
\hline barriers/respondent & 2.25 & 0.5 & 2.75 \\
\hline action/no action & & & \\
\hline
\end{tabular}

Table 6.16. Issue expansion score vs. perceived barriers and actions undertaken. Issue expansion: 3

N respondents: $\quad 8$

Composition group:

professionals
consumers
NGOs
political officers
bureaucrats
research organizations
political parties

2

alction no action total

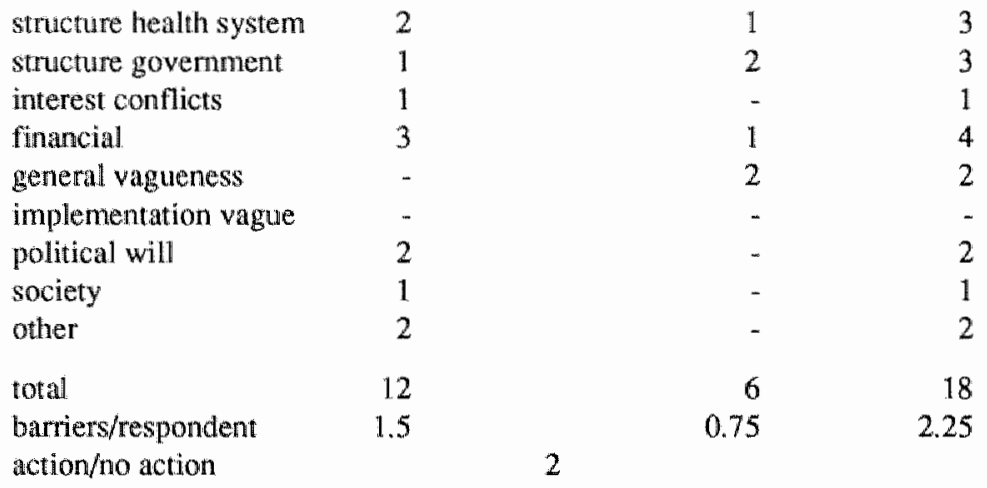


Table 6.17 Issue expansion score ws. perceived barries and actions undertaken. Issue expansion: 2

N respondents: 6

Composition group:

structure health system

structure government

interest conflicts

\begin{tabular}{|c|c|}
\hline professionals & 1 \\
\hline consumers & 1 \\
\hline NGOs & - \\
\hline political officers & m \\
\hline bureaucrats & - \\
\hline research organizations & 4 \\
\hline political parties & - \\
\hline action & \\
\hline- & - \\
\hline - & 1 \\
\hline - & 3 \\
\hline 2 & - \\
\hline - & 2 \\
\hline - & 1 \\
\hline 1 & 1 \\
\hline 1 & 1 \\
\hline 1 & - \\
\hline 5 & 9 \\
\hline 0.53 & .5 \\
\hline
\end{tabular}

Table 6.18. Issue expansion score vs. perceived barriers and actions undertaken. Issue expansion: 1

$N$ respondents: 2

Composition group:

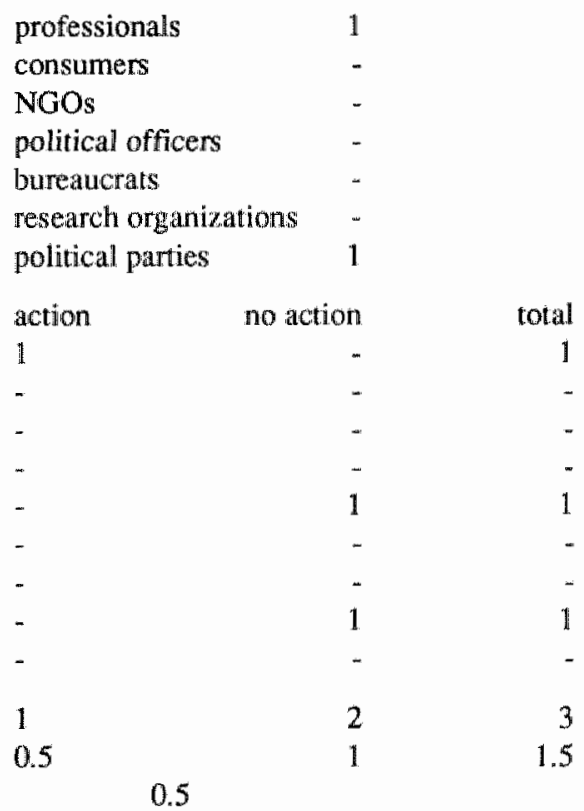


Table 6.19. Issue expansion score ws. perceived barriers and actions undertaken.

Issue expansion: 0

N respondents: 2

Composition group:

$\begin{array}{ll}\text { professionals } & 1 \\ \text { consumers } & - \\ \text { NGOs } & 1 \\ \text { political officers } & - \\ \text { bureaucrats } & - \\ \text { research organizations } & - \\ \text { political parties } & -\end{array}$

structure health system

action no action total

structure government

interest conflicts

financial

general vagueness

implementation vague

politicall will

society

other

total

barriers/respondent

-

1

-

-

$-$

$-$

$-$

$-$

action/no action

$\begin{array}{ll}- & - \\ 1 & 1 \\ 1 & 1 \\ - & 1 \\ - & - \\ - & - \\ 1 & 1 \\ - & - \\ 3 & 4 \\ 1.5 & 2\end{array}$

0.33

clearly pollutes the outcomes presented in table 6.14.

When asked to comment on the issue expansion section in the second Delphi-round, no respondent produced remarks.

\subsubsection{Issue expansion and organizational documents}

We have reviewed 82 organizational documents in order to analyze in which way Nota 2000 was covered. Results are in table 6.20.

Contrary to what issue expansion criteria have led to believe, it has become clear from table 6.20 that Nota 2000 plays an extremely limited role in the work of organizations. Remarkable is again the fact that consumer organizations do not seem to support issue expansion criteria as derived from interviews in their organizational documents.

Although we have seen in table 6.6 that several organizations have reflected on Nota 2000 , factual use of any concept from Nota 2000 is limited.

"Thus, issue expansion criteria may score quite well in relation to the feasibility question, but factual work with explicit reference to Nota 2000 is nearly non-existent. Respondents blame the non-challenging nature of Nota 2000. This obserwation is in fact contrasting the stance taken in the agenda-building theory where an issue has to be ambiguous (or not challenging) to acquire agenda status.

On the other hand, as several respondents have remarked, not explicitly using a concept from Nota 2000 does necessarily mean that Nota 2000 is denounced: organizations may use their own conceptualizations of health policy. However, as we have already remarked above, this is only valid for one or two organizations (cf. 6.2).

\subsubsection{Media issue coverage}

Finally, the agenda-building theory asserts that media, symbolism and the use of metaphors 
Table 6.20. Orgamizational document analysis: presence concepts Nota 2000

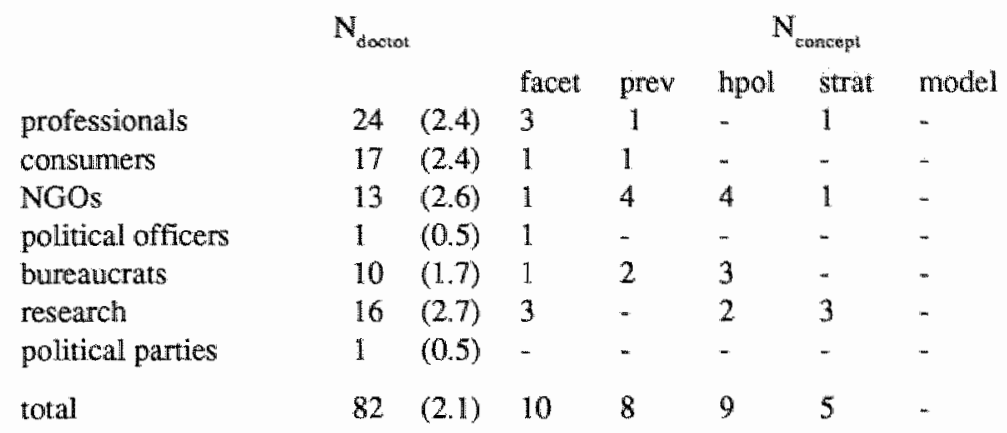

$$
\begin{array}{lll}
\mathrm{N}_{\text {doctot }} & : \begin{array}{l}
\text { total number of documents (between brackets: documents/ } \\
\text { respondents) }
\end{array} \\
\mathrm{N}_{\text {concept }} & : \begin{array}{cl}
\text { number of documents in which a concept from Nota } 2000 \text { is used } \\
\text { facet } & \text { : facet policy } \\
\text { prev } & \text { : prevention policy } \\
\text { hpol } & \text { : health policy } \\
\text { strat } & \text { : strategic action/health targets } \\
\text { model } & \text { : Nota } 2000 \text { health basis model }
\end{array}
\end{array}
$$

are important instruments in the expansion of issues. We have reviewed in which way the media have covered Nota 2000, and have distinguished between single issue coverage (in this respect meaning that only a limited part is taken out of Nota 2000 -such as prevention, of budget cuts, or future trends-) and comprehensive coverage (Nota 2000 as a total set of health policy). The results are presented in figure 6.4. It appears that 6.1 of 95 coverages are of a comprehensive nature. There seems to be no time trend in the proportion between single issue and comprehensive coverage.

Comprehensive coverage does not lend itself to the use of metaphors or symbolism. Most comprehensive coverages relate to the nature of Nota 2000 (future-orientation, focus on health, etc.), while most single issue coverages relate to a specific health sector (mental health, prevention). About one sixth of all coverages (newspapers and magazines) uses some form of metaphor, mostly referring to future trends (caption: 'More Disease by 2000 !" or "Budget Cuts: people have to take care of themselves."). Only two coverages use a vitual metaphor: 'Nota 2000 Fairy Tale' and 'The Evil Nightmare from WHO'.

\subsubsection{Issue expansion: in sum}

Data from interviews and delphi response indicated that measured against criteria formulated in 4.2, the issue of Nota 2000 (Nota 2000) was expanded sufficiently well. This would mean that the issue was to be placed on the systemic agenda. However, data from the organizational document analysis and media analysis showed that this was not at all the case.

Attention for Nota 2000 in documents was limited and media have not contributed effectively to issue expansion.

This leads us to conclude that, although the criteria formulated in 4.2 may be appropriate, the mechanisms for issue expansion have not worked effectively; in any case, they do not reflect a thrust of the issue of health policy onto the systemic agenda. This observation is endorsed by a substantial proportion of respondents: they assert that most organizations in the field are still abiding the consequences of Nota 2000 . 
"It's a bit of governmental hubris."

"There is no real opposition, but we all just don't do a

thing, nothing will happen. That's our position."

"They" re all waiting for the cat to jump."

\subsection{Opposition}

Respondents were asked to indicate any opposition to furthering Nota 2000. Again, the analyses with KAP and Kwalitan were in full concordance.

Fifteen respondents could see no opposition whatsoever; they attributed this to the vagueness

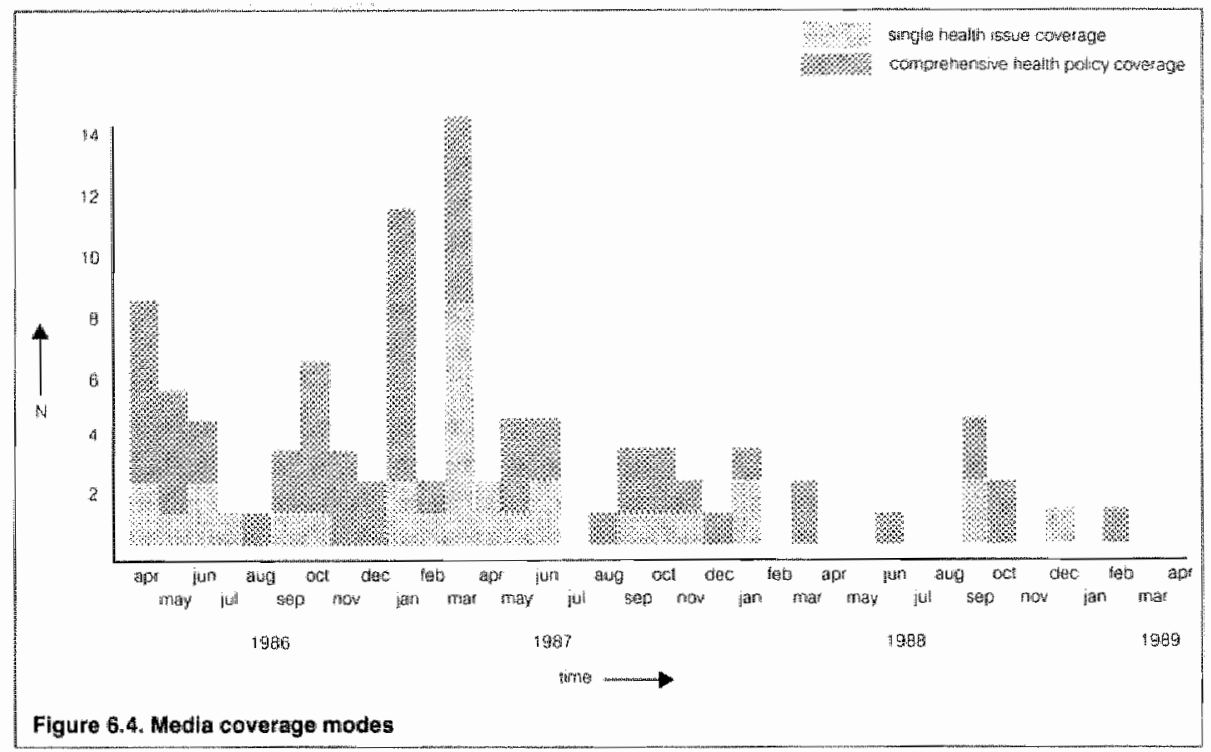

of the document, but also to the analytic characteristics of it: as a data resource Nota 2000 is considered quite valuable. The other 24 respondents saw in total 45 groups and clusters opposing Nota 2000 (lable 6.21 ).

Especially institutional care groups and those who finance health care are perceived to be in opposition $(10+10+14=34$ out of 45 opponents). Remarkable is furthermore, that political officers do not see any opposition, and that NGOs are not considered opponents of Nota 2000 by any of the organizations. Finally, seven out of ten professional organizations cannot mention anyone opposed to the memorandum, although they are perceived to be in opposition by most other organizations.

In 2.3.3, we have reviewed the initial opposition against Nota 2000. Only medical specialists, the National Hospital Council and the Association of Health Insurance Funds were generally in opposition. Meanwhile, though, the latter Association has modified its position and views Nota 2000 to be a valuable piece. The perception by respondents of opposition is therefore generally adequate, although many negative ideas are attributed to the category of professionals. The only observation which is fully correct is that NGOs are not in opposition. In the second Delphi round, all respondents acknowledged the situation described above, though sometimes under conditions (e.g. professional groups acknowledging that "the others" are indeed in opposition). 
Table 6.21. Respondents ws. perceived opposition to Nota 2000

\begin{tabular}{|c|c|c|c|c|c|c|c|c|c|c|c|}
\hline & prof & con & $\mathrm{NG}$ & & bur & res & par & fin & care & tot: & no \\
\hline professionals & 1 & 1 & - & 1 & $=$ & - & 1 & 2 & 3 & 9 & 7 \\
\hline consumers & 4 & 1 & - & - & - & - & - & 2 & 2 & 9 & 2 \\
\hline NGOs & - & - & - & - & 3 & - & - & 2 & 3 & 8 & 1 \\
\hline political officers & - & - & - & - & - & - & $\approx$ & - & - & - & 2 \\
\hline bureaucrats & 1 & 1 & - & - & - & - & - & 2 & 3 & 7 & 2 \\
\hline research & 3 & - & - & - & 1 & 1 & 1 & 1 & 2 & 9 & $=$ \\
\hline political parties & 1 & - & - & - & - & - & $\therefore$ & 1 & 1 & 3 & 1 \\
\hline total & 10 & 3 & - & 1 & 4 & 1 & 2 & 10 & 14 & 45 & 15 \\
\hline prof: & \multicolumn{11}{|c|}{ professional groups } \\
\hline con: & \multicolumn{11}{|c|}{ consumer organizations } \\
\hline NGO: & \multicolumn{11}{|c|}{ Non-governmental organizations } \\
\hline pol: & \multicolumn{11}{|c|}{ political officers } \\
\hline bur: & \multicolumn{11}{|c|}{ bureaucrats } \\
\hline res: & \multicolumn{11}{|c|}{ research organizations } \\
\hline par: & \multicolumn{11}{|c|}{ political parties } \\
\hline fin: & \multirow{2}{*}{\multicolumn{11}{|c|}{$\begin{array}{l}\text { financial organizations (insurance companies, etc.) } \\
\text { institutional care organizations }\end{array}$}} \\
\hline care: & & & & & & & & & & & \\
\hline
\end{tabular}

"Professionals refuse to see any opposition because they're powerful enough to deny any of it."

"Only real implementation will cause real opposition."

"It"s playing Black Peter."

\subsection{Prevention policy}

Respondents were asked to identify the ways and means by which they could contribute to a comprehensive public prevention policy. Response has been categorized (Table 6.22) into 'prerequisite-setting', 'preventive action' (actual intervention, educational campaigns, etc.), "policy" (a direct contribution to making prevention policy) and "lobby' (an active role in influencing decision-makers). Further, informal contribution has been distinguished from formal contribution, the latter being a statement or position paper.

It turns out that the majority of respondents perceives a role in prerequisite-setting, probablly because this role is not really committing the organization to any formal policy. The formalized contribution is reflected in lip-service-like statements to prevention in organizational documents. Some organizations are carrying out prevention activities, but only half of them have formalized these contributions. All those who have direct access to prevention policy making (ministerial or govemmental circles) have formalized their contribution. A substantial number of respondents feels to have a role in lobbying for prevention policy, half of which has also formalized that contribution (mostly in their organizational statement of mission). A minority of four does not feel to have any role. Further, prevention policy is by most respondents understood to be the act of prevention itself, without the need to structure this in some sort of plan, with time table, instruments, resources and concrete targets (cf. our policy definition).

Finally, it should be remarked that the said formal contributions are generally not tuned to 
Table 6.22. Regpondents $\%$ s. irtention and said formal contribution to prevention policy prerequisites action pollicy lobby no total

$\begin{array}{lrrrrrr}\text { professionals } & 5(4) & 6(3) & -(-) & -(-) & 2 & 13(7) \\ \text { consumers } & 4(2) & 5(2) & -(-) & 2(-) & - & 11(4) \\ \text { NGOs } & 4(3) & 3(2) & 1(1) & 1(1) & - & 9(7) \\ \text { political officers } & 1(1) & -(-) & 1(1) & 1(1) & 1 & 4(3) \\ \text { bureaucrats } & 4(3) & 1(1) & 3(3) & 3(1) & - & 11(8) \\ \text { research } & 6(6) & -(-) & 1(1) & 2(1) & - & 9(8) \\ \text { political parties } & 1(1) & -(-) & 1(1) & -(-) & 1 & 3(2) \\ & & & & & & \\ \text { total } & 25(20) & 15(8) & 7(7) & 9(4) & 4 & 60(39)\end{array}$

prerequisites: establishing conditions for other to make prevention policy

action: preventive action(campaign, education) without direct policy effect

policy: direct contribution to making policy

lobby: $\quad$ active role in influencing decision-makers

Betweeno: formalized contribution (i.e. on paper, statement, etc.)

the comprehensive Nota 2000 framework (the health basis model), not even those made by some ministry of health bureaucrats. Instead, they refer to previous limited or single-sector prevention intentions.

Quotes from the Kwalitan-analysis were further illustrative, and when asked about the questionable status quo of prevention policy in the Delphi questionnaire, respondents made some more noteworthy remarks. Although some felt that adequate prevention policy is already in effect, 13 respondents represented two broad attitudes toward such a policy: on the one hand, there are those who say that prewention is in the end a responsibility of individuals, while others state that prerequisites for prevention policy are at the moment poorly formulated. The latter especially relate to a concrete operationalization of what constitutes prevention policy and the establishment of challenging prevention proposals.

"There should be a more structural and insurance-technical financing of prevention."

"Everybody is dancing around the amorphous hot prewention pulp."

"Various organizarions ma experience present public policies differently."

"Prevention" needs a more sound intersectoral operationalization first."

"Not everybody has the ability to carry out preventive interventions, but everybody can work on prerequisites"."

\subsection{Child accident prevention policy}

To test some of the issues raised above, respondents were confronted with a case-study (question 19, annex VIII). They were asked to identify the possible effectiveness of a prevention policy for the specific problem. The majority $(\mathrm{N}=28)$ agreed that, sometimes under conditions, the problem could effectively be addressed by public policy (Table 6.23). Those who could not see $\mathrm{so}_{w}$ stem from organizations with a limited scope of activities (disease categories, specific research areas, etc.). When asked what accident prevention policy should look like (Table 6.24), a very large proportion of respondents indicated it 
should contain educational measures. However, they did not feel responsible for the actual intervention or a formal contribution to policy-making (cf: Table 6.21 and related response. in which respondents remarked that either they were already performing preventive action or were creating prerequisites). Generally, they referred to the one organization involwed with safety and health in The Netherlands (Stichting Consument en Veiligheid) having solely a role in creating and lobbying conditions for such a policy.

When the policy would have been adopted, most organizations would be willing and able to commit themselves to it. In terms of intersectoral cooperation, though, they do not feel a role in initiation, adoption and operationalization of such a scheme.

The pattem in the responses to the case-study is clear. although most organizations feel that child home accidents are an important problem with a large magnitude which can be addressed by a mix of interventions, educational measures have their preference. Legislative measures are favoured also by a small majority, but there the responsibility for initiation and creation of such measures is laid with governmental and parliamentary circles. At the same time, these measures are thus, according to the respondents, not to be planned or carried out by them, but only by one agency: the Stichting Consument en Veiligheid (SC\&V, the

Table 6.23. Respondents vs. perceived effectiveness of a prevention policy to reduce accidents in/around the home among children $0-5$ years

\begin{tabular}{lccccc|} 
& yes & depends don't know & no & total \\
professionals & 7 & 1 & 2 & - & 10 \\
consumers & 5 & 1 & 1 & - & 7 \\
NGOs & 2 & 1 & 2 & - & 5 \\
political officers & - & 1 & 1 & - & 2 \\
bureaucrats & 4 & 1 & - & 1 & 6 \\
research & 3 & - & 3 & - & 6 \\
political parties & - & 2 & - & - & 2 \\
total & 21 & 7 & 9 & 1 & 38
\end{tabular}

Consumer Safery Foundation). Although SC\&V cooperates with some organizations, intersectoral action outside the specific SC\&V realm on the issue will therefore not be very feasible, although the problem has an explicit intersectoral nature.

The response in the second Delphi round is entirely in support of this observation. Respon dents agree that the problem is important, but feel that SC\&V addresses the issue wery well. and that in consequence, there is no role for any other organization.

"SC\&V has a very adequate and powerful lobby."

"There is an extremely low domain consensus on the issue."

"No-one really has experience with such intersectoral work, and apart from that:

SC\&V is pushing itself tremendously."

"Why frustrate all these efforts by SC\&V by doing our own things in the same area?"

"Not everybody is equipped to prevent." 
Table 6.24. Respondents vs, preferred intervention type to reduce child home accidents legislate sanction facilitate educate counsel other total

$\begin{array}{lrrrrrrr}\text { professionals } & 1 & - & 2 & 8 & 2 & 4 & 17 \\ \text { consumers } & 4 & 1 & 1 & 7 & - & 2 & 15 \\ \text { NGOs } & 2 & 2 & - & 4 & - & 2 & 10 \\ \text { political officers } & 2 & - & 1 & 2 & - & - & 5 \\ \text { bureaucrats } & 2 & 1 & 2 & 5 & - & 1 & 11 \\ \text { research } & 2 & - & 1 & 5 & - & 1 & 9 \\ \text { political parties } & 1 & - & - & 2 & - & - & 3 \\ \text { total } & 14 & 4 & 7 & 33 & 2 & 10 & 70\end{array}$

\subsection{In sum}

In this chapter diverse data have been presented. In this last section we will try to present these findings in a concise way, and reflect on the general conclusions on feasibility respondents draw in the second Delphi round.

Response has been adequate, amounting up to $87 \%$ of the research population. Also w wide range of organizational documents and media coverages has been collected. The response rates of political officers, bureaucratic officers and political parties have been lower than those of professional, consumer, and non-govemmental organizations. Non-response may at the most be regarded as limited interest in the issue of Nota 2000. An inference that it would also indicate a low feasibility for Nota 2000 seems to be very tentative, although nearly half of the respondents in the second Delphi round does not comment on that observation.

Although Nota 2000 has been launched as a discussion document, possibly leading to more concrete policy, a considerable proportion of respondents (nearly a quarter) yet regards the document to be factual policy. However, a somewhat larger group attributes symbolic, analytic, or political characterizations to the document, thereby signifying that Nota 2000 serves neither discussion nor policy purposes.

All respondents were familiar with Nota 2000 , and knew to some extent its thrusts. Less consensus exists over the value of the document. A majority of respondents ( 6 out of 10 ) regards Nota 2000 as a whole to be a valuable document, while 2 out of 10 view the document to have limited value, and another 2 out of 10 do not see any value. Relatively, professional organization consider the document to be of little value. Consumer organizations and bureaucratic officers have the same perception of the high value of the document. However, neither organizational document analysis nor media coverage analysis yielded the same result: the value of Nota 2000 may at best be considered marginal evaluating these documents. A critical coverage of Nota 2000 is especially persistent in the media analysis. Although in section 2.3.1 we have evaluated the involvement by outside actors in the Nota 2000 initiation process to be minimal, 15 of 39 respondents regard themselves as having participated in this stage of making policy. There was no significant relation between involvement and subsequent action undertaken. By cluster, professional organizations feel generally not to have been involved, and they have not employed any action. Nota 2000 does not seem to serve professional organizational purposes. The contrary seems to be valid for consumer organizations. Assessing media coverage and organizational documents, the professional organizations' stance is supported, but consumer organizations" artitude from the interviews is not reflected in these data sets. A large majority of respondents blames the character of Nota 2000 for this relative inertia. The document is too vague to employ action, 
and is not challenging to organizations.

No respondents regarded Nota 2000 as it is to be feasible. Many barriers to this feasibitity were mentioned; the barriers listed most often do not resemble the ones we might have expected from our literature review $(3,22)$. Structure of government, financial bartiers. general vagueness, failing political will and trends in society not compatible with health policy are the main barriers. These are not exclusive problems for health policy, but rather for the prevailing structure of health care policy in Dutch society. The problems listed in the literature hindering health policy are those barriers respondents are less likely to act upon. Those respondents who considened Noti 2000 to be valuable had more intentions to work on barriers. However, these intentions have not formally been expressed in either organizational documents or media coverages.

Employment of the issue criteria of the theory of agenda-building showed that a large majority (between $56.4 \%$ and $82.0 \%$ ) indeed found the issue to be ambiguous, of social and temporal relevance, of a non-technical nature, and without precedent. A substantial proportion of professional organizations, and in more limited numbers consumer organizations and research institutes found however the issue to be socially irrelevant.

However, the theory would predict that the width of the score found meant that the issue has expanded onto the systemic agenda, and might be considered for policy at the institutional level. The issue expansion score has been related to the ratio between actions and no actions on barriers found. The relation was consistent: the better respondents scored on issue expansion criteria, the higher the ratio became. This would indicate that indeed the theory could hold, and that the criteria are appropriate. However, neither organizational documents showed that the issue played a significant role in organizations, nor did the media use the types and attitudes of communications supposed by the theory of agenda-building.

Regarding perceived opposition, a substantial number of respondents could see no opposition to Nota 2000 whatsoever; the document was seen to be totally unthreatening because of its symbolic, analytic, or vague character. Those who perceived opposition mentioned institutional care groups, professional organization and those responsible for financing the care system to be in opposition. However, these groups did not regard themselves as being in opposition.

Prevention policy has been analyzed as being far from factual comprehensive implementation. Respondents were willing to work on prerequisites for establishment of such policy non-committingly, or stated that they already were performing prevention activities. However, an activity is not yet a policy. Barriers for prevention policy were an 'indiwidualist' attitude expressed by respondents (people have to do it themselves') and the norion that government has as yet not made challenging policy proposals.

The same pattem has been revealed in the child accident prevention case. In terms of intervention types (cf. 3.2.2.3) respondents preferred educational measures and to a lesser extent legislative interventions. The Consumer Safety Foundation was generally fell to be the sole responsible organization for further lobbying and establishment of a comprehensive child accident prevention policy and related interventions.

The Dekker-report has been mentioned consistently in all Jprevious sections as a factor of major importance prevention further operationalization of Nota 2000. Respondents saw the status of Nota 2000 as being decreased by 'Dekker', the value of Nota 2000 was perceived to be less than the other report, action on Nota 2000 has been frustrated by it, it is mentioned to be a major barrier to Nota 2000 , issue expansion is felt to be less than when the Dekker report would nor have been published, and prevention policy is relatively underexposed in the Dekker report, which is finally perceived to be of more imminent concem than Nota 2000 . 
"In the light of "Dekker", Now 2000 is fully unfeasible."

"The sad thing about Nota 2000 is that the political

culture has changed between the phase of initiation and fur ther operationalization."

"The "craze of the day' nakes us interested in concrete matters like "Dekker."

"The status of Nota 2000 has completely been minimized by 'Dekker'."

"Nota 2000 is a magnificent piece for the library.

But it has been overtaken by 'Dekker" like a T-Ford by a Chevrolet Camaro." 


\section{DISCUSSION AND CONCLUSION}

In this final chapter we will draw conclusions on the feasibility of Dutch health policy. We will use all of the previous chapters, and one additional data set collected in the second Delphi round.

The latter will be described in 7.1. It will represent the perceptions by respondents of the feasibility of Nota 2000 on the basis of the above analysis, by own organizational preference, and by perceived collective preference. In 7.2 we will reject or accept the tentative hypotheses suggested in 4.4 . In 7.3 the conclusions will be presented, and research questions answered. "They will be discussed in 7.4.

Finally, in 7.5 we will address the adequacy of the theory of agenda-building employed throughout this investigation. Some modifications will be suggested.

\subsection{Perceived conclusions}

In the second Delphi round, respondents were asked to ewaluate the analysis presented and draw their own conclusion. Furthermore, they were also asked to indicate which type of conclusion the organization would like to commit itself to, and finally, they were asked to assess what conclusion the majority of respondents would favor.

The conclusions presented ranged from conditional feasibility, conditional non-lieasibility to unconditional non-feasibility (table 7.1). Results are presented below.

It is notable that a substantial number of professional organizations, NGOs, and research organizations do not choose a conclusion. The analysis itself apparently does not give a basis for organizations to take a decisive stand, although a relative majority (II) adheres to conclusion III.

As organizations, especially NGOs and bureaucrats commit themselves to future feasibility of Nota 2000 , but they correctly perceive that the majority of respondents does not adluere to that stance. It is noteworthy that consumer groups perceive their own standpoint to be the same as the one of the majority (limited future feasibility). The political offices are generally quite pessimistic about feasibility, while bureaucrats almost in consensus find that health policy will be regarded as partly feasible by the majority of respondents, although they would understandably commit themselves to the more positive conclusion I. 
Table 7.1. Perceived conclusions by respondents

Professionals

$\begin{array}{lllll}\text { analysis } & 2 & 1 & 2 & 2 \\ \text { organization } & 1 & 2 & 2 & 2 \\ \text { collective } & 0 & 2 & 1 & 4\end{array}$

consumers

analysis $\quad \begin{array}{llll}0 & 2 & 1 & 0\end{array}$

organixation $0 \quad 2 \quad 1 \quad 0$

$\begin{array}{lllll}\text { collective } & 0 & 2 & 0 & 1\end{array}$

NGOs

$\begin{array}{lllll}\text { analysis } & 2 & 0 & 1 & 3\end{array}$

$\begin{array}{lllll}\text { organization } & 1 & 3 & 0 & 2\end{array}$

$\begin{array}{lllll}\text { collective } & 1 & 1 & 1 & 3\end{array}$

political off.

$\begin{array}{lllll}\text { analysis } & 0 & 1 & 1 & 1 \\ \text { organization } & 0 & 0 & 2 & 1 \\ \text { collective } & 0 & 1 & 1 & 1\end{array}$

bureaucrats

$\begin{array}{lllll}\text { analysis } & 1 & 4 & 1 & 1 \\ \text { organization } & 4 & 1 & 1 & 1 \\ \text { collective } & 0 & 6 & 0 & 1\end{array}$

research

$\begin{array}{lllll}\text { analysis } & 1 & 3 & 0 & 2 \\ \text { organization } & 0 & 2 & 0 & 4 \\ \text { collective } & 0 & 3 & 0 & 3\end{array}$

pol. parties

\begin{tabular}{|c|c|c|c|}
\hline analysis & 1 & 0 & 0 \\
\hline organization & 1 & 0 & 0 \\
\hline collective & 0 & 0 & 1. \\
\hline analys is & 6 & 11 & 6 \\
\hline organization & 6 & 10 & 6 \\
\hline collective & 1 & 15 & 3 \\
\hline
\end{tabular}

\section{CONCLUSION 』}

The policy intentions of Nota 2000 are in the long run fully feasible. The barriers and opposition found in this investigation will disappear with the implementation of the recommendlations of the Dekker-Committee. After that, the intended policy from Nota 2000 can be made more concrete. The theory of agenda-building predicts that, under the presently analyzed conditions, there is sufficient public pressure to do so.

\section{CONCLUSION II}

The policy intentions of Nota 2000 are in the long run partly feasible. But even if "Dekker" is implemented to overcome the analyzed barriers and opposition, there will be few stimuli to really concretise the intentions. The "iron ring' and 'iron triangle' around Dutch health care will even post-Dekker remain intact. This frustrates full implementation of Nota 2000. 


\section{CONCLUSION III}

Nota 2000 will remain to be an intention document. Analytically, the memorandum is acceptable, but its political objectives are unachievable. Implementation of the recommendations of the Dekker-Committee will not change that; conflicting interests and trends in society which are a counter-force to Nota 2000 will remain to exist. The analysis according to the theory of agenda-building supports this view.

*: no answer

analysis: organization:

conclusion chosen by respondent on the basis of Delphi report conclusion chosen by respondent on the basis of own organizational commitment

collective: $\quad$ conclusion chasen by respondent to be the conclusion chosen by majority of respondents

When reviewing the overall perceptions of all respondents, limited feasibility of Nota 2000 is favored. Especially with regard to the perception of the majority choice, a large proportion of respondents views Nota 2000 to have limited feasibility. In 4.3.1 we have related "perception" to "reality" and noticed that organizational perception is reality. If the perception by publics is that Nota 2000 has only limited feasibility, our inference would be that in fact, the proposed policy will not be feasible.

In conclusion, we again have shown that feasibility of Dutch health policy will be limited, although there are quite a few organizations willing to commit themselves to more favorable feasibility options. Nevertheless, the Dekker report and the traditional barriers in the making of policy for Dutch health care frustrate the efforts to further concretize Nota 2000. 'This obserwation is in accord with the analyses in Chapter 6.

\subsection{Hypotheses}

In this section we will try to accept or reject the tentative hypotheses formulated in 4.4 . We will make reference to relevant sections in the previous chapters. For all "if-then" (causal) hypotheses we will have to keep two aspects of these tentative hypotheses in mind. First, we have only described qualitative tendencies in the previous chapters and sections, so that finalcausal relations are very hard to establish. Second, the theory of agenda-building we have employed comes as a "package deal': only it all hypotheses pertaining to the theory are consistently accepted or rejected, may a more validated conclusion be drawn.

Further, it will appear that -as neither of the hypotheses will have the possibility of rigorous testing- two types of inferences can be made: first, testing the hypotheses on the basis of the data acquired empirically in this investigation, and second, testing whether the hypotheses in themselves have been logically consistent and testable inferences of the theoretical framework developed.

Finally, it should be noted that the theoretical framework does not state temporal frameworks. There is no reference whatsoever to time frames in which the processes described are supposed to take place. Therefore, our concllusions as to acceptance or rejection of hypotheses are only relevant for the moment the empirical part of the investigation was concluded.

\section{Hypothesis 1:}

If public support for health policy is high enough, health policy will have a position on the systemic agenda, and therefore seriously be considered for operationalization, "mplemenia * tion and allocation of resources on the institutional health agenda.

The framing of this hypothesis does not seem to have been adequate. The hypothesis is made up of too many components ("public support', "systemic agenda", "institutional health 
agenda $)$ to draw a reliable conclusion on acceptance or rejection of this hypothesis.

However, we tend to reject the thrust of this general hypothesis. There seems not to be sufficient public support for health policy. The issue is acknowledged to be important, but not challenging organizations to actively support it (6.4). Such challenges would consist of adequately addressing organizational interests in health policy by the policy proponents. Especially professional organizations -the most powerful group in the health system- are, although not in blatant opposition, not in support of a fundamental reorientation of policy. Prevention policy and facet policy have at present no powerful advocates; prevention policy is by many understood to be the act of educational intervention. Some bureaucrats, and a substantial proportion of $\mathrm{NGOs,} \mathrm{would} \mathrm{be} \mathrm{advocating} \mathrm{this} \mathrm{subset} \mathrm{of} \mathrm{health} \mathrm{policy,} \mathrm{but} \mathrm{are} \mathrm{not}$ adequately challenged by the stans quo (6.8). Regarding intersectoral policy, the problems are as urgent. In 6.5 we have seen that intersectoral policies are not even considered as long as there are the ad-hoc problems pertaining to the siruation in Dutch health care: the dichotomy between planning and financing of health, the perceiwed non-challenging nature of the ministry of health, and failing politicall will.

Although the bureaucrats within the ministry of health are still working on operationalization of health policy (cf. Chapter 8, Epllogue), there is no powerful public support for such action.

\section{Subhypothesis 1.1:}

The perceived feasibility of Dutch health policy will be high if the issue is perceived to be little specific, of high societal relevance, with temparal relevance, litule technocratic, and with few or no historical precedents.

Although the issue of health policy seems to have expanded quite well (respondents score sufficiently high on the five issue expansion criteria mentioned, and per se the theory holds when related to degree of issue expansion and actions undertaken among respondents, $c f$. 6.6.1), the perceived feasibility of Nota 2000 is low. Thus, we have to reject this hypothesis. The various components of the theory of agenda-building come as a "package deal": issue expansion in itself is not sufficient. Adequate reflection of the issue in media coverage and organizational documents seems to be an essential prerequisite as well $(6.6 .2,6.6 .3)$.

Moreover, a high score on issue expansion criteria does not necessarily mean public support The content of the criteria can be acknowledged without the inference to be made according to the theory. This inference would have to be that, because of the problematic nature of the issue and the scores on issue expansion criteria, publics would collectively demand policy to be considered. This inference does not hold in the case of Dutch health policy.

\section{Subhy pothesis 1.2:}

The perceived feasibility of Dutch health policy will be high if the issue of health policy is known by all relevame publics.

Although Nota 2000 is known by all respondents in this investigation (6.3.1), and there has been extensive media coverage $(6.3 .3)$, feasibility is not perceived to be thigh. Therefore, this hypothesis has to be rejected as well.

In the feasibility and barriers section (6.5) we have seen that the various publics are still struggling too much with the present problems in the health care system, and are therefore not prepared to meet new challenges.

In other words, too much of their perceived and actual interest is linked to the power resources they get from the current system. Without a promise to get something "better" (i.e. a stimulus to their interests) wia Nota 2000 , attention to it would be an unnecessary diversion of attention for organizational resources.

Thus, although all relevant publics know about the issue, the imminent problematic nature of the care system demands nearly all attention. Only non-govemmental organizations, to a lesser extent bound to govemmental policies, have the capacity to reflect more adequately on 
the issue of health policy.

\section{Hypothesis 2:}

The mobilization model of the theory of agenda-buiding adequately establishes public support for health policy on systemic and institutional agendas.

In 2.3.1 we have investigated the initiation process of Nota 2000. It was shown that the initiation was largely an effort by ministerial bureaucratic offices. Further, Nota 2000 was launched as a discussion document to create wide public deliberations. We conclude that the mobilization model of the theory of agenda-building (4.1.3) has been employed. However, above we have shown that public support of the issue still is limited. Therefore, we have to reject this hypothesis. However, it may be possible that the process of creating public support is not yet finished (cf. Chapter 8), and that further public discussion will possibly establish larger public support.

Apart from that, in 2.3.3 and 3.2.2.1 we have reviewed that the mobilization model is probably the only option to reorient public health policy toward healthy public policy (the Netherlands' system being a 'bargaining society' in which mixed-scanning decision-making seems to be prevalent). Further development of the mobilization process may be expected to yield some results in the future. In spite of that, it is doubtful, judging from available data, whether feasibility will be increased to a comprehensive scale. This again refers to the temporal limitations described in the beginning of this section.

\section{Hypothesis 3:}

If the feasibility of Dutch health policy is perceived to be low by professional publics, general perceived feasibility will be low.

In chapter 6 we found a consistent tendency that professional groups do not support health policy. Although there is no powerful opposition lobby, professional groups take a distant attitude. This attitude influences perceived feasibility by other groups. Therefore, we have to accept this hypothesis.

The character of Nota 2000 causes neither vigorous support, nor blatant opposition. This is true for most organizations. Further discussion may induce either. In the next sections we will explore options to structure that discussion process effectivelly.

\section{Hypothesis 4:}

If thedia coverage is characterized by the persistent use of positive metaphors andior symbolism in relation to Dutch health policy, the feasibility of Dutch health policy will be high.

We have not found that media issue coverage has used metaphors or symbolism in a persistent way (6.6.3). Also, feasibility of Nota 2000 is perceived to be low. Therefore, we tend to reject this Hypothesis.

Again, the complex nature of the issue at hand maty be blamed for this relation: health policy does not easily lend itself to the use of metaphors. It is too complex to deal with in simple metaphorical ways. This would lead to the conclusion that the theory of agenda-building does not apply to broad societal policies. The issue as we have defined it in 4.2 may be too complex, and more advanced modes of issue exploration may have to be sought for.

\section{Hypothesis 5:}

If the media cover Dutch health policy consistently ower time, the feasibility of Dutch health policy will be high.

In figures 1 through 4 we have analyzed that media coverage on Nota 2000 has decreased over time. The issue therefore is not covered with temporal consistency and intensity. If the development described is extrapolated, attention by the media for Nota 2000 will in the end 
be minimal or non-existent. If there are tio firther developments of the discussion phase of the mobilization model, the issue of health policy will clearly disappear from the systemic agenda. A reversed version of this hypothesiss (If the media cover Dutch health policy inconsistenilly over time, the feasibility of Dutch health policy will be low ${ }^{2}$ should be accepted. Therefore, we will reject this hypothesis, whether or not feasibility is perceived to be light.

\section{Hypothesis 6:}

If there has been high perceived involvement among publics in the preparatory stages of Dutch health policy, the feasibility of Dutch health policy will be high.

From sections 2.3.1 and 6.4 it has become clear that involvement by relevant publics in the initiation process of Nota 2000 has been limited. Respondents perceived their role to have been limited as well (6.4). Feasibility of Dutch health policy is perceived to be low (6.5). Therefore, we tend to reject this hypothesis, although the causality in it may be doubtfull, and based on the assumptions we laid down in 4.3 .2 .

\section{Hypothesils 7:}

If publics perform actions in the light of Dutch health policy (Nota 2000), the feasibility of Dutch health policy will be high.

As we reviewed in 6.4, there was no distinct relation between involvement in the initiation process of Nota 2000 and actions taken. We furthermore remarked that, although actions may be activities to remove barriers for Nota 2000 , or activities in the light of the health pollicy framework of Nota 2000, that distinction is hard to make.

The number of actions has been limited, and shows no consistent relation to the degree of involvement in the policy process. Howewer, we found a correlation between the ratio actions/no actions and degree of issue expansion. A high issue expansion score, however, is not related to feasibility in this investigation. These observations lead to rejection of this hypothesis.

\section{Hypothesis 8:}

If the institutional health agenda is heterogeneous, the feasibility of Dutch health policy will below.

In 6.10 we summarized that the Dekker report has been confusing, frustrating and diverting respondents int their relation to Nota 2000. Clearly, the two issues have been competing for systemic health agenda status, and at the time of this investigation, the Dekker report seems to have had more imminent agenda status than Nota 2000. Yet, the Dekker recommendations have not been carried out either.

Although we do not have data on the imaginary situation where ceteris paribus only one issue was on the health agenda, we tend to accept the hypochesis. Nota 2000 has clearly been clouded by "Dekker". This is not to say that if Nota 2000 were the only issue, feasibility necessarily would increase. Data presented in 6.5 clearly show that the same barriers may be present for Nota 2000 and the Dekker report. They are the traditional ones in the Netherlands' health system. We will go into this matter to some more extent in 7.3 .

\subsection{Conclusion}

In Chapter I we have asked ourselves the following questions:

a. what are thrust and status of Nota 2000;

b. What do the relevant groups in Dutch society know of Nota 2000

c. what use do they make of its ideas in their own organizational policy making, thus laying a basis for inferring

d. whether full implementation of Nota 2000 is feasible. 
More concretely, research questions are:

- In which phase of the policy process is Nota 2000 ? What are the prospects for progress of that process?

- Which actors are and have been involved in that process? What is their role in the progress of the process?

- Is 'healthy public policy' a feasible option for Dutch health policy?

- What are the prospects for a prevention policy in the light of Nota 2000 ?

- How do partners in health perceive the feasibility of a specific healthy public policy for accidents in the home among children $0-5$ years of age?

In this section and the following we will answer these questions and balance them against the available body of literature. Further, the applicability of the theory of agenda-building to health policy is discussed.

With regard to thrust and status of Nota 2000 , no organization in this investigation was in vigorous opposition to the document. The status of Nota 2000 has clearly been blamed for that stance: it is too wague, and not challenging organizations. This does not mean that organizations are in support of it. Generally, organizations are awaiting further operationalization of health policy, and are in the meantime focusing their efforts on the more imminent problems of the 'Dekker' report.

Generally, respondents agreed that Nota 2000 marks a shift from instrumental policy toward content policy. A majority of organizations ackmowledges the value of this reorientation, although further implications are abided. It may be concluded that although Nota 2000 is not rejected, much effort has to be put into the establishment of satisfactory frameworks for further discussion of the precise thrusts of Dutch health policy, operational aspects of allocation of objectives and resources, and the weighing of consequences for warious organizations' interests.

Professional organizations especially are perceived to be in opposition by most organizations in the field. It is for this reason that most organizations reflect on the health care consequences of health policy (as professional organizations seem to be most influential in directing thrusts of policy), and that no powerful lobby seems to exist for prevention policy and facet policy.

Although some authors (Van der Werff, 1987) suggest that bureaucrats and consumer organizations should try to establish partnerships in order to strengthen prevention efforts, in this irvestigation we have found that consumer organizations are not particularly interested in the prevention issue, but rather in patients rights. Further, no strong role was found for the two prime prevention organizations, who seem to have been reactive and remedial rather than active and innovative in this realm. Again, some NGOs seem to be the most promising candidates for membership of the prevention lobby. Those within government with interests in adequate prevention policy should acknowledge these positions.

In the deliberations on further development of health policy these aspects have to be explored carefully; in the end, in 2.1 and 3.2 we have seen that health care is only one deterninant of health status. Respect for traditional organizational thrusts and openings for new approaches have to be explored. This could only be done in the framework of total health policy, thus also encompassing the discussion on structure and financing the health care system (Dekker report). This relation has to be clarified.

Very few organizations employ concrete activities in the light of Nota 2000. When referred to, Nota 2000 is most often used as a resource book or a legitimation for old activities. Some activities in the field of health promotion (the Healthy Cities Project, some projects of the Heart Foundation) are tailored to meet the ambiguous challenges of Nota 2000. No more than three or four organizations cooperate intersectorally in these efforts. 
When exploring the options for feasibility, no organization regarded Nota 2000 as it is to be unconditionally feasible. Data in the light of the theory of agenda-building support this view. Although the issue of health promotion seems to be expanded sufficienty well, this does not necessarily induce public support for the issue, and a demand for it to be placed on the instiututional agenda more rigorously. The mediating structures for issue expansion (media coverage and organizational documents) do not reflect such public support. Whether the theory per se does not hold, or the issue at hand does not lend itself for application of the theory will be explored in the next section.

The barriers found for feasibility of health policy most specifically pertain to the structure and linancing of the health care system. The problems outlined in 3.2 .2 are as yet not on organizational agendas. Nota 2000 does not seem to thave succeeded in clarifying the nonhealth care sector aspects of health policy among health sector workers. The ministry of health also has not succeeded in mobilizing support for such policy outside the sector. The respondent organizations perceive the structure and culture of the Ministry of Health to be unfortunate, and also, we have noted in 3.2.2.2 that there is no formal means for the ministry of health to get health targets and health consequences from other sectoral policies on the agendal of the Cabinet. In establishment of intersectoral cooperation outside the governmental realms this seems to be an important prerequisite.

With regard to the process of Nota 2000 and the involvement of organizations in that process we already have made some remarks. In 2.3 .1 we saw that only a limited number of organizations has been consulted for the development of Nota 2000 , and even then, contacts at that time seem to have been established on a personal and somewhat informal level. The consequence is that Nota 2000 may be read as a scientific resource book, an analytic piece signifying future trends, but less as an adequate reflection of organizational standpoints. It was initially intended for Nota 2000 to become a set of future-oriented health policies. In the finalization process, this status decreased until it could only be launched as a discussion document.

All organizations participating in this investigation were involved in the discussion sessions. However, discussion is non-committal, and very few organizations seem to have stressed formally the need for concrete follow-up, offering their participation in such a process. We found that most organizations, even within the health bureaucracy, and most prominently among the professional groups, seem to be unable to reorient their organizational objectives toward health policy ends. We expected, annong the publics in the health realm, that all organizations would have some "higher goal" in terms of "maintenance and improvement of health" and that the objectives of comprehensive health policy would therefore have a perfect fit with organizational objectives. However, this is not found. Organizational objectives seem to have been formulated first and foremost in terms of organizational survival, and only secondarily in terms of societal goals. This observation is in line with Weick (1979) who puts it even more blatantly: 'Organizing is not necessarily an attempt to reach some goal" (p. 18) even though we might go as far as speculating that something "as nebulous as survival, attainment of welfare or attainment of control over the environment is the "reason " why people unite." Nota 2000 has not induced organizations to reconsider whatever their reason for organizing has been.

Consequently, Nota 2000 has been 'bleeding to death' slowly from lack of organizational concern. This was illustrated by our analysis of media coverage $(6.1 .3)$.

Whether healthy public policy is an option for Dutch health policy is a question we have to answer negatively, at least at the moment. Present barriers are of a level preceding barriers for healthy public policy. Perceived barners pertain to structure and financing of the health 
care system, and not to issues of intersectoral collaboration and comprehensive health and prevention policy making. It might have been expected that professional organizations play a crucial role in keeping up these barriers, as the present status quo in the health care system seems to be serving their interests adequately to a certain extent: However, such a trend has not been found in this irvestigation. Although professional organizations are least in support of health policy, the intertwinedness of their interests with those of consumer organizations, bureaucrats and research organizations makes it hard to blame the professional groups solely (cf. the "iron circle' and 'iron triangle" around the health bureaucracy described in 4.1.1. "Critical appraisal"). The ministerial bureaucracy is blamed by many organizations for the little challenging efforts in the realm of health policy. However, the scope of work of the health bureaucracy is necessarily limited by the boundaries set by the "iron circle', and by contending intemal organizational interests between the "instrumentalists" and "healthists". It was remarked by many respondents in this investigation that the barriers for Nota 2000 will be removed by implementation of the Dekker recommendations. This may be true, but Cabinet has thus far not accepted the full package of Dekker recommendations, and has only focussed on those measures resulting in budget cuts. Yet, in the case where "Dekker" were going to be implemented comprehensively, the perceived barriers are not going to be removed, because they seem to be inherent to the composition and structure of the Netherlands' health care system, and modes of health policy and health decision making (cf. 7.4).

The prospects for prevention policy are somewhat better than for comprehensive healthy public policy. Our analysis (6.8) showed that a large majority of respondents was willing to work on the establishment of prerequisites for prevention, and that a considerable proportion was already carrying out preventive actions. However, a willingness to work on prerequisites may not be more than lip-service to public policies in which the importance of prevention is stressed time and again, while preventive activities not necessarily contribute to the establishment of prevention policy beyond the single-shot educational intervention.

We already noted that efforts in prevention policy have been reactive and remedial. A more powerful role in stimulating organizations to develop prevention policy frameworks and more structural approaches to health education, and a more visible and powerful mediating and advocating function of the National Health Education Centre may be recommended. Certainly there is a trend toward prevention. However, prevention as a concerted effort in a policy framework still seems to be rare. Nevertheless, prevention is promoted by government, though not supported rigorously with resources and objectives to achieve. Respondents in this investigation acknowledged that pattern. They called for more challenging incentives and facilitation from government, such as the AIDS-programme. Meanwhile, isolated prevertion activities continue to be carried out. That might possibly lead up to the establish ment of a comprehensive prevention policy. In this respect, prevention policy seems to be more promising than healthy public policy.

It should be noted, however, that there is not a strong lobby to place prevention on institutional agendas. Neither professionals nor consumer organizations press for the urgent need for prevention, maintaining that either sufficient efforts are carried out, or that patient services are more important. The non-governmental organizations seem to have the most (financial and organizationaly discretion to press for prevention policy.

The latter is supported by our analysis of a case on child home accident prevention. All respondents acknowledged that a child home accident prevention policy could be effective. Preferred interventions included educational intervention and legislation. However, with regard to the educational intervention, respondents found that it was not their responsibility to develop and implement those programmes, although generally they felt they could support it. With regard to legislation, they felt that there was no role for organizations in putting 
further pressure on government. For both purposes, it was felt, the Consumer Safety Foundathon was the prime responsible body.

The case illustrates two issues. "Prevention" indeed is non-committal, so that anybody can easily state it is important and should be done. Second, in the realm of intersectoral collaboration, a tendency may exist to establish single problem-oriented intersectoral bodies (rather that a comprehensive health council), so that organizations perceived to be irrelevant to the issue are left out. This may be a dangerous development if these single problem bodies have little power and cannot secure adequate participation by all relevant organizations; they may become token organizations preventing the establishment of health policy.

Finally, we will focus on the theory employed throughout this investigation. Is the mobilization model within the theory of agenda building a satisfactory tool for the study of health policy in the Netherlands?

On the one hand it may, on the other hand it may be not.

In 6.6.1 we have reviewed whether there was a relation between issue expansion degree and the ratio between actions undertaken in the light of Nota 2000 versus no action undertaken. Indeed such a relation existed. "This would indicate that the general theory of agenda-building holds. If this is true, the perceived and factual non -feasibility of Nota 2000 may be attributed to insufficient challenges of the issue at hand. Issue mediation by media coverages and issue reflection in organizational documents show that interest in the main thrust of Nota 2000 has been quite limited.

Yet, the producers of the document seem to have adequately followed the qualifiers of the mobilization model of the theory: Nota 2000 has been launched as a discussion document, and on many occasions the issue has been debated. This would lead us to conclude that either the strategy followed for the mobilization process has been inadequate, or that such a broad issue in a complex environment cannot be dealt with adequately within the framework of the theory of agenda-building.

The mobilization process has been followed quite well. It may be that the issue has not been challenging to the contestants in the field. We have reviewed that the Dekker report has to some extent frustrated attention to Nota 2000 . This leads us to conclude that the immensely complicated environment of health policies, made complex by almost simultaneous publication of two major documents, does not lend itself to be dealt with in the framework of the theory of agenda-building. The latter apparently is only applicable to policy environments which are homogeneous to a certain extent. The Ministry of Health has either failed to present its two-track pollicy in a consistent way, or the field of health in the Netherlands is too complicated to present policy issues consistently.

In 7.5 we will discuss theoretical implications of this study further.

\section{7,4 Discussion; empiricism}

Are our findings and conclusions in accord with other investigations and the available body of literature? The question is hard to answer.

In chapters 1 and 4 we have explained why this inwestigation had to have the nature of a qualitative exploratory inquiry: there is little experience with empirical studies of health policy, and if there were, they would thave to have been carried out in other countries, with other health policy cultures (i.e. styles of making policy which are clearly regulatory or (re)distriburive cf. Ch. 3). In a descriptive analysis of four national case-studies (Canada, Hungary, Ireland and the USSR) Milio (1988) describes the process of development of health-promoting policies and its implications. The general pattern is quite similar to the Netherlands' process: the policies were initiated under conditions of economic constraints by a small group of health bureaucrats and generally widely circulated as discussion documents. 
Bureaucrats used the "power of information' rather than the "power of regulation' to induce strategic discussions among interest groups. Thus they all are apparently consistent with the mobilization model of the theory of agenda-building (4.1.3). We will go deeper into the exact extent of the "power" of information in 7.5.2.

Coordination or monutoring bodies were set up to work on further implementation. Their authorities varied, ranging from ondering measures to suggesting activities. However, Milio finds that these policies had the potential for mobilizing previously less active groups such as community groups. Although Nota 2000 may have had that potential in the Netherlands, this investigation shows nothing of that pattern. Further, Milio asserts that the health policies were perceived as having provided a common language to thelp bind some what disparate units and programmes together within the bureaucracy' (p. 310). We have not found the effect of such common language. Nota 2000 is found to be too vague, and Dekker (1986) even acknowledges that inside the Department of Health there is a deep gap remaining between the ministerial "instrumentalists' and "healthists". This division is even more clouded by a continuous and rather unsuccessful series of reorganizations and reorientations of suborganizational turfs within the Ministry of Welfare. Health and Cultural Affairs (De Lange, 1989). According to De Lange, the Ministry -and especially the Department of Health- had to face rigorous pragmatism and the tyranny of the guilder due to these reorganizations and reorientations. This caused the Department to lose its final threads of contact with 'the field", according to De Lange. However, Juffermans (1982) and Van der Grinten (1987) assert that these contacts have never been very whole-hearted. However, in the changing culture within the Ministry, and also due to the shifting political culture since 1982 , it is felt -in retrospective- that putting energy into comprehensive governmental planning capacities for health was an utterly wasted effort (De Lange, 1989, p. 7). The organizational turbulence has also caused a lack of corporate culture within the Ministry, as well as within the department of Health. Although Dekker (1986) suggests a simple distinction between the instrumentalists and healthists, a former ministerial staff member (cf. 2.3.1) also blames the rigid and inert structure of the civil service for the absence of staff quality.

Finally, Milio finds that even less supportive groups in the countries of the case studies were stimulated to reconsider their activities. We have not found such a pattern unequivocally in The Netherlands. We would suggest that the failure of Nota 2000 to provide some groups with higher status, bureaucrats with a common language, and a reconsideration of activities may be attributed to the culture of health care policy making in the Netherlands.

Therefore, we can only reflect on the meager body of literature dealing empirically with the structure of policy making for health care in the Netherlands. Studies by Juffernans (1982) and Grunwald (1987), and reviews by Van der Grinten $(1985,1987)$ are exemplary. Juffermans (1982) has, as we have already reviewed in 3.1.1, described the chronic inertia of the state in the establishment of adequate health policies. Government, in his view "is only prepared to play a remedial and responsive role. Social-economic considerations and ani. entanglement in a multitude of pillared parastatal bodies and professional organizations (Van der Grinten, 1987) prevent government from operationalizing fundamental reorientations. The partly failing Memorandum on the Structure of Health Care (Structuumota, 1974), and the repealed Health Services Act (WVG) are typical examples of the limited capacities of govemment to present fundamental changes in health care structure.

Although health care is only one part of health policy, we have clearly shown in the above that as long as this former subset of policy is not managed unequivocally in the future, comprehensive health policy as suggested in Nota 2000 will not be feasible. Early in this investigation, some respondents and consultants suggested that implementation of the Dekker recommendations would remove these barriers. Initially, this was considered a reasonable assumption. However, in the follow-up on the Dekker report, Cabinet in its deliberations has only managed to focus on the immediate socio-economic gains of implementation of limited 
parts of the recorminendations (Van der Grinten, 1987), in spite of the principal preamble testimorial that the recommendations would have to be implemented as one package deal. Such a posture of Cabinet leads to pessimistic prospects for health policy.

Van der Grinten (1985) and Gninwald (1987) try to suggest ways of dealing with these inert and agglutinated modes of making health (care) policies. Three strategies may be employed to get out of the impasse: leave the matter to govemment completely; install of a group of independent consultants with wide-ranging responsibilities; and appeal to professional and societal groups to work on solutions.

In the above we have seen that none of these options singly has worked out. All three have their drawbacks. Van der Grinten (1985) suggests that the only way out is an optimal combination of these three: Government must have a certain responsibility, especially in the fielld of establishment of conditions for collective prevention. The consultancy group may be seen by some to be represented by the Dekker Commintee, although the latter had a distinctive liberal/right-wing signature. Finally, the societal appeal may have been stimulated through the mobilization and discussion procedures of Nota 2000.

However, these three strategies may be seen as having been some what isolated from each other. Although the secretary of state for health has repeatedly reassured that government was following a two-track policy approach (Dekker and Nota 2000, in a framework of already existing policies and regulations), field organizations clearly have not managed to integrate the tracks.

Van der Grinten suggests that a reorientation of policy might only be feasible (he assures that it is only a tentative suggestion; no-one seems to be able to come up with the "final" solution) if all three strategies are combined in one integral policy approach.

This approach would thus have to encompass a clear distinction between governmental responsibilities for (providing incentives for) collective prevention, an unequivocal and comprehensive follow-up on recommendations of the consultancy group, and a clear and challenging appeal on professional and societal responsibilities. All of these would have to be presented in a concise policy framewror.

Nevertheless, the apparent inert nature of government and the complexities of the multitude of parastatal bodies would require long-winded and careful deliberations with regard to objectives and comprehensive instrumentation of such a policy framework. The partners in health could be confronted with concrete health policy objectives in order to stimulate them to reconsider their organizations' work.

The culture of the Netherlands' health field does not allow for strict regulation by govemment of professional groups and lower governmental levells; in addition, the intramural care services have as yet a more powerful lobby than preventive services; new partnerships will thave to be established for further operationalization of especially the collective prevention and societal responsibility components of the framework. Van der Werff (1987) indicates that new coalitions will have to be stimulated to form, especially between bureaucratic offices and consumer organizations to press for the need of prevention.

The question remains whether such a strategy is feasible, and whether initiation of such a procedure would increase the feasibility of Nota 2000.

In Chapter 8 we will explore the latest developments in this realm, and review whether Nota 2000 is acquiring new impetus from these developments.

\subsection{Discussion; agenda-building reconsidered}

What are the theoretical implications of this study? In chapter 4 we have discussed the theory of agenda-building at length, and suggested that the mobilization model of that theory might have a fit with the reality of making health policy in The Netherlands.

Now the time has come to reconsider the theory and suggest modifications where necessary. 
The mobilization model of the theory has three major components:

a. The systemic expansion of the issue.

b. The mobilization process.

c. The nature of the issue.

In the following we will focus on these components. Further, we will examine what the theory and our suggested modifications may contribute to understanding the policy development process that can offer guidance to practitioners as well as analysts.

\subsubsection{Intrinsic and extrinsic issue qualities}

Throughout this study we have noted that 'health policy' is a hard to grasp notion. First, because it is an intrinsically complicated concept (cf. 3.2), and second, because of its functional conception, organizations (or, in agenda-building theoretical terms: publics) have a hard time identifying themselves with the concept as a whole (cf. 6.3 and 6.6).

A first conclusion to be drawn has thus to be that the theory of agenda-building has no generalizable value; there ane some issues (such as health policy) that do not lend themselves to application of the clear-cut components of the theory. Cobb and Elder assume, namely, that all issues over which conflict arises are likely to enter the systemic (and possibly institutional) agenda if only the five issue expansion criteria are adhered to. We have found this to be an assumption with only limited value. Clearly, the theory has to distinguish between the intrinsic nature of an issue, and its extrinsic nature.

Intrinsically, an issue can be complicated to an extent that the theory is not readily applicable; in such a case the issue does not lend itself easily to symbolic or metaphorical media coverage, and publics can not identify their own objectives and interests with the comprehensive issue. Health policy is an intrinsically complicated issue (3.2) where completely new realms have to be opened up to a traditionally confined policy sector. Intersectoral collaboration, integral intervention mixes, comprehensive health-oriented strategic policy sets, to name a few are alien notions to almost all of the traditional publics in the health sector. For an intrinsically complex issue, the extrinsic qualities (i.e. the perception by publics of its nature in terms of specificity, social and temporal relevance, technical nature, and available historical precedents, as well as the translation of the issue in media coverage) are not easily understood in terms of organizational relevance and will therefore not acquire effective issue expansion status. Although -as we hawe seen in this inquiry-issue expansion criteria have a sufficiently high score, an intrinsically complex issue with an extrinsically hard to cover nature will not necessarily follow the developmental route indicated by the theory.

Extrinsically complex issues are therefore those issues (such as health policy) over which conglomerates of publics have been contesting a substantial period of time without increas. ing the probability of resolution of (parts of) the initial problem.

In the case studied here, an intrinsically complex issue has been translated into an exirinsically complex affair. Other combinations are possible as well. We summarize these combinations in Figure 7.1, and suggest the applicability of the theory to the various combinations of intrinsic and extrinsic qualities.

It is clear that the lower row of Figure $7 . I$ indicates that if publics define the extrinsic quality of the issue to be unequivocal, the theory may be applied to the issue at hand. An intrinsically unequivocal issue may have difficulties acquiring complex extrinsic quallities, and we would not consider the theory applicable to that combination.

Specificity, the first issue expansion criterium (cf. 4.2.1) is of course heawily related to extrinsic qualities of the issue. However, specificity relates more distinctively to concrete relevance of the issue to organizational objectives (appropriateness for further action of the organization), while extrinsic quality refers to more abstract aspects of the issue in the policy context. Specificity may therefore be a function of extrinsic complexity.

However, as we have noted, some organizations find an issue vague and complicated beyond 
comprehension. The ore ganizations sem to have combined equivocal perceptions of the issue with its extrinsic complex quality.

In sum, 'healith policy" seems to be an "ssue not having an immediate 'fit' with the proposed theory. In the above have suggested a major modification of the theory; only extrinsically unequivocal issues of the types described in table 7.1 will lend itself to immediate application of the theory of agenda-buiding. The other yypes may be considered through the theoretical framework in a longer lasting iterative process; the qualities of the issue may be changing

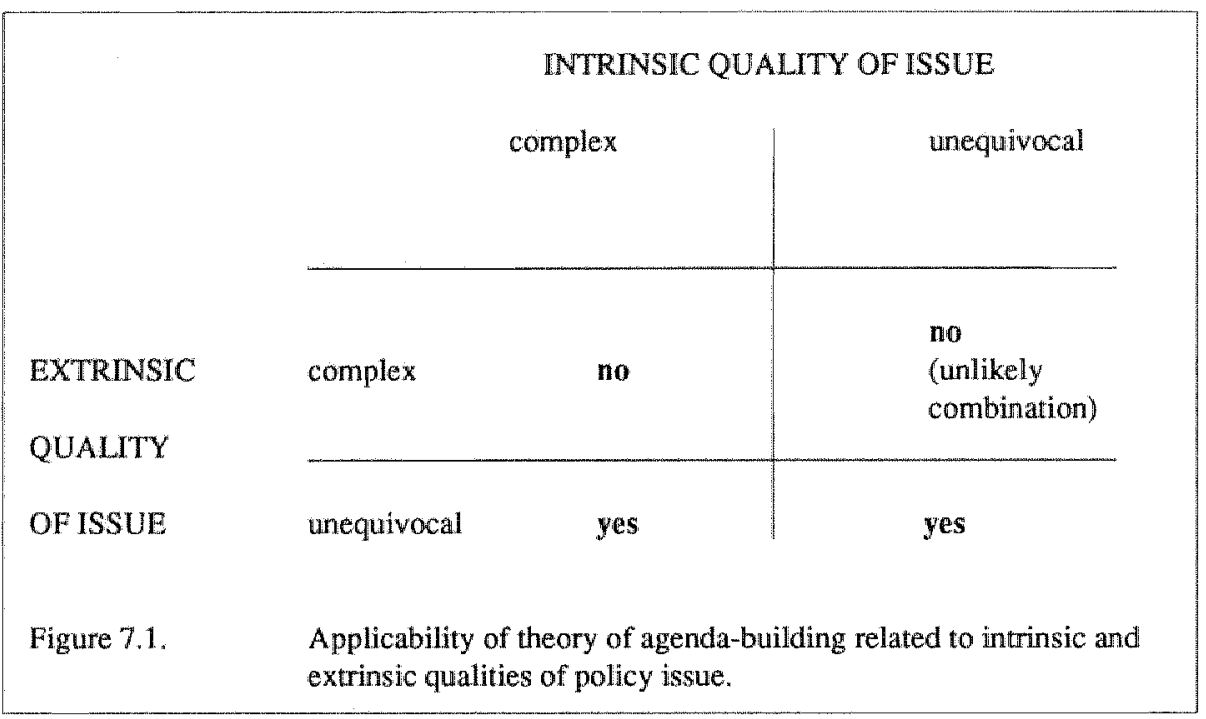

over time through substantial media coverage and a consistent effort the increase issue expansion by those with an interest in it and thereby acquire less complex qualities. When such a process is initiated by policy-makers, the mobilization process as presented by Cobb, Ross and Ross (1976) may be applicable.

Thus, the mobilization process suggested by the mobilization model of the theory might if carried out adequately, possibly lead to a redefinition of extrinsic qualities of an issue, in such that the issue may again be appropriate for application of the theory. We will focus on the adequacy of the mobilization process in the next section.

\subsubsection{The mobilization process}

Cobb. Ross and Ross (1976) have not formalized the qualifiers of their mobilization model of the theory of agenda-building. They suggest that the mere presentation of a debatable policy issue to various publics will lead to issue expansion, systemic agenda status, the call for formal policy, and finally, institutional agenda status and the probability of the issue to be addressed by policy-makers.

However, such a pattern with regard to health policy initiation has not been uncovered, neither in Milio's overview of four health policy case studies (1988), nor, to an even lesser extent, in our study.

The reason for this relative inertia by publics seems obvious: as long as partners in the policy game are not urged to reconsider their organizational objectives in the light of concrete but for the moment optional future getneral system changes, most organizations will not commit themselves to fundamental discussion regarding their own role in those changes. We have analyzed such a pattern in chapter 6 .

This observation would lead to a modification of the mobilization model; the issue presented 
to publics should have cenain characteristics, and if the policy-makers seriously want the issue to end up on the institutional agenda, the communication process between policy-: makers and stimulation of communication among publics should adhere to eartaila characteristics.

In this secrion we will focus on the process of communication for mobilization, and in the last section we will address issue characteristics.

Although organizational behatior may not readily be compared with human behavior, some commanication principles seem to be applicable to both types of behavior (Weick, 1979). As noted above, communication has to play an important role in the mobilization process of agenda-building. Cobb, Ross and Ross (1976) have not made this conponent explicit. Damoiseaux (1989) suggests that communication has to be active and intentional to render effect. Govemmental public communication ('overheidsvoorlichting') seems to have been reactive and remedial, and to a certair degree normative, in the past. Only recently the functions of governmental public communication have received substantial attention (Brinkman, 1985), and many knowledge gaps still have to be filled.

Govemmental public communication may be considered an explicit policy instrument, i.e. an instrument to be employed to reach set policy objectives (Katus \& Volmer, 1985). Further, Stappers (1985) distinguishes the publicizing, service and public relations functions of governmental public communication. In the realm of the theory of agenda-building alli of those seem to be playing roles in issue expansion, but particularly the publicizing and instrumental functions of communication are important.

Several reports have shown that intentional and integral approaches to governmental public communication may create public support of policies proposed, and effective participation of all partners in the specific policy realm, inside as well as outside governmental bureaucratic circles (Winsemius, 1985, Stoof, 1989). Van Riel (1986) furthermore shows that innovarive and creative use of less traditional intermediary echelons and organizations optimizes governmentall public communication.

In our modification of the mobilization model of the theory we would therefore suggest the following aspects pertaining to the conmunication process:

* governmental public communication has to be active and intentional, i.e., the objectives of the communication and mobilization process will have to be clear;

* the instrumental and publicizing functions of governmental public communication have to be integral parts of the policy process if bureaucrats choose to employ the mobilization model of agenda building:

* intermediary echelons and organizations outside the traditional policy realm (including composite organizations of QUANGOs) should be involved in the communication process and preferably express commitment to the process (not mecessarily its objectives or preferred outcomes).

Reflecting on our investigation two important observations will have to be made: first, neither of the communication principles formulated abowe have been expressed explicitly by the governmental health bureaucrats in the Nota 2000 time frame investigated (we will get back to this issue in chapter 8 , where we will suggest that in follow-up documents some of these principles are adhered to to a somewhat larger extent).

Second, these communication principles could have been carried out in the realm of health policy through employment of readily available structures, organizations and methods. The health policy sector is well-equipped with expertised health education and communication specialists; in addition, in 3.2.2.3 and elsewhere (De Leeuw, 1989) we have alleady expressed that health education types III and IV would have to address health issues in policy relevant terms. Such activities should be carried out along the lines of the above formulated communication principles. 


\subsubsection{The issue presentation}

In 7.5. I we have suggested that 'health policy' is not an issue to which the theory of agendabuilding may be applied easily. Moreover, in testing hypothesis 8 we have found that the policy agenda has to be homogeneous, $\mathrm{i}, \mathrm{e}$, that it seems counterproductive to place two apparently contradictory issues on the institutional agenda.

These observations have theoretical consequences. In this last section we will focus on issue presentation under assumption that the modified mobilization model (cf. 7.5.2) would have been employed adequately, and assuming that health policy is an intrinsically as well as extrinsically complex issue (cf. 7.5.1) in a heterogeneous policy environment (i.e., perceived to be competing for attention with the Dekker report, cf. 7.2 and 7.3).

If, under such conditions, agenda status is sought for the issue through a mobilization process, it seems that the issue has to have characteristics in addition to those responsible for issue expansion (specificity, societal and temporal relevance, non-technical and without precedents).

First and foremost, the issue will have to presented as having not anly societal relevance, but most importantly, as having orgamizational relevance. The most rigorous way of presenting such organizational relevance is coupling the issue with financial or status incentives and disincentives. In complex situations, with many intertwined and vested interests, the suggestion of such (dis) incentives may already be sufficient stimulus.

In cases of extrinsically complex issues in which the mobilization model is followed it might be worthwhile for the initiating bureaucrats to probe the possibilities to break down the issue into more manageable segments. However, in the realm of health policy the ecological interconnectedness of segments of the issue is crucial to an understanding of the problem. It could be suggested that the principles of health policy remain to be standing up, but that the issue could be segmented into age groups, disease categories, etc. A theoretical implication would be that issues may be segmented as long as the principles of the issue remain to pertain to the single segments. A separate statement on principles may be issued in addition. In case other issues are competing for attention on systemic and institutional agendas, an effort should be made to present all issues consistently and with credibility. Not only a statement in the sense that "nothing is wrong with seemingly contradictory issues' would be intelligent, but factual presentation of the compatibility of the apparently conflicting issues is also appropriate. In case issues indeed are incompatible, this approach does not seem feasible, and bureaucrats will have difficulty reconciliating the policy making process.

\subsubsection{The statics of agenda-building}

In 4.3.4 we already acknowledged that the theory of agenda-building -even when considering the mobilization model which seems to include dynamics of process- may be a rather static model presenting the state of affairs. The theory, we noted, leaves out conflict characteristics which may be supposed to be explanatory of that state of affairs. In addition, these characteristics may indicate the course of action to be employed through the mobilization model. By investigating these characteristics (relative organizational power and vested as well as perceived interests) we would be able to explain how agenda status and feasibility of Nota 2000 have been brought about, and furthermore, infer possibilities to increase agenda status and feasibility.

In fact, in this chapter we have regularly come across the notion of policy-makers having to "challenge" organizations, i.e. show them how their interests may (positively) be affected by implementation of the Netherlands" health policy.

Powerful groups perceiving that such a policy threatens their interests take a position of opposition or 'benign neglect' of Nota $2000(6.4,6.5)$. Less powerful groups, in addition, will not be stimulated to employ their resources for furthering Nora 2000 objectives unless 
there is a realistic outlook on success.

Therefore, an analysis of relative power positions and perceived as well as intendled (by Nota 2000 ) interest challenges is supposed to yield indications with regard to actions to undertake by the various publics to increase agenda status and feasibility.

Ideally, a relative power hierarchy would have to be established first. Van de Vrie and Van Elzakker (1988) have suggested a tentative power rating, although they assert that there is no information on how to proceed to establish the actual rating.

Juffermans (1982) has shown that any power rating of the Netherlands ' health system actors is superficial. Van der Grinten (1985, 1987) basically denounces such an effort because of the continuously shifting organizational priorities, intertwined responsibilitities and interests. simultaneous representation on advisory boards and QUANGOs, and an extremely wide range of contextual factors affecting power positions.

Neither Juffermans (1982), nor Schrijvers (1986), Grunwald (1987) or Van der Maessen (1987), all investigating the issues of control and innovation in the Dutch health care system, attempted or succeeded in establishing this much-needed power rating for the above reasons.

TABLE 7.2. Interest of respondent organizations

\section{Organization}

professional organizations

01

02

03

04

05

06

07

08

09

10

\section{Consumer organizations}

11

12

13

14

15

16

17

\section{Non-governmental organizations}

18

19

20

21

22

\section{Research organizations}

23

24

25

\section{Interest Nota $2000^{1}$}

promote (238)

promote $(239-241)$

promote (241-249)

promote $(207-222)$

neglect

promote $(132,247)$

neglect

neglect

neglect

threat $(207-221)$

promote $(21-48,214)$

promote $(229.235)$

promote (21:199)

promote (25-27)

promote $(229.235)$

promote (183-195, 229-235)

neglect

promote $(79-91)$

promote (92-103)

promote $(44-49)$

promote $(239-249)$

promote $(8-20,207-222)$

\section{Perceived}

interest ${ }^{2}$

promote

neglect

threat

promote

neglect

promote

threat

threat/promote *

threat

threat

neglect

promote

neglect

neglect

neglect

neglect

neglect

promote

neglect

neglect

promote * *

promote

promote (207-259)

threat

promote $(207-222)$

promote

threat $(207-221,258,272-302)$ threat 
neglect

threat

\section{Political offices}

29

30

neglect

promote $(28-34)$

neglect

promote

\section{Bureaucratic offices}

\section{1}

32

33

34

35

36

\section{Politicall parties}

37

38

39 promote $(1-381)$
promote $(8,340-344)$
promote $(1-222,312)$
promote $(1-381)$
promote $(1-381)$
promote $(12-17,311-322)$

promote

neglect

promote

neglect

neglect***

promote

*: shift in position between 1986 and $1989 / * *$ : although the organization welcomes Nota 2000 , no resources can be made available to support it / ***: no consultation requested; neglect perceived as result.

\footnotetext{
1 The interest described is the 'objective" evaluation of the intention of Nota 2000; figures between brackets indicate page numbers with the interests addressed.

For 1 and 2: 'promote' indicates Nota 2000 to be promotiwe for organizational interests, 'threat' to have negative effects, while 'neglect' indicates no expression of interests addressed

${ }^{2}$ Interst as perceived by respondent organization. Data from $\mathrm{Ch}_{n} 6$.
}

We recognize that such an effort may yield faulty, misleading and inappropriate indications of the position of actors, not only for the reasons mentioned (Van der Grinten. 1985, 1987), but also because "power" is a hard to measure construct.

Wrong (1979) describes two main approaches to the establishment of power ratings. The first is the reputational method, the second the decisional method. For neither method we have measurements or data available; neither the literature nor this investigation produced such data.

However, Wrong asserts that the bases of power are prestige, wealth, legitimate authority derived from office, personal appeal, and skill or specialized knowledge (p. 125). Nevertheless, he continues that such power bases not necessarilly constitute actual or potential power. Actual power depends on the power holder's reasons, motives and resources to exert the former.

In spite of all these difficulties, we have attempted to establish a power rating of the organizations initially participating in this investigation (Annex IX).

This rating into more and less power groups is brought in relation with the intentions of Nota 
2000 with regard to organizational interests, as well as the organizations' perceived interests in Nota 2000 (Table 7.2).

In tables 7.3-7.5 these relations are presented. Especially the columns with the "more powerful' are interesting for analysis. These organizations may supposed to play a role in hindering or stimulating efforts to increase feasibility of Nota 2000 . Cells $\mathrm{A}, \mathrm{G}$, and M are filled with those organizations which are powerful and may thave some interest in Nota 2000. Cell $\mathrm{M}$ represents those more powerful organizations which perceive their interests as intended by Nota 2000 . Therefore, they may be expected to play a most prominent role in furthering Nota 2000 . Addressing those by people working on enhancement of Nota 2000 is a first priority.

Howewer, our KAP- and Kwalitan-material shows that none of these five organizations has thus far employed resources to work on Nota 2000. Two of those are (indirectly) financed by govermmental monies. This means that, if the Ministry of Health also intends

Table 7.3 Relation between relative power position (Annex IX) and perceived interest relative power position more powerful less powerful

perceived interest

Nota 2000 promotive to the interests of organization

interests neglected

Nota 2000 threatens the interests of organization
A

$N=6$

C

$\mathrm{N}=5$

E

$N=5$
B

$\mathrm{N}=10$

D

$\mathrm{N}=10$

F

$N=3$

Table 7.4 Relation between relative power position and "actual" Nota 2000 interest relative power position more powerful less powerful

actual interest

Nota 2000 promotive to the interests of organization

interests neglected

Nota 2000 threatens the interests of organization
G

$\mathrm{N}=11$

H

$N=15$

I

$N=5$

J

$N=3$

K

$\mathrm{N}=2$
L 
Table 7.5 Overlap between tables 7.3 and 7.4

(i.e. organizations perceiving interests as intended by Nota 2000)

\author{
relative power position \\ more powerful \\ less powerful
}

interest

\begin{tabular}{|c|c|c|}
\hline Nota 2000 promotive & $\mathbf{M}$ & $\mathbf{N}$ \\
\hline to the interests of & $\mathbb{N}=5$ & $N=7$ \\
\hline & 0 & $\mathbf{P}$ \\
\hline interests neglected & - & $N=1$ \\
\hline Nota 2000 threatens & $Q$ & $\mathbf{R}$ \\
\hline $\begin{array}{l}\text { the interests of } \\
\text { organization }\end{array}$ & $N=2$ & $N=2$ \\
\hline
\end{tabular}

to further Nota $2000_{\text {n }}$ there are some options for financial incentives for those organizations to work on health policy. These incentives are presently not awailable.

Those "more powerfun" organizations which derive their monies from other sources (membership fees and donations) could be stimulated to employ their resources for Nota 2000 by other means. Either government could produce non-material incentives (such as increased status, created through invitations of those organizations to participate in networks relevant to health policy), or -when budgetary openings allow for it-financial incentives in the form of 'trugger subsidies' (cf. Milio, 1988).

The same strategies may be employed for those organizations whose interests are positively addressed by Nota 2000 , but do not perceive so (difference between cells $A$ and $G$ ).

Through an enhanced communication process (cf. 7.5.2 and 7.5.3) the advantages of Nota 2000 to the organization could be highlighted, while in addition incentives could be presented to those organizations. However, most of these organizations are found in bureaucratic circles, and are therefore already supposed to be in favour of health policy. Thus, also inside governmental bureaucracy a clesar challenge to work on Nota 2000 should be presented.

A second priority for those working on increasing the feasibility of Nota 2000 are those "more powerful" organizations whose interests are either neglected or threatened by Nota 2000 , or perceived to do $s 0$ by organizations (cells $C_{*}$ E, I, K and Q).

Those 'more powerful' organizations whose interests are actually threatened by Nota 2000 (cell $\mathrm{K}$ ) present decision-makers with a dilemma. Either the intended policy has to be modified (in the sense that the previous presentation of it is denounced), or sufficient counterforces have to be mobilized in order to get these "more powerful." groups not to oppose the policy. In the case where it concems the national intramural care institutions" organization, such a counterforce may be mobilized through (financial and status) stimuli to consumer organizations in their effort to advocate more humane and preventive services in these circles. Such a strategy, however, may not be expected to yield immediate results. It appears that especially non-governmental organizations (which are 'more powerful') perceive to be neglected in Nota 2000. Indeed, although the general intentions of Nota 2000 might be supportive of their work, their role is scarcely highlighted. Yet, our KAP- and $K$ walitan-analyses indicate that these organizations would be willing to work in the realm of 
health policy. In spite of the full independency of non-gowemmental organizations, suggesting total liberty in their policies, Nota 2000 in itself has not urged them to adopt it as it is.

More specific targets in their field of work, and further communication on the value of Nota 2000 for their objectives, may induce them to adopt the policy more rigorously. In addition; the subsidies already given by government to these organizations could be partly reallocated and labeled to Nota 2000 activities.

With regard to a third priority -addressing less powerful groups, which generally feel that Nota 2000 is promotive to their interests, or is neglecting them-, decision-makers may want to reallocate resources in order to give these organizations opportunities to follow up on Nota 2000 . However, it may not be expected that such a reallocation will cause a shift in power positions. Therefore, this approach deserves less priority.

However, a major obstacle continues to be the little powerful position (at least in our computation presented in Annex (X) of political and bureaucratic offices, as well as political parties. Although they seem to be the prime responsible groups for decisions as described (reallocation of funds, redefinition of policy, incentive-presentation, etc.), they have a little solid power base in the light of health policy. Their interests are of another levell than those of the other organizations.

The theory of agenda-building clarifies this. Professional groups, consumer organizations, non-govemmental organizations and research organizations ("field organizarions") together constitute the systemic agenda. In this, they may be assisted by governmental and political. offices. However, the latter in fact constitute the institutional agenda. Interests of political groups (offices, as well as parliamentary representatives) are less directly related to the content of Nota 2000, and more to the interests in their constituencies. Thus, only if "field organizations" call for policy (assisted by the incentives mentioned), these "institutional' bodies will consider the latter. Support and stimulus of the interests of field organizations by bureaucrats thus creates a call for policy, and in turn an interest among bureaucratic and political offices to work on health policy.

The situation described seems to be at deadlock: feasibility of Nota 2000 may -as describedbe increased especially by incentive-setting to field organizations (particularly financial incentives). Allocation of resources is generally done by political groups in power, and bureaucrats. They will only allocate such resources if they perceive their interests will be served by it. At this moment, such a thrust does not seem to be present. Resources will therefore not easily be reallocated. The only option seems that bureaucrats will reallocate resources which are put at their discretion. Such funds are generally limited. Increasing feasibility of health policy will therefore be a long-lasting process.

Research and dewelopment activities, finally, also direct the attention of those potentially interested. In accord with Nota 2000 , govemment published a health policy research memorandum in 1988 (Tweede Kamer, 1988). However, the memorandum did not present research institutes with fundamental shifts, i.e., they could perceive the memorandum as being 'business-as-usual'. Especially the specific pitfalls of healthy public policy (cf 3.3 ) are not addressed by the research policy: it is mainly content-oriented. It is impossible to infer further challenges to research institutes stemming from this research policy, as no data were acquired on that issue in this studly.

\subsection{Research implications}

What are the implications for health policy research stemming from this investigation? It is possible to structure this section along the following (interrelated) lines: implications for research on the contents of health policy on the one hand, and implications for research on the process bringing about health policy on the other. Further, it would be possible to formulate research implications with regard to implementation of health policies; we have summarized these already in 3.2.2.1 and 3.2.2.2. 
Reyarding the contents of health policies, we have sufficiently well demonstrated that mere presentation of a rationale for health policy (cf. a Nota 2000) including classical epidemiological, demographic and structural data is not enough to appeal to the variety of groups to be involved in health policy. Apart from investigation of processes clarifying current contents of health policy to those groups in order to bring the former about, research on the contents themselves is urgent. Abelin (1986) has described the indicators for health promotion (i.e.: the contents of health policy). They include societal ${ }_{1}$ community and individual levels, and specifially indicators in realms of health balance (e.g. subjective well-being), health potential (e.g., physical function capacity), health resources (accessibility of resources and services), health promotion (e.g., existence of appropriate legislation), liwing conditions (e.g., literacy and employment rates), and environmental health challenges (waste load, etc.). Present research in the field of health policy does not seem to have produced or used these indicators, particularly not at the cormmunity level, which is believed to be of urmost importance (De Leeuw, 1989, pp. 95-97). Future reserach should be aimed at production of these data, as well as the reformulation process of these data into societally relevant information. Further, on the issue of contents of health policy, the notions of intersectoral and integral interventions in health policy need dire attention. The relevance and synergistic effects of fine-tuned interventions (facilitation, regulation, education) have hardly been investigated empirically. The call for intersectoral cooperation (facet policy) may be found to be attractive, but we have not found concise frameworks from which appropriate groups could derive their particular responsibilities and interconnections. This field needs research attention as well.

The processes bringing about health policy have been the prime subject of this exploratory investigation. Three fields for further investigation of these processes are distinguished: first, the realm of interest and power constellation inquiry; second, the area of communications research; and thind of course further exploration of the applicability of the theoretical framework presented in this investigation including the modifications suggested in this chapter.

With regard to interest and power constellation inquiry, we have met extensive problems. It should be stimulated to proceed to investigate power positions in relation to factual and perceived interests for health policy in general, and health policy developments in the Netherlands in particular. Literature on inter-and intra-organizational relations and political sociology may enable future researchers to establish more appropriate methods and methodologies to investigate these. As we have recognized that 'power' is always contextual, such research should adequately pinpoint the problematic nature of health policy and preferably. as we suggestad in 7.5 .3 , investigate a limited set of health policies to which the principles of the whole remain to apply.

Communications research is a second important field of inquiry. We have found this in 7.5 , an observation endorsed by Milio (1988). Application of communication principles as presented in 7.5 .2 should be put to a test, while further research into the communication capacities of various groups (i.e. access to the media, possibilities to manipulate source, medium, message and/or receiver, etc.) should be included to shed further light on the function of communication. Specifically, it could be suggested to test whether social psychological theories of behavior change apply to organizational communications as well. Finally, reiterating word on method and methodology already presented in chapter 5 . Qualitative inquiry at present seems to produce the most challenging and promising data on health policy development. However, we would urge to proceed to develop effective combinations of qualitative and quantitative approaches to research in order to produce higher degrees of validity and reliability in this type of inquiry. 
Abelin, T. (1986) Positive indicators in health promotion and protection. World Health Statistics Quarterly, $39(4)$, pp. 353-364

Brinkman, L.C. (1985) Toesprak bij de opening van het symposium Actuele vraagstukken van de overheidsvoorlichting. pp. 5-10 in: Katus, J. \& L.C. Beets (eds.) Actuele vradgstukken wan de overheidsvoorlichting. Coutinho, Muiderberg

Cobb, R., J-K. Ross \& M.H. Ross (1976) Agenda-building as a Comparative Political Process. The American Political Science Review, 70, pp. 126-138

Damoiseaux, V.M.G. (1989) Gezondheidswoorlichting. In: Gent, B. van \& J. Katus (eds.) Voorlichting: theorieën, werkwijzen en terreinen. Derde druk, Samsom, Alphen a/d Rijn (in print)

Dekker, E. (1986) De realisering van gezondheidsbeleid: een kwestie van marges. Ch. 5, pp. 74-90 in: Dekker, E. \& B. Wijnberg (eds.) Gezondheidsbeleid over de grenzen van de gezondheidszorg. Reeks gezondheidsbeleid, deel 1, Samsom Stafleu, Alphen a/d Rijn

Grinten, T.E.D. van der (1985) Rite of ratio; de beleidsstructuur van de gezondheidszorg. $\operatorname{TSG}, 63(16), \mathrm{p} .699$

Grinten, T.E.D. van der (1987) Ordening van de gezondheidszorg. Een beschouwing naar aanleiding van het advies van de commissie Dekker. TSG, 65 (21), pp $678-681,694$

Grunwald, C.A. (1987) Beheersing van de gezondheidszorg. Dissertatie Rijksuniversiteit Utrecht, VUGA, Amsterdam

Juffermans, P. (1982) Staat en gezondheidszorg in Nederland. Socialistiese Uitgeverij Nijmegen, Nijmegen.

Katus, J. \& W.F. Volmer (1985) Ontwikkelingslijnen van de overheidsvoorlichting. Coutinho, Muiderberg

Lange, W. de (1989) De Wording van WVC. Binnenlands Bestuur Management, 2 (2), pp. 6-11

Leeuw, E de (1989) The Sane Revolution. Van Gorcum, Assen/Maastricht

Maessen, L.J.G. van der (1987) Transformatie van de gezondheidszorg in Nederland tussen 1974 en 1987. Van Gorcum, Assen/Maastricht

Milio, N. (1988) Strategies for health-promoting policy: a study of four national case studies. Health Promotion - An Intemational Joumal, 3 (3), pp. 307-311

Riel, C.B.M. van (1986) Overheidswoorlichting en intermediaire kaders: een studie naar de intermediaire rol van organisaties in het woorlichtingsproces van de centrale overheid.

Eburon, Delft

Schrijvers, G. (1986) Regrionalisatie en financiering van de Engelse, Zweedse en Nederlandse gezondheidszorg. De Tijdstroom, Lochem

Stappers, J.G. (1985) De functies van overheidswoorlichting. pp. 47-54 in: Katus, J. \& L.C. Beets (eds.) Actuele vraagstukken van de overheidswoorlichting. Coutinho, Muiderberg

Stoof, J. (1989) VROM lanceerde Vierde Nota wia nieuwe methode; directe belanghebbenden kregen actieve rol toegemeten. Binnenlands Bestuur Management, 2 (4) " pp. $57-59$ 
Structumota gezondheidscorg (1974) Tweede Kamer, zittingsjaar 1973-1974, 13012, nrs. $1-2$

Tweede Kamer (1988) Nota Onderzoksbeleid. Tweede Kamer, zittingsjaar 1987-1988, kamerstuk 20423 , nr. 2

Vrie, R. wan de \& A. van Elzakker (1988) Gezondheidsbeleid en machtsversnippering. 1: gezondheidsbeleid en de verdeling van macht. Medisch Contact, 43 (38), pp. 1119-1122

Weick, K.E. (1979) The social psychology of organizing, Addison-Wesley, Reading Mass.

Werff, A. van der (1987) Facetbeleid: partners in gezondheid. Ch. 6, pp. 45-56 in: De Nota 2000: Theoretische en praktische aspecten van gezondheidsbeleid. Rijksuniversiteit Groningen, Groningen

Winsemius, P. (1985) Communicatie en overheidbeleid. pp. 71 -84 in: Katus, J. \& L.C. Beets (eds.) Actuele vraagstukken van de overheidsvoorlichting. Coutinho, Muiderberg

Wrong, D. (1979) Power. Its forms, bases and uses. Basil Blackwell, Oxford 


\section{EPILOGUE: HEALTH POLICY FOLLOW-UP}

Usually, new material on an issue becomes available after an investigation has been concluded. In chapter 1 we have noted this.

In this chapter we will review formal developments in the realm of health policy in the Netherlands beyond the chronology presented in chapter 2. In 8.1 these developments are presented, and in 8.2 we will tentatively test whether the suggestions of chapter 7 are followed up on.

\subsection{Collective Prevention Act and Core Document}

On December 19, 1988, a proposal for a Collective Prevention Act (WCP, "Wet collectieve preventie volksgezondheid', Tweede Kamer, 1988) was sent to Parliament. The Act would establish the role in collective prevention of municipalities and municipal health departments (MHDs) -or, formally, the Basisgezondheidsdiensten (primary health departments); there is some superficial debate over the naming of local level collective public health units-.

In the explanatory memorandum to the WCP explicit reference is made to Nota 2000 and its notions of prevention and facet policy. Also, the Healthy Ciries Project (il WHO-project in the framework of the Health Promotion Programme) is presented as an exemplary case for the Act.

The municipal and city councils are given the responsibility to promote the establishment and continuity of collective prevention as well as the tuning of collective prevention programmes to health care services. The councils are supposed at least to

1. acquire insight in the health situation of the population through epidemiological anally ses;

2. guard health aspects in all local decisions and policies;

3. promote hygiene and psycho-hygiene;

4. contribute to the establishment, implementation and coordination of prevention programmes, including health education.

In the explanatory memorandum the guiding principles of Nota 2000 in the establishment of such programmes are reaffirmed. However, in the initial parliamentary deliberations, representatives asked for explicit reference to the warious determinants of health as laid down in the Nota 2000 Health Basis Model (figure 2.3). In his reply (Dees, 1989), the secretary of state for health stated that the use of the model was supposed to be obvious, as "prevention' relates to all of these determinants. The explanatory memorandum indeed is cleat on the 
appropriateness of local facet policy $(\$ 2$.

Implicit to the Act, though, is the pertaining govemmental ideology to decentralize responsibilties. In the initial parliamentary debate, some concems were voiced with regard to the specific responsibilities given to local authorities. The efficiency of local authorities in the establishment of local facet policy was doubted, as well as the efficiency of local (mammacarcinoma) screening programmes. The secretary of state, in his rebuttal, nevertheless confirmed that decentralization of responsibilities was to be pursued. Kaasjager, Van der Maesen and Nighus (1989) show that such an approach indeed may be fruitful, though encountering many paradoxes.

The Core Document ('Ontwerp-Kemdocument Gezondheidsbeleid', also referred to ass 'target document", WVC, 1989a) presented by the Ministry of Health on April 5, 1989, clarifies some of the conceptual problems relating to the content of collective prevention and the role of national and local govemments, as well as other groups in society.

The Core Document is intended to synthesize Nota 2000 and discussions that have sprung from it the Dekker recommendations, and the general thrusts of governmental policy making, and present these to the partners in health for further discussion. In spite of such a broad scope, the Core Document itself contains only 56 pages. Background documents discussion pieces as well-accompany the Core document. They contain the foundations, explanations, and further operationalizations of the proposals in the Core Document.

The Core Document teframes some of the issues presented in Nota 2000. The notion of denial of the importance of health care services, so perceived by health care deliverers (cf. chapter 6 and 7 , and Dekker (1989)), is refuted. Health care now is put at the center of health promotive activities. Further, the importance of local facet policy and prevention beyond the educational intervention is reaffirmed. In the document it is acknowledged that government is retreating from regulation in the field of health care (stimulating market mechanisms with set limitations), whereas it should have an explicit role in the realm of collective prevention (WCP). However, the instrumentarium needed for strengthening prevention policy as well as facet policy still seems to be weak. Especially establishment of prerequisites (in financial and facilitating terms) for creation of such an instrumentarium remains at the same minimal level presented in Nota 2000. The financial consequences of establishment of health policy are dealt with in a marginal chapter of one page without concrete suggestions (WVC, 1989a, p. 48). It is acknowledged in the Core Document that government has very limited capacities to restructure its funding capacities within the prevailing govemmental objectives. Funding of health policy, it is said. "may expected to take place by the parties in the field". Specifically, the background documents deal with health policy regarding cardiovascular diseases, mental health, health care policy, prevention policy, local health policy and education and training ('Basisdocument', WVC, 1989b); the elderly and prevention (WVC, $1989 \mathrm{c}$ ); rheumatism policy (WVC, 1989d); suicide prevention (WVC, 1989e); prevention in mental health (WVC, 1989 ); cancer control (WVC, 1989g); accidents and traumatology (WVC, 1989h); epidemiology and informatics (WVC, 19891); and legal information services in health care (WVC, 1989j).

The procedure for these discussion documents is, that the suggested targets, and proposed roles and activities of societal organizations to pursue those are presented in a comprehensive framework (Core Document (WVC, 1989a) and Base Document (WVC, 1989b)). Targets and roles are subsequently discussed with those groups concemed with the specific area. The outcomes of the discussions will be reflected in a final version of the Core Document, to presented to parliament by the end of 1989 (cf. the request of parliamentary representatives to produce concrete follow-ups on Nota 2000, 2.3.3).

To structure the discussions, the Core Document presents potential participants with the following questions (WVC, 1989a, p. 49):

1. Is the analysis of health situation and its determinants presented correct? 
2. Are the targets presented, to your knowledge, realistic and therefore foasible?

3. Which (sub)targets are within the domain of your organization?

4. Which (sub)targets are for your organization realizable in the present situation?

5. Which -preferably described as concisely as possible-prerequisites are necessary for you to adopt the targets set?

6. What instrumentarium would be needed for that?

The discussions on these questions and their outcomes are supposed to give feasible policy options, to be presented to parliament, where final decision-making will take place.

\subsection{Core Document: increased feasibility of health policy?}

Our suggestions for actions to increase feasibility of health policy in the Netherlands. presented in chapter 7 , centered around three main themes:

1. an enhanced communication process $(7.5 .2$,

2. adequate issue presentation $(7.5 .3$, );

3. stimulation of interests of more powerful groups (7.5.4, ).

In this section we will review whether, and to which extent, the Cone Document and its discussion documents represent the characteristics suggested.

First, however, it should be noted that the mere publication of such a set of documents constitures increased feasibility. It shows that the issue of health policy continues to be the institutional agenda, and that bureaucrats still employ their resources to evoke public support for it.

\subsubsection{Enhanced communication}

In chapter 7 , we noted that gowemmental public communication may be considered to be more effective if it is active and intentional, if it is an integral part of policy. and if intermediary echelons are involved in the process.

With regard to the Core document, all of these characteristics seem to be available. The intentions of the Core Document are clearly stated (questions 1-6, above), while the procesis is an integral part of health policy coming up on the parliamentary agenda. Furthermore, intermediary echelons are stimulated to participate in the communication process. Various networks outside the traditional partners of communication (Healthy Cities, epidemiologists, etc.) have been invited to co-organize discussion sessions to answer the questions pased.

\subsubsection{Issue presentation}

In 7.5.3 we have presented some suggestions as to the ways in which issues should be presented to groups having to participate in health policy formulation and implementation. The first characteristic of issue presentation is that the issue is not only supposed to have societal relevance, but particularly organizational relevance. In this respect, the Core Document has improved on Nota 2000. In its targets and roles, many organizations are mentioned as being invited to be partners in further establishment of health policy. Review of the document reveals that it deals adequately with all organizations which should play roles in health policy. However, no factual challenges are posed to these organizations, as suggested on p. 200. They are only requested to reframe the targets presented in the Core Document in their own terms, but there do not seem to be financivil or status incentives to induce factual roles (cf. 8.2.3). However, it could be expected that parliament after its deliberations would include such (dis)incentives when establishing the final policy document toward the end of 1989 . At the moment, though, the status of the Core Document in this: respect does not differ from Nota 2000.

Our second suggestion was to break down the issue of health policy into manageable segments. This has been done more or less adequately, as described in 8.1. The Core Document presents the main thrusts and intentions of health policy, while specifics are 
addressed in the set of discussion papers. Our theoretical addition ("issues may be segmented as long as the principles of the istue remain to pertain to the single segments") has largely been followed, making health policy a more reviewable effort. Nevertheless, there are some inconisistencies with regard to terminology use in the various background documents. Prevention is not taken in the unequivocall meaning given to it in the Core Document. In some of the discussion docurnents, prevention specifically is taken to mean thealth education" (WVC, 1989e). This may cause confusion.

Finally, we have suggested that all (apparently competing) issues should be presented consistently and with credibility. Explicitly, the Core Document aims to be the synthesis of all previously perceived inconsistent policy frameworks (p. 4). However, to some extent the document contains hollow phrases with regard to the further development of these frameworks. This is particularly due to the unfinished decision-making procedures regarding the Dekker recommendations and the Collective Prevention Act, as well as Cabinet having ended its term in May, 1989. New elections in September, 1989, and consequent formation of a new Partliament and Cabinet will have to create new options for further clecision-making.

\subsubsection{Interests of more powerful groups}

Finally, we have suggested that feasibility of health policy may be increased through specific addresses of the interests of more powerful groups. It seems as if the more powerful groups indeed are addressed by the Core Document. They have been invited to participate in the discussions, and their interests are put more at the center of health policy (health care, oppottunities for $\mathrm{NGOs}$, etc.).

However, we have suggested some strategies to challenge their interests. These included material and immaterial incentives. The Core Document, as noted, has a very weak financial paragraph, and the wordings of the various targets and roles in health policy are framed little imwitational ("The development of home care technology has priority', target 4, WVC, 1989a, p. 32; 'integration of home care and family care', role for societal organizations, WVC, 1989 a, p. 32).

Thus, in spite of many good intentions, the prerequisites for an implementation instrumentarium in this realm seem to be virtually non-existent. Our findings (chapter 6) and discussion (chapter 7) -supported by wiews in STG (1989)- have shown that mere goal-setting and tertative description of organizational roles will not induce positively shifting organizational positions toward health policy.

Virtual health policy in the Netherlands under the above conditions has very limited feasibility. 


\section{References}

Dees, D.J.D. (1989) Brief aan de voorzitter wan de Tweede Kamer der Staten-Generital: wetsvoorstel collectieve preventie volks gezondheid (20977). Memorie van antwoord en nota van wijziging. DGVgz/AGZ/BGZ nr. 110975. Rijswijk. 21 juni 1989

Dekker, E. (1989) Gezondheidsbeleid en de Nederlandse gezondheidszorg. Ch. 26, pp. 297308 in: Maas, P.J. van der, A. Hofman \& E. Dekker (eds.) Epideniologie en gezondheidsbeleid. Reeks Gezondheidsbeleid 3, Samsom Stafleu, Alphen a/d Rijn

Kaasjager, D.C., L.J.G. van der Maesen, H.G.J. Nijhuis (1989) The New Public Health in an Urban Context. Paradoxes and Solutions. WHO Healthy Cities papers no. 4. FADL, Copenhagen

STG (1989) Reacties Kerndocument. Tijdschrift Sociale Gezondheidszorg, 67 (10), pp. $358-$ 364

Tweede Kamer (1988) Regels met betrekking tot collectieve preventie op het gebied van de volksgezondheid (Wet collectieve preventie volksgezondheid). Vergaderjaar 1988-1989, 20 977, nrs. $1,2,3$

WVC (1989a) Doelgericht veranderen. Ontwerp-Kerndocument Gezondheidsbeleid voor de jaren 1990-1995. Discussienota. Rijswijk, april 1989.

WVC (1989b) Discussienota Basisdocument bij het ontwerp-Kerndocument Gezondheidsbeleid. Rijswijk, april 1989

WVC (1989c) Discussienota veroudering en preventie. Rijswijk, april 1989

WVC (1989d) Nota Reumabeleíd. Tweede Kamer, vergaderjaar 1.988-1989,21010, nrs. 1-2 WVC (1989e) Discussienota suïcidepreventie. Rijswijk, april 1989

WVC (1989f) Discussienota Preventie Geestelijke Volksgezondheid. Rijswijk, april 1989 WVC (1989g) Discussienota Kankerbestrijding. Rijswijk, april 1989

WVC (1989h) Discussienota Ongevallen en Traumatologie. Rijswijk, april 1989

WVC (1989i) Discussienota Epidemiologie en Informatice. Rijswijk, aprill 1989

WVC (1989j) Wettelijke informatievoorziening in de gezondheidszorg. Rijswijk, april 1989 


\section{SUMMARY}

'Health policy' is a comprehensive type of policy aimed at maintenance and improvement of health by addressing environmental, hereditary, lifestyle and health care system factors that affect health.

Since the early 1970 s the call for such a policy, beyond control and regulation of health care facilities, has been growing. Since the late 1970s the World Health Organization has stimulated the formulation of national health policies. The Netherlands were among the first countries to publish a document on the issue: Nota 2000 ("facts, considerations and policy intentions').

Central questions of this investigation focussed on the processes bringing aboul an operational health policy in the Netherlands, and on the perceptions by partners in these processes of the statis and problems of such policy. Answering these questions, the prospects for a feasible health policy may be determined.

In chapter 1 the rationale for the inquiry is presented, as well as the lay-out of this book. Specific research objectives are presented in 1.3.

In chapter 2 the historical material leading up to Nota 2000 is given. This material includes the writings by Henrik Blum. He gave us the force-field and well-being paradigms of health presented in a molel as the rationale for development of virtual health policies. The Canadian Lalonde report is the first public document in which such policies are advocated. Its premises are discussed, and although the landmark report has not immediately caused a shift in policy priorities, its importance for the further devellopment of health policy is recognized. Various WHO programmes have brought new impetus to health policies, and they are discussed in 22. Their main common thrust is the recognition that medical care systems can only partly be held responsible for the health of populations. In diminishing stages of abstractness the Primary Health Care ideology, the European Health for All plans, and the health promotion progranme are discussed.

Development of Nota 2000 may be placed in the latter realm. The chronology of its development shows that health policy has had limited priorities, and that creation of Dutch health policy is anatter of compromises. The more or less ambiguous character of the piece, described in 2.3.2, reflects these. Also, the formal discussions following its publication show an ambiguity among the partners in health: although the general objective of Nota 2000 is commended, most actors regard the propositions and concrete consequences utopian to less or larger extents. 
In chapter 3 the state-of-the-art in academic writing about health policy is presented. In WHO jargon, the term "healthy public policy", as opposed to "public health policy", is coined. Differences are explored, where the more traditional "public health policy' (setting the stage for healthy public policy) is analyzed in 3.1. Public policy for health seems to have been suffering from a proverbial inertia in state action. In this climate corporatist tendencies grew, leading to an entangled and complicated intertwined health system.

The largelly anglo-saxon body of literanure relating to health promotion and health policy is reviewed in search for the problems these approaches are facing. Specifically, mixedscanning and mixed bottom-up/top-down approaches to policy development and implementation are favored. Intersectoral cooperation, a prime characteristic of health policy, is discussed. Seven barriers to coordination are listed, but no concise theoretical framework seems to be available for the study of the phenomenon. Integral intervention mixes, line-tuning legislation, facilitation and education are discussed, but here as well, no empirical studies on the issue have been found. Finally, in the crucial realm of measurement and evaluation of health policy, effective combination of qualitative and quantitative indicators for health policy on longitudinal scales is suggested.

In chapter 4 a theoretical framework is developed, based on the theory of agenda-building. The theory outlines processes and factors leading to the development of formal policy. It contains three major elements: 1 the existence of different publics (i.e. interest groups) contesting over issues on a 'systemic agenda' to be considered for policy on the "institutional agenda ; 2 the use of media and symbolism in the expansion of an issue from a small circle of groups toward a larger one, thereby increasing the probability of the issue to become policy; and 3 the character of the issue as perceived by these groups. If an issue is perceived to have an equivocal character, to be of social relevance, relating to the long term technical, and having few historical precedents, the probability will be higher that the issue will be addressed through policy.

Three models are suggested: the outside-initiative model (in which societal, or 'systemic' groups are held responsible for pressing an issue on the formal policy agenda), the insideinitiative model (where policy is created at the institutional level, and systemic support is to be emanated), and the mobilization model (where an issue is identified as having importance for policy-making on the institutional agenda, but launched only as an issue onto the systemic agenda, hoping that the process will lead to systemic support for an eventual policy). The chapter proceeds by presenting operational definitions of the warious components, and formulation of hypotheses, where it is suggested that the relevant process with regard to Nota 2000 has followed lines of the mobilization model and hus thus caused policyeffects.

A major flaw of the theory is recognized: it is static, and does not give indications with regard to adlequately influencing the processes leading to agenda status, formal policy, or feasibillity of policy.

In chapter 5 , the methods and methodology of the investigation are presented and discussed. The methodology is largely of a qualitative nature, as the inquiry as a whole is exploratory because very little empirical work is available on the issue of health policy. The rationale for qualitative inquiry is found in the character of healthy public policy; the dynamic character of health policy-making; the content of health policies; the sample size; and the nature of units and wariables for research on healthy public policy.

Types of quality control in qualitative inquiry (confidence, validity, and reliability) are discussed. Reliability is the most prominent type, and assured in this investigation through triangulation. Triangulation is the process of comparison and analysis of different data 
sources, investigators, theoriess, and methods.

Resulfs from semi-structured interviews were analyzed by two methods (thus triangulated), and consequently laid down in a repont, which was fed back to the total research population for corminents (using a semi-structured questionnaire). The results were triangulated with a media cowerage anialysis. The complete set of information was triangulated with documents produced by the various groups in the poipulation, and compared with the chronology of Nota 2000 cllescribed earlier. Reliable measurements have thus been secured.

In chapter 6 the results of the data collection are presented. Response has been adequate (combined responses $87 \%$ ), although political offices were found to be little interested in the health policy issue. Eighty-two organizational documents were acquired, mainly annual reports, policy documents, and public statements. Ninety-five media coverages were retraced, of which the majority was found in specialized magazines. Radio/television cowerage was found once.

Among respondents, there is no consensus whatsoever on the status of Nota 2000. To some it is policy, to others a mere symbolic piece. All respondents knew what Nota 2000 was about. About two-thirds of respondents regard the document as valuable. There was no clear correlation between evaluation and type of respondent organization.

Nota 2000 plays a minor role in all organizational documents; NGOs, bureaucrats and research organizations mention the document most. Consumer organizations pay almost no attention to Nota 2000. The attitude toward Nota 2000 expressed through the documents is generally reflective. Only one-sixth is critical. The media have been substantially more critical, but that attitude has been decreasing over time.

A relation between involvement in the developmental process by organizations, and subsequent activities in the realm of health policy has not been found. Of all groups, particularly NGOs have employed action, whether or not they were involved in the developmental process.

No respondent considered Nota 2000 unconditionally feasible. Ninety-seven barriers for implementation were mentioned. Generally, the structure of government, financial barriers, general vagueness of health policy, political will and trends in society were thought to be major barriers. These barriers relate directly to problems of the current health care system. With regard to the issue expansion criteria formulated in the theory of agenda-building, the issue of health policy has reached a sufficiently wide circle of groups, while the issue is generally perceived as suggested by the theory (unequivocal, socially significant, temporally relevant, non-technical ${ }_{\text {and }}$ with few precedents). The consistency of these characteristics is confirmed by comparison with value attributed to Nota 2000 . However, health policy is not yet formalized at the institutional level. This indicates that other processes than proposed by the theory may play a role.

Reviewing media coverage and use of symbolism in the light of the theory, it appears that coverage does not meet the theoretical propositions. The mechanisms predicted by the mobilization modell of the theory apparently have not worked.

About one-third of respondents perceived no organizational opposition to Nota 2000 whatsoever. Its non-feasibility is attributed to the character of health policy. Those who did see opposition mentioned particularly institutional care groups and financiers of care. Prevention policy -constituent part of health policy-was felt to be important, and most respondernts would contribute to its development. However, most contributions were formulated rather abstractly: prerequisite-setting, or any preventive action was felt to be contributing. Concretely, child accident prevention policy was generally felt to be worthwhile, although firm commitment to its development was left to only one organization.

In chapter 7 the findings are discussed, and conclusions drawn with regard to health policy 
in the Netheriands as well as the theory employed.

The interest groups involved in the investigation found health policy in the Netherlands not feasible. This outcome was reaffirmed when they were confronted with the initial research findings. Funther, most hypotheses as formulated on the bases of literature review and theoretical framework had to be rejected. There is no sufficient public support for health policy, nor do the appropriate theoretical issue characteristics imply increased systemic or institutional agenda status.

The mobilization model of the theory has thus not brought about the intended support for health policy. Although professional groups are not in support of health policy, the perceived non-feasibility may not only be attributed to these groups.

The use of metaphors and symbolism -as predicted by the theory- has been nearly nonexistent, in spite of rather extensive media coverage. Whether non-feasibility of health policy may therefore be attributed to the absence of these factors has not been clarified.

No consistent relation was found between involvement in the development of health policy and subsequent activities undertaken by relevant groups. This would be an indicator for limited feasibility of health policy, as well as an indicator for the limited value of the theory. The publication of the Dekker-report-recommendations by a group of consultants with a conservative signature, aiming at introduction of market mechanisms in the Netherlands" health care- has clearly clouded interest in health policy. Its implications are twofold: first, the feasibility of health policy is felt to have decreased by its publication; and second, the theory of agenda-building does not give options for such a two-track policy approach. Two fields of interest are discussed: empirical data on health policy, and the value of the theory of agenda-building.

Supported by the literature, it is concjuded that health policy is facing at least the same problems as health care policy. No immediate way out of the dilemma is found. At the very minimum, the national government should clearly state its commitments and purposes, as well as responsibilities. Where responsibilities do not coincide with goverment's, it should be made clear to professional and societal groups where their responsibilities and opportunities lay. The mobilization model of the theory could give indications as to the process to follow in this clarification.

However, the theory of agenda-building has been found to have its flaws. First, it is suggested that not all "issues" lend themselves to application of the theory. "Health policy" may be a too complicated construct to grasp adequately by interest groups. Extrinsic qualities of an issue are translated characteristics of the intrinsic qualities, and as such perceived by interest groups. "The" issue therefore does not exist as intended by, for instance, institutional agenda-keepers. This may cause problems in the application of the mobilization model of the theory.

Whth regard to this mobilization model, several additions to the model are proposed. In using the model, three communication principles will have to be used explicitly while using existing intermediary structures. Further, we suggest that an intrinsically complex issue may be segmented as long as the principles of the general issue remain to pertain to the segments. Finally, it is recognized that the theory is too static to infer activities to increase the options for feasibility of health policy. We hawe attempted to develop a power constellation for groups possibly interested in health policy. Government could use proposed links between more or less powerful groups and perceived or intended stimulation of those groups to further health policy.

Finally, some research recommendations have been formulated, as well as conditions under which such research could be carried out.

In chapter 8 the most recent developments in the realm of heaith policy in the Netherlands are reviewed. They are the Collective Prevention Act and the Core Document Health Policy. 
Although these developments certainly constitute higher feasibility of thealth policy, only limited attervtion is paid to the flaws discussed in chapter seven. The conclusion remains that healith policy, even under thege improved conditions, has very limited feasibility. 


\section{SAMENVATTING}

Dit proefschrift is niet zonder reden in het Engels geschreven. Het onderhavige aandachtsgebied lijdt enigzins aan een overvloed van (engelstallig) jargon. Deze Nederlandse samenyatting zal daarom niet vrij zijh van anglicismen en, voor de ingevoerden in het Engelse jargon, vertalingen die 'krom' aandoen.

"Gezondheidsbeleid" is een breed type beleid dat zich richt op de handhaving en bevordering van gezondheid. Dat laatste gebeurt door aandacht te schenken aan omgevingsfactoren, erfelijke factoren, leefwijzen en het gezondheidszorgsysteem.

Sinds het begin van de zeventiger jaren is de roep op 20 ' $n$ beleid, dat verder gaat dan beheersing en regulering van het zorgsysteem, steeds krachtiger geworden. Vanaf het eind van de zeventiger jaren heeft de wereldgezondheidsorganisatie (WHO) de formulering van nationaall gezondheidsbeleid in haar lidstaten gestimuleerd. Nederland was onder de eerste landen waar een document over gezondheidsbeleid werd gepubliceerd: de Nota 2000 ("feiten, beschouwingen en beleidsvoornemens").

De centrale vragen in dit onderzoek richtten zich op de processen die tot operationeel gezondheidsbeleï in Nederland leiden, en op de percepties van de deellnemers in die processen over de status en problemen wan een dergelijk gezondheidsbeleid. Door deze vragen te beantwoorden kunnen we de woonutzichten woor een haabaar gezondheidsbeleid vaststellen.

In hoofdstuk 1 wordt de aanleiding voor dit onderzoek gepresenteerd, alsnede de indeling van dit boek. Specifieke doelstellingen van het onderzoek worden gegeven in paragraaf 1.3

In hoofdstuk 2 wordt de historische ontwikkeling van Nota 2000 beschreven. Daartoe behoort onder andere het werk van Blum. Hij beschreef paradigmata op het gebied van welbevinden en de krachtenvelden die voor gezondheid belangrijk worden geacht. Daarmee gaf hij de rationale voor de ontwikkeling van waarachtig gezondheidsbeleid. In het Canadese Lalonde-rapport wordt voor het eerst dergelijk gezondheidsbeleid door een overheid aangehangen. De premissen van dat rapport worden besproken, en hoewel de publicatie van het stuk niet onmiddellijk geleid heeft tot verschuivende beleidsprioriteiten moet erkend worden dat het stuk een mijlpaal in de ontwikkeling van gezondheidsbeleid mag worden geacht.

Verschillende programma"s van de WHO hebben nieuw elan gebracht in het streven naar gezondheidsbelleid. Ze worden beschreven in paragrat 2.2. Hun voornaamste overeenkomst 
is de enkerning van het feir dat medische zorgsystemen slechts in beperkte mate kunnen bijdragen an de gezondheid wan de bevolking. In afnemende mate wan abstractheid worden de Primary Health Care-ideologic, de Health for All-plannen, en het gezondheidsbevorderings-programma besproken.

De ontwikkeling van Nota 2000 kan met name gerelateerd worden aan het laatste. Uit de chronologie van haar ontwikkeling kan worden afgeleid dat de ontwikkeling van gezondheidsbeleid slechts beperkte pricriteit heeft gehad. Vaststelling van Nederlands gezondheidsbeleid is een zak van compromissen. Het tweeslachtige karakter van het stuk, zoals beschreven in 2.3.2, illustreert dat Voorts is ook een zekere tweeslachtigheid onderkend onder de gezondheids-organisaties tijdens de discussies die volgden op publicatie van Nota 2000: hoewel men het eens is met de algehele doelstelling van het stuk vinden de meeste actoren de stellingen en concrete consequenties wan de Nota 2000 in meerdere of mindere mate utopisch.

In hoofdstuk 3 wordt de academische stand van zaken met betrekking tot gezondheidsbeleid uiteengezet. In WHO-jargon wordt de term "gezond overheidsbeleid" bedacht, in tegenstelling tot 'overheids-volksgezondheidsbele id'. De verschillen tussen beide benaderingen worden beschouwd. Het volksgezondheidsbeleid (dat tenslotte het toneel vormt voor gezond overheidsbeleid) wordt geanalyseerd in 3.1. Het volksgexondheidsbeleid lijkt te hebben geleden onder een spreekwoordelijke inertie van de staat. In dat klimaat groeiden corporatistische tendenzen, die leidden tor een verstrikt en gecompliceerd samenhangend systeem. Een overzicht van de voomamelijk angelsaxische literatuur op het gebied van gezondheidsbevordering en gezondheidsbele id wordt gepresenteerd om de problemen bij deze benaderingen te achterhalen. Men geeft de voorkeur aan 'mixed-scanning' en een gemengde vorm wan 'bottom-up' en 'top-down' benaderingen bij beleidsvorming op dit gebied. Intersectoralle samenwerking ('facetbeleid'), een belangrijke karakteristiek van gezondheidsbeleid, wordt beschouwd. Er worden zeven barrières genoemd voor intersectorale coördinatie, maar er blijkt geen theoretisch raamwerk beschikbaar te zijn voor de studie van het fenomeen. Integrale interventie-mixen die interventies als wetgeving, facilitering en voorlichting op elkaar moeten afstemmen worden eveneens beschouwd, maar ook hier wordt geen empirisch materiaal gevonden.

Tenslotte wordt op het gebied wan onderzoek en evaluatie van gezondheidsbeleid het gebruik van een effectieve combinatie van kwalitatieve en kwantitatieve indicatoren voor gezondheidsbeleid llangs longitudinale schalen gesuggereerd.

In hoofdstuk 4 wordt het theoretisch kader voor dit onderzoek geconstmeerd. Dat gebeurt op basis van de agenda-bouw theorie. Deze theorie heeft betrekking op processen en factoren die tot de totstandkoming wain formel beleid leiden. De theorie bestaat uit drie componenten: 1 het bestaan wan verschillende "publieken" (belangengroepen) die zich ervoor inzetten om zaken die op een 'systeem-agenda" staan op de "institutionele agenda" voor beleid te krijgen; 2 het gebruik van media en symboliek om een bepaalde zaak ("issue") ook wan belang te laten worden voor een grotere groep belanghebbenden, opdat daarmee de waarschijnlijkheid dat het in beleid wordt ingepast wordt vergroot; 3 het door de groepen ervaren karakter van het 'issue". Als een "issue" ervaren wordt als weinig eenduidig, met maatschappelijke relevantie, een lange-termign belang, weinig technisch, en zonder precedenten, voorspelt de theorie dat de kansen groter worden dat het aangepakt wordt met formeel beleid.

Drie modellen worden voorgesteld: het "van buiten-initiatief" model (waarbij malatschappelijke groepen verantwoordelijk worden geacht woor het op de formele beleidsagenda plaatsen van een issue), het "binnenuit-initiatief" model (waar beleid wordt gemaakt op het institu* tionele niveau -de overheid- waarwoor vervolgens maatschappelijke steun moet komen), en het mobillisatie-model (waarbij op het institutionele niveau wordt erkend dat een issue 
beleidsbelang heeft, maar vervolgens het issue op de systeen-agenda wordt geret. Daarbiji hoopt men dat op die wijze het mobilisatie-proces zal leiden tot matschappelijke steun voor het uiteindelije beleid): Het hoofdstuk verwolgt met operationele definities van de verschillende componenten, en de formulering van hypotheses. Daarbij wordt verwacht dat het beleidsvormings-proces woor de Nota 2000 de lijnen van het mobilisatie-model heef gevolgd en ats zodanig beleidseffect heeft.

Een belangrijk minpunt van de theorie wordt hierbij erkend: ze is statisch, en geeft geen indicaties hoe de verschillende processen die leiden tot agenda-status, formeel beleid, of haalbaarheid van beleid beïnvloed kunnen worden.

In hoofdstuk 5 worden methoden en methodologie van het onderzoek beschouwd. De methodologie is voomamelijk kwalitatief ondat het onderzoek exploratief van aard is aangezien er bijzonder weinig empirisch werk op dit gebied beschikbaar is. De meer preciese rationale voor kwalitatief onderzoek wordt gevonden in het karakter van gezondheidsbeleid, het dynamisch karakter van het gezondheidsbeleidsvormings-proces, de inhoud van gezondheidsbeleid, de omvang en aard van de onderzoekspopulatie, en de eigerwschappen van eenheden en variabelen die onderzocht dienen te worden.

Verschillende types wan kwaliteits-bewaking bij kwalitatief onderzoek (confidentie, walliditeit, en betrouwbaarheid) worden beschouwd. Betrouwbaarheid is het meest prominent, en wordt verzekerd door triangulatie ("driehoeksmeting"). "Triangulatie is het proces waarbij verschillende data-bronnen, onderzoekers, theorieën en methoden worden vergeleken en geanalyseerd.

De resultaten uit halfgestructureerde interviews werden met twee methoden geanalyseerd (en dus getrianguleerd), en wervolgens neergelegd in een trapport dat voor commentaar (met een gestructureerde vragenlijst) aan de onderzoekspopulatie werd teruggezonden. De resultaten hiervan werden getrianguleerd met een analyse van hetgeen de medlia over gezondheidsbeleid naar voren brachten. Dit geheel werd vervolgens getrianguleerd met documenten geproduceerd door de verschillende groepen in de onderzoekspopulatie, en vergeleken met de ontwikkelingsgang van Nota 2000 . Betrouwbare metingen zijn daarmee zo goed mogelijk verkregen.

In hoofdstuk 6 worden de resultaten van de data-verzameling gegeven. Respons was adequaat (de gecombineerde respons was $87 \%$ ), hoewel ministers en staatssecretarissen weinig geinteresseend bleken in gezondheidsbeleid. Tweë̈ntachtig organisationele documenten werden verkregen: woomamelijk jaarverslagen, beleidsstukken en openbare uitlatingen, Verder werden 95 media-uitingen achterhaald, warvan de meenderheid in gespecialiseerde tijdschriften werd gevonden. Er werd slechts een radio/televisie-uitzending gevonden. Onder de respondenten bestaat geen enkele consensus over de aard van de Nota 2000. Voor sommigen is het beleid, voor anderen een slechts symbolisch stuk. Alle respondenten wisten waarover Nota 2000 gaat. Ongeveer twee-dende van de respondenten achten het stuk waardevol. Er was geen correlatie tussen waardering en het soort organisatie.

Nota 2000 speelt slechts een geringe rol in de organisationele documenten. Niet-gouvernementale organisaties (NGOs), bureacraten en onderzoeksorganisaties noemen het stuk het meest. Consumenten-organisaties besteden vrijwel geen aandacht aan de Not it 2000 . In het algemeen neemt men een reflecterende houding aan in de documenten. Slechts een-dende is kritisch. De media zijn aanzienlijk kritischer geweest, maar die houding is door de tijd genomen werminderd.

Er is geen relatie gevonden tussen betrokkenheid bij het ontwikkelingsproces van de Nota 2000 , en vervolgens ondemomen activiteiten op het gebied van gezondheidsbeleid. Van alle groepen hebben met name NGOs activiteiten ontplooid, of ze nu bij dat ontwikkelingsproces waren betrokken of niet. 
Gexen whele respondent vond de Nota 2000 onvoonwardelijk haalbaar. Er werden 97 hindemissen woot implementatie genoend. Men vond met name ovetheidsstructuur, finaricielte barriêres, algehele valaheid van gezondheidsbeieid, politieke wil en trends in de samenleving een problesm. Deze zaken hebben een directe relatie met de problemen in het thuidige zorgsysteem.

War betreft issue-expansie zoals geformuleerd in de theorie heeft de notie van gezondheidsbeleid een voldoende wijde cirkel groepen bereikt, terwil het issue over het algemeen ervaren wordt zoals de theorie woorspelt (weinig cenduidig, maatschappelijk relevant, lange termijn, niet technisch en met weinig precedenten). De consistentie van deze karakteristieken is bevestigd door een wergelijking met de wardering van Nota 2000. Toch is gezondheidsbeleid thans niet geformaliseerd op het institutionele niveau. Dat geeft aanwijzingen dat andere processen dan die welke de theorie voorspelt een rol zouden kunnen spelen.

Wanner media-uitinger en symboliek darin in het licht wan de theorie beschouwd worden, blijkt dat deze niet in overeenstemming zijn met de uitgangspunten van de agenda-bouw theorie. De mechanismen die in het mobilisatie-model worden gesuggereerd hebben klaarblijkelijk niet gewerkt.

Ongever een derde van de respondenten ervoer geen enkele organisationele oppositie tegen de Nota 2000. Haar onhaalbaarheid wijt men aan het allgemene karakter van het concept gezondheidsbeleid. Diegenen die well oppositie zagen noemden met name de institutionele zorguerleners en financiers.

Preventiebeleid *en onderdeel van gezondheidsbeleid-erwoer men als belangrijk, en de meeste respondenten hadden dan ook de intentie om aan de ontwikkelling ervan bij te dragen. De mogelijke bijcragen daartoe werden echter nogal abstract geformuleerd: het werken aan voorwatarden, of preventie-activiteiten zag men als een bijdrage. Meer concreet vond men preventie van ongevallen bij kinderen de moeite waard, maar men liet het eventuele commitment aan dit beleid over aan slechts én organisatie.

In hoofdstuk 7 worden de bevindingen in breder kader beschouwd, en conclusies getrokken over enerzijds gezondheidsbeleid in Nederland, en anderzijds de gebruikte theorie.

De belangemgroepen de betrokken zijn geweest bij dit onderzok vonden gezondheidsbeleid in Nederland niet haalbaar. Deze bevinding werd bevestigd toen ze werden geconfronteerd met de resultaten van de eerste onderzoeksronde. Voorts moesten de meeste hypotheses zoals die (op basis van literatuurverkenning en theoretisch kader) geformuleerd waren, verworpen worden. Er is onvoldoende steun voor gezondheidsbeleid, noch betekent het dat de issuekarakteristieken zoals de theorie die bevat een toegenomen systeem-af institutionele agendastatus met zich meebrachten.

Het mobilisatie-model van de theorie heeft dus niet de voorgestelde steun voor gezondheidsbeleid teweeg gebracht. En hoewel professionele groepen nilet vótr gezondheidsbeleid zijn, betekent dit niet dat haar onhaalbaarheid dan ook aan deze groepen toegeschreven mag worden.

Het gebruik van do media en symboliek -zoals de theorie die voorsteli- is vrijwel afwezig geweest, ondanks de veelheid aan media-uitingen. Of de ervaren onhalbaarheid van gezondheidsbeleid nu mag worden toegeschreven an de afwezigheid van deze facroren is in dit onderzoek niet aan het עicht gekomen.

Er is geen consistente relatie gevonden tussen de betrokkenheid bij de ontwikkeling van Nota 2000 en de vervolgens in dat licht ondemomen activiteiten. Enerzijds is deze bevinding een indicator voor de beperkte haalbaarheid wan gezondheidsbeleid, maar anderzijds kan het ook wijzen op de beperkte warde van de gebruikte theorie.

De publicatie van het rapport van de commissie-Dekker (gericht op introductie van markmechanismen in de Nederlandse gezondheidszorg) heeft de belangstelling voor gezondheidsbeleid duidelijk overschaduwd. De implicaties hiervan zijn ten eerste dat door 
'Dekker' de haalbaarheid van gezondheidsbeleid is beperkt, en ten tweede dlat de agendabouw theorie geen mogelijkheden geeft om zo"n duidelijk tweesponen-lxeleid helder te bestuderen.

Twee aandachtswelden worden tenslotte beschouwd: empirische gegevens over gezondheidsbeleid, en de waarde van de agenda-bouw theorie.

De bevinding dat gezondheidsbeleid vooralsnog exact dezelfde problemen kent als gezondheidszorgbeleid wordt ook ondersteund in de literatunt. Er is geen onmiddelijke oplossing voor de daar gerezen dilemma"s. De meest minimale randvoorwaarde lijkt wel dat de overheid duidelijk haar "commitments", doelstellingen en verantwoordelijkheden meerlegt.

Waar hun verantwoordelijkheden niet samenvallen met die van de overheid, moet aan. professionele en maatschappelijke organisaties duidelijk worden gesteld waar zij wel liggen. Her mobilisatie-model van de theorie kan handvatten geven over de wijze waarop deze verheldering kan plaatsvinden.

De agenda-bouw theorie blijkt echter haar minpunten te hebben. In de eerste plaats moet worden erkend dat het waarschijnlijk zo is dat niet alle 'issues' zich lenen voor toepassing van de theorie. Zo kan "gezondheidsbeleid" een te ingewikkeld construct zijn om adequaat te bevatten door belangengroeperingen. Extrinsieke kwaliteiten van een issue zijn de "vertaalde" karakteristieken van de intrinsieke kwaliteiten. 'Het' issue bestaat dus nooit zonls voorgesteld door bijwoorbeeld institutionele agenda-houders. Dit kan tot problemen leiden in de toepassing van de theorie.

Wat betreft het mobilisatie-model worden verschillende aanvullingen op het oorspronkelijke model voorgesteld. Drie met name genoemde communicatie-principes moeten worden aangehouden, waarbij gebruik dient te worden gemaakt van intermediaire structuren. Verder wordt voorgesteld dat een intrinsiek complex issue gesegmenteend mag worden zolkng de generieke principes van toepassing blijwen op de segmenten.

Tenslotte wordt erkend dat de gebruikte theorie te statisch is om daaruit activiteiten af te leiden om de haalbaarheid van beleid te wergroten. Er is getracht een machts-constellatie van betrokken groeperingen op te stellen. Op basis van de verhoudingen tussen enerzijds meer en minder machtige groepen en anderzijds de voorgenomen of feitelijke stimuli door gezondheidsbeleid voor die groepen, kan de overheid actie ondememen om de totstandkoming van gezondheidsbeleid te bevorderen.

Tenslotte worden in dit hoofdstuk een aantal onderzoeksaanbevelingen gedaan, alsmede condities aangegeven waaronder dergelijk onderzoek zou moeten geschieden.

In hoofdstuk 8 worden de meest recente ontwikkelingen op het gebied vari gezondheldsbeleid in Nederland beschouwd. Dat zijn de Wet Collectieve Preventie Volksgezondheid en het Kemdocument Gezondheidsbele id. Hoewel deze ontwikkelingen zeker bijdragen aan cen grotere haalbaarheid van gezondheidsbeleid wordt weinig aandacht besteed ann de problemen zoals die in hoofdstuk zeven zijn beschreven. Conclusie blijft dat gezondheidsbeleid, zelfs onder deze verbeterde omstandigheden, als weinig halabaar mag worden gezien. 


\section{Annex I: targets for health for all}

Targets in support of the Regional Strategy for HFA2000

Document EUR/RC33/9 corr. 1, 19 August 1983

This document contains 82 targets, divided into 7 secrions:

* Health for All in Europe by 2000

* Prerequisites for health

* Lifestyles conducive to health

* Healthy environment

* Appropriate care

* Research: a basic element in planning change in support of heallth for all

* Support measures

The 13 targets related to 'Lifestyles conducive to health' are:

\section{TARGET 33}

By 1990 , the public policy of every member state will make healthy lifestyles the easier lifestyles to choose

TARGET 34

By 1987, all countries will have ensured effective community participation at all levels of policy-making concerned with developments relating to lifestyles and their implementation

TARGET 35

By 1990 , people in all countries will be better able to make mature decisions regarding their own choice of lifestyle

TARGET 36

By $1990_{*}$ at least $(90 \%)$ of individuals of all groups and communities in every country will be aware of the health implications of their lifestyles, be motivated to protect their health and regard unhealthy behaviour as socially less acceptable

TARGET 37

By 1990 , each country will have developed measures to strengthen family and other social networks so as to enable people to choose, want and maintain healthy lifestyles TARGET 38

By $1995_{4}$ in all countries, at least $(90 \%)$ of people will have healthy eating habits; and in no member state will obesity affect more than $(5 \%)$ of the population

\section{TAROET 39}

By 1990 , at least $(90 \%)$ of the people of the region will have the opportunity and the motivation to spend the amount of time on physical activity needed for good health TARGET 40

By 1995 , in every country at least $(90 \%)$ of the people, particularly vulnerable groups (such as the elderly, the disabled, the widowed, youth and migrant workers) will have the opportunity and resources to participate in social life at a level which provides a sense of identity, self-esteem and general well-being

TARGET 41

By 1995 , in every country at least ( $80 \%$ ) of the people -including wulnerable groups such as those in institutions, the disabled, the elderly, etc., will have an opportunity of leading an emotionally satisfying sexual life in harmony with the needs, beliefs and values of the indivictual and society

TARGET 42

By 1990 , tobacco consumption in all countries will have been reduced by at least $(50 \%)$ 
and in each country at least $(80 \%)$ of the population will be non-smokers.

TARGET 43

By 1990 , no country or group within a country will have a consumption of pure allohol per person aged 15 years and over of more than (15) litres per year; countries almeady below that level in 1980 will have reduced it to less than (10) litres; countries alleady below the ten-litre level in 1980 will have reduced it further by at least ( $20 \%$ ) and will try to eliminate significant differences between socio-economic groups.

\section{TARGET 44}

By 1995, the use of illicit psychoactive drugs in the region will be (substantally) reduced TARGET 45

By the year 1995, in all countries of the region at least (95\%) of all drivers will be safe and considerate.

In each sub-section of one target backgrounds, bases and problems concerning the target are given, as well as possibilities, methodology and approaches to reach the target.

* Figures between brackets tentatiwe pending approval by member states

Regional targets in support of the regional strategy for health for all Document EUR/RC34/7, 14 July 1984

The document contains 38 targets, divided into 6 sections:

* Health for All in Europe by the year 2000

* Lifestyles conducive to health

* Healthy environment

* Appropriate care

* Research: a process of obtaining the knowledge needed to attain health for all

* Health development support

The 5 targets in the section 'Lifestyles conducive to health' are:

\section{TARGET 13}

By 1990 , national policies in all member states should ensure that legislative, administrative and economic mechanisms provide broad intersectoral support and resources for the promotion of healthy lifestyles and ensure effective participation of the people at all levels of such policy-making

TARGET 14

By 1990 , all member states should have specific programmes which enhance the major roles of the family and other social groups in deweloping and supporting healthy lifestyles TARGET 15

By 1990 , educational programmes in all member states should enhance the knowledge, motivation and skills of people to acquire and maintain health

TARGET 16

By 1995, in all member states, there should be significant increases in positive health behaviour, such as balaneed nutrition, nonsmoking, appropriate physical activity and good stress management

TARGET 17

By 1995 , in all member states, there should be significant decreases in health damaging behaviour, such as ovenuse of alcohol and pharmaceutical products, use of illicit drugs: and dangerous chemical substances, dangerous driving and violent social behaviour. Each subsection conceming a target contains sections such as introduction, Larget. problem statement, and suggested solutions. 


\section{Annex II: Delphi-questionnaire}

respondentrit:

QUESTIONNATAE HIMY "FLASIBILITY OP DUTCH HEALTH POLICY"

1. Do you have any general comments regarding the "Outcomes" section of the report?

2. Do you have any comments regarding the description of resporse (1. 86-107)?

3. Do you have any contrents regarding the analysis of perceived status of Nota 2000 (1. $112-124)$ ?

4. Do you have any corments regarding the analysis of knowledge and perceived value of Nota $2000(1,125-175) ?$

5. Would you be able to comment on the conclusion that consumers and bureaucrats seem to perceive status and walue of Nota 2000 similarly, while professionals give a lower rating $(1.160-175)$ ?

6. Could you explain that there is no coherent relationship between perceived involvement in the policy-development process and action undertaken subsequent $y(1,176-216)$ ?

7. Do you have any comments on the analysis of feasibility of Nota 2000 and perceived barriers $(1.217-267)$ ?

8. Although the theory of agenda-building seems to have a good fit with empirical findings, Wota 2000 is not considered to be feasible $11.268-2871$. could you list explanations for this, other than those described in "feasibility" (1.217-267) and 'opposition' (1.287-300)?

9. Do you find the description of "opposition" (1.287-300) adequate, and does it reflect your own position?

10. Factual comtributions to the establishment of prevertion policy are amalyzed being questionable (1.301-321). Do you have any conments on this?

11. The respongibility for creating ary accident prewention policy is given to the stichting consument en veiligheid $(1.334-342)$. This is in juxtaposition to the principles of the intended prevention policy. Could you explain this?

12. The first issue in the "discussion and interpretation" section is that bureaucrats and consumers seem to agree on the social rellevance of Nota 2000. while professionals address the issue less unequivocally (1.347-357). Could you explain this?

13. The perception anong responcents is that they are forced to deal with "the craze of the day". While in fact they would be willing to undertake strategic action. could you coment?

1. There is no conclusion attached to the present report. Below, three posisible conelusions have been formulated.

a. Could you choose the most plausible conclusion on the basis of the analusis of the report? (circle)

I. 11 
b. Could you choose the conclusion with which your organization woula be most comfortable?

c. Would you be able to choose the conciusion chosen by the majority of respondents? (if you cannot answer this question "circle "*")

II

III

CONCUUSTON I

The policy intentions of Wata 2000 are in the long run fully feasible. The barriers and opposition found in this investigation wild disappear with tive implementation of the recommendations of the Dekker-Committee. After that, the intended policy from Wota 2000 can be made more concrete. The theory of agenda-building predicts that, under the presentiy analysed conditions. there is sufficient public pressure to do so.

\section{CONCLUSION II}

The policy intentions of Nota 2000 are in the long run partly feasible. But even if "Dekker" is implemented to overcome the analysed bartiers and opposition, there will be few stimuli to really concretise the intentions. Fhe "iron ring" and "iron triangle" around Dutch health care will even post-Dekker" remain intact. This frustrates full implementation of Nota 2000.

\section{CONCLUSION III}

Nota 2000 will remain to be an intention document. Analytically, the menorandum is acceptable, but its political objectives are unachievable. Implementation of the recomendations of the bekker-conmitee will not change that; conflicting interests and trends in society which are a counter-force to Nota 2000 will remain to exist. The analysis according to the theory of agenda-building supports this view.

Nota bene: please, in commenting on the report, clearly distinguiglu between comments on the report, and comments on interpretations. Thank you. 


\section{Annex III: Document score sheet}
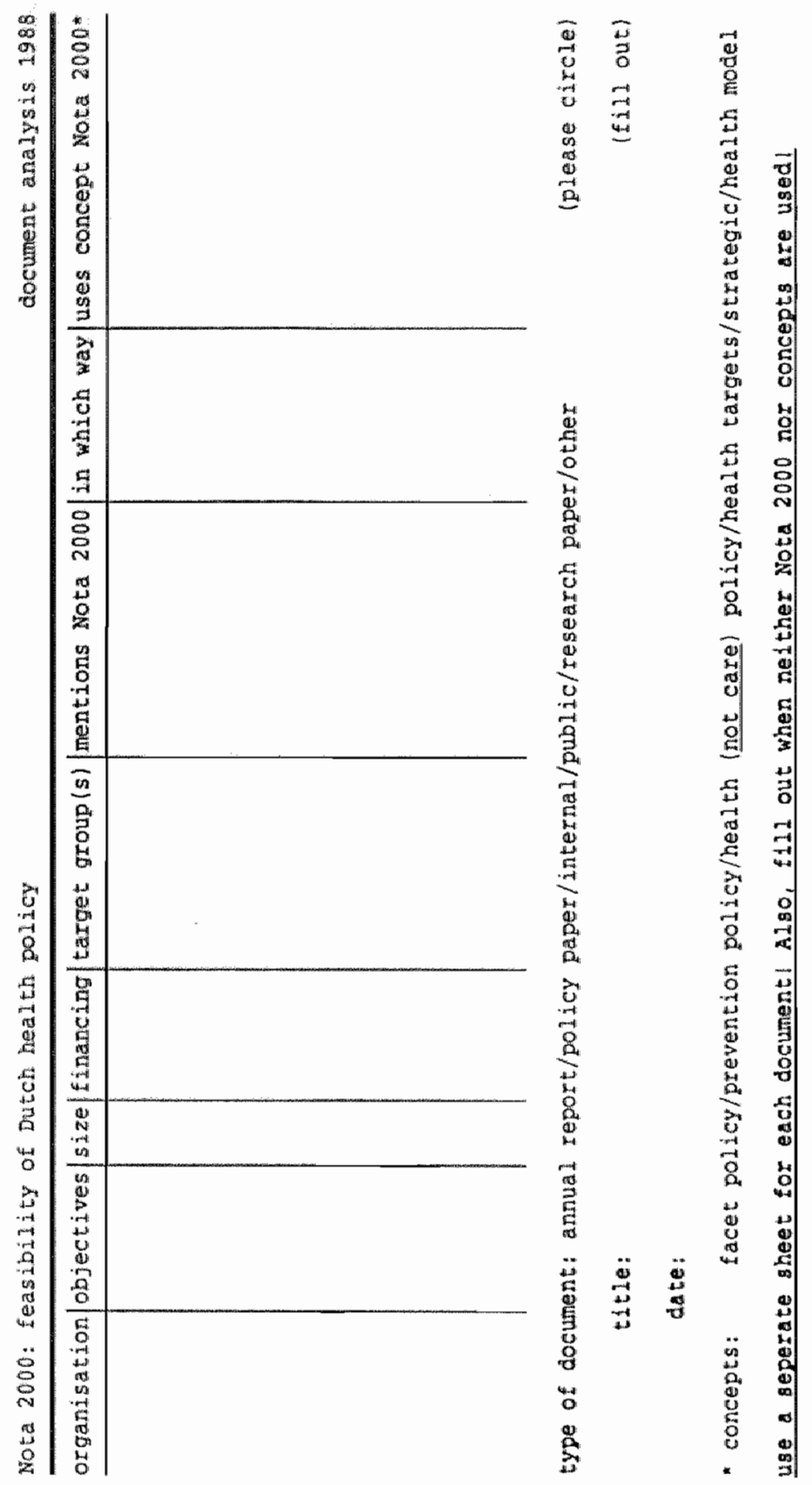


\section{Annex IV: Kwalitan code book. Between brackets: initial question (Annex VIII)}

main cade Lcode

\section{ORGANISATIE (0)}

organisatie politiek arganisatie professi organisatie consumen organisatie NGO organisatie research organisatie overhpol organisatie overhbur

NAAMRESPONDENT (0) naamrespondent man naamrespondent vrouw

RANG (O)

rang leiding

rang inhoud

INTERVIEWER (0)

interviewer Evelyme interviewer vicole

DOEL (1)

doel belangenbehart doel onderzoek doel steun/dienstv doel ideologie doel advies-beleid doel beleidmaken

\section{OMVANG (1)}

omwang ledem klein omwang leden midde omwang leden groot omwang buro klein omvang buro midden omvarg buro groot

GELD (1)

geld bron wvc geld bron contribu geld bron extern geld bron opbrengst geld omvang klein geld omvang midden geld omvang groot

\section{DOELGROEP (1)} doelgroep leden doelgroep volk doelgroep overheid doelgroep anderen meaning

remarks

political organization professional organization consumer organization non-governmental organization research organization government, political organization government, bureaucratic organization

name respondent. male name respondent, female

position managenent position content

when doubt: *nanagement

interviewer kvelyne interviewer Nicole

goal interest adwocacy

goal research

goal support/service

goal ideological

goal consultancy for policy

goal making policy

size membership $<20,000$

size membership $20,000-100,000$

size membersinip $>100,000$

size secretariat $\$ 10$

size secretariat $10-25$

size secretariat $>25$

money source department of health (Wvc) money source contributions of nembers money source external revenues money source selt-generated income budget $<$ dif. 500,000 budget df $1.500,000-$ df J. 1,500,000 budget > de1.1,500,000

target group members

target group general population

target group government

target growp others 
LERWLIO (1)

leeftija jong

leeftija miden

leet tija oud

\section{TADTTIR II}

traditio stat ideol traiditie state objec traditie dyna visie cxaditie dyma berei

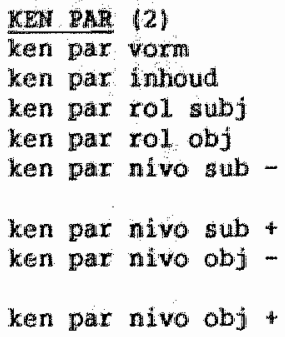

KEN NPAR (2)

ken npar vorm

ken npar inhoud

ken mpar rol subj

ken npar rol obj

ken npar nivo sub -

ken mpar nivo sub *

ken npar nivo obj -

ken mpar nivo obj *

CONCEPT (3)

concept preventie concept facet

concept toekonst

concept giezondheid

concept gezfeiten

comcept steuninfras

concept model

concept ather

DOELNOTA2000 (3)

doel nota2000 WHO

doelnotazoon stat

doelnota2000 disc

doelnota2000 ande

SOORTDOC (4)

soortaloc bellejd soortoloc discusise soortdoc symbool soortdoc analyse soortdoc politiek

\section{KWALDOC (4)}

Xwaldoc realistisch kwaldoc irreeel kwaldoc idealist kwaldoc wardevol

\section{STATUSDOC (4)}

statusdoc belangrijk statusdoc onbelangr age young (estabilished afeer 1970 )

age mediun (1945-1970)

age old (before 1945)

static tradition, ideological focus

static tradition. "objectivity"

drmanic tradition, shift in mission

dymamic tradition, shift in range

inminemt knowledge format Nota 2000

imminent knowledge content wota 2000

imminent knowledge contribution organization to $\$ 2000$ imminent knowledge meaning Nota 2000 for organization imminent knowledge on level of importance of 2000 for organization (negative)

(positive)

imminent knowledge on contribution of organization in light of Nota 2000 (negative)

(positive)

non-imminent knowledge (classification as KEN PAR)

N2000 concept prevention or prevention policy

N2000 concept facet policy

N2000 concept future orientation

N2000 concept health orientation

N2000 concept health needs

N2000 concept supportive infrastructure

N2000 concept Basis Model

N2000 concept other

abjective 12000 commiment to who

abjective N2000 overview tacts figures

objectiwe 2000 discussion

objective 2000 other

perceived type of document: policy perceived type of document: discussion perceived type of document: symbolic percelved type of document: analys is perceived cype of document: political

quality of document: realistic guality of document: unrealistic quality of document: idealistic quality of document: valuable

status document important status document minor 


\section{VRAAGBI JDR (5) \\ vraagbijar form voor vraagbijar form na vraagbijar inf voor vraagbijar inf na vaagbijdr and route}

\section{BI JDRRGE (6)}

bijdrage form woor bijdrage form na bijdrage inf voor bijarage inf na bijdrage and route

\section{FORMPROBLEEM (6a)}

formprableem

POSITIE (6b)

positie geheel positie dlaspecten positie specifiek

\section{CONSULT $(6 c)$}

consult

\section{INVLOED (6a)}

invloed veel

invloed relatief

invloed weinig

IMPLEROL (6e)

impleral busasusual implerol innov samen implerol innov nwact

\section{BIJDRWENS (6E)}

bijdrwens bel rol bijdrwens ja indiff bijdrwens ja ander bijdrwens nee funct bijdrwens nee ideol bijdrwens nee ander

AMDERORG (7) anderorg nu politick. request contribution, formal before W2000

request contribution, formal atter w2000

request contribution, informal before $\mathbf{2 0 0 0}$

request contribution, informal after 12000

request contribution, ather route

factual contribution

\section{(classification as VRAGGIJDR)}

contribution to framing of problem

agreement between mission of organization and $\mathrm{N}^{2000}$ full agrement on aspects

agreement on specifics

degree of consultation

degree of perceived influence high

degree of perceiwed influence relative

degree of percelved influence low

perceived role implementation: business-as-usual perceiwed role implementation: innovation cooperation perceived role implementation: innovation, new actions

desired contribution: yes, important rolle desired contribution: yes, why not?

desired contribution: yes, other reason

desired contribution: no, functional barriers

desired contribution: no, ideological barriers

desired contribution: no, other reason

other organizations to be involved in Nota 2000 
anderom ring professi anderorg mon consumen anderorg nm 160 anderorg mo resereh anderorg nim overlypol andexorg nim overhbur anderory jum anderen anderorg politiek anderorg kw profess i anderorg kw consunen anderorg Mo anderorg kw reareh anderorg overhpol anderorg overhbur anderorg kw abderen

\section{WAALEAADELLID 183}

ha lbar beleid ja haalbaarbeleid dlasp halabarbeleid spec

\section{MHLBRDEL (9)}

nhlbrbel struc zorg nhibrbel struc over nhlbrbel belangen nhlbrbel financier nhibrbei vaag alg nhlbrbel vaag impl nhlbrbel polit il. nhibrbel samenleving nhlbrbel ander

\section{CONCROL (11)}

concrol busasusual concral innov samen concrol innov nwact concrol spec strzorg concrol spec strover concrol spec belange concrol spec financi concral spec vaagalo concrol spec vaagimp concral spec poliwil concrol twec samenle concrol pec ander concrol doelstelling

\section{TEGENORG (16)}

tegenorg nom politiek tegunorg nm professi cectenorg nu consumen tegenorg nim NGO

tegenorg research tegenorg $\mathrm{nm}$ overhpol tegenorg $\mathrm{nm}$ overhbur tegenorg $\mathrm{nm}$ anderen

$$
\begin{aligned}
& \text { rw = mentioning organization name } \\
& \text { w }^{-} \text {mentioning degree of involvement }
\end{aligned}
$$

(classitication as ORGAMISATIE)

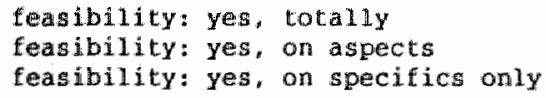

non-feasibility: structure health care system non-feasibility: structure of government norw feasibility: vested interests non-feasibility: financial barriers nor-feasibility: general vagueness non-feasibility: implementation vagueness non-feasibility: (lackingl political will non-feasibility: (tendencies in) society non-feasibility: other reasons

concrete rolle for barriers: business-asmbial concrete role for barriers: innovation cooperation concrete role for barriers: innovation s new actions

lconcrete rol for organization to work on barriers. Classification as NHLBRBEL

concrete role already in misgion organization

organizations perceived to be in opposition

(classification as ANDERORG) 


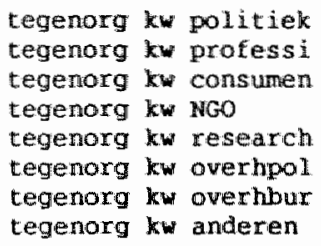

REALPREV (17)

realprev voorwaarden realprev directactie realprev bel voorw

Tealprev bel vrwacti

\section{FORMPREV (18)}

formprev voorwaarden

formprew directactie realprev bel voorw

realprew bel vrwacti

\section{EFFONGEV (19a) \\ effongev weetniet \\ effongev relatief \\ effongev natuurlijk}

ACTONGEVAL (19b)

actongeval wet actongeval sanctie actongeval facilit actongeval voorlich actongeval counsel actongeval anderen

VOORKEURACTONGEVAL (19b) voorkeuractongeval * voorkeuractongeval-

ROLONGEVALBEL (19c) rolongevalbel ja rolongevalbel indif rolongevalbel afhank

CONONGEVALBEL (19d) comongevalbel ja comongevalbel indif comongevalbel afhank

COMOMGBELt (19d1) comongbe 1+ uitsprak comongbe1t actie comongbelt document comongbe $1+$ anders contribute realization prevention policy: prerequisites contribute realization prevention policy: direct action contribute realizatiom prevention pollicy: policy prerequisite setting contribute realization prevention policy: advocate

formal contribution to realization prevention policy (classification as REALPREV)

perceived effectiveness accident prevention: don ${ }^{\mathrm{t}} \mathrm{t} \mathrm{know}$ perceived effectiveness accident prevention: depends perceived effectiveness accident prevention: of course

activity to address accident problem: legislation sanctioning facilitation education counseling other

preference for one specific type of activity disagreement with one specific type of activity

role establishment accident prevention policy: yes role establishment accident prevention policy: why not role establishment accident prevention policy: depends

comitment to accident prevention policy: yes commitment to accident prevention policy: why not comitment to accident prevention policy: dependa

intended commitment: statement

intended comitment: action intended commitment: document intended commitment: other

FEITONGBEL (19d2) 
fer congbel uitsprat ter torighe 1 actice

Geitomibe 1 document

fet tongbel anders

BAHOWGBEL (19))

barongbed ideologie

barongbel fimandiee 1

barongbel functione 1

barongibel anders

\section{MEMO}

mentiso

$11 !$

ctite factual comitment: statement

factual commitment: acton

factual conrin itment: document

factual commitment: other

barriers cor intended/factual commtant: idealogical barriers for intended/factual comatment: financial

barriers for intended/factual comitment: functional barriers for intended/factual communt: other

remark by interviewer

jook out: answer may be inconsistent or not correct remarkable response 


\section{Annex V: Delphi report}

REPORT ON THE FEASIBILITY OF DUTCH HEALTH POLICY (WOTA 2000)

drs. Evelyne de Leeuw MPH Vakgroep GVo

Rijksuniversiteit Limburg

Postbus 616

$6200 \mathrm{MD}$ Maastricht

$(043-887308 / 887334 / 210920)$

February, 1989 
Evelyne de Leeww

\section{STMTRODUCTION}

In Hay, 1986, Dutch government published a meinorandum, wata 2000. It was a discussion document with very few concrete policy intentions; the thrust of the Mota, however. was clear: policles for health of the Dutch should no longer only 10focus on infrastructural and financial aspects of health care. but rather on the determinants of health, including the health care system, environmental factors, Iifestyle and hereditary factors. A model was presented to structure the various aspects of a health policy deriving from these determinants. The purpose

150 the document was to sitimulate, on the basis of analysis of the statug-quo and uging forecasting-techniques, strategic chinking Into the future among the partners involved in Dutch health. Shortly after publication of Nota 2000 , but also when government had changed, the "Dekker report" on efficiency and cost-contain-

$20 m e n t$ in Dutch health care was published.

\section{RATIONALE}

Nota 2000 marks a shift from health care toward health policy. For the first time in putch history. the content of health became

25 an important policy objective of govermment. This development has synchronicity ith a renewed interest in public health, health promotion and healthy public pollicy in international realms (WHO) .

Actual feasibility of such a policy direction is a fascinating

30research objective. An inquiry has been carried out to retrace the development of Nota 2000 and perceived feasibility among the various actors.

\section{RESEARCH QUESTIONS}

35The objective of the current research is threefold:

first, to investigate thrust and status of Nota 2000 ;

second, to review whether relevant groupsi in Dutch society have knowledge of Nota 2000 and use its ideas in their own organizational policy making, thus

40third, finding out whether full implementation of Nota 2000 plans is a feasible option.

More concrete, research questions were:

$>$ In which phase of the policy process is Nota 2000 ? what are the prospects for progress of that process?

45) Which actors are, have been or should be involved in that process? What is their role in the progress of the process?

$>\quad$ Ig "healthy public policy" a feasible option for Dutch health policy?

> What are the prospects for a prevention policy in the light

50 of Nota 2000?

$>$ How do partners in health perceive the feasibility of a healthy public policy for accidents in the home among children $0-5$ years?

\section{SMETHODOLOGY}

Fifty-seven groups and organizations have beem identified as 
being partners in health. The 57 organizations have been divided into seven clusters: professionals, consumer groups, non-governmental organizations, political offcers, bureaucrats. research

600 ganizations and political parties (Table l). All were invited to participate in a semi-structured interview (Annex 1 ). The questions were operationalized out of the initial wesearch questions.

\section{THEORY}

A theory to predict the feasibility of policy is the mobilization model of the agenda-building theory. The theory distinguishes between an institutional (governmentall agenda for policy and a systemic (societal) agenda. Options for policy will only be

Toconsidered if an 'issue conflict" is expanded among sufficiantly enough actors in society. They should have a definite perception of the definition of the issue. The criteria for 'issue expunsion" are that an issue will enter systemic and institutional. agendas if the perception among actors is that it:

75) is ambiguous $1 y$ defined;

$\checkmark$ has large social relevance;

ᄀ has relevance over a longer period of time:

is non-technjcal of nature;

> has no clear precedents.

80The mobilization model of the theory proposes that actors on the institutional level may establish an issue for consideration for policy, and try to expand the scope of the issue by introducing it to the groups who make up for the systemic agenda.

\section{BSFINDINGS}

Response. Response to interviews has been reasonable (thable 1 ). overall, 42 out of 57 organizations have participated in research. This is 73,7 . These figures include a double counting of political parties, as they have a societal as well as

90 political function. Counted once, the overail figure becomes 39 out of 53 (748). Divided into clusters, the figures are following: professionals 10 out of 10 (100\%), non-governmental organizations 5 out of $6(83 \%)$, research organizations 6 out of 7 $(85,7 \%)$. consumer organizations 7 out of $8(87,5 \%)$ or 10 out of 9512 (838) when political parties are also considered consumers, political officers (ministers) 2 out of $7(28,68)$. bureaucrats 6 out of $11(54,5)$, and political parties 3 out of 41758 . Interpretation: It is remarkable that for clusters in which policy is considered to be created polifical and bureaucratic officers, 8 out of 18 , or only 4, 4he response has been disappointingly low. However, when non-response is considered to be response fin the sense that the "Mota 2000 issue" is not taken seriously by non-respondents) this outcone may be a first indicator for the non-fedis bility of Nota 2000.

Characterizations. Nota 2000 has explicitly been launched as a discussion document. The factual development of Nota 2000 is thus 110 supportive for the assumptions of the mabilization model of the agenda-building theory. Perception of this status has been tested among respondents. Generally. their perception is less unequi- 
vocal Thirty-elght respondents give 52 qualificacions to wota 2000. These have been grouped in tive categories: policy.

11.5discussion, symbolic, analys is and political (Table 2). Nearly half of respondents tinds Wota 2000 is a discusion piece. Mbout one third considers the memorandum to be ackual policy. Especially bureaticrats and research organizations feel so. Further, it is interestung to see that the 10 professional organizations give 13

120 characterizations; only a minority perceives Nota 2000 intended to be a diacusision piece.

Interpretation: The fact that the status of the document is unclear probably obscures further development of policy.

125knowledge and value of Wota 2000 . All respondents identified Nota 2000 to be a health and content oriented strategic (i.e.

future-orientedy document. Further, the perceived organizational and societal value of the document has been tested. whe thrust of this relevance is less uniquely identif ied: 24 of 42 (57,28)

130 respondents feel that Nota 2000 is a valuable document. Twentyone percent feels that it is valuable on aspects le.g." trend analys is or for specific groups) and 21,4 say the document is not valuable at ail. The same analysis has been carried out by organizetional cluster. Among professionals $\mid K=10 \%$ " Mota 2000 is

135 considered substantially less valuable: one fifth of professionals views the document unconditionaly valuable. The non-govermmental organizations $(\mathrm{N}=5)$ give another pattern: all view Nota 2000 to be of some value. Two respondents see chose valuable aspects of the document which apply to their own

140 organizational objectives (reduction of certain disease categories). As to the political officers $(\mathbb{N}=2)$. we may see the same pattern, although the number of respondents may in fact be too small to generalize this. In the cluster of research organizations $(\mathbb{N}=6)$ the pattern is the same as for all respondents. Two

1450 the research organizations do not consider Nota 2000 valuable at al1; these organizations can be identified to have "reactionary' objectives (see also below', clusters 'political left' and "right"). In the cluster of political parties ( $N=3)$ there is a "full spread" over the "value spectrum". For the consumer 150organizations $(\mathrm{N}=10) 80$ considers Nota 2000 valuable. Bureaucrats $(N=6)$ all consider Nota 2000 valuable. Finally, some organizations have been clustered into political 'right' and "left". It was assumed that political leaning would relate to atti tude toward Mota 2000 more homogemeously. For the cluster

155"right" (Na6) the assumption is not entirely supported, al though 50 of respondents find the document not valuable. "This is a substantiai proportion, certainly when related to the owerall. view. As to the cluster "left" $(\mathrm{N}=4)$ " all find the document valuable, one of which only on aspects.

160Interpretation: It is remarkable that consumer organizations seem to have similar perceptioms of status and value of Nota 2000 as bureaucrats; this would indicate that Mota 2000 has high social relevance and seems to be tuned to consumer needs and demands rather than to those of professional interest groups. This distinction is of course also reflected in the views of the political left and right, respectively 
focused on (consumer) emancipation vo. ma intenance of the status guo in health care policy. In the Iight of the present putch politigal constellation lcenter-right government this would in turn indicate a low probability for Nota 2000 to become actual policy endorsed by parlitament.

Inwolvement and action. It as assumed that the degres of involvement in the policy-making process of Nota 2000 would have a significant relation with willingness to undertake action in the light of Nota 2000. This assumption has been tested. An

180 organizational KAP-chart has been produced (Table 3 in which perceived walue of Nota 2000 is related to perceived involvement and action undertaken. overall results have been represented in a $2 \times 2$ table and a chi-square test has been carried owt "Table 4 . Analysis does not yield significant results: there is no relakion

185 between perceived involvement and actions undertaken. Seventy percent of professional orgarizations has not undertaken any action in the light of Nota 2000 while 80 feels they have not been involved. However, there is no distinct relation between involvement and action.

190Interpretation: Yet, here is a strong indicator that Nota 2000 may not serve professional organiational purposes.

Four of $f$ ive NGOs have undertaken action, although 3 of 5 have not been involved. This indicates that NOOS generally have been

195 stimulated to undertake action by Nota 2000 , whether or not they feel to have been involved. The political afficers both feel that they have been involved, and both undertook action. But they feel that, being political officers. they are committed to relevant. governmental activities. Of the research organizations, 4 out of

2006 they feel they have contributed in some way to wota 2000 . by supplying data). Three of those also hawe undertaken action. Yet, in cotal only $50 \%$ of these organizations took action. The others feel that action is not of legitimate concern to a research organization. In the cluster of political parties, 2 of

2053 feel they have been involved and took action in the select Committee for Health. Moreover, one party stands for Nota 2000-1ike ideas in its platform. Of the consumer organizations, only 30 z consider themselves to have been involved. Of the 7 not involved, substantial number (5) has yet taken action.

210Interpretation: This again supports the view that Nota 2000 is of high societal relevance.

of the six bureaucratic respondents, I feel to have been involved, although six have employed activities. Again was wh the political of icers-. they have done so because of comminunt

215to governmental actions. An analysis of political left and right clusters did not yield any signiflcant result. Feasibility and barriers. When directly asked, no respondent considered Nota 2000 unconditionally feasible. Barriers for feasibility were explored, and 42 respondents gave 97 barriers.

220 these have been grouped into the following clusters the structure of the health care system, structure of government lgenerally the strength of the Ministry of Mealth), conflicting interests, financial barriers, general vagueness of Nota 2000. vagueness on options for implementation, failing politicall will 
225 to work wh Wota 2000 , trends in society, and 'other barriers. megults are in tables 5-8, In table 5 (all respondents it is most remarkale that structure of government, financial barriers, gerieral waguents, political will and trends in society score highest. Wegarding the structure of governinent, as many respon-

$230 d e n t s$ fed they can employ actions to overcone this barrier as there are who leel not. "wice as many would like to work on flnamclal barrters as those who do not feel like that. The watgueness of Nota 2000 is not a barrier respondents would 1 ike to work ori .

235 Interpretation: The fact that they do not want to give concrete form to the policy üntentions indicates that the status quo in health care policy is of far higher concern.

Mearly all respondents who see political barriers feel they could 240work on creating more political will. Finally, trends in society opposing Wota 2000 thrusts do not call for much specific action. interpretation: It is remarkable that the types of barriers referred most to, are the same barriers that are addressed in the "Dekker"-report. This leads us to conclude that when the Dekkerrecommendations are carried out "Nata 2000 will have higher feasibility to enter the institutional policy-making agenda again. It could be feared, though, that by that time the content-oriented thrust of healthy public policy is forgotten.

Next, perceived barriers Vs. actions have been clustered in the groups of perceived value. Most significant is, that those organizations who consider Nota 2000 valuable see relatively more 255 barriers, but at the same time are also more willing to address these barriers. In the 'not valuable'-cluster, the nine organizations see only few barriers, but are not inclined to work on thein.

\section{Interpretation:}

265
Of course, the analysis is merely a confirmation of what almeady was known: those organizations who feel Nota 2000 is not valuable and has no relevance in terms of their own arganizational objectives, have no inclination to work on furthering the objectives of Nota 2000. And again, these groups may be identified with the present right-wing Dutcth political constellation. Issue expansion. When the issue of Nota 2000 la virtual health policyl is sufficiently well expanded anong interest groups, this 270 would indicate public pressure high enough to get a health policy on the systemic and in turn on the insticutional agenda. It would also mean that failing political will could disappear. An analysis has been carried out of the perception of issue. criteria as presented abowe. In general, the issue seems to be

275expanded sufficlently well (Table 9). A minority of respondents views the anbiguity of Nota 2000 to be inappropriate: it is too vague to enploy any action. Remarkable is the number of respondents who regard Nota 2000 as having no social significance (W=14): the issue of a health policy does not prompt them to 280 employ policy action. Those who find the issue to have a 
technical nature feel that the "policy technicians" boneaucrats and political leaders) have a prime responsibility to make assumptions. goals and means for policy more contrete; those who score "yes" on issue exparision criteria are wiling to work on

285 Nota 2000 . This would indicate that the mobilitation model ot the agenda-building theory is appropriate.

Opposition. Respondents were asked to indicate any opposition to furthering Nota 2000 . Fifteen respondents did see no opposition whatsoever; they atcributed this to the vaguemess of the

290document, but also to the analytic characteristics of it: as a data resource Nota 2000 is considered quite valuable. he other 24 respondents saw in total 45 groups and clusters opposing Nota 2000. Especially institutional care groups and those who inance health care are perceived to be in opposition $[10+10+14=34$ ont of

29545 opponents). Remarkable is furthermore, that political officers do not see any opposition, and that NGOs are not considered opponents of Nota 2000 by any of the organizations. Finally. seven out of ten professional organizations do not mention anyone opposed to the memorandum, al though they axe perceived to be in

3000 pposition by most other organizations:

Prevention policy. Respondents were asked to identify the ways and means by which they cowld comtribute to a comprehensive public prevention policy. Response has been categorized into "prerequisite-setting" "preventive action" factual incervertion,

$305 e d u c a t i o n a l$ campaigns "etc.). "policy" (a direct contribution to making prevention policyl and "lobby" (an active role in influencing decision-makers]. Further, informal contribution has been distinguished from formal contribution, the latter being a public statement or position paper. It turns out that the

310 majority of respondents perceives a role in prexequisite seting. probably because this role is not really comitting the organization to any formal policy. The formalized contribution is reflected in statements to prevention in organizational documents. Some organizations are carrying out prevention activities,

315 and half of them have formalized these contributions. All those who have direct access to prevention policy making have formalized their contribution. A substantial number of respondents feels to have a role in lobbying for prevention policy, half of which has also formalized that contribution (mostly in their

320 rganizational statement of mission). A minority of four does rot freel to have any role.

child accident prevention. To test some of the is sues raised above, respondents were confronted with a case-study qquestion 19. annex 1 . They were asked to identify the posible ef fective-

325 ness of a prevention policy for the specific problem. who majority $(N=28)$ agreed that, sometimes under conditions, the problen could effectively be addressed by public policy (lable 191. Those who could not see so. stent from organizations with a Iimited scope of activities ldisease categories. speciflc

330 research areas, etc. I. When asked what accident prevention policy should look like (Table 20), a very large proportion of respondents indicated it should contain educational measures. However. they did not feel responsible for the actual interwention or a formal contribution to policy-making $\{c f$. Table 19\}. Generaliy,

335 they referred to the one organization involved with safety and health in "lhe Netherlands (Stichting consument en veiligheid) 
having solely role in creating ard lobbying conditons for such a policy. When the policy would have been adopted, nost organizations would be willing and able to comnt themselwes to it. In

340 terms of intersectoral cooperation, though, they do not feel a role in initiation, alloption and operationalization of such a sichene.

\section{DTSCHSSIOH AHD THTERTRETATION}

345 thespondents do not unequivocally identify the Nota 2000 as a discussion document. Its ambiguously defined status may be a reason for tagnating policy development, However, actors in the policy process may also choose co perceive the status of the document incorrecty in order to keep legitimizing their own

350 organiadional objectives. This thrust is also marked by the fact that bureaucratic and political officers, as well as consumer orgamizations, consider Nota 2000 to be a socilly significant paper. On the other hand, professional groups with a more clearly digtinguished set of objectives do not consider Nota 2000

355 socially relewant. This could mean that professional groups may be unable to translate their organizational objectives into socially relevant ones.

In general, some value is atcached to Nota 2000 . Respondents feel that the memorandum is a good state-of-the-art paper, and that a

360 substantial effort has been made to present the complex intertwinedness of health matters in a consistert wa. There is no relation between degree of involvement in the policy-process of Nota 2000 and actions undertaken by warious respondents. This. indicates that the paper has induced activities among other than

365 traditionally policy-oriented organizations. The meaning of this could again be that there is a sufficient degree of public support for the menorandum. Some organizations legitimize their own objectives by reference to Nota 2000 , others have been prompted to develop longer-term plans themselwes. However, most.

370respondents feel that there is a strong contradiction between Nota 2000 and the Dekker-report, and report that they are forced to deal with "the craze of the day' (the Dekker report) rather than with strategic thinking. Barriers listed by respondents reflect this dualism: financing and institutional interests

375 (addressed by "Dekker") are considered the most crucial problems. apart from that the ministerial health bureaucracy is not seen as competent to deal with issues raised by Mota 2000 . If they were. respondents feel, they would have been able to deal with the apparant inconsistency between "Dekker' and Wota 2000. Our

380 conclusion, however, would be that "Dekker' deals with the percelved bariers quite adequately. Nota 2000 would have another chance ater full implmentation of the Dekker scheme. Nevertheless, Nota 2000 should keep out of the 'policy refrigerator'. and it might not be unexpected to see that ewen if 'Dekker' is

385 fully implenented, organizations will remain to see other bariciers.

In spite of that, the theory of agenda-building would predict that in the present context there is enough "issue expansion' to keep Nota 2000 on the systemic agenda. It might be questionable

390 whether the present political constellation ill allow for a continued presence of wota 2000 on the insticutional agenda. Again. the role of political and bureaucratic officials is 
crucial, and some organizations doubt their strength. with regard to prevention policy in terms of $10 t a 2000$ la

395 comprehensive policy schene beyond educational measures) most organizations are paring 1 ip service to these objectives : they report a preference for prerequisite-setting rather than actual involvement in the policy process. This outcome is supported by the data derived from the case-study on child accicient preven 400tion: most organizations refer to the only Dutch organization foc consumer health for that responsibility, rather than to make an inventory of their own possible contributions to that end. 


\section{Annex VI: KAP-chart I (knowledge, attitude and perception)}

* Value, feasibility, barriers and action

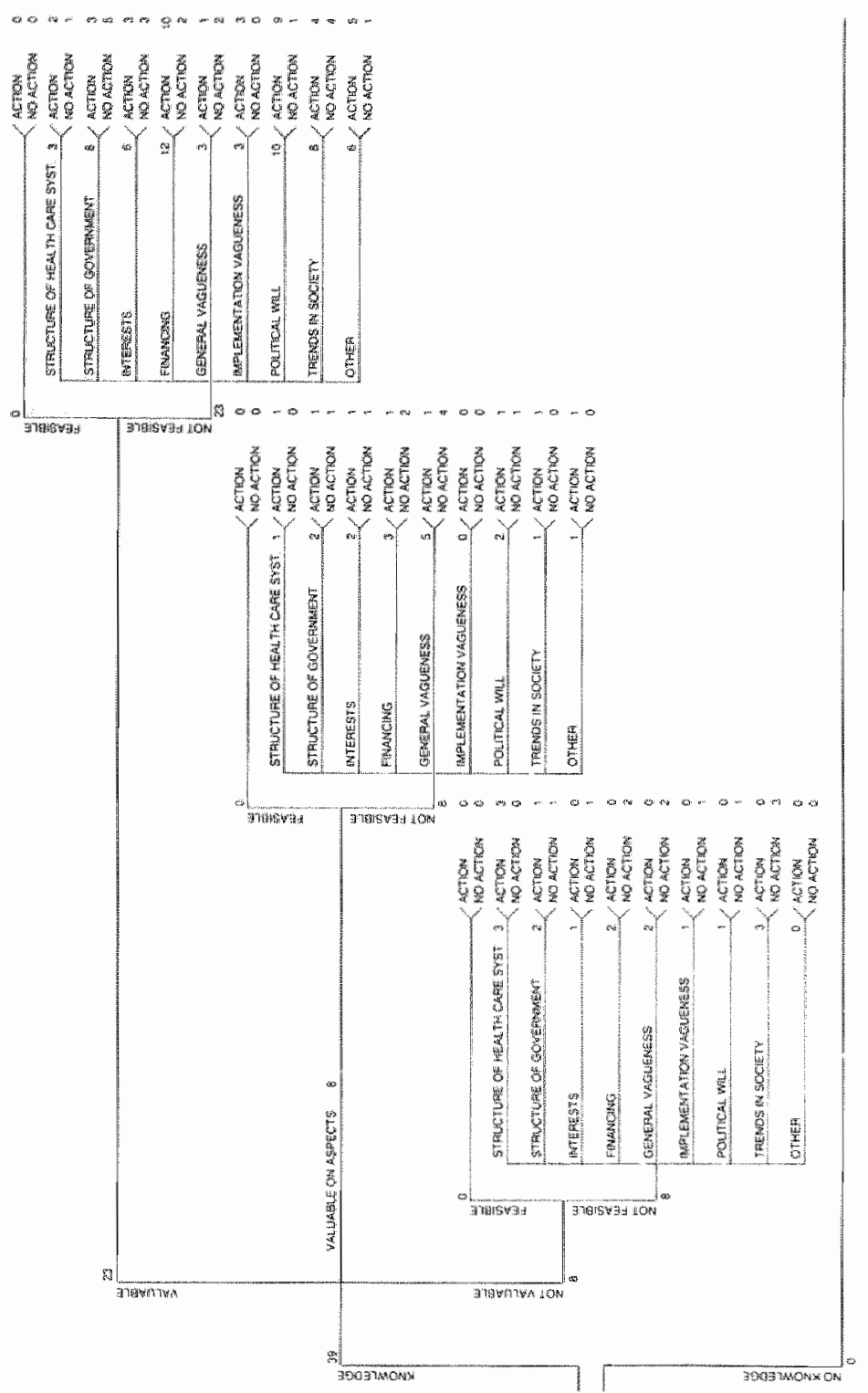




\section{Annex VII: KAP-chart II (knowledge, attitude and perception)}

* Value and action

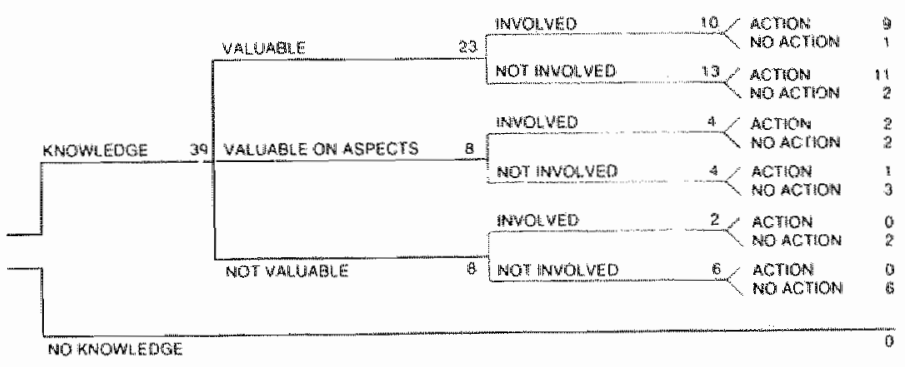




\section{Annex VIII: semi-structured interview}

1. Describe your organization(al unit) in terms of mission, size, funding, and population to be served. What is the age and tradition of your organization?

2. Do you know of the existence of Nota 2000 ?

(if yes, continue)

(if no, finish interview)

3. Could you describe the main thrusts of Nota 2000 as intended by the national authorities?

4. What is the exact status of Nota 2000 in general?

5. Have you been asked to contribute anything in any way to the Nota 2000 ?

6. Have you contributed in any way to Nota 2000 ?

(if yes, $\rightarrow$ questions 6a. through 6e.)

$($ if no, $\rightarrow$ question $6 \mathrm{f}$.)

6a. Have you contributed to the formulation of the problem?

6b. Do you think the scope of the problem as presiented in Nota 2000 reflects your position?

6c. Is it your impression that you have been consulted sufficiently well in the design of the Nota 2000 ?

6d. How much influence do you think you had in development of the Nota 2000 ?

6e. What should be your role in implementation of the Nota?

6f. Would you have wanted to contribute to Nota 2000 ? (yes/no $\rightarrow$ ) Why?

7. Who do you think should at least be involwed in furthering the objectives of Nota $2000 \%$ Mention either some categories, or some actual organizations.

8. Would you consider Nota 2000 to be a feasible national health policy?

(if yes, $\rightarrow$ question 15 )

$($ if no, $\rightarrow$ question 9)

9. Why not?

10. What is the one major problem you see?

11. Should there be any concrete role for your organization(al unit) to overcome this problem?

12. How?

(no role at all, $\rightarrow$ finish interview)

(some role, $\rightarrow$ question 13)

13. What exactly should this role be like?

14. And why particularly the role you describe?

15. Are there any barriers in furthering the objectives of Nota 2000 when you consider your own role and mission?

16. Would you be able to identify any organization frustrating the realization of the objectives of Nota 2000 ?

17. Prevention policy and facet policy, supported by policy on infrastructural resources, are the three "legs" Nota 2000 is standing on. How would you describe the prospects of your organization in realizing a prevention policy?

18. Does your organization have itself committed in some way or another to prevention policy relevant measures or plans? What are those? Have they been formalized?

19. A case to illustrate some of the thrusts of Nota 2000:

Accidents involving children $0-5$ years in and around the home are considered to be a major health problem in most industrialized nations. The problem has been identified in the Nota 2000 as well.

19a. Is this a problem which can be tackled effectively? 
19b. Could you identify some of the components of a policy approach (preferably in tems of Nota 2000 ) to tackle the problem?

19c. Is there any role for your organization(al wint) in formulation, adoption or implementation of such a policy?

$19 \mathrm{~d}$. Would your organization(al anit) be able to commit itself to such a policy?

(if yes, $\rightarrow$ questions $19 \mathrm{~d} 1,19 \mathrm{~d} 2$ and 20 )

(if no, $\rightarrow$ question $19 \mathrm{e}$ )

19d1. If yes, in what way would that be done?

$19 \mathrm{~d} 2$. Has it already been done?

19e. If no, what are the things that would prevent you from doing so? Are there any ideological, funancial or functional barriers?

20. Thank you for this interview. Is there anything you have been missing, or is there anything you would like to add? Would you have any document underlining the position of your organization(al unit) as you have just described it? Could you give it to me? What is its status? Could you give me your annual report? 


\section{Annex IX: power base of respondent organizations}

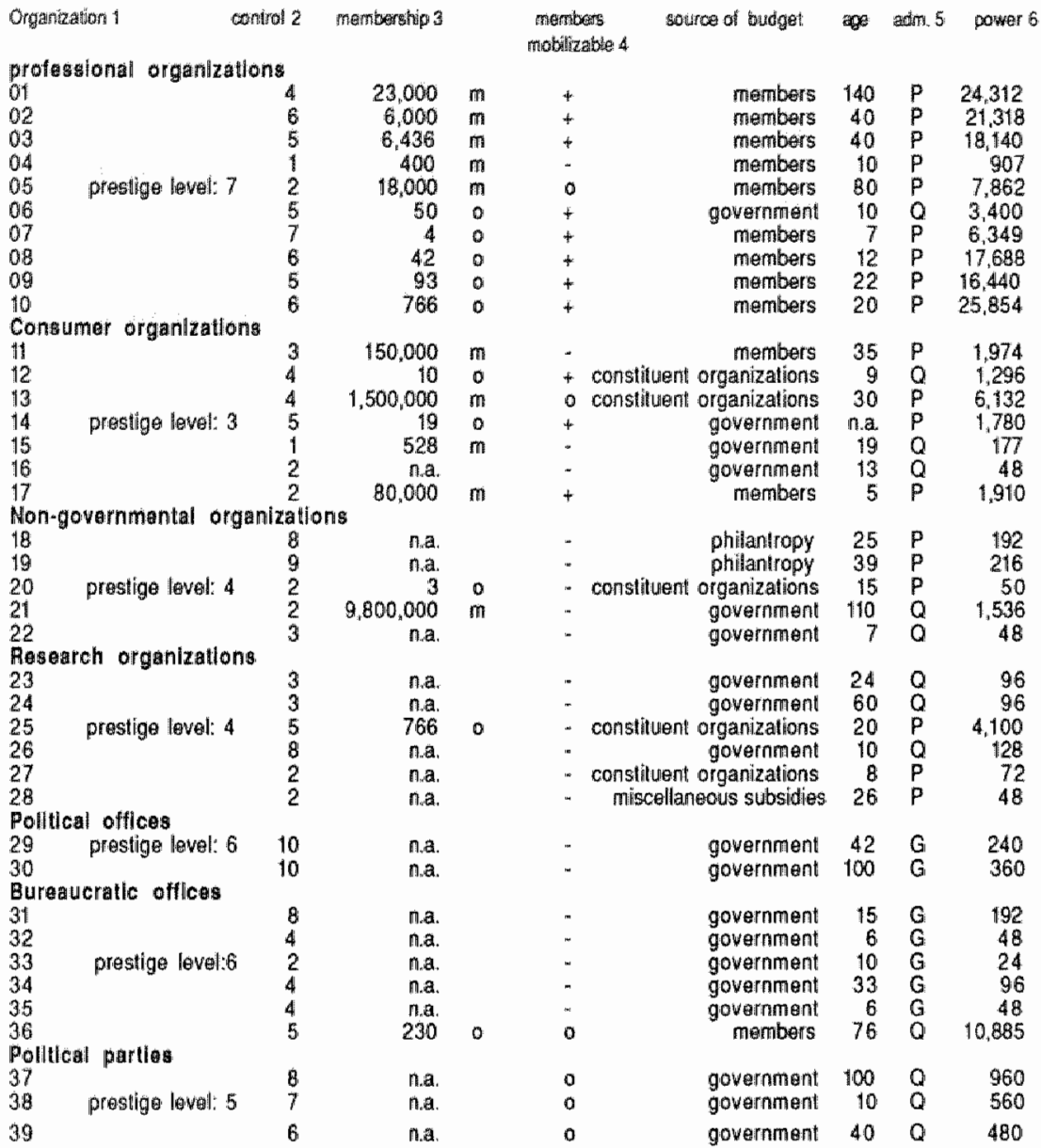

1. Prestige levels derived trom Bureau of Stalistics profossional status statistics.

2. Polential control over oxternal power resources (access to media, authority, funder / client constituencies, emplover femployee positions). 1=very little control; 10 highth

3. mernbership either indicated by individual members (m=2) or member organizalions (om3). Non-membership power base score $=1$

4. $+(-3) ;$ members ate readlily mobilizable (evidence from past activilies)

- (2): members have the potential to be mobilized, though no evidence available

- (wi) members not mobilizable, eilher for lunctional or organizational reasons

5. Type of administrations. Pprivale (3); Q:OUANGO (2); G: government (1)

6. Relative polential power, computed:prestige $x$ control over external fesources $x$

(1 + log membership) $x$ lype membership $x$ member mabilizability $x$ independency of budget source $x$ agie $x$ type of admiristration (ct. explanatory text).

More powerful: score $>1,000$ Less powertul: score $<1,000$ 
The bases of power are, according to Wrong (1979), individual and collective resources. These may be material as well as immaterial. Dahl (1961) lists the following: "an individual's own time; access to money, credit and wealth; control over information; esteem or socilal standing; the possession of charisma, popularity, legitimacy, legality, the rights pertaining to public office; solidarity: the capacity of a member of one segment of society to evoke support from others who identify him (her) as like themselves because of similarities in occupation, social standing, religion, ethnic origin, or racial stock; the right to vote; intelligence; education; and perhaps even one "s energy level."

Although it might seem a feasible option to operationalize and quantify these power base variables, no such effort has seriously been made in the past.

Wrong $(1979$, p. 125$)$ asserts that resources for a power base not necessarilly constimte power. The potential power holder will have to be in some sort of relation to other lesspower holders, and have sufficient interest in exerted power to consider employment of these resources in that relation.

Computation of a power rating therefore may be a superficial effort, especially as power is always contextual.

Howewer, for analytic reasons, a quantification of some of the power bases mentioned is proposed. Only those power bases which have become available in this investigation, or those which could be retraced without extensive research, are included in the above table. In line with Dahl's list, they include: prestige $(\mathrm{P})$; control over external power resources such as information (C); membership (M); type of membership (Mt); membership mobilizability $(\mathrm{Mb})$; independency of the source of budget in relation to other power holders $(\mathbb{I})$; age of the organization $(A)$; and type of administration in relation to administrations of other power holders ( $T$ ).

As these variables probably have synergistic effects, they showld be multiplied rather than addled to each other. Further, to limit the range of outcome figures, the logarithm of membership is taken. Our computation thereby becomes:

\section{Potential relative power $=\mathrm{P} \times \mathrm{C} \times(1+\operatorname{logM}) \times \mathrm{Mt} \times \mathrm{Mb} \times \mathrm{I} \times \mathrm{A} \times \mathrm{T}$}

where: P between 3 and 7 (status figures)

$C$ between 1 and 10

$\mathrm{M}$ is membership figure for all organizations

Mt is scored: organizational members $=3$

individual members $\quad=2$

non-membership $\quad=1$

Mb is scored: mobilizable $=3$

potentially mobilizable $=2$

non-mobilizable $\quad=1$

I is scored: membership fees $=3$

contributions $=2$

governmental monies $\quad=1$

$A$ is the number of years (or 1 , when not available)

$T$ is scored:

private

QUANGO

$=3$

government

$=2$

$=\mathbb{1}$

The chart presented in this annex presents us with somewhat surprising outcomes, such as the limited potential power of political and bureaucratic offices, and of political parties. However, as noted, power is contextual, and in the present constellation around health policy making, their powers indeed seem to be limited. 


\section{References}

Wrong, D. (1979) Power. Its forms, bases and uses. Basil Blackwell, Oxford

Dahl. A.A. (1961) Who governs? Democracy and Power in an American City. Yale Universily Press, New Haven 